ISSN: 1981-1896

REVISTA

A U G U S T U S

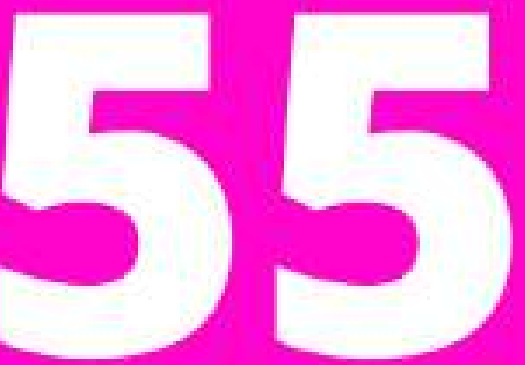

Rio dejaneiro | v.28 | n.55 | out/dez 2021 OVO UNISUAM 
REVISTA AUGUSTUS

Rio de Janeiro: UNISUAM, 2021. Semestral.

DOI: 10.15202/1981-1896.v28n55 


\section{REVISTA AUGUSTUS}

ISSN: 1981-1896

Rev. Augustus Rio de Janeiro $\quad$ v. 28 n. 55 p. 1-229 out./dez. 2021. 


\section{CONTATO}

Avenida Paris, 84 - Bonsucesso - Rio de Janeiro - RJ

CEP: 21041-020

\section{Contato Principal}

Prof. Dra. Maria Geralda de Miranda

Centro Universitário Augusto Motta - UNISUAM

Telefone (21) 3882-9797 Mestrado

revistaaugustus@unisuam.edu.br

Contato para Suporte Técnico

Prof. Bruno Matos de Farias

revistaaugustus@unisuam.edu.br

\section{DADOS PARA CATALOGAÇÃO}

Revista Augustus [recurso eletrônico] / Centro Universitário Augusto Motta - Vol. 28, n. 55 (dez. 2021).

Dados eletrônicos. - Rio de Janeiro: Centro Universitário Augusto Motta, 2011- v.; $30 \mathrm{~cm}$.

Semestral.

Modo de acesso: Internet:

$<$ http://revistas.unisuam.edu.br/index.php/revistaaugustu s> ISSN 1981-1896

Catalogação baseada no mais antigo número disponível na plataforma utilizada para produção da revista.

Início da publicação online no ano de 2001, de acordo com informações do site da revista.

1. Desenvolvimento científico. 2. Desenvolvimento tecnológico.

3. Desenvolvimento cultural. I. Centro Universitário Augusto Motta. 


\section{Revista Augustus \\ Periodicidade: quadrimestral \\ Tipo: temática}

\section{EQUIPE EDITORIAL}

\section{Editora-Chefe}

Maria Geralda de Miranda, Centro Universitário Augusto Motta (UNISUAM), Brasil

Editora-Seção Temática

Arlinda Cantero Dorsa, Universidade Católica Dom Bosco (UCDB), Brasil

\section{Editor-Gerente}

Bruno Matos de Farias, Centro Universitário Augusto Motta (UNISUAM), Brasil

Denise Moraes do Nascimento Vieira, Centro Universitário Augusto Motta (UNISUAM), Brasil

Francisco Alexandre Araújo Barros, Centro Universitário Augusto Motta (UNISUAM), Brasil

Marcos Antonio Diniz, Centro Universitário Augusto Motta (UNISUAM), Brasil

\section{Conselho Editorial}

- Adriana Martins Correia, Universidade Federal Fluminense (UFF), Brasil

- Agnaldo José Lopes, Centro Universitário Augusto Motta (UNISUAM), Brasil

- Alessandra Ésther de Mendonça, Universidade Federal Fluminense (UFF), Brasil

- Alexandre Palma, Universidade Federal do Rio de Janeiro (UFRJ), Brasil

- Ana Carolina Kalume Maranhão, Universidade Católica de Brasília (UCB), Brasil

- Andreia Regina Moura Mendes, Universidade Federal do Rio Grande do Norte (UFRN), Brasil

- Arlinda Cantero Dorsa, Universidade Católica Dom Bosco (UCDB), Brasil

- Arthur de Sá Ferreira, Centro Universitário Augusto Motta (UNISUAM), Brasil

- Clarissa Seixas Terenzi, Universidade Federal de Minas Gerais - Campus Macaé, Brasil

- Cláudia Costa, Centro Universitário Augusto Motta (UNISUAM), Brasil

- Cleyson de Moraes Mello, Universidade do estado do Rio de Janeiro (UERJ), Brasil

- Edilene Maria de Oliveira, Instituto Federal Matos Grosso do Sul (IFMS), Brasil

- Eduardo Barbuto Bicalho, Universidade Federal Fluminense, UFF, Brasil

- Eduardo Winter, Centro Universitário Augusto Motta (UNISUAM), Brasil

- Elaine Franco dos Santos Araujo, Universidade Federal do Rio de Janeiro (UFRJ)

- Elizabete Aparecida Sola, Universidade Federal do Paraná (UFPR), Brasil

- Everton Rangel Bispo, Centro Universitário Augusto Motta (UNISUAM), Brasil

- Fabiana Ferreira Koopmans, Centro Universitário Augusto Motta (UNISUAM), Brasil

- Felix Garcia Lopez Junior, Instituto de Pesquisa Econômica Aplicada (IPEA), Brasil

- Flavia Cristina Morone Pinto, Universidade Federal de Pernambuco (UFPE), Brasil

- Flavio Maldonado Bentes, Universidade Federal do Rio de Janeiro (UFRJ), Brasil

- Heitor Romero Marques Júnior, Universidade Católica Dom Bosco (UCDB), Brasil

- Helena Portes Sava de Farias, Centro Universitário Augusto Motta (UNISUAM), Brasil

- Jacqueline de Cassia Pinheiro Lima, Universidade Estadual do Norte Fluminense Darcy Ribeiro (UENF), Brasil

- Jesús Galindo Cáceres, Benemerita Universidad Autónoma de Puebla, Puebla- México, México

- José Luiz Fernandes, Centro Federal de Educação Tecnológica Celso Suckow da Fonseca (CEFET-RJ), Brasil

- Juliano de Carvalho Cury, Universidade Federal de São João Del-Rei (UFJS), Brasil

- Katia Cristina Montenegro Passos, Universidade Veiga de Almeida (UVA), Brasil

- Keyla Cristiane do Nascimento, Universidade Federal de Santa Catarina (UFSC), Brasil

- Leila Marques da Silva, Centro Federal de Educação Tecnológica Celso Suckow da Fonseca (CEFET-RJ), Brasil

- Ludmila Mourão, Universidade Federal de Juiz de Fora (UFJF), Brasil

- Luís C. Bittencourt, Universidade Veiga de Almeida (UVA), Brasil

- Luis Carlos Ferreira, Universidade Federal da Integração Lusíada Internacional da Lusofonia AfroBrasileira, Brasil

- Magda Guimarães de Araujo Faria, Universidade Federal do Rio de Janeiro (UFRJ), Brasil 
- Márcia Teixeira Cavalcanti, Universidade Santa Úrsula (USU), Brasil;

- Maria Augusta de Castilhos, Universidade Católica Dom Bosco (UCDB), Brasil

- Maria Geralda de Miranda, Centro Universitário Augusto Motta (UNISUAM), Brasil

- Miriam Maciel Nobrega, Centro Federal de Educação Tecnológica Celso Suckow da Fonseca (CEFET-RJ)

- Monique Ribeiro de Assis, Universidade do Estado do Rio de Janeiro (UERJ), Brasil

- Moraima Torres-Morillo, Universidad Pedagogica Experimental Libertador, Venezuela

- Patrícia dos Santos Vigário, Centro Universitário Augusto Motta (UNISUAM), Brasil

- Patrícia Maria Dusek, Centro Universitário Augusto Motta (UNISUAM), Brasil

- Raquel Villardi, Universidade do Estado do Rio de Janeiro (UERJ), Brasil

- Reis Friede, Centro Universitário Augusto Motta (UNISUAM), Brasil

- Sara Lucia Silveira de Menezes, Centro Universitário Augusto Motta (UNISUAM)/ Universidade Federal do Rio de Janeiro (UFRJ), Brasil

- Valeria Ferreira Romano, Universidade Federal do Rio de Janeiro (UFRJ), Brasil

- Yara Lacerda, Centro Universitário Celso Lisboa (UCL), Brasil

Pareceristas e Revisores Ad hoc

- Adriana Martins Correia, Universidade Federal Fluminense (UFF), Brasil

- Adriano Rosa da Silva, Universidade Santa Úrsula (USU), Brasil

- Agnaldo José Lopes, Centro Universitário Augusto Motta (UNISUAM), Brasil

- Alessandra Ésther de Mendonça, Universidade Federal Fluminense (UFF), Brasil

- Alexandre Palma, Universidade Federal do Rio de Janeiro (UFRJ), Brasil

- Alexandre Tourino Mendonça, Universidade Federal de Lavras (UFLA), Brasil

- Alisson Souza de Oliveira, Universidade Federal de Lavras (UFLA), Brasil

- Ana Carolina Kalume Maranhão, Universidade Católica de Brasília (UCB), Brasil

- André Luiz Carvalho Cardoso, Universidade Federal do Rio de Janeiro (UFRJ), Brasil

- Andréa Batista de Andrade Castelo Branco, Pontifícia Universidade Católica de Minas Gerais (PUCMinas), Brasil

- Andreia Regina Moura Mendes, Universidade Federal do Rio Grande do Norte (UFRN), Brasil

- Antonio José Caulliraux Pithon, Centro Federal de Educação Tecnológica Celso Suckow da Fonseca (CEFET-RJ), Brasil

- Arthur de Sá Ferreira, Centro Universitário Augusto Motta (UNISUAM), Brasil

- Aurivan Soares de Freitas, Universidade Federal de Lavras (UFLA), Brasil

- Carlos Alberto Figueiredo da Silva, Universidade Gama Filho (UGF), Brasil

- Carlos Alberto Mourão Júnior, Universidade Federal de São Paulo (UNIFESP), Brasil

- Christine de Sousa Veviani, Universidade Federal Fluminense (UFF), Brasil

- Clarissa Seixas Terenzi, Universidade Federal de Minas Gerais - Campus Macaé, Brasil

- Cláudia Costa, Centro Universitário Augusto Motta (UNISUAM), Brasil

- Claudia de Freitas Lopes Costa, Universidade do Estado do Rio de Janeiro (UERJ), Brasil

- Cleyson de Moraes Mello, Universidade do Estado do Rio de Janeiro (UERJ), Brasil

- Ediana Abreu Avelar, Universidade Católica de Petrópolis (UCP), Brasil

- Eduardo Barbuto Bicalho, Universidade Federal Fluminense (UFF), Brasil

- Eduardo Henrique Loreti, Universidade Federal do Espírito Santo (UFES), Brasil

- Eduardo Winter, Centro Universitário Augusto Motta (UNISUAM), Brasil

- Elaine Franco dos Santos Araujo, Universidade Federal do Rio de Janeiro (UFRJ)

- Eliana Alcantra, Universidade Federal de Lavras (UFLA), Brasil

- Elisa Dias de Melo, Universidade Federal de Viçosa (UFV), Brasil

- Elizabete Aparecida Sola, Universidade Federal do Paraná (UFPR), Brasil

- Emerson Ferreira da Rocha, Universidade do Estado do Rio de Janeiro (UERJ), Brasil

- Everton Rangel Bispo, Centro Universitário Augusto Motta (UNISUAM), Brasil

- Fabiana Ferreira Koopmans, Centro Universitário Augusto Motta (UNISUAM), Brasil

- Felipe Bernardes Silva, Universidade Federal de Viçosa (UFV), Brasil

- Felipe da Silva Triani, Universidade do Grande Rio (UNIGRANRIO), Brasil

- Felix Garcia Lopez Junior, Instituto de Pesquisa Econômica Aplicada (IPEA), Brasil

- Flavia Cristina Morone Pinto, Universidade Federal de Pernambuco (UFPE), Brasil

- Flavio Maldonado Bentes, Universidade Federal do Rio de Janeiro (UFRJ), Brasil

- Geraldo Motta Azevedo Júnior, Universidade Federal do Rio de Janeiro (UFRJ), Brasil

- Jacqueline de Cassia Pinheiro Lima, Universidade do Grande Rio (UNIGRANRIO), Brasil 
- Jesús Galindo Cáceres, Benemerita Universidad Autónoma de Puebla, Puebla- México, México

- João Olinto Trindade Junior, Universidade do Estado do Rio de Janeiro (UERJ), Brasil

- José Lúcio Nascimento Júnior, Universidade do Estado do Rio de Janeiro (UERJ), Brasil

- José Luiz Fernandes, Centro Federal de Educação Tecnológica Celso Suckow da Fonseca (CEFET-RJ), Brasil

- Josiel Gonçalves dos Santos, Centro Federal de Educação Tecnológica Celso Suckow da Fonseca (CEFET/RJ), Brasil

- Juliano de Carvalho Cury, Universidade Federal de São João Del-Rei (UFJS), Brasil

- Katia Cristina Montenegro Passos, Universidade Veiga de Almeida (UVA), Brasil

- Kátia Eliane Santos Avelar, Universidade Federal do Rio de Janeiro (UFRJ), Brasil

- Keyla Cristiane do Nascimento, Universidade Federal de Santa Catarina (UFSC), Brasil

- Klever Paulo Leal Filpo, Universidade Gama Filho (UGF), Brasil

- Letícia Rodrigues da Fonseca, Universidade Presbiteriana Mackenzie (MACKENZIE), Brasil

- Louise Calil Deterling, Instituto Biofísica Carlos Chagas Filho (IBCCF), Brasil

- Ludmila Mourão, Universidade Federal de Juiz de Fora (UFJF), Brasil

- Luís C. Bittencourt, Universidade Veiga de Almeida (UVA), Brasil

- Luis Carlos Ferreira, Universidade do Estado do Rio de Janeiro (UERJ), Brasil

- Luiz Carlos Ferreira, Universidade Federal de Minas Gerais (UFMG), Brasil

- Luiza Ferreira Rezende de Medeiros, Instituto Federal Goiano (IF Goiano) / Universidade Paulista (UNIP), Brasil

- Magda Guimarães de Araujo Faria, Universidade Federal do Rio de Janeiro (UFRJ), Brasil

- Marcia Teixeira Cavalcanti, Universidade Santa Úrsula (USU), Brasil

- Marcos dos Santos, Instituto Tecnológico da Aeronáutica (ITA), Brasil

- Marcus Alexandre de Padua Cavalcanti Bastos, Universidade do Grande Rio (UNIGRANRIO), Brasil

- Maria Alice Nunes Costa, Centro de Estudos Sociais da Universidade de Coimbra (CES/UC), Portugal

- Maria Geralda de Miranda, Centro Universitário Augusto Motta (UNISUAM), Brasil

- Miriam Maciel Nobrega, Centro Federal de Educação Tecnológica Celso Suckow da Fonseca (CEFET-RJ)

- Monique Ribeiro de Assis, Universidade do Estado do Rio de Janeiro (UERJ), Brasil

- Moraima Torres-Morillo, Universidad Pedagogica Experimental Libertador, Venezuela

- Newton José Ferro, , Universidade Federal Fluminense (UFF), Brasil

- Nilza Rogéria de Andrade Nunes, Universidade de Brasília (UnB), Brasil

- Patrícia dos Santos Vigário, Universidade Federal do Rio de Janeiro (UFRJ), Brasil

- Patrícia Maria Dusek, Centro Universitário Augusto Motta (UNISUAM), Brasil

- Paulo de Sá Filho, Instituto Federal Goiano (IF Goiano), Brasil

- Rafael Reis Pereira Bandeira de Mello, Universidade do Estado do Rio de Janeiro (UERJ), Brasil

- Ramiro Machado Rezende, Universidade Federal de Lavras (UFLA), Brasil

- Raquel Villardi, Universidade do Estado do Rio de Janeiro (UERJ), Brasil

- Reinaldo Viana Alvares, Universidade Federal do Estado do Rio de janeiro (UNIRIO), Brasil

- Renato Nunes Bittencourt, Universidade Federal do Rio de Janeiro (UFRJ), Brasil

- Rodrigo Grazinoli Garrido, Universidade Federal Rural do Rio de Janeiro (UFRRJ), Brasil

- Rosane Cristina de Oliveira, Universidade do Estado do Rio de Janeiro (UERJ), Brasil

- Rosângela Francisca de Paula Vitor Marques, Universidade Federal de Lavras (UFLA), Brasil

- Sandrelena da Silva Monteiro, Universidade Federal de Juiz de Fora (UFJF), Brasil

- Sara Lucia Silveira de Menezes, Centro Universitário Augusto Motta (UNISUAM)/ Universidade Federal do Rio de Janeiro (UFRJ), Brasil

- Susana Ortiz Costa, Universidade Federal do Rio de Janeiro (UFRJ), Brasil

- Tânia Horsth Noronha Jardim, Pontifícia Universidade Católica do Rio de Janeiro (PUC-Rio), Brasil

- Thiago Araújo, Universidade Santa Úrsula (USU), Brasil

- Tiago Miguel Patrício Ribeiro, Centro Universitário Augusto Motta (UNISUAM), Brasil

- Tiago Miguel Patrício Ribeiro, Centro Universitário Augusto Motta (UNISUAM), Brasil

- Valeria Ferreira Romano, Universidade Federal do Rio de Janeiro (UFRJ), Brasil

- Yara Lacerda, Centro Universitário Celso Lisboa, Brasil

- Yzel Rondon Súarez, Universidade Estadual Paulista Júlio de Mesquita Filho (UNESP), Brasil 


\section{SUMÁRIO}

\begin{tabular}{|c|c|}
\hline & $\begin{array}{l}\text { APRESENTAÇÃO } \\
\text { Os Editores }\end{array}$ \\
\hline & |ARTIGOS \\
\hline & $\begin{array}{l}\text { ABORDAGENS TEÓRICAS E CONCEITUAIS ACERCA DO CURRÍCULO NO } \\
\text { ENSINO EM CIÊNCIAS } \\
\text { Marcus Alexandre de Pádua Cavalcanti Bastos, Eliane Cristina Tenório Cavalcanti, } \\
\text { Marcelo de Jesus Pereira, Shirley Araújo Cabral, Nathan da Costa Cavalcanti Bastos }\end{array}$ \\
\hline & $\begin{array}{l}\text { PRÁTICAS EDUCATIVAS: OPINIÃO DE DISCENTES DE UMA INSTITUIÇÃO } \\
\text { FEDERAL DE ENSINO SUPERIOR } \\
\text { Maria Clara Soares Dantas, Ana Cláudia de Queiroz, Roberta Karlla Oliveira Guedes, } \\
\text { Luciana Dantas Farias de Andrade }\end{array}$ \\
\hline & $\begin{array}{l}\text { GESTÃO DE MUDANÇAS E LIDERANÇA: ANÁLISE DE CASO } \\
\text { ENVOLVENDO UMA INSTITUIÇÃO FEDERAL BRASILEIRA } \\
\text { João Batista Coelho, Maria Alice Nunes Costa }\end{array}$ \\
\hline & $\begin{array}{l}\text { O CONSUMO DE MEMES COMO FORMA DE MINIMIZAÇÃO DA } \\
\text { ANSIEDADE EM JOVENS ADULTOS NO BRASIL } \\
\text { Mariane Nascimento Reis }\end{array}$ \\
\hline & $\begin{array}{l}\text { TERRITÓRIOS RELIGIOSOS E SUAS INTERFACES TEMÁTICAS } \\
\text { Valdery Ferreira Zotelli; Michael Hideky Kubota; Arlinda Cantero Dorsa }\end{array}$ \\
\hline & $\begin{array}{l}\text { A DIMENSÃO HUMANA DO HERÓI NA GUERRA DO PARAGUAI (1864- } \\
\text { 1870) } \\
\text { Gustavo Ribeiro Capibaribe, Luiz Jeha Pecci de Oliveira, Wilson Cardoso de Sá, Heitor } \\
\text { Romero Marques }\end{array}$ \\
\hline & $\begin{array}{l}\text { O IMIGRANTE E O RESPEITO ÀS SUAS LIBERDADES INSTRUMENTAIS NO } \\
\text { BRASIL } \\
\text { Tânia Regina Silva Garcez, Ana Paula Martins Amaral }\end{array}$ \\
\hline & $\begin{array}{l}\text { A MIGRAÇÃO CONTEMPORÂNEA EM MATO GROSSO DO SUL } \\
\text { Arlinda Cantero Dorsa, Michele Nakazato, Thiago Henrique Conde Britts }\end{array}$ \\
\hline & $\begin{array}{l}\text { ESTUDOS DOS PADRÕES DE CONSUMO DE ÁLCOOL } \\
\text { MULTITERRITÓRIOS POR ADOLESCENTES } \\
\text { Maria Romilda da Silva, Giusepe Favieri, Maria Augusta de Castilho }\end{array}$ \\
\hline
\end{tabular}




\begin{tabular}{|l|l|l|}
\hline 187 & $\begin{array}{l}\text { POLÍTICAS PÚBLICAS (D)E SAÚDE EM CAMPO GRANDE-MS NO } \\
\text { CONTEXTO DA PANDEMIA DE COVID-19: APROXIMAÇÕES ES } \\
\text { DISTANCIAMENTOS COM DESEJOS E EXPECTATIVAS DA POPULAÇÃO } \\
\text { Gustavo Ribeiro Capibaribe, Antônio Henrique Maia Lima }\end{array}$ \\
\hline 209 & $\begin{array}{l}\text { ANÁLISE SOBRE AS AÇÕES DE RECUPERAÇÃO DAS JAZIDAS DO } \\
\text { PROJETO “EÓLICAS DE CASA NOVA" } \\
\text { Cícero Natanael de Oliveira Silva, Romilson Marques Cabral, José Lincoln Pinheiro } \\
\text { Araújo, Rebert Coelho Correia }\end{array}$ \\
\hline
\end{tabular}




\section{APRESENTAÇÃO}

Os editores da Revista Augustus apresentam a Edição 55, que traz onze estudos de pesquisadores e professores de diversas instituições de ensino e pesquisa do Brasil. O artigo que abre este número, ABORDAGENS TEÓRICAS E CONCEITUAIS DO CURRÍCULO NO ENSINO EM CIÊNCIAS, tem como objetivo apresentar algumas questões acerca do currículo em ciências por meio da abordagem pós-crítica onde essa perspectiva apresenta várias contraposições ao currículo tradicional, que tem como base o pensamento moderno.

Já o segundo artigo intitulado, PRATICAS EDUCATIVA: OPINIÃO DE DISCENTES DE UMA INSTITUIÇÃO DE ENSINO FEDERAL, procura conhecer a opinião de discentes de uma Instituição Federal de Ensino Superior acerca das práticas educativas que ancoram os processos de ensino e avaliação em uma Universidade Federal do interior da Paraíba-PB-Brasil.

O terceiro artigo, GESTÃO DE MUDANÇAS E LIDERANÇA: ANÁLISE DE CASO ENVOLVENDO UMA INSTITUIÇÃO FEDERAL BRASILEIRA, tem como objetivo identificar como os gestores (lideranças) atuaram na gestão de mudanças, decorrente de um alinhamento estratégico que resultou na fusão de diversos setores de uma organização do poder público brasileiro.

Dando seguimento, no quarto artigo, O CONSUMO DE MEMES COMO FORMA DE MINIMIZAÇÃO DA ANSIEDADE EM JOVEM E ADULTOS NO BRASIL, procura compreender como os memes humorísticos da internet, compartilhados por jovens adultos (adultos emergentes) podem contribuir para a amenização do sentimento ansioso vivenciado por esta população, especialmente no momento pandêmico de Covid-19.

O quinto artigo, TERRITÓRIOS RELIGIOSOS E SUAS INTERFACES TEMÁTICAS, busca elaborar uma síntese integrativa do estado de conhecimento sobre a referida temática, visibilizar e divulgar a cientificidade, facilitando assim o acesso, a pesquisa e o aprofundamento desta área de conhecimento, válida para todos os membros da comunidade acadêmica de diferentes áreas de conhecimento, sejam eles alunos de graduação, pós-graduação e docentes pesquisadores e orientadores. 
Dando continuidade, no sexto artigo, A DIMENSÃO HUMANA DO HERÓI NA GUERRA DO PARAGUAI (1864-1870), procura analisar um novo conceito sobre o herói e o heroísmo, inserindoo na análise da Guerra do Paraguai (1864-1870), pontuando a dimensão humana da figura sobre a qual se aplica esse conceito.

O sétimo artigo, O IMIGRANTE E O RESPEITO ÀS SUAS LIBERDADES INSTRUMENTAIS NO BRASIL, teve como objetivo trazer a visão sobre as liberdades instrumentais do imigrante no Brasil e especificamente conhecer a migração e a cidadania frente ao direito do desenvolvimento e o respeito à sua liberdade instrumental.

Já o oitavo artigo, A MIGRAÇÃO CONTEMPORÂNEA EM MATO GROSSO DO SUL, traz questões ligadas às várias reflexões produzidas sobre os problemas sociais contemporâneos. Com relação aos estudos migratórios, nos últimos anos, é uma realidade que vêm inspirando muitos pesquisadores ao aprofundamento dessa discussão.

No nono artigo, ESTUdOS DOS PADRÕES DE CONSUMO DE ÁlCOOL EM MULTITERRITÓRIOS POR ADOLESCENTES, a questão central é um estudo que tem como ponto de partida a problemática sobre o consumo de álcool entre adolescentes.

POLÍTICAS PÚBLICAS (D)E SAÚDE EM CAMPO GRANDE-MS NO CONTEXTO DA PANDEMIA DE COVID-19 é o penúltimo artigo que procura responder à problemática básica de "quais as convergências e divergências entre as políticas públicas de saúde adotadas pelo Município de Campo Grande - MS no contexto do combate a pandemia de COVID-19 e aquilo que a população da cidade desejava/esperava.

Por fim, o décimo primeiro artigo ANÁLISE SOBRE AS AÇõES DE RECUPERAÇÃO DAS JAZIDAS DO PROJETO - EÓLICO DE CASA NOVA, projetou-se na geração comercial de energia eólica, a causa dos impactos ao meio ambiente e à população residente nas proximidades dos parques eólicos. Tal pesquisa ocorreu por meio de relatórios e entrevistas semiestruturadas.

Desejamos a todos uma boa leitura!

Os Editores 


\title{
ABORDAGENS TEÓRICAS E CONCEITUAIS ACERCA DO CURRÍCULO NO ENSINO EM CIÊNCIAS
}

\author{
Marcus Alexandre de Pádua Cavalcanti Bastos \\ Doutor em Educação em Ciências e Saúde \\ Universidade Federal do Rio de Janeiro - UFRJ Rio de Janeiro, RJ, Brasil \\ marcus_nathan120@hotmail.com \\ Eliane Cristina Tenório Cavalcanti \\ Doutoranda em Educação em Ciências e Saúde \\ Universidade Federal do Rio de Janeiro - UFRJ Rio de Janeiro, RJ, Brasil \\ eliane.cavalcanti@hotmail.com.br
}

Marcelo de Jesus Pereira Mestrando em Educação em Cências - Unigranrio - Universidade do Grande Rio, marcelo.pereira@transluxtransportes.com.br

Shirley Araújo Cabral Mestre em Desenvolvimento Local - Centro Universitário Augusto Motta - UNISUAM shirleyacabral@gmail.com.br

Nathan da Costa Cavalcanti Bastos Bacharelando em Farmácia Universidade Estácio de Sá Rio de Janeiro, RJ, Brasil nathan-psytrance@hotmail.com

\section{RESUMO}

O trabalho em tela pretende apresentar algumas questões acerca do currículo em ciências por meio da abordagem pós-crítica. Essa perspectiva apresenta várias contraposições ao currículo tradicional, que tem como base o pensamento moderno, e que marca profundamente o modelo atual de educação, especialmente no currículo em ciências. A abordagem tradicional promove a compartimentarização do conhecimento, em que o conteúdo é tratado de forma fragmentada e separada da complexidade da realidade. Além disso, ele também preconiza que é possível atingir científico universal e verdades absolutas válidas para todos. Em contrapartida, o currículo pós-critico considera a influência que as dimensões política, social e cultural têm na produção do conhecimento. Essa perspectiva promove a heterogeneidade e estabelece conexões entre os diversos saberes. De caráter teórico-bibliográfico, a pesquisa toma como principais referências as contribuições de Michel Foucault (1986), Gilles Deleuze (1995), Jacques Derrida (1995), Alfredo Veiga Netto (2002), Silvio Gallo (2007), Tomaz Tadeu da Silva (1994, 1993, 2004, 2006, 2009), Lopes e Macedo (2002) e outros. Como resultado, a vertente pós-crítica para o currículo em ciências, possibilita a integração entre as disciplinas sem uma filiação ou um eixo organizador único. Ela permite sair do aprisionamento, da fixidez, do essencialismo metodológico imposto pela filosofia moderna que tanto têm marcado os processos educacionais contemporâneos, especialmente o currículo.

Palavras-chave: pós-estruturalismo, modernidade, currículo em ciências. 


\section{ABSTRACT \\ THEORETICAL AND CONCEPTUAL APPROACHES ABOUT THE CURRICULUM IN SCIENCE TEACHING}

The work on screen intends to present some questions about the science curriculum through the post-critical approach. This perspective presents several contrasts with the traditional curriculum, which is based on modern thinking, and which profoundly marks the current model of education, especially in the science curriculum. The traditional approach promotes the compartmentalization of knowledge, in which the content is treated in a fragmented way and separated from the complexity of reality. In addition, he also advocates that it is possible to achieve universal scientific and absolute truths valid for all. In contrast, the post-critical curriculum considers the influence that the political, social and cultural dimensions have on the production of knowledge. This perspective promotes heterogeneity and establishes connections between different types of knowledge. Theoretical-bibliographic, the research takes as main references the contributions of Michel Foucault (1986), Gilles Deleuze (1995), Jacques Derrida (1995), Alfredo Veiga Netto (2002), Silvio Gallo (2007), Tomaz Tadeu da Silva (1994, 1993, 2004, 2006, 2009), Lopes and Macedo (2002) and others. As a result, the postcritical aspect of the science curriculum makes it possible to integrate disciplines without a single affiliation or organizing axis. It allows us to escape from imprisonment, from fixity, from the methodological essentialism imposed by modern philosophy that has so marked contemporary educational processes, especially the curriculum.

Keywords: post-structuralism, modernity, science curriculum.

Recebido em: 25/03/2021. Aceito em: 16/12/2021. 
ABORDAGENS TEÓRICAS E CONCEITUAIS ACERCA DO CURRÍCULO NO ENSINO EM CIÊNCIAS
Marcus Alexandre de Pádua Cavalcanti Bastos Eliane Cristina Tenório Cavalcanti

Marcelo de Jesus Pereira Shirley Araújo Cabral

Nathan da Costa Cavalcanti Bastos

\section{INTRODUÇÃO}

A preocupação com o currículo faz-se notar, com constância, nas políticas, nas práticas e nas pesquisas da área da educação. Embora todos os campos de conhecimento sejam marcados por diferentes teorias, no campo curricular tem-se procurado inventariar teorias que funcionem como esquemas explicativos da realidade. No que se refere ao currículo de ciências, este sempre foi influenciado pelo pensamento moderno, que tem em seu fundamento uma perspectiva linear, universal e formal (SILVA, 1993). Essa perspectiva promoveu a compartimentarização do conhecimento, em que o conteúdo é tratado em sua forma fragmentada da realidade. Essa separação deu origem à especialização do conhecimento e, consequentemente, ao formato disciplinar da educação tradicional (GALLO, 2003). Vale ressaltar que o conhecimento corporificado no currículo carrega marcas indeléveis das relações sociais de poder (SILVA, 2009). As relações de poder que se estabelecem entre currículo e conhecimento indicam qual conhecimento deve ser ensinado, e quais as maneiras de se relacionar no espaço educativo, dado que o currículo resulta sempre de escolhas, seleções e diferenciações que não são neutras, mas, sim, condicionadas por pressupostos, interesses e intenções historicamente determinados (SILVA, 2009; MACEDO, 2006).

De fato, o reconhecimento da necessidade de uma redefinição do currículo, tendo em vista a criação de um espaço de diálogo e de articulação entre diferentes culturas e interesses sociais, é mantido pelo enfoque pós-crítico, através da utilização de algumas abordagens pósmodernas ${ }^{1}$ e pós-estruturalistas. Essa perspectiva surgiu na segunda metade do século XX e tece várias críticas ao pensamento moderno que reforça concepções essencialistas de que é possível atingir conhecimento científico universal e verdades absolutas válidas para todos, que ainda marca a educação contemporânea, especialmente o currículo (SILVA, 2009; MACEDO, 2006; PARAÍSO, 2004; LOPES, 2013).

O currículo pós-crítico em ciências tende a enfatizar as noções de diferença, promovendo a heterogeneidade, privilegiando a pluralidade e a diversidade dos saberes. Essa tendência

\footnotetext{
${ }^{1}$ Moreira (2003) constata a presença do pós-modernismo no campo da teoria curricular há quase vinte anos, tal presença: tem-se acentuado, nos últimos anos, a influência do pensamento pós-moderno no discurso curricular contemporâneo, tanto no Brasil como em outros países. Macedo (2013, p.438) faz a mesma constatação, afirmando que a partir da década de noventa, a hegemonia quase absoluta do pensamento marxista entra em declínio nos estudos curriculares, com a forte incorporação, pelo campo, de perspectivas pós-estruturais.
} 
ABORDAGENS TEÓRICAS E CONCEITUAIS ACERCA DO CURRÍCULO NO ENSINO EM CIÊNCIAS
Marcus Alexandre de Pádua Cavalcanti Bastos Eliane Cristina Tenório Cavalcanti

Marcelo de Jesus Pereira Shirley Araújo Cabral

Nathan da Costa Cavalcanti Bastos

vê o currículo como um campo de saber que não é dado e sim construído, criando conexões entre os diversos saberes. É neste contexto que se insere a crítica ao currículo na que possuem perspectiva humanista, na tecnicista e, ainda, às propostas emancipatórias de currículo tradicionais.

Para problematizar questões relativas ao currículo, buscamos apoio em importantes autores, tais como Michel Foucault (1986), Gilles Deleuze (1995), Jacques Derrida (1995), Alfredo Veiga Netto (2002), Silvio Gallo (2007), Tomaz Tadeu da Silva (1994, 1993, 2004, 2006, 2009), Lopes e Macedo (2002) e outros autores que nos provocam a pensar e a problematizar questões anteriormente dadas como naturais. Esses autores nos auxiliam a pensar na seguinte questão: Como pensar um currículo em ciências a partir da perspectiva pós-crítica?

Essa questão nos parece pertinente para realizarmos algumas aproximações com o campo do currículo em ciências, pois nos vemos movidos pelo desejo de respostas adequadas à atual realidade curricular que não mais comporta o atual modelo disciplinar. Desse modo, iniciamos nosso trabalho apresentando a construção do pensamento na modernidade e sua influência na formação curricular. Em uma segunda parte, buscamos a perspectiva rizomática para pensar o currículo em ciências, esse posicionamento rompe com o modelo arborescente do currículo tradicional moderno que reproduz a fragmentação cartesiana do saber.

\section{CURRÍCULO EM CIÊNCIAS: PERSPECTIVAS PARA O CONHECIMENTO}

De acordo com Veiga Neto (2002) o currículo moderno caracteriza-se por apresentar uma ordem vertical e disciplinar, que constitui o eixo de todo o processo educativo. Nesta perspectiva de entendimento, pode-se dizer que as instituições de ensino são produtos da modernidade e emergem dessas sociedades (FOUCAULT, 1986). Neste sentido, também sob uma perspectiva que se aproxima de evidências foucaultianas, o currículo "molda condutas de forma disciplinar (VEIGA NETO, 2002).

Com essa afirmação, o autor nos mostra como o currículo escolar foi relevante no projeto da Modernidade.

O currículo é pensado e funciona como uma estrutura classificatório-disciplinar; por isso ele é estruturante. $\mathrm{E}$, por ter uma estrutura disciplinar, ele funciona como um estruturante disciplinador. A consequência disso é que ele gera, no âmbito em que atua, o entendimento não apenas de que os saberes têm (naturalmente) uma distribuição disciplinar que é espacial, mas também de que o próprio mundo tem 
ABORDAGENS TEÓRICAS E CONCEITUAIS ACERCA DO CURRÍCULO NO ENSINO EM CIÊNCIAS
Marcus Alexandre de Pádua Cavalcanti Bastos Eliane Cristina Tenório Cavalcanti

Marcelo de Jesus Pereira Shirley Araújo Cabral

Nathan da Costa Cavalcanti Bastos

essa, e apenas essa, espacialidade. Na medida em que ele se estabelece disciplinarmente e na medida em que a sociedade moderna é uma sociedade em que os indivíduos mais e mais se individualizam e se autodisciplinam (como nos mostrou Michel Foucault) (VEIGA NETO, 2002, p.171)

Dessa forma, o currículo de ciências acaba sendo influenciado por um conhecimento cientifico pensado como neutro que busca solucionar os problemas por meio de uma verdade, ou seja, a ciência busca, assim, em seu processo se hegemonizar como única referência e substituir sistemas, práticas cotidianas pela crença na objetividade.

Veiga Neto (2002) afirma que como consequência disso, é possível perceber uma geometrização de saberes e do mundo como um todo. $\mathrm{O}$ autor critica a visão determinista e reprodutiva do currículo e sugere uma abordagem imanente para o currículo. A imanência só pode ser entendida como algo que é nela mesma, o plano de imanência suscita questões e problemas decorrentes da experiência (DELEUZE; GUATTARI, 1995). Desse modo, um currículo imanente adota uma nova postura que desloca a hierarquia e põe as conexões criadoras em fluxo. Ele não busca mais o homogêneo, o único, o idêntico, sua busca é pela multiplicidade.

Veiga Neto (2002) sustenta que a abordagem imanente representa uma crítica ao humanismo, ao sujeito racional e autônomo, às pretensões universais da razão e da ciência. Assumir o pós-estruturalismo como perspectiva epistemológica para o currículo em ciências implica na desconstrução de metanarrativas ${ }^{2}$ elaboradas na modernidade que marcam a produção do conhecimento nessa área. As metanarrativas podem ser compreendidas como explicações gerais, amplas e universalizantes sobre o mundo e a sociedade (LYOTARD, 1984). Como exemplo, podemos citar a construção de um sujeito racional; o uso da ciência e da tecnologia como fonte de progresso; a liberdade e autonomia do sujeito; a política baseada em certezas e, entre outras coisas, o desejo de explicações com caráter totalizante (LYOTARD, 1984; PETERS, 2000). No que se refere à educação, Silva (1994) afirma que as vertentes curriculares que buscam dar respostas a todos os anseios e problemas relacionados do ensino não passam de metanarrativas educacionais.

Para legitimar este descrédito surgem novas perspectivas interpretativas da realidade, entre elas os estudos pós-críticos. Essa vertente tece críticas a verdade, dá ênfase na

\footnotetext{
2 Ao problematizar as metanarrativas modernas e expor o caráter histórico, contextual, inerente ao processo de construção do conhecimento, essa perspectiva epistemológica tem provocado uma série de inquietações, de dúvidas, de descontinuidades que repercutem nos processos investigativos na área (SILVA, 1994).
} 
ABORDAGENS TEÓRICAS E CONCEITUAIS ACERCA DO CURRÍCULO NO ENSINO EM CIÊNCIAS
Marcus Alexandre de Pádua Cavalcanti Bastos Eliane Cristina Tenório Cavalcanti

Marcelo de Jesus Pereira Shirley Araújo Cabral

Nathan da Costa Cavalcanti Bastos

pluralidade da interpretação; soma-se a isso o fato do entendimento de que a linguagem, por ser fluida, está sempre a reconstruir significados, o que impediria a existência de discursos válidos universalmente. A perspectiva pós-crítica parte do pressuposto de que todas as narrativas seriam parciais na medida em que dependem da posição de seus emissores e que não haveria uma posição privilegiada para emissão de discursos. Ela também assume uma epistemologia antifundacionalista e perspectivista (LOPES E MACEDO, 2002).

Silva (1994, p. 124) argumenta que uma atitude pós-crítica em relação ao currículo procuraria fazer uma desconstrução dos "inúmeros binarismos de que é feito o conhecimento que constitui o currículo tradicional". Derrida (2004) afirma que desconstruir não significa apenas negar os valores dados como universais pela filosofia ocidental; antes, trata-se de abalar o fundamento que sustenta o que já foi pensado pelo homem, posto em prática e tornado hegemônico. Esses autores procuram mostrar que a desconstrução não significa destruição, mas sim um procedimento que busca desorganizar, desmantelar os discursos adotados pela metafísica para dar-Ihes diferentes funcionamentos. Para Derrida e Roudinesco (2004, p. 9) a desconstrução expressa "um certo modo de resistir à tirania do um, do logos da metafísica (ocidental) na própria língua que é enunciada, com a ajuda do próprio material deslocado, movido com fins de reconstruções cambiantes". Com a atenção voltada às palavras pelos autores, podemos afirmar que a desconstrução causou um forte impacto no pensamento metafísico ocidental, ao proporcionar questionamentos e deslocamentos de conceitos que eram considerados canônicos.

Os estudos pós-críticos afastam-se dos pressupostos modernos que sustentam a unidade e identidade, universalidade, assumindo a diferença como importante perspectiva em seu pensamento. Ele considera também a participação da cultura e do devir histórico na elaboração do conhecimento (SILVA, 2004).

Essa abordagem não pode ser reduzida a um método, a uma teoria ou até mesmo a uma escola; "é melhor referir-se a ele como um movimento de pensamento - uma complexa rede de pensamento - que corporifica diferentes formas de prática crítica" (PETERS, 2000, p. 29). Nesse sentido, todo o conhecimento, inclusive aqueles produzimos em nossas pesquisas, não é a descoberta de algo que estava velado, mas é um ato de criação e invenção que nada tem de neutralidade e objetividade. 
ABORDAGENS TEÓRICAS E CONCEITUAIS ACERCA DO CURRÍCULO NO ENSINO EM CIÊNCIAS
Marcus Alexandre de Pádua Cavalcanti Bastos Eliane Cristina Tenório Cavalcanti

Marcelo de Jesus Pereira Shirley Araújo Cabral

Nathan da Costa Cavalcanti Bastos

Tomaz Tadeu da Silva (2004) explicita que a vertente pós-crítica assume a crítica ao modelo linear de currículo que prescreve uma trajetória de aprendizagem baseada em uma concepção essencialista dos conteúdos que teriam a pretensão de atingir conhecimento científico universal, capaz de fornecer verdades sobre o mundo. Essa concepção de conhecimento decorre da metafisica clássica e sustenta-se na ideia de um sujeito transcendental dotado de razão que possui a priori capacidade de conhecer, de representar a essência dos objetos.

Segundo Silva (1994, p.7), “é preciso não interpretar o currículo como resultado de um processo evolutivo, de contínuo aperfeiçoamento em direção a formas melhores e mais adequadas", mas sim como seleção de conteúdos socialmente dominantes. Em oposição aos paradigmas universalistas, Silva (2004) propõe uma concepção de currículo que tenderia a enfatizar as noções de diferença, promovendo a heterogeneidade, privilegiando a pluralidade e a diversidade dos conhecimentos, produzidos conexões entre os mesmos. Essa perspectiva enfatizaria, fundamentalmente, o processo pelo qual algo é tomado como verdade. Para a perspectiva pós-criticas, a verdade seria constituída mediante articulações entre jogos, regras, estratégias de poder, mecanismos que pertencem às nossas práticas sociais e culturais.

Propondo uma forma de comportamento por meio de múltiplas aberturas que recusa a imposição de um conhecimento dado a priori, compreendido como verdade absoluta, Silva (2004), baseando-se em Deleuze e Guattari, propõe uma forma que supere a proposta de neutralidade científica imposta pelos pensadores da modernidade e que seja também afirmada uma postura imanente, aberta à experimentação que não vise apenas repetir resultados ou reproduzir o mesmo. Tal currículo estimularia o pensamento e o que se produz para além da representação de mundo. Desse modo, o autor procura compreender a produção do currículo como a construção de "um mapa, sempre desmontável, conectável, reversível, suscetível de receber modificações constantemente" (DELEUZE; GUATTARI, 1995, p.33).

A partir desta perspectiva, Gallo (2007) aponta que o currículo tradicional pode ser pensado como uma grande árvore. $\mathrm{O}$ autor afirma que:

O paradigma arborescente implica numa hierarquização do saber, como forma de mediatizar e regular o fluxo de informações pelos caminhos internos da árvore do conhecimento. $O$ paradigma arborescente representa uma concepção mecânica do conhecimento e da realidade, reproduzindo a fragmentação cartesiana do saber resultado das concepções cientificas (GALLO, 2007, p. 88 e 89). 
ABORDAGENS TEÓRICAS E CONCEITUAIS ACERCA DO CURRÍCULO NO ENSINO EM CIÊNCIAS
Marcus Alexandre de Pádua Cavalcanti Bastos Eliane Cristina Tenório Cavalcanti

Marcelo de Jesus Pereira Shirley Araújo Cabral

Nathan da Costa Cavalcanti Bastos

Desse modo, seria possível perceber que a relação do currículo de ciências com fatores externos ainda é pouco explorada em âmbito escolar, isto é, os currículos elegem a ciência como uma necessidade humana, mas pouco se problematizam seus feitos, seus modos. Não há uma "postura crítica em relação aos conhecimentos científicos e tecnológicos", mas quase sempre uma aceitação (MACEDO, 2004, p.35)

Nessa perspectiva, a ciência passa a ser vista como uma forma de legitimar conhecimentos, isto é, só é aceito um tipo de conhecimento se este for cientificamente comprovado. Mais ainda, os conhecimentos científicos chegam às salas de aulas como resultado de um conhecimento cumulativo, regular, linear e homogêneo. Paralelamente, o ensino proposto pelo currículo moderno de ciências também é tido como universal. Professores e alunos são postos no processo educacional como indivíduos neutros. Assim, a neutralidade é imposta pelo professor quando ele simplesmente transmite o que deve ser ensinado, da mesma forma, é neutro o aluno que apenas assimila o que é transmitido. Dessa forma, o currículo permanece fixado como um grande eixo de onde se originam normas, técnicas e práticas do que se deva ensinar e como se deve aprender (GALLO, 2007).

Gallo (2007), em sua obra Deleuze e a Educação, desloca o conceito de rizoma para ser pensado na educação e propõe um modelo de currículo rizomático ${ }^{3}$ que

\footnotetext{
Reuniria em seu eixo a totalidade do conhecimento ela começa a desenvolver galhos das mais diversas especializações que, embora mantenham suas estreitas ligações com o tronco - apontam para as mais diversas direções, não guardando entre si outras ligações que não seja o seu "tronco comum". Embora não consigam, no contexto deste paradigma, relacionar-se entre si (GALLO, 2007, p. 89).
}

\footnotetext{
3 Deleuze e Guattari (1995) propõem como alternativa para a relação hierárquica, nos quais os saberes se estabelecem: o rizoma. Uma planta rizomática, ao contrário da árvore, tem um sistema radicular complexo, com tantas conexões que não se sabe em que lugar começa e em que lugar termina o sistema radicular. Suas raízes se entreconectam por bulbos e radículas. As plantas rizomáticas têm raízes e caules tanto subterrâneos (escondidos, obscuros) quanto aéreos (que aparecem ao olhar). Tudo (caules aéreos e subterrâneos, raízes aéreas e subterrâneas) está conectado com tudo, formando, assim, um emaranhado de caminhos, de sentidos. Uma relação não mais hierárquica, mas em rede. Assim, o funcionamento rizomático, em vez de decalcar, cria um mapa. Isso porque, no rizoma, não há uma estrutura ou mesmo hierarquia entre os elementos. Ele funciona com suas conexões múltiplas. Por esse motivo, não há como estabelecer previamente as relações entre os elementos da rede.
} 
ABORDAGENS TEÓRICAS E CONCEITUAIS ACERCA DO CURRÍCULO NO ENSINO EM CIÊNCIAS
Marcus Alexandre de Pádua Cavalcanti Bastos Eliane Cristina Tenório Cavalcanti

Marcelo de Jesus Pereira Shirley Araújo Cabral

Nathan da Costa Cavalcanti Bastos

Contrapondo-se a isso, compreendemos que é possível pensar em uma perspectiva rizomática de currículo para o ensino de ciências, que não estaria caracterizada por pontos e posições a priori, isto é, estaria além do pensamento arborescente. Como afirma Deleuze (1995, p. 31)

Diferentemente das árvores ou de suas raízes, o rizoma conecta um ponto qualquer com outro ponto qualquer, e cada um de seus traços não remete necessariamente a traços de mesma natureza, ele põe em jogo regimes de signos muito diferentes, inclusive estados de não-signos. O rizoma não se deixa reduzir nem ao Uno nem ao múltiplo... Ele não é feito de unidades, mas de dimensões, ou antes, de direções movediças. Não tem começo nem fim, mas sempre um meio pelo qual ele cresce e transborda. Ele constitui multiplicidades.

Nessa perspectiva o currículo poderia ser pensado como um elemento que produz movimentos, conexões, mais ainda, está composto numa multiplicidade (escola, alunos, professores) que possibilita outras multiplicidades nos corpos daqueles que o constitui, antes mesmo de ser percebido como algo que organiza disciplinas pura e simplesmente, por exemplo. E esses movimentos dinamizam-no. O currículo escolar passa a se organizar a partir das conexões, das relações, das variações, que possibilitam uma integração entre as disciplinas, as especialidades, sem uma filiação ou um eixo organizador único, apontando as direções que se tem que seguir, mas possibilidades, caminhos e todos conectados entre si.

\section{MODELO DE CURRÍCULO RIZOMÁTICO EM CIÊNCIAS}

O Modelo de currículo rizomático em ciências rompe com um modelo arborescente do currículo tradicional e introduz um pensamento que desfaz a concepção mecânica do conhecimento e da realidade que reproduz a fragmentação cartesiana do saber, resultado das concepções científicas modernas. Gallo (2007, p.301) cita como exemplo a "ecologia que faz intersecção com diversos campos como a biologia, a geografia, a ciência política, a sociologia e mesmo a filosofia". O modelo de currículo rizomático em ciências nos remete para a ideia de multiplicidade. Levando em consideração os fluxos, as interconexões existentes entre as diferentes áreas do conhecimento científico, elementos que remetem uns aos outros e mesmo para fora do próprio conjunto, "pois o rizoma, sempre aberto, faz proliferar pensamentos" (GALLO, 2007, p.301). 
ABORDAGENS TEÓRICAS E CONCEITUAIS ACERCA DO CURRÍCULO NO ENSINO EM CIÊNCIAS
Marcus Alexandre de Pádua Cavalcanti Bastos Eliane Cristina Tenório Cavalcanti

Marcelo de Jesus Pereira Shirley Araújo Cabral

Nathan da Costa Cavalcanti Bastos

Na perspectiva de currículo rizomático, os saberes se conectam sem obedecer a uma linha prévia, pois considera o devir, a variação, a experimentação, a abertura ao tempo, os acontecimentos. Nesse sentido, utilizamos o conceito de rizoma de Deleuze e Guattari (1995) para e relacioná-lo com o currículo em ciências.

De acordo com Deleuze e Guattari (1995) o rizoma é regido por seis princípios. Os dois primeiros são o de conexão e o de heterogeneidade. Eles afirmam que os pontos de um rizoma podem e devem se conectar a quaisquer outros pontos, promovendo a heterogeneidade. A partir do momento em que concebemos o modelo rizomático de currículo em ciências como conectado a diferentes pontos, essas conexões podem se dar através das diversificações. Reconhecer a conexão e a heterogeneidade do currículo de ciências é reconhecê-lo como apenas um currículo dos muitos que fazem parte da vida dos alunos e professores.

O terceiro princípio é o de multiplicidade que concebe o currículo como algo que é produzido na e pela diversidade; e essa diversidade deve levar em consideração o devir, sempre instalado, no ensino e na aprendizagem. Um currículo que considera a multiplicidade não deve ser visto como um eixo, um pivô de onde partem todas as direções e normas a serem seguidas, conforme o determinado e sim de que "não existem pontos ou posições. Existem somente linhas" (DELEUZE, 1995, p. 17), que o processo educacional pode acontecer a partir do encontro com algo que muitas vezes pode estar fora desse conjunto e fazê-lo proliferar. É nesse sentido que o currículo segue o devir, daí por que um conteúdo nunca possa ser separado de seu exterior.

Nesse sentido, Gallo (2007) afirma que a grade curricular do ensino de ciências conheceria seus acontecimentos mediante suas determinações históricas e singulares - de conceitos, teorias, leis - desterritorializando-se a partir de suas conexões. Assim, uma linha que constitui o currículo em ciências "pode ser quebrada e conectada a outro lugar qualquer" (DELEUZE, 1995, p. 17).

O quarto princípio é o de ruptura a - significante. Esse princípio indica que uma linha pode ser quebrada e conectada a outro lugar qualquer e ser retomada segundo uma ou outra de suas linhas. Nesse sentido, Ramos e Brito (2011, p.09) apontam que

Assim como o rizoma, o currículo é feito de linhas segmentares, estratificadas, contudo, mesmo organizado, territorializado, podem ocorrer "explosões" em linhas de fuga em desterritorialização, isto é, mas, do que apresentar nomes, teorias leis, cálculos, modelos científicos como verdades prontas os conteúdos deveriam ser 
ABORDAGENS TEÓRICAS E CONCEITUAIS ACERCA DO CURRÍCULO NO ENSINO EM CIÊNCIAS
Marcus Alexandre de Pádua Cavalcanti Bastos Eliane Cristina Tenório Cavalcanti

Marcelo de Jesus Pereira Shirley Araújo Cabral

Nathan da Costa Cavalcanti Bastos

apresentados como possibilidades abertas, isto é, problematizar por que as coisas acontecem de um modo e não de outro.

Gontijo (2008) acrescenta que o princípio de ruptura a - significante do currículorizoma é desprovida de uma filiação ou ordem. A autora acrescenta que "em vez de perguntar o que significa alguma coisa, teoria ou outra coisa, poderia perguntar o que eles podem pensar e fazer com o foi feito naquela aula" (GONTIJO, 2008, p. 93).

Desse modo, mais do que a preocupação em transmitir conhecimento, o ensino de ciências deveria apontar meios para que os alunos possam ampliar seus conhecimentos e não mais pensar o conhecimento como um eixo. Pensar o conhecimento em ciências dessa forma é pensá-lo "estratificado, territorializado, organizado, significado, atribuído, etc. sem compreender suas linhas de desterritorialização, pelas quais ele foge sem parar" (DELEUZE; GUATARRI, 1995, p.18).

Os princípios de cartografia e de decalcomania indicam que os rizomas não podem ser modelados, seguindo estruturas ou assumindo pontos específicos que orientam o conhecimento. Deleuze e Guattari (1995) se referem a mapas que tem como objetivo nortear, indicar caminhos, mas também requerer novos traços. Eles expressam algo por vir, um devir. Assim, os mapas podem ser revistos, rediscutidos e ressignificados. Para os autores, não existem cópias, sobreposições perfeitas de ideias. Existem releituras, recriações a partir de algo criado, em que transformamos os conceitos dos quais nos apropriamos para criar algo novo.

Dessa forma, segundo Gallo (2007), é possível compreender a educação na perspectiva rizomática, seja na escola ou na universidade, como um campo de construção de conhecimento que requer, sobretudo, a compreensão de que existem diversas formas de conhecimento, e que elas dialogam entre si dentro de diversos contextos históricos e sociais. Os conteúdos abordados criam conexões múltiplas entre elementos dos mais variados campos do saber. Biologia, física, matemática, química se comunicam entre si e estabelecem redes interligadas de construção de conhecimento.

Compreendemos que a proposta de um currículo rizomático em ciências possibilita as mais diversas articulações entre os mais variados campos científicos, pois ele é um sistema aberto de multiplicidade sem pontos e posições fixas definido pelas linhas que o atravessam, permitindo assim movimentos de invenção e criação. 
ABORDAGENS TEÓRICAS E CONCEITUAIS ACERCA DO CURRÍCULO NO ENSINO EM CIÊNCIAS
Marcus Alexandre de Pádua Cavalcanti Bastos Eliane Cristina Tenório Cavalcanti Marcelo de Jesus Pereira Shirley Araújo Cabral

Nathan da Costa Cavalcanti Bastos

\section{CONCLUSÃO}

Concluímos que a utilização da vertente pós-crítica para o currículo em ciências implica a desconstrução de metanarrativas elaboradas na modernidade, possibilitando a integração entre as disciplinas sem uma filiação ou um eixo organizador único. A perspectiva pós-crítica de currículo em educação contesta as atuais e rígidas segmentações curriculares e nos permite sair do aprisionamento, da fixidez, do essencialismo metodológico imposto pela filosofia moderna que tanto têm marcado e ainda marcam os processos educacionais.

\section{REFERÊNCIAS}

RAMOS, M. N. C. ; BRITO, M. R. Uma abordagem de um currículo rizomático e ensino de ciências. In: Encontro Nacional de Pesquisa em Educação em Ciências, 2011, Campinas. Atas do VIII ENPEC e I CIEC, 2011. p. 01-11.

DELEUZE, Gilles; GUATTARI, Felix. Mil Platôs: capitalismo e esquizofrenia. Vol.1. Ed: 34. Rio de Janeiro. 1995.

DERRIDA, Jacques. Autoimunidade: suicídios reais e simbólicos. IN: BORRADI, Giovanna. Filosofia em tempo de terror. Diálogos com Habermas e Derrida. Tradução Roberto Muggiati. Rio de Janeiro: Zahar, 2004, p. 95-145.

FOUCAULT, Michel. Microfísica do poder. Rio de Janeiro, Ed. Graal, 1984.

GALLO, Silvio. Deleuze e a Educação. 2 ed. Belo Horizonte: Autêntica, 2007.

GONTIJO, Pedro Ergnaldo. Nos caminhos de uma educação por vir: ressonâncias e deslocamentos em Deleuze. Campinas. UNICAMP. 2008. 157p. Tese (Doutorado em Educação). Faculdade de Educação. Universidade Estadual de Campinas. 2008.

LOPES, Alice Casimiro. MACEDO, Elizabeth. Contribuições de Stephen Ball para o estudo de Políticas de Currículo. Ball, Stephen; Mainardes, Jefferson (org). In: Políticas Educacionais: questões e dilemas. São Paulo: Cortez, 2011.

LOPES, Alice Ribeiro Casimiro. Teorias pós-críticas, política e currículo. Educação, Sociedade \& Culturas, no 39, 2013. 
ABORDAGENS TEÓRICAS E CONCEITUAIS ACERCA DO CURRÍCULO NO ENSINO EM CIÊNCIAS
Marcus Alexandre de Pádua Cavalcanti Bastos Eliane Cristina Tenório Cavalcanti Marcelo de Jesus Pereira Shirley Araújo Cabral

Nathan da Costa Cavalcanti Bastos

LYOTARD, Jean-François. A condição pós-Moderna. Trad. Ricardo Corrêa Barbosa. Rio de Janeiro: José Olympio, 1984.

MACEDO Elizabeth; LOPES; Alice Casimiro. A estabilidade do currículo disciplinar: o caso das ciências. In: LOPES, A. C. \& MACEDO, E. (Orgs). Disciplinas e Integração Curricular: História e Políticas. Rio de Janeiro: DP\& A, 2002, p. 73-94.

MACEDO, Elizabeth. Currículo como espaço-tempo de fronteira cultural. Revista Brasileira de Educação, v. 11, n. 32 , p. 285-296, 2006.

MOREIRA, Antônio Flávio Barbosa (Org.). Currículo: questões atuais. 7ed. Campinas, SP: Papirus, 2003.

PARAÍSO, Marlucy. Um currículo entre formas e forças. Educação (Porto Alegre, impresso), v. 38, n. 1, p. 49-58, jan.-abr. 2015.

PEREIRA NOVAES, M. Experimentação em sala de aula, currículo imanente e o pensamento da diferença a filosofia como prática de formação de professores. Ixtli. Revista Latinoamericana de Filosofía de la Educación, 2014.

PETERS, M. Pós-estruturalismo e filosofia da diferença: uma introdução. Belo Horizonte: Autêntica, 2000.

RAMOS, M. N. C. ; BRITO, M. R. Uma abordagem de um currículo rizomático e ensino de ciências. In: Encontro Nacional de Pesquisa em Educação em Ciências, 2011, Campinas. Atas do VIII ENPEC e I CIEC, 2011. p. 01-11.

SILVA, Tomaz Tadeu (Org.). O sujeito da educação: Estudos foucaultianos. Petrópolis: Vozes, 1994.

SILVA, T. T. O Adeus às metanarrativas educacionais. In: (org.) $\mathbf{O}$ sujeito da educação: estudos foucaultianos. Petrópolis: Vozes, 1993. p. 247-258.

A filosofia de Deleuze e o Currículo. Faculdade de Artes Visuais. 2004.

Currículo: pensar, sentir e diferir. Rio de Janeiro: DP\&A, 2006.

Documentos de identidade: uma introdução às teorias do currículo. 3 ed. - Belo Horizonte: Autêntica, 2009.

VEIGA NETO, Alfredo. De Geometrias, Currículo e Diferenças IN: Educação e Sociedade, Dossiê Diferenças. Campinas: $n^{\circ}$ 79, 2002. 


\title{
PRÁTICAS EDUCATIVAS: OPINIÃO DE DISCENTES DE UMA INSTITUIÇÃO FEDERAL DE ENSINO SUPERIOR
}

\author{
Maria Clara Soares Dantas \\ UFCG \\ dantasclarinha@gmail.com
}

Ana Cláudia de Queiroz

UFCG

claudia.ana.queiroz@gmail.com

\author{
Roberta Karlla Oliveira Guedes \\ UFCG \\ rkog92@gmail.com
}

Luciana Dantas Farias de Andrade

UFCG

luciana.dantas.farias@gmail.com

RESUMO: Objetivo: conhecer a opinião de discentes de uma Instituição Federal de Ensino Superior acerca das práticas educativas que ancoram os processos de ensino e avaliação em uma Universidade Federal do interior da Paraíba-PB-Brasil. Metodologia: Estudo de natureza predominantemente qualitativa ancorado no prisma metodológico do materialismo histórico dialético foi possível emergir as contradições das atividades docentes a partir das entrevistas virtuais realizadas com 14 estudantes dos cursos de bacharelado em Física, Química, Matemática, Biologia, Enfermagem, Nutrição e Farmácia no período de junho, julho e agosto de 2020. Resultados: os temas principais oriundos das falas dos entrevistados permitiram a depreensão de duas categorias empíricas: I- Aspectos potencializadores das práticas educativas; II- Aspectos limitadores das práticas educativas. Ficou evidente a escolha por diversas estratégias pedagógicas nas atividades laborais dos professores da saúde e educação. Conclusão: essa diversidade convergiu para uso de abordagens pedagógicas emancipatórias e não emancipatórias, na opinião dos entrevistados, demonstrando avanço pedagógico diante da possibilidade de reconsiderar as ações docentes em vistas à superação de metodologias tradicionais através da operacionalização dos pressupostos da Resolução Nacional que institui as Diretrizes Curriculares dos Cursos.

Palavras-chave: Educação. Pessoal de educação. Mercado de trabalho. 


\section{ABSTRACT \\ EDUCATIONAL PRACTICES: OPINION OF STUDENTS OF A FEDERAL HIGHER EDUCATION INSTITUTION}

Objective: to know the opinion of students of a Federal Institution of Higher Education about the educational practices that anchor the teaching and assessment processes in a Federal University of the Interior of Paraíba-PB-Brazil. Methodology: Predominantly qualitative study anchored in the methodological prism of dialectical historical materialism, it was possible to emerge as contradictions of teaching activities from virtual sources carried out with 14 students of bachelor's degrees in Physics, Chemistry, Mathematics, Biology, Nursing, Nutrition and Pharmacy in the period of June, July and August 2020. Results: the main themes arising from the interviewees' statements allowed the understanding of two empirical categories: IPotentializing aspects of educational practices; II- Limiting aspects of educational practices. The choice of pedagogical subjects in the work activities of health and education teachers was evident. Conclusion: this diversity converged to the use of emancipatory and nonemancipatory pedagogical approaches, in the opinion of the interviewees, demonstrating pedagogical progress in view of the possibility of reconsidering teaching actions with a view to overcoming previous methodologies through the operationalization of the assumptions of the National Resolution establishing the guidelines Course Curriculum.

Keywords: Education. Educational Personnel. Job market. 


\section{INTRODUÇÃO}

A presente investigação está vinculada ao Grupo de Estudos e Pesquisas Interdisciplinares em Saúde e Enfermagem (GEPISE) e é fruto de inquietações em face da importância das discussões envolvendo a formação acadêmica de estudantes universitários de uma Instituição de Ensino Superior do interior do nordeste brasileiro, devido à atuação docente e discente das pesquisadoras em observar o interesse dos estudantes para aspectos tecnicistas em detrimento aos componentes curriculares epistemológicos voltados à reflexão e aprofundamento acadêmico.

As discussões reflexivas no contexto dos grupos de pesquisa promovem a formação de novos pesquisadores, produz conhecimentos avançados com necessidade de infraestrutura física, pessoal, organizativa e logística. Considera que a prática da produção de conhecimentos é um processo coletivo, dinâmico, contínuo e complementar, além de integrar tecnologias da informação e comunicação na produção, consumo e disseminação do conhecimento, por esta razão, faz-se alusão às discussões no âmbito do GEPISE e sua importância para a construção de uma proposta que reflita a importância da formação acadêmica no âmbito da universidade (ERDMANN et al, 2013; FIOCHI, 2016).

No planejamento do ensino, os objetivos específicos antecipam resultados e processos esperados do trabalho conjunto do professor e dos alunos, expressando conhecimentos e habilidades (conteúdos programáticos) a serem assimilados de acordo com as exigências metodológicas (estratégias com procedimentos e recursos) para finalmente sofrerem a avaliação sobre sua validade. (FARIAS; SILVA, 2008)

A elaboração das práticas educativas envolvendo o ensino e avaliação para a formação de recursos humanos acarreta para os professores da graduação/bacharelado a necessidade de optar por uma, entre duas posições: limitar-se ao repasse de conhecimentos já consagrados, investindo no desenvolvimento de algumas capacidades muito gerais, fora de qualquer referência a situações e práticas sociais, aqui denominados de Planejamento de Ensino Não Emancipatório, ou podem assumir toda a responsabilidade na escolha das práticas sociais optando por referenciais teóricos - práticos, com enfoque em questões que podem ser problematizadas tanto no plano individual como no coletivo, potencialmente para a formação de um perfil profissional que atenda às necessidades da política de saúde vigente, o qual denominou de Planejamento de Ensino Emancipatório (LIBÂNEO, 2005). 
Nesse sentido, os processos de ensino precisam apresentar-se com potencial transformador, sobretudo depois do advento do Plano Nacional de Educação - PNE, que instituiu as Diretrizes Curriculares Nacionais. Isso significa que o novo enfoque requer igualmente novas tendências técnico-pedagógicas, além de alterações nas estratégias de ensino no âmbito do processo formativo.

Mediante a possibilidade de realização das novas tendências teórico-pedagógicas das práticas educativas em enfermagem e das consequentes alterações nas estratégias de ensino e avaliação do processo formativo, questiona-se: qual a opinião dos discentes dos cursos do Centro de Educação e Saúde de uma Instituição Federal de Ensino Superior acerca das práticas educativas?

Este estudo tem como objetivo geral conhecer a opinião de discentes de uma Instituição Federal de Ensino Superior acerca das práticas educativas que ancoram os processos de ensino e avaliação em uma Universidade Federal do interior da Paraíba-PBBrasil. Como objetivos específicos: 1. Caracterizar o perfil sociodemográfico dos estudantes do CES; 2. Elucidar as transformações históricas da formação acadêmica no âmbito da universidade; 3. Conhecer as contradições existentes na opinião de discentes.

Justifica-se a sua realização face à constatação de que o ensino das disciplinas experimentam, nos dias atuais, a possibilidade de implementação de novas tendências teórico-pedagógicas, com alterações nas suas estratégias de ensino, devido ao advento das Diretrizes Curriculares que proporcionou às Universidades o direito de definir as estruturas curriculares de seus cursos, explicitando as competências e habilidades que desejam desenvolver junto a seus alunos, a partir de um Projeto Político Pedagógico capaz de atender às necessidades educacionais em âmbito local.

\section{MÉTODOS}

Este trabalho utiliza o prisma teórico metodológico do materialismo histórico dialético que, dentre outros princípios, trabalha a contradição por entender que para pensar a realidade é preciso elucidar os extremos para se aproximar do essencial, ou seja, partindo do empírico, do real aparente, avançando para reflexões, teorias e abstrações faz-se possível o acesso à essência daquela realidade tendo leituras diretas alimentadas por feedbacks (MINAYO, 2007; COSTA; LOUREIRO, 2019). 
O estudo do tipo exploratório-descritivo, foi desenvolvido a partir da abordagem qualitativa. O cenário consistiu no contexto dos cursos oferecidos no Centro de Educação e Saúde (CES) de um campus em expansão da Universidade Federal de Campina Grande respeitando os trâmites do comitê de ética (Resolução 466/12 conforme apêndice B), necessários à viabilização de uma pesquisa envolvendo seres humanos, com estimativa para o início do trabalho de campo compreendido entre os meses de novembro, dezembro de 2019, janeiro e fevereiro de 2020.

Contudo, devido ao atraso na emissão do parecer do Comitê de Ética para dezembro de 2020, férias acadêmicas em janeiro e fevereiro/2020 o cronograma foi alterado para início da coleta de material empírico para março de 2020. Infelizmente, em março de 2020, quando entrou em contato com os alunos para agendar a entrevista presencial, a UFCG emitiu nota informativa orientando professores e alunos da necessidade de isolamento social em decorrência da pandemia do novo Coronavírus.

Diante do novo cenário de isolamento social, as entrevistas tiveram que ser adaptadas e foram realizadas de maneira virtual através da plataforma Google Meet nos meses de junho, julho e agosto de 2020. A população foi constituída por estudantes dos cursos oferecidos no CES: Cursos de Bacharelado em Física, Química, Matemática, Biologia, Enfermagem, Nutrição e Farmácia. A amostra foi composta por 14 estudantes que convergiram com os critérios de inclusão, não desistiram do estudo em nenhuma das etapas realizadas até a saturação teórica por exaustão, ou seja, quando a interação entre o campo de pesquisa e o investigador não mais fornece elementos para balizar a teorização do objeto de estudo (FONTANELLA et al, 2011; SILVA; RUSSO, 2019).

Foram adotados os seguintes critérios de inclusão para realização da pesquisa com os estudantes: i) estudantes com idade superior a 18 anos; ii) estudantes regularmente matriculados no sistema de informação da Instituição de Ensino Superior. Com relação aos critérios de exclusão, foram respeitados os seguintes: i) acadêmicos que não estavam cadastrados no sistema de informação da Universidade; ii) interferências acadêmicas, religiosas, culturais ou qualquer natureza que interferisse na lisura da pesquisa. Apenas dois alunos não quiseram participar da pesquisa, não expuseram o motivo e a decisão foi respeitada. 
Entende-se como fatores de risco nesta pesquisa: constrangimento, estresse emocional, omissão de respostas relacionadas aos sentimentos de intimidação pela entrevista. Mesmo não tendo benefícios diretos aos sujeitos da pesquisa por participarem deste estudo, indiretamente fortalece a compreensão do fenômeno estudado e estimula a produção do conhecimento científico.

Para auxiliar o desenvolvimento da investigação foi utilizada entrevista com uso de roteiro semiestruturado, pois valorizou a presença virtual do investigador e ofereceu as perspectivas possíveis para que o informante tivesse liberdade e espontaneidade necessárias a uma investigação de enfoque qualitativo. Essa técnica parte de certos questionamentos básicos, permitindo ao informante a liberdade para seguir a linha de seu pensamento e de suas experiências dentro do foco principal colocado pelo investigador. (TRIVIÑOS, 2001; SILVA; RUSSO, 2019).

Após a assinatura do Termo de Consentimento Livre e Esclarecido (TCLE), no qual o entrevistado tinha acesso por e-mail, assinava, digitaliza e enviava ao pesquisador ficando com a via original, foram realizadas as entrevistas utilizando a gravação do áudio com duração em média de 9 minutos, sendo feitas em horários marcados em combinação com o entrevistado através da plataforma Google Meet com a transcrição na íntegra no mesmo dia, juntamente com a organização dos dados sociodemográficos.

Para assegurar o sigilo das informações, os depoentes foram numerados do "1" ao "14", conforme a sequência das entrevistas, e identificados pela letra "E".

A partir das transcrições na íntegra foi feita a depreensão dos temas principais que foram organizados e agrupados em blocos de significação, em que foi possível codificar os fragmentos das falas dos estudantes, dado bruto extraído, em unidades de representação daquilo que descreviam acerca das práticas educativas dos professores de uma Instituição Federal de Ensino Superior. Após leituras e releituras do dado bruto foi possível, pela técnica de análise de discurso de Fiorin, a compreensão das opiniões discentes expressas pelos estudantes por meio das categorias empíricas (FIORIN, 2005).

\section{RESULTADOS}


Descrição da caracterização do perfil sociodemográfico dos estudantes e apresentação dos elementos oriundos das transcrições de suas falas, contemplando, desta maneira, a amostra empírica de (5) graduandos de cursos da área da saúde, sendo (3) do curso de enfermagem, (1) da nutrição e (1) da farmácia; e (9) graduandos de cursos da área da educação, sendo (3) de ciências biológicas, (2) da química, (2) da física e (2) da matemática. Todos os graduandos eram alunos da Instituição Federal de Ensino Superior, portanto, viabilizando o confronto com o embasamento teórico da literatura pertinente.

Os dados coletados permitiram conhecer os aspectos sociodemográficos dos estudantes levando em consideração seus dados pessoais e acadêmicos. Compreendendo que a formação acadêmica é um pilar primordial para a construção e estruturação de um senso crítico, foi questionado aos entrevistados se estes já haviam tido contato ou formação em outro curso, tendo assim um predomínio de 93\% que não possuía outra formação enquanto $7 \%$ relatou formação técnica.

No que se refere ao estado civil, em torno de $93 \%$ afirmaram ser solteiros e $7 \%$ casados, apresentando um perfil acadêmico jovem com expectativas para contribuição social em curto, médio e longo prazo. Dos 14 entrevistados, 05 (36\%) cursam na área da saúde e $100 \%$ são do sexo feminino. Já os outros 09 participantes (64\%) cursam na área da educação sendo 04 (44\%) do sexo masculino e 05 (56\%) do sexo feminino. Desta forma, houve predomínio do sexo feminino nesta pesquisa.

A partir dos depoimentos, e baseado na técnica de análise de discurso, foi possível emergir duas categorias empíricas: I- Aspectos potencializadores das práticas educativas; IIAspectos limitadores das práticas educativas.

\subsection{Aspectos potencializadores das Práticas Educativas}

No tocante à análise dos depoimentos dos entrevistados foi possível observar o relato das práticas educativas que ancoram os processos de ensino e avaliação realizados pelos docentes que ministram aulas no Centro de Educação e Saúde (CES), sendo possível observar aspectos potencializadores nos depoimentos expostos:

Têm umas formas de avaliação em algumas disciplinas, principalmente as disciplinas pedagógicas da gente, então que eu acho muito interessante que as professoras, elas estimulam muito a gente a pensar, a desenvolver a nossa criatividade, o nosso senso crítico inclusive a pensar em novos métodos de avaliação pra gente usar na nossa profissão, elas usam muito a questão do debate na sala de aula, da 
participação do aluno e eu acho muito interessante essa questão, esse ponto de avaliação, principalmente o debate por que no debate é onde você pode perceber o que o aluno entende sobre aquele assunto, então fica bem melhor do que uma prova escrita. (Linha 123 a 137) E5 - estudante de um curso da área da educação

Muita gente não gosta, mas eu gosto de seminário, eu gosto de mapas mentais, ajuda bastante e alguns professores utilizaram, fizeram uso desse método. Investigação, assim, um estudo mais por investigação, o professor dá um determinado tema e faz com que a gente busque isso, faça uma investigação e eu gosto muito de artigo, quando os professores passam artigo para ser debatido em sala de aula e eu gosto também quando eles colocam vídeos, assim, pequenos, mas que são bem didáticos. (Linha 49 a 60) E7- estudante de um curso da área da educação

Na sala de aula a gente ter oportunidade de participar ativamente das aulas e fazer discussão e sempre as aulas parecerem que estão acontecendo, que tá rolando uma conversa e não ficar pesado. (Linha 52 a 56) E9 - estudante de um curso da área da saúde

Os professores são muito didáticos, a maioria, né? Como a gente tem muitas horas de aula, às vezes duas aulas seguidas, dá pra ver a teoria bem direitinho. (Linha 32 a

35) E3- estudante de um curso da área da saúde

\section{Aspectos limitadores das Práticas Educativas}

Quando os entrevistados foram questionados quanto aos aspectos limitadores das práticas educativas que ancoram os processos de ensino e avaliação utilizados pelos docentes que ministram aulas no Centro de Educação e Saúde (CES), foi possível visualizar a opinião dos estudantes nos trechos abaixo:

... por que aquele negócio de aula, só prova com passar o conteúdo e prova, eu acho que não tem muito aprendizado (Linha 44 a 46) E2 - estudante de um curso da área da saúde

Eu acho que precisava ter mais aula prática, acho que deixa um pouco a desejar nisso de ter pouca aula prática. (Linha 2 a 5) E3 - estudante de um curso da área da saúde

... porém na universidade eu sinto muito ainda aquele ensino tradicional por parte de alguns professores, aquele ensino onde o professor chega joga aquele conteúdo ali no quadro e explica e a gente, se não absorver ali, tem que meio que se virar sozinho. (Linha 48 a 54) E5 - estudante de um curso da área da educação

A avaliação em si não se dá, se dá pelo professor, né? Que, às vezes, a gente vai ter que fazer a prova, infelizmente a gente tem que fazer essa prova escrita, mas os professores geralmente dessa área abusam, né? Das provas. Por que não sabem outros métodos de avaliação, podem ser usados outros métodos de avaliação, né? Infelizmente, vai ter a prova, mas pode se usar as outras notas para fazer outras avaliações abertas que não sejam exatamente a prova. (Linha 45 a 55) E11 estudante de um curso da área da educação 


\section{DISCUSSÃO}

Aspectos potencializadores das Práticas Educativas

Pelos relatos, os professores utilizam diversas estratégias pedagógicas em suas práticas educativas: estímulo no pensamento crítico e reflexivo, debates, seminários, mapas mentais, investigação, discussão de artigos científicos e exposição de vídeos.

Entendendo que seja um aspecto potencializador das práticas educativas, não se pode assegurar se esses acadêmicos têm conhecimento dos tipos de práticas educativas e seus aspectos positivos e negativos. No entanto, seus relatos expressam admiração na escolha pedagógica dos professores quanto à diversidade de estratégias que têm utilizado no tocante ao ensino.

Parte-se do princípio que as práticas educativas que ancoram os processos de ensino e avaliação envolvem aspectos de cunho ideológico, ou seja, a atuação docente apresenta-se isenta de parcialidade e parte da triangulação do aprendizado do discente: a efetivação da ação educativa dos professores, o conteúdo programático e o espaço de tempo determinando (VIEIRA et al, 2020).

Essa triangulação do aprendizado pode ser apontada nas falas de E9 e E5, ao enfatizarem a participação ativa do aluno no ambiente acadêmico, principal característica das abordagens pedagógicas emancipatórias: “... a gente ter oportunidade de participar ativamente das aulas e fazer discussão" (E9), "... da participação do aluno" (E5). O diálogo entre professor e aluno assume o seu papel emancipatório por meio da relação horizontal, visando empatia, troca e respeito mútuo, entendido como aspecto potencializador das atividades laborais dos professores da Instituição de Ensino Superior pesquisada (VIEIRA et al, 2020).

Aspectos limitadores das Práticas Educativas

Diante da concepção empirista, o aluno é visto como ser passivo, desta forma, nele é depositada as informações e conhecimentos que, na teoria freiriana, é denominada de "educação bancária". Dispondo de atividades centradas unicamente no professor para a condução do processo ensino-aprendizagem e solicitação da reprodução desse 
conhecimento, ou seja, dependente unicamente do potencial cognitivo para efetivação da aprendizagem, pode-se afirmar a aproximação com a educação bancária, postulada por Paulo Freire, em professores da área da educação e saúde. (RUIZ-MORENO; PITTAMIGLIO; FURUSATO, 2008; ANDRADE et al, 2018).

Os métodos de avaliação tradicionais aspiram à fiel reprodução do conteúdo passado em sala de aula e devem ser armazenados pelos alunos, tendo maior importância a quantidade, em detrimento à qualidade dos assuntos entendidos. A ênfase na execução de provas escritas (objetivas ou subjetivas) como principal meio avaliativo, calculado por notas, ainda é praticado na sociedade em defesa da aquisição do patrimônio cultural (GURGEL; LEITE, 2007; ANDRADE et al, 2018).

Vale ressaltar que alunos da área da saúde apontam como aspecto limitador a oferta mínima de aulas práticas preconizadas pelas Resoluções Nacionais que instituem as Diretrizes Curriculares dos Cursos. As aulas práticas convergem com a pedagogia histórico-crítica pelo propósito de oportunizar o exercício profissional de maneira dinâmica e diferenciada ao estimular melhor atitude e desempenho docente, melhor interação professor e aluno, processo avaliativo diferenciado por levar em consideração as peculiaridades do desempenho de cada aluno, além do desenvolvimento psíquico diante da atividade fictícia realizada (SILVA, 2014; QUEIROZ et al, 2020).

Desta forma, observam-se atividades docentes que se aproximam de práticas educativas emancipatórias como as insuficientes aulas práticas, embora com processos avaliativos concentrados na realização de provas, na opinião de estudantes da área da saúde e da educação, revelando opção por práticas educativas não emancipatórias.

\section{CONSIDERAÇÕES FINAIS}

Diante dos resultados expostos foi possível conhecer os aspectos potencializadores e limitadores das práticas educativas docentes ficando evidente a escolha por diversas estratégias pedagógicas em suas atividades laborais: estímulo no pensamento crítico e reflexivo, debates, seminários, mapas mentais, investigação, discussão de artigos científicos, exposição de vídeos, aulas práticas e utilização da prova como método avaliativo principal. 
Esse arsenal de práticas educativas ancora abordagens pedagógicas emancipatórias e não emancipatórias demonstrando avanço pedagógico diante da possibilidade de reconsiderar as ações docentes em vistas à superação de metodologias tradicionais por meio da operacionalização dos pressupostos da Resolução Nacional que institui as Diretrizes Curriculares, como as aulas práticas.

Embora seja realizada em uma Instituição Federal de Ensino Superior de um pequeno município paraibano, este estudo poderá levar à reflexão a necessidade de atualização da Matriz Curricular dos Cursos de Bacharelado, atendendo aos anseios modernos por práticas educativas emancipatórias, podendo subsidiar futuras pesquisas docentes no tocante ao aprofundamento teórico da formação acadêmica, em nível de graduação/bacharelado, dos cursos das áreas de educação e saúde.

O aprofundamento da temática, embora limitada ao espaço micropolítico do desenvolvimento de um Centro Universitário, poderá contribuir de forma efetiva para reflexões frutíferas envolvendo estratégias emancipatórias voltadas à formação do enfermeiro.

\section{REFERÊNCIAS}

ERDMANN, A.L.; SANTOS, J.L.G.; KLOCK, P.; SODER, R.M.; SASSO, G.T.M.D.; ERDMANN, R.H. Políticas, gerência e inovação de grupos de pesquisa para a excelência em enfermagem. Aquichan, Chía, Colombia, 2013. v. 13, n. 1, p. 92-103. Disponível em: <https://docs.bvsalud.org/biblioref/2020/09/49939/2346-14467-1-pb.pdf> Acesso em: 09 mai 2018.

FIOCHI, P.I.C.Q. (2016). Uma reflexão sobre a pesquisa e a produção de conhecimento na universidade. Revista de Psicologia da UNESP, 15(1), 17-25. Disponível em: $<$ http://pepsic.bvsalud.org/scielo.php?script=sci_arttext\&pid=S198490442016000100002\&lng=pt\&tlng=pt>. Acesso em: 15 Jun 2021.

FARIAS, L.D.; SILVA, C.C. Administração em enfermagem: desvelando as bases conceituais, metodológicas e pedagógicas de seu ensino em João Pessoa-PB. Cienc. Cuid Saúde, 2008. v. 7, n. 1, p. 37-44. Disponível em:

$<$ http://www.ccs.ufpb.br/ppgeold/dissertacoes2007/dissertacaolucianadantas.pdf $>$. Acesso em: 15 Jun 2021.

LIBANEO, J.C. Democratização da Escola Pública: a pedagogia crítico - social dos conteúdos. 20. ed. São Paulo: Loyola, 2005. Acesso em: 15 Jun 2021. 
MINAYO MCS. O Desafio do conhecimento: pesquisa qualitativa em saúde. 10. ed. São Paulo: Hucitec/Abrasco, 2007. 406 p. Acesso em: 15 Jun 2021.

COSTA, C.; LOUREIRO, C. (2019). Interdisciplinaridade, Materialismo Histórico-Dialético e Paradigma da Complexidade: Articulações em Torno da Pesquisa em Educação Ambiental Crítica. Pesquisa em Educação Ambiental. 14. DOI: https://doi.org/10.18675/2177580X.vol14.n1.p32-47. Acesso em: 15 Jun 2021.

BRASIL. Ministério da Saúde. Resolução 466/12 do Conselho Nacional de Saúde/MS: Diretrizes e Normas Regulamentadoras de Pesquisa envolvendo seres humanos. Diário Oficial da União, 13 de junho de 2013. Disponível em: http://conselho.saude.gov.br/resolucoes/2012/reso466.pdf. Acesso em: 09 mai 2018.

FONTANELLA, B.J.B.; LUCHESI, B.M.; SAIDEL, M.G.B. RICAS, J.; TURATO, E.R.; MELO, D,G. Amostragem em pesquisas qualitativas: Proposta de procedimentos para constatar saturação teórica. Cad. Saúde pública, Rio de Janeiro, 2011. v.27, n.2, p.389-394. Disponível em: https://www.scielosp.org/article/csp/2011.v27n2/388-394/. Acesso em: 09 mai 2018.

SILVA, L.; RUSSO, R. (2019). Aplicação de entrevistas em pesquisa qualitativa. Revista de Gestão e Projetos, 10(1), 1-6. DOI: https://doi.org/10.5585/gep.v10i1.13285. Acesso em: 15 Jun 2021.

TRIVIÑOS, A.N.S. Bases teórico-metodológicas da pesquisa qualitativa em ciências sociais. Caderno de Pesquisa, 2001. v. 4, n.1, p. 73-106. Acesso em: 09 mai 2018.

FIORIN, J.L. Elementos de análise do discurso. São Paulo: Contexto 2005. Acesso em: 09 mai 2018.

VIEIRA, S.L.; SILVA, G.T.R.; SILVA, R.M.O.; AMESTOY, S.C. Diálogo E Ensino-Aprendizagem Na Formação Técnica Em Saúde. Trab. educ. saúde, Rio de Janeiro, 2020. v.18, supl. 1, e0025385. DOI: https://doi.org/10.1590/1981-7746-sol00253. Acesso em: 15 Jun 2021.

RUIZ-MORENO, L. PITTAMIGLIO, S.E.L.; FURUSATO, M.A. Lista de discussão como estratégia de ensino-aprendizagem na pós-graduação em Saúde. Interface (Botucatu), Botucatu, 2008. v.12, n.27, p.883-892. DOI: https://doi.org/10.1590/S1414-32832008000400017. Acesso em: 24 Set 2020.

ANDRADE, L.D.F.; GERMANO, H.S.; PINTO, M.B.; OLIVEIRA, L.C.S.; MEDEIROS, H.A.; LIMA, E.A.R. (2018). Práticas educativas que ancoram a formação de recursos humanos em um curso de bacharelado em enfermagem. Revista de Enfermagem e Atenção à Saúde, [Online]. Jan/Jul 2018, v.7, n.1, p. 89-101. DOI: https://doi.org/10.18554/reas.v7i1.1989. Acesso em: 15 Jun 2021.

GURGEL, C.R.; LEITE, R.H. Avaliar aprendizagem: uma questão de formação docente. Ensaio: Avaliação e Políticas Públicas em Educação [online], Rio de Janeiro. 2007, v.15, n.54, p. 145168. DOI: https://doi.org/10.1590/S0104-40362007000100009. Acesso em: 24 Set 2020. 
SILVA, V.C.; VIANA, L.O.; SANTOS, C.R.G.C. Prática social e pedagógica do enfermeiropreceptor: um estudo de caso. Online Braz J Nurs [online]. 2014; 13(1):102-12. Disponível em: <http://www.revenf.bvs.br/pdf/objn/v13n1/v13n1a12.pdf>. Acesso em: 15 Jun 2021.

QUEIROZ, A.C.; DANTAS, M.C.S.; QUEIROZ, A.M.; ANDRADE, L.D.F. Concepção de discentes acerca das práticas educativas que ancoram a disciplina gestão em enfermagem ii. SALUSVITA, Bauru, v. 39, n. 3, p. 671-682, 2020. Disponivel em: <https://secure.unisagrado.edu.br/static/biblioteca/salusvita/salusvita v39 n3 2020/salusv ita v39 n3 2020 art 04.pdf>. Acesso em: 15 Jun 2021. 


\title{
GESTÃO DE MUDANÇAS E LIDERANÇA: ANÁLISE DE CASO ENVOLVENDO UMA INSTITUIÇÃO FEDERAL BRASILEIRA
}

\author{
João Batista Coelho \\ Mestrado em Sistemas de Gestão (MSG) \\ Laboratório de Tecnologia, Gestão de Negócios \& Meio Ambiente (LATEC) \\ Universidade Federal Fluminense (UFF) \\ Maria Alice Nunes Costa \\ Instituto de Arte e Comunicação Social (IACS) e \\ Programa de Pós-Graduação em Sociologia e Direito (PPGSD) da \\ Universidade Federal Fluminense (UFF)
}

\begin{abstract}
RESUMO
O objetivo deste estudo concentra-se na identificação de como os gestores (lideranças) atuaram na gestão de mudanças decorrente de um alinhamento estratégico que resultou na fusão de diversos setores de uma organização do poder público brasileiro. Foi realizada uma investigação empírica - com entrevistas semiestruturadas e aplicação de questionário - e comparados os resultados com a literatura existente a fim de observar como os gestores conduziram o processo de mudança organizacional. Dentre os achados figura a percepção de que a literatura científica serve como um bom parâmetro para o desenvolvimento de estudos preventivos que possam minimizar impactos em processos de gestões de mudanças. Este estudo contribui para a abordagem sobre a atuação de lideranças em gestões de mudança e em processos que demandem fusões setoriais, no sentido de que integra a literatura sobre organizações dos setores público e privado, enriquecendo a literatura e ampliando as possibilidades de observações sobre o tema. Fornece evidências empíricas sobre a atuação das lideranças nos níveis estratégico, tático e operacional, no âmbito da administração pública, colaborando para a redução de complexidades em processos similares por vir.
\end{abstract}

Palavras-chave: cultura organizacional, gestão de mudança, fusão setorial, liderança na gestão pública. 


\section{ABSTRACT}

\section{CHANGE MANAGEMENT AND LEADERSHIP: CASE ANALYSIS INVOLVING A BRAZILIAN FEDERAL INSTITUTION}

The focus of this study is to identify how leaders acted in the change management of a strategic alignment which resulted in the merger of several sectors of a public brazilian institution. An empirical investigation was conducted - with semi structured interviews and quiz application and the results were compared to existing literature in order to observe how the leaders drove the process of organizational change. Among findings is the perception that scientific literature is a good parameter for developing preventive studies able to minimize impacts on change management processes. This study contributes to the approach on the role of leaders in change management and in processes that demand sectoral mergers, in the sense that it integrates the literature on public and private sector organizations, enriching the literature and expanding the possibilities of observations on the subject. It provides empirical evidence on the role of leaders at the strategic, tactical and operational levels within the public administration, helping to reduce complexities in similar processes to come.

Keywords: organizational culture, change management, sectorial merger, leadership in public administration. 


\section{INTRODUÇÃO}

Este trabalho apresenta uma análise das práticas de liderança em um processo de gestão de mudanças em uma instituição pública brasileira. Neste propósito, realizou-se um survey junto aos servidores que integravam os setores de duas unidades administrativas, que passaram por um processo de fusão administrativa entre os anos de 2013 e 2016. Utilizou-se como instrumento de coleta de dados um questionário auto aplicado para 221 servidores que integraram esse processo de unificações setoriais, o qual envolveu 8 (oito) áreas distintas das duas organizações.

Um dos temas recorrentes no âmbito da administração pública no Brasil tem sido a permanente necessidade de se otimizar as práticas administrativas, a fim de que possa adotar estratégias da iniciativa privada e acompanhar as evoluções nos métodos gerenciais que guiam o mundo empresarial e, assim, modernizar a prestação de serviços públicos (BERGUE, p. 38,2020$)$.

As demandas por maior qualidade e agilidade na prestação de serviços vem se somando às exigências da sociedade para que o Estado reduza custos e fiscalize com austeridade os recursos utilizados pelas organizações públicas. A fim de satisfazer tais condições, faz-se visível que as modernas metodologias de gerenciamento, utilizadas na iniciativa privada, vêm sendo progressivamente incorporadas à gestão pública (ALVES, 2015; MATIAS-PEREIRA, 2014; NOGUEIRA et al., 2012).

A Emenda Constitucional no 19, de 4 de junho de 1998, estabeleceu, dentre outros, o Princípio da Eficiência na administração pública brasileira, passando a exigir que a atividade administrativa fosse "exercida com presteza, perfeição e rendimento funcional". (MEIRELLES, 2016). Em consonância com as determinações constitucionais, o Conselho Nacional de Justiça (CNJ), órgão que visa, dentre outros objetivos, o aperfeiçoamento do sistema judiciário, em 18/03/2009, emitiu a Resolução no 70, que definiu as diretrizes do planejamento estratégico nacional do Poder Judiciário brasileiro e um roteiro de gestão administrativa a ser seguido em todas as instâncias judiciárias do país, a fim de que a prestação jurisdicional, em sua totalidade, alcançasse níveis similares, e melhores, de eficiência. Em seu artigo 2ำ a resolução determinou que todos os tribunais brasileiros elaborassem seus planos estratégicos, adotando uma metodologia única, que trouxesse, para a estrutura organizacional do Judiciário, ferramentas, processos de trabalho e soluções também utilizados pela iniciativa privada. Para tanto, foram 
definidos, os macro desafios do Poder Judiciário Nacional, ou seja, metas a serem alcançadas. Foram propostos para o quinquênio de 2009 a 2014 e, posteriormente, revisados pelas Resoluções do CNJ no 198/2014 e no 325/2020, respectivamente, para os períodos de 2015 a 2020 e de 2021 a 2026.

Segundo Vasconcelos (2009), para que o planejamento estratégico ocorresse de forma adequada e as metas estipuladas pelo CNJ fossem cumpridas, cada unidade organizacional do Judiciário deveria estabelecer suas estratégias coerentemente alinhadas ao Plano Estratégico Nacional. Nesse sentido, um dos órgãos do Judiciário, visando à necessidade de aprimorar recursos materiais e humanos, e tendo como alvo a uniformização de procedimentos e a fixação de diretrizes únicas para a sua administração realizou um alinhamento institucional promovendo a junção de setores com atividades afins, de unidades organizacionais distintas. O alinhamento implicou a adoção de dependências únicas para o corpo funcional e na reestruturação de cargos e funções comissionadas. Assim, a partir de 2013, serviços administrativos similares que eram até então realizados simultaneamente pelas duas unidades, começaram a ser executados por setores únicos.

O alinhamento em questão, além de ter mobilizado fatores objetivos, de ordem material, envolveu aspectos de ordem humana. Consoante, houve reações pessoais em virtude de questões como os remanejamentos, temporários ou permanentes, de pessoal e local de trabalho, as trocas de chefias, as perdas de funções comissionadas, dentre outros motivos. Destarte, o processo envolveu o campo das percepções, dos valores individuais, assim como das identidades coletivas (grupais), convergindo para uma análise de como os gestores/lideranças atuaram na gestão de mudança.

O problema desta pesquisa origina-se, portanto, no aparente desempenho insatisfatório das lideranças em situações de gestão de mudanças nas instituições públicas brasileiras. Este trabalho apresenta uma análise das práticas de liderança no universo das organizações do poder público. Para isto, realizou-se um levantamento bibliográfico dos principais modelos de liderança e de gestão de mudanças e, a seguir, uma pesquisa do tipo survey junto aos stakeholders críticos, utilizando-se como instrumento de coleta de dados um questionário auto aplicado, com base na escala de Likert. (SILVA JUNIOR; COSTA, 2014).

Este artigo está dividido em quatro seções. A seção 1 faz uma revisão da literatura a fim de referenciar a pesquisa em sua trajetória de esclarecimentos, a partir dos problemas 
levantados; a 'seção 2', faz um delineamento da pesquisa e descreve os métodos utilizados para apurar os problemas levantados; a 'seção 3' faz uma análise e discute os resultados; e na 'seção 4' constrói-se a conclusão e sugestões para pesquisas futuras.

\section{REVISÃO DA LITERATURA}

Considerando que nas diretrizes do alinhamento institucional proposto para o Judiciário, priorizou-se a adoção de ferramentas e de soluções utilizadas pela iniciativa privada, ao tentar entender o papel das lideranças nos processos de gestão de mudança e de fusões organizacionais, examinaram-se fontes teóricas voltados para a administração pública e abordagens temáticas centradas no universo da gestão empresarial.

Drucker (1981), defendendo a necessidade de se ampliar a visão sobre o campo de aplicação da prática gerencial e da aferição de resultados destacou que nossa concepção de gestão se baseia na distinção que fazemos entre as organizações com fins lucrativos e as com fins sociais, mas para ele, a presença de um lucro convencional é uma diferença secundária entre as organizações. Destacou ainda que as entidades não empresariais, cujo fim último não é o lucro, por existirem para atender ou satisfazer algum tipo de necessidade ou interesse coletivo da sociedade, costumam sofrer, em seus quadros, carência de pessoal com aptidão ou conhecimento para exercerem os cargos de gerenciamento o que, consequentemente, possibilita o aparecimento de más gestões e planejamentos organizacionais precários (DRUCKER, 1981).

Para superar a carência de bons gestores nos quadros técnicos dos órgãos públicos, existe o recurso da livre nomeação de pessoas, que podem ocupar cargos de chefia ou assessoramento. Conhecidos como cargos de confiança, eles não criam vínculos estatutários e são regidos pela CLT (Consolidação das Leis Trabalhistas), ou seja, são de contratação direta e dispensam concurso público. Tais cargos estão previstos na Constituição Federal (Inciso XIII/Art. 40) e podem ser ocupados por pessoas do quadro institucional ou não.

No tocante à possibilidade de se fazer uso da livre contratação de pessoas para cargos comissionados, sejam elas servidores do quadro ou pessoas de fora da organização, faz-se visível na esfera da política brasileira, a frequente utilização de tais cargos como cabides de emprego, a fim de beneficiar protegidos políticos. Matias-Pereira, em Deda (2008), lembra que a livre nomeação, além de colaborar para a ineficácia administrativa, aumenta a 
possibilidade de corrupção na esfera do Poder Público, pois os indivíduos contratados para exercerem tais cargos, acabam criando apenas vínculos temporários, em decorrência das constantes mudanças políticas, não assumindo assim, de forma duradoura, "compromisso com a máquina pública, diferentemente do que ocorre com os concursados." Destaca ainda que há um excesso de cargos em comissão no país, e, à guisa de comparação, lembrou que na Inglaterra "o ministro só nomeia o seu secretário particular. Abaixo dele, todos os servidores são de carreira" (DEDA, 2008).

Ao criticar o crescimento do número de cargos comissionados no governo federal, Matias-Pereira lembrou que "quando loteiam cargos no governo, o critério não é de competência nem de postura ética. O critério é político." (SAMPAIO, 2015). Moreira (2009) destaca que a designação de pessoas, pautada apenas no relacionamento com quem as indica, sem respeitar o critério da competência técnica necessária ao cargo é tão ofensiva aos princípios constitucionais da administração - legalidade, impessoalidade, moralidade, publicidade e eficiência - quanto à pratica do nepotismo direto, vetada pela Súmula Vinculante $n$ o 13, do STF. No caso da designação pautada em critérios unicamente políticos, fruto de interesses subjetivos entre agentes públicos e privados existe a ideia de que tais conexões gerem perda de produtividade (COELHO \& BARROS, 2021).

Teixeira, Bassoti e Santos (2014), destacam, na administração pública brasileira, os apadrinhamentos como grandes dificultadores para a existência de gestões mais eficazes. Lembram que o modelo weberiano burocrático, que dá ênfase à eficiência, alcançada por meio da informalidade e impessoalidade, nunca foi plenamente aplicado em nosso país.

Após os processos de reforma por que passou a administração pública em diversos países do mundo, a partir da década de 1980, motivados pelo neoliberalismo que prosperou em conjunto com a interdependência global da economia, os princípios do modelo weberiano, passaram a ser considerados deficientes. Países como a Grã-Bretanha e diversos outros da Europa, EUA, Canadá, Austrália, Nova Zelândia, saíram na frente em busca de um modelo de gestão no setor público que seguissem regras que se aproximassem da iniciativa privada (FAGANELLO, 2017, p.47).

Muito tem se falado sobre a contínua necessidade de mudanças nas organizações a fim de acompanharem um mundo corporativo cada vez mais dinâmico e competitivo. Tais mudanças, recorrentemente acabam por implicar a necessidade de produção de novos sentidos, no que 
tange aos valores que direcionam e impulsionam a vida da organização. Esses valores são, assim, os reveladores de uma cultura organizacional.

Partindo de uma observação mais ampla sobre cultura organizacional, a fim de caminhar para uma aproximação maior com as questões implícitas na gestão de mudanças, há que se destacar pontos básicos da visão de três dos maiores pensadores da cultura organizacional. Hofstede (1991), ao falar de cultura organizacional destaca que a cultura é como uma programação mental, quando os indivíduos vão apreendendo, ao longo da vida, padrões de pensamento, sentimentos e propensões para agir. Essa programação é que distingue um grupo de outro. Organizacionalmente, a cultura reflete a forma como os funcionários foram socializados por sua organização de trabalho. Trompenaars (2000), por seu turno, enfatiza que uma determinada cultura organizacional não é nada mais do que a maneira pela qual os grupos se organizaram ao longo dos anos para resolver problemas e desafios que Ihes são apresentados. Schein (2009), ao adentrar em gestão de mudanças, destaca que os conceitos para se tornarem úteis devem partir de fatos observáveis e darem sentido ao que existe de misterioso e pouco entendido no campo comportamental e atitudinal na vida de grupos e organizações. Ao abordar a complexidade das mudanças culturais nas organizações, o autor conclui que a mudança cultural surge da necessidade de solucionar problemas organizacionais.

Sobre o tema, Bastos et al. (2011) apontam dois padrões de mudanças: episódico e contínuo. As episódicas se caracterizam como mais radicais, amplas, descontínuas e intencionais; as mudanças contínuas são demarcadas por sua frequência continuada e natureza incremental e não intencional. Estas últimas são fomentadas pelos processos de aprendizagem que se dão no decorrer das atividades diárias da organização.

Ao abordar os vínculos do indivíduo com a organização Pinho, Bastos e Rowe (2015) destacam que a literatura vem dedicando especial atenção ao tema do comprometimento e da obediência organizacionais. Inserem ao tema os construtos de "consentimento" e "entrincheiramento". Explicam entrincheiramento como sendo um processo de "aprisionamento do indivíduo à organização empregadora, um comportamento marcado pela acomodação, pois o empregado necessita se manter na organização em função dos benefícios que recebe e para garantir a própria sobrevivência". Os autores descrevem o consentimento como "uma condição de subserviência para o trabalhador, condição que o submete a uma 
avaliação negativa enquanto pessoa e profissional." Segundo eles, entrincheiramento e consentimento são reveladores de um quadro de adoecimento organizacional que envolve tanto o indivíduo como a organização.

Em pesquisa realizada por eles, onde aplicaram 400 questionários para servidores das administrações públicas Municipal, Estadual e Federal, incluindo órgão do Poder Judiciário, constataram que no tocante aos vínculos de comprometimento e entrincheiramento dos servidores públicos, há mais servidores comprometidos do que entrincheirados. Indivíduos casados, com filhos e alto grau de responsabilidade, apresentam nível de comprometimento e entrincheiramento altos e, também, quanto maior o nível educacional, mais alto é o nível de entrincheiramento (RODRIGUES E BASTOS, 2013).

Para Dom e Ahmad (2019), o desempenho organizacional é o resultado de uma empresa medido em relação às metas planejadas. Para os autores, é fundamental que os gestores de uma empresa entendam o desempenho organizacional para realizar uma mudança cultural. Kuipers, em Steijn et al. (2016), lembra que, em muitos órgãos do poder público, equipes são montadas a partir do entendimento de que, para que existam, basta juntarem mais que uma pessoa. Kuipers, destaca que "equipes são muito mais do que a soma de suas partes" e que não é tão simples pensar que, para a melhor execução de uma tarefa, seja suficiente uma equipe para se superar o desempenho do fazer individual.

Kuipers e Groeneveld (2014), em pesquisa voltada para o desempenho na Gestão Pública, com equipes distritais holandesas de profissionais que atuam para o bem-estar infantil, constataram que o grau de envolvimento dos profissionais, era invariavelmente, elevado. Perceberam a importância de três fatores para o sucesso: a cooperação entre os profissionais para alcançarem objetivos comuns; a colaboração orientada para as tarefas, onde se constatou que quanto maior a troca de informações e conhecimentos entre os profissionais, melhor era o desempenho das equipes e, no tocante à liderança, percebeu-se que onde existiam gerentes que melhor comunicassem a visão envolvida, dando autonomia para os membros individuais da equipe, melhor era o desempenho desta.

Agune (2014) projeta um escritório governamental do futuro e diz que em vez de salas isoladas deverá haver estímulos às atividades intersetoriais e transdisciplinar com utilização de novas mídias e tecnologias que permitam "flashs" instantâneos de problemas ou situações a serem enfrentados, substituindo relatórios burocráticos que só mascaram a realidade e 
postergam a ação de governo, e, também, a criação de laboratórios de gestão onde problemas inéditos, e/ou de alta complexidade poderão ser examinados em profundidade e de forma criativa, dando origem a protótipos de vários tipos - novos serviços, aplicativos internos, aplicativos para smartphones, metodologias para participação em mídias sociais, etc. (AGUNE, 2014).

Sena Neto (2019) menciona que embora comumente associe-se gestão governamental eletrônica apenas ao desenvolvimento das Tecnologias da Informação e Comunicação (TIC), a ideia de Governo Eletrônico traz consigo outras questões importantes como a ideia de controle social, quando a população passa a poder intervir diretamente nas ações públicas, opinando e participando da gestão pública.

Perides et al. (2020) enfatizam que o principal objetivo do gerenciamento de mudanças é minimizar o impacto da resistência à mudança. Sobre a resistência à mudança, Kuipers (2014) lembra que apesar de ser um tema comum na literatura de gestão de mudança, estudos vem mostrando que no âmbito da gestão pública a resistência à mudança ainda é uma questão importante, no entanto, não parece haver um consenso sobre o que provoca as resistências e como elas podem ser superadas (KUIPERS et al., 2014).

Aristos et al. (2018) em estudo focado na incorporação entre duas empresas da iniciativa privada, ao revisar a literatura com foco na resistência às mudanças, afirma ser esse um grande desafio e demonstra que a literatura aponta os impactos culturais como grandes responsáveis pelos insucessos das fusões. Phul e Procópio (2014), em estudo de caso sobre a administração do Poder Judiciário Federal, apontam este Poder como o mais resistente a mudanças no Brasil, entretanto lembram que as modernizações organizacionais ganharam força com o processo de democratização do país, após Constituição de 1988.

Kuipers (2014), citando Oreg (2007), que validou uma escala de resistência à mudança, destacou que encontrou na personalidade e no contexto da mudança os motivos para as resistências. Segundo ele, funcionários públicos resistem às mudanças, porque antecipam resultados indesejados, mas lembra que Vann (2004) não considera que as expectativas dos funcionários possam ser influentes. Kuipers conclui que é necessário examinar a evolução das respostas do funcionário às mudanças ao longo do tempo, ou seja, compreender as respostas que surgem de baixo para cima. Kuipers destaca que Branco (2000) aponta a estratégia de gestão de mudança como a chave para o sucesso e evidencia que uma abordagem de 
gerenciamento de mudanças de cima para baixo não funciona porque leva os funcionários a um processo de muita resistência.

Pieterse (2012), indo além das respostas dos funcionários aos processos de mudança, centrou-se nas possíveis diferenças presentes na linguagem usada pelos profissionais que trabalham em projetos de mudança e inovação. Ele evidencia que apesar das organizações mudarem e se adaptarem continuamente para se manterem competitivas, a eficácia em mudanças organizacionais ainda é muito baixa. Ele lembra que estatísticas recentes revelam que apenas um terço dos esforços de mudança organizacional foram considerados bem sucedidos.

Pieterse et al. (2012) aborda os processos de mudança a partir de uma perspectiva do discurso e argumenta que cada programa de mudança contém dimensões subjetivas que envolvem produção de sentido e interações informais. Para ele, a maneira como as pessoas interpretam um projeto de mudança é refletida na linguagem. Quando diferentes grupos profissionais que cooperam num programa de mudanças dão significados diferentes para a situação da mudança, essas diferenças podem resultar em resistências.

Hameed et al. (2019) em sua pesquisa sobre gestão de mudanças no setor público, partindo do pressuposto de que fatores contextuais, como comunicação envolvida, afetam a capacidade cognitiva dos funcionários, concluem que funcionários com uma identificação organizacional (OID) forte, são mais propensos a aceitarem mudanças e que as incertezas em torno da mudança podem dificultar o processo de mudança. Voet, Kuipers e Groeneveld (2013), dizem que em um processo planejado de mudança, a elevada qualidade da comunicação e o alto grau de participação devem ambos ser esperados a fim de influenciar positivamente o compromisso afetivo dos funcionários para mudarem. Destacam que o papel da liderança é geralmente visto como essencial durante a execução da mudança organizacional, mas a atenção fica muitas vezes focada na alta administração ou na equipe de coalizão administrativa da mudança. Além disso, pautados em Holt, Armenakis, Feild \& Harris (2007) lembra que o apoio da alta gerência é de suma importância para a iniciativa de mudar. Mencionam ainda que embora o papel da alta administração seja frequentemente enfatizado durante o início da mudança, supervisores diretos desempenham um papel muito importante durante a implementação da mudança (VOET; KUIPERS; GROENEVELD, 2013)." 
Cameron (2008) parte do pressuposto de que toda mudança organizacional não requer apenas liderança, mas também "campeões" e "proprietários". Para ele as mudanças de cultura não correm frouxas nas organizações, elas demandam a presença de líderes que ajam e dirijam todo o processo de forma consistente. Ele destaca, dois postos-chaves que devem ser considerados. Um deles é que cada aspecto do processo da mudança de cultura (iniciativa estratégica, processo de comunicação etc.) precisa de um campeão ou alguém que aceite a sua propriedade a fim de que a implementação da mudança seja bem-sucedida. A responsabilidade será também mais bem mantida quando designada uma equipe de "proprietários" da iniciativa, pois este conjunto de indivíduos garantirá maior participação e compromisso. Lembra ainda que não somente os líderes atuais da organização devem defender a mudança, mas um grupo de futuros líderes deve estar preparado para liderar a organização quando a mudança de cultura for colocada em prática. Menciona que pesquisadores contemporâneos abordam a liderança como uma forma de interação social que envolve componentes afetivos, motivacionais, éticos, atitudinais dentre outros.

Tee, Ashkanasy e Paulsen (2013) destacam que na última década houve um aumento da percepção do importante papel que as emoções desempenham na relação lideresseguidores. As pesquisas vêm se liberando do pressuposto de que apenas a lógica e a racionalidade são objetos importantes de observações nos processos de liderança. Tse, Ashkanasy e Dasborough (2012) abordam a visão de que as relações de troca interpessoais entre os líderes, os subordinados e os colegas de trabalho estão interligados e incorporados dentro de uma rede social maior nas organizações. Eles sugerem que estas relações de trocas são interdependentes e podem exercer influências mútuas. Apontam, em particular, a qualidade diferencial das relações descritas na Teoria LMX, de Intercâmbios entre Líderes e Membros, que analisa a amplitude das negociações líder-membro a partir de referenciais psicológicos de comparação interpessoal. Eles postulam que a identificação social tem o potencial de aumentar a auto compreensão que está relacionada com a forma como os funcionários se percebem e se imaginam em um grupo de trabalho e que, por conseguinte, também podem estar associadas às suas reações comportamentais.

Yukl (2013) entende a liderança como sendo "o processo de influenciar os outros a entender e concordar sobre o que precisa ser feito e como fazê-lo, e o processo de facilitar os esforços individuais e coletivos para alcançar os objetivos compartilhados". Em HASSAN et al. 
(2013), Yukl fala das lideranças éticas e do "empoderamento" de lideranças - que seria a delegação de confiança do gestor a funcionários capacitados para decidirem em seu lugar quando estiverem ausentes. Em tempos atuais de crises financeiras, recessões e constantes escândalos envolvendo líderes de organizações privadas e governamentais, a ética, a superação da dependência e a liberdade para decidir passaram a ser valorizados.

Para Banks et al. (2021), a liderança ética e suas práticas continuarão ganhando relevância no século XXI. HASSAN et al. (2013), dizem que a ética e o "empoderamento" de membros da organização são comportamentos suscetíveis de serem associados com a alta qualidade de relacionamentos de troca líder-membro da LMX. Liderança ética e liderança "empoderada", na LMX, podem estar associadas a uma variedade de resultados importantes, incluindo a motivação subordinada, a satisfação, o desempenho, os comportamentos pró-sociais entre outros. Líderes com relações de troca favoráveis são mais propensos a serem percebidos como eficazes e capazes de induzirem os subordinados a compromissos afetivos com a organização. Para HASSAN et al. (2013) as relações de troca de alta qualidade são mais prováveis de ocorrer quando os líderes são honestos, dignos de confiança, e genuinamente preocupados com o bem-estar de seus seguidores.

Segundo Kavanagh e Ashkanasy (2006), os autores Van Knippenberg e Hogg (2003) e Van Dick (2004) argumentam que, em grupos de alta relevância com os quais as pessoas se identifiquem fortemente, a eficácia da liderança é significativamente influenciada pela forma como o líder é percebido pelos membros do grupo. E ainda ressaltam que Conger e Kanungo (1988) e Kotter (1988) enfatizam que os líderes precisam entender que a gestão se refere a processos de planejamento, organização e controle, enquanto a liderança é o processo de motivar as pessoas a mudar.

Salem et al. (2019), somam aos desafios a exigência de que os líderes reconheçam e respeitem proativamente as identidades de subgrupos distintos na cultura da organização. Segundo Hoog, Van Knippenberg e Rast (2012), um dos achados mais robustos da pesquisa sobre o comportamento intergrupal é que os grupos definem quem somos. O desafio para a liderança intergrupal é superar práticas competitivas e abrandar as diferenças entre os grupos, a fim de construir a cooperação e colaboração a serviço de uma visão única e de mesmos propósitos. Eles lembram que é a percepção subjetiva dos membros que impulsiona os comportamentos intergrupais. 
Citando Nadler, Thies e Nadler (2001), Kavanagh e Ashkanasy (2006) lembram que para que ocorram mudanças efetivas e, em particular, mudanças culturais, é imprescindível o envolvimento ativo do CEO e da equipe executiva. A esse posicionamento pode-se associar o resultado das investigações de Collins (2011) que revelou que os melhores líderes são pessoas humildes, capazes de se sacrificarem em nome da organização e de abrirem mão de seu bemestar pessoal visando o bem comum da organização (COLLINS, 2011).

Kavanagh e Ashkanasy (2006) consideram a necessidade de se observar as gestões de topo, pois muitas fusões se perdem por estarem mal enquadradas pelo topo. Lembram que Weber (1989 e 1996) e Weber, Schweiger e Lubatkin, (1992), dizem que quando em uma fusão por aquisição existem diferenças culturais entre as equipes de topo, e se são percebidas pelo parceiro não dominante (empresa adquirida), grandes problemas de recursos humanos serão experimentados pela adquirente (KAVANAGH; ASHKANASY, 2006 apud WEBER, 1989 e 1996 e WEBER; SCHWEIGER; LUBATKIN, 1992).

Weber (2011), relata que os pesquisadores de comportamento organizacional afirmam que a principal causa de falhas em fusões e aquisições é a desatenção com o fator humano durante o processo de planejamento e implementação da fusão. Dirva e Radulescu (2018) em caminho parecido, atribuem a causa do insucesso nos mesmos processos à relutância do funcionário em mudar. Weber (2015) conclui que os processos de fusões de empresas, apesar de cada vez mais intensificados no mundo inteiro, vêm apresentando um histórico de baixo desempenho e a apuração dos motivos desses maus resultados ainda deixa muito a desejar, mantendo-se parcialmente incógnitos.

Lubis \& Hanum (2020) destacam que uma cultura forte se refletirá no alto desempenho organizacional e para finalizar, vale lembrar o clássico Trompenaars (2000), que ao conceituar cultura organizacional cita que uma cultura é relativamente estável quando as normas refletem os valores do grupo. Se não for este o caso, muito provavelmente haverá uma tensão desestabilizadora.

\section{METODOLOGIA}

A pesquisa foi estruturada a partir das relações entre gestores/lideranças e colaboradores que se estabeleceram no universo das fusões setoriais ocorridas, configurando- 
se destarte o objeto de estudo como um fenômeno ativo, onde os sujeitos entrevistados afirmavam valores diante das mudanças. Para conduzir o presente estudo, formulou-se então as seguintes questões norteadoras: “'questão (i)' Existe alinhamento entre as práticas de liderança identificadas na pesquisa de campo e a literatura científica sobre o tema?" e “'questão (ii)’ Quais as deficiências das lideranças em processos de mudança administrativa em instituições públicas?"

De caráter descritivo-exploratório, a pesquisa foi realizada de janeiro a maio de 2016 e teve como objeto de estudo a atuação das lideranças em processo de gestão de mudanças caracterizado por fusões setoriais no âmbito da administração pública, tema pouco explorado, que por si, já se insere nas premissas metodológicas do ineditismo em pesquisa. O objetivo foi avaliar o alinhamento entre práticas e teoria, confrontando a práxis do processo estudado com os referenciais teóricos vinculados à temática (VAGARINHO, 2019).

O método de pesquisa adotado foi o survey, que tem por objetivo a descrição de fenômenos através da coleta estruturada de dados, com a utilização de questionários ou entrevistas (BRYMAN, 1989). É um método que permite a participação de um número grande de entidades, sem a intervenção direta do pesquisador na coleta de dados. E diante da mencionada carência de pesquisas voltadas para as fusões organizacionais no setor público, e no Poder Judiciário, que tivessem estudado a atuação de lideranças em gestões de mudanças, a abordagem quali-quantitativa se fez mais apropriada, destarte foram realizadas entrevistas semiestruturadas e aplicação de questionários, com o intuito de abranger todos os níveis de gestão: estratégico, tático e operacional.

$\mathrm{Na}$ impossibilidade de entrevistar individualmente todos os integrantes do universo estudado, foram realizadas 6 (seis) entrevistas semiestruturadas com 2 (dois) magistrados, 2 (dois) gestores e 2 (dois) servidores, considerando-se a posição estratégica e o nível de participação destes no processo estudado. Foram assim coletados, por meio de gravação, um total de 4 horas e 34 minutos de depoimentos.

As entrevistas semiestruturadas serviram para se obter um melhor entendimento do processo e orientar na elaboração do questionário único. Nelas, foram considerados aspectos interligados ao processo, das primeiras comunicações oficiais sobre o alinhamento até as ações estratégicas em curso. Como roteiro guia, foram elaboradas as 18 perguntas a seguir: 
Figura 1: Roteiro guia das entrevistas semiestruturadas

\begin{tabular}{|c|c|c|}
\hline \multicolumn{2}{|c|}{ Perguntas básicas: } & \multirow[t]{2}{*}{ Observações } \\
\hline 01 & $\begin{array}{l}\text { Como o(a) senhor(a) tomou } \\
\text { conhecimento da decisão de se fundir } \\
\text { setores? }\end{array}$ & \\
\hline 02 & Como o(a) senhor(a) reagiu? & \\
\hline 03 & $\begin{array}{l}\text { Qual foi sua primeira impressão a } \\
\text { respeito dessa decisão? }\end{array}$ & \\
\hline 04 & $\begin{array}{l}\text { Como o corpo funcional/ os seus } \\
\text { funcionários/ os colegas reagiram à } \\
\text { decisão? }\end{array}$ & Dependendo se juiz, gestor ou funcionário \\
\hline 05 & $\begin{array}{l}\text { O que é a fusão para o(a) senhor(a) em } \\
\text { uma única palavra? }\end{array}$ & \\
\hline 06 & $\begin{array}{l}\text { Quais foram os principais desafios } \\
\text { enfrentados no processo de fusão? }\end{array}$ & \\
\hline 07 & Quais os pontos fortes da fusão? & \\
\hline 08 & E os pontos fracos? & \\
\hline 09 & $\begin{array}{l}\text { Houve resistências à fusão em seu } \\
\text { setor? }\end{array}$ & \\
\hline 10 & Quais foram as resistências? & \\
\hline 11 & E quais as motivações? & \\
\hline 12 & $\begin{array}{l}\text { Qual foi a solução encontrada para resolver } \\
\text { os conflitos decorrentes da fusão? }\end{array}$ & \\
\hline 13 & $\begin{array}{l}\text { O que acha que poderia ter sido feito para } \\
\text { a fusão ter sido totalmente bem sucedida? }\end{array}$ & Condicionada às respostas anteriores \\
\hline 14 & E o que poderia ter sido evitado? & Idem \\
\hline 15 & $\begin{array}{l}\text { Qual a importância dos gestores para a } \\
\text { fusão? }\end{array}$ & \\
\hline 16 & $\begin{array}{l}\text { Como os gestores motivaram o grupo à } \\
\text { mudança (fusão)? }\end{array}$ & \\
\hline 17 & $\begin{array}{l}\text { Quais as maiores dificuldades } \\
\text { encontradas pelos gestores? }\end{array}$ & \\
\hline 18 & O que faltou para os gestores? & \\
\hline
\end{tabular}

Pautando-se nos principais pontos de interesse percebidos nas seis entrevistas semiestruturadas, e considerando-se as reflexões construídas com a revisão da literatura, formulou-se um questionário único para ser aplicado a todos os funcionários envolvidos no processo de fusão setorial. Esse questionário teve 6 (seis) "perguntas-chave", apurando características básicas - origem funcional, estágio alcançado pelos setores na fusão, função ocupada pelo servidor durante o processo, nível de escolaridade, faixa etária e tempo de casa -e 25 afirmações a fim de se auferir pela escala de Likert as percepções dos entrevistados sobre o processo de fusão. 
Figura 2: Questionário com as referências teóricas

As 6 (seis) primeiras perguntas, de caráter objetivo, intituladas "perguntas-chave", serviram para definir os traços principais do perfil dos respondentes. As 25 afirmações seguintes foram formuladas pela Escala de Likert a fim de auferir as percepções individuais no tocante a fusão, assim como visões gerais relativas ao processo. Para a apuração dos dados, considerou-se que toda a população, composta por 221 integrantes em exercício, identificados diretamente através das chefias dos setores envolvidos, esteve representada na amostra, composta, ao final, por 171 respondentes.

Gráfico 1: Percentuais de questionários respondidos em relação ao total de formulários distribuídos e em relação ao universo total
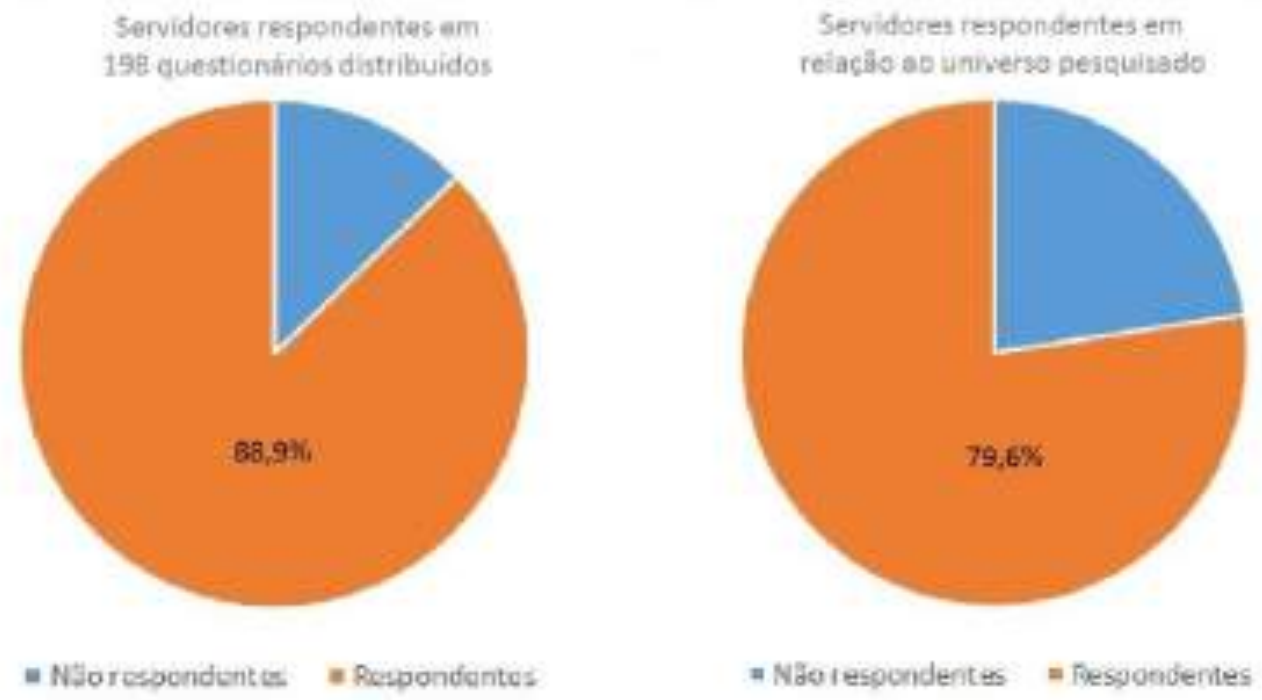

Fonte: o autor, 2016

Cada uma das 25 afirmações apresentadas foi analisada individualmente e entrecruzadas com as 6 (seis) perguntas-chave. 0 entrecruzamento das 6 perguntas-chave com as 25 afirmações produziu um total de 181 gráficos percentuais, entretanto para responder às duas questões de pesquisas aqui propostas foram priorizados os resultados de 94 gráficos do total produzido.

\section{ANÁLISE E DISCUSSÃO DOS RESULTADOS}

Para se proceder a uma análise de resultados sobre atuações de liderança, foi importante saber, antecipadamente nas entrevistas, o que se espera de um líder. Nos depoimentos dos 6 
(seis) entrevistados as expectativas sobre a atuação dos gestores nas fusões setoriais fizeram-se claras. Na fala de um dos depoentes, lembrou-se que um dos desafios das lideranças era "convencer os servidores a irem trabalhar com outros, sem que houvesse uma aproximação prévia, e convencê-los de que aquele procedimento seria benéfico para a instituição e para eles." Foi lembrado ainda que uma de suas funções nas fusões setoriais era minimizar conflitos, que são inevitáveis no processo, e conseguir nivelar conhecimentos e procedimentos entre equipes que sempre operaram de modos distintos. Kavanagh e Ashkanasy (2006), destacam a necessidade de uma gestão voltada para atender aos fatores humanos e culturais nos processos de fusões e de mudanças culturais.

Nos depoimentos colhidos, ao apontarem os desafios enfrentados pelos gestores no processo de fusão, os entrevistados fazem críticas à falta de planejamento, a falta de transparência e a falta de humildade dos responsáveis para reconhecerem erros. Esses relatos, que ilustram parcialmente a 'questão (ii)', remetem ao resultado das investigações de Collins (2011) que revelou que os melhores líderes são pessoas humildes, capazes de se sacrificarem e abrirem mão de seu bem-estar pessoal visando ao bem comum da organização. HASSAN et al. (2013), fala também das relações de troca de alta qualidade possíveis de acontecer quando os líderes são honestos, dignos de confiança, e genuinamente preocupados com o bem-estar de seus seguidores.

Ainda com foco na 'questão (ii)', uma das queixas ao planejamento do processo foi a não previsão de tempo, pelos gestores de topo, para que os servidores pudessem se dedicar ao aprendizado das muitas tarefas novas que surgiram com a fusão. Um depoente ressaltou que o volume de atividades que os servidores executavam já era imenso antes da fusão. Em complemento, ele disse ter tido a sorte de ter uma chefia que detinha conhecimento amplo do funcionamento de tudo e que esta assumiu todos os problemas como se fossem seus. Nesse ponto, faz-se visível que o servidor via seu líder como um "proprietário" e um "campeão", aspectos imprescindíveis para o sucesso das mudanças, segundo Cameron (2008).

Ressaltando deficiências no nível estratégico, o que se junta à 'questão (ii)', um dos depoentes falou na importância em se trabalhar com resultados em um processo de unificação setorial. Ele explicou que "trabalhar com resultados, no início, é sempre difícil por que tem que se fazer uma readequação de toda a estrutura, rever as chefias". Sobre essa revisão dos postos de gestão, Cameron (2008) diz que não somente os líderes atuais da 
organização devem defender as mudanças, mas um grupo de futuros líderes já deve estar sendo preparado para liderar a organização quando as mudanças forem colocadas em prática. Os novos líderes que serão necessários à futura cultura devem ser escolhidos e as diferenças entre os requisitos da liderança atual e os da futura devem ser especificadas. Nesse sentido, as atividades de aprendizagem são determinantes para aprimorar os conhecimentos e competências de liderança.

Em relação aos questionários, apresentamos a análise sobre as opções selecionadas pelos respondentes, em relação às afirmações propostas. Para responder à 'questão (i)', serão aqui consideradas as afirmações 3, 10, 18, 19, 21, 22 e 25 formuladas no questionário aplicado.

Com a afirmação 3, teve-se o intuito de se perceber em que nível de gestão se deu a materialização das fusões propostas. A maioria dos servidores $(32,7 \%+17 \%)$ acreditou ter havido maior peso das estratégias traçadas pelos gerentes de área no processo de fusão do que de um plano estratégico institucional. Voet, Kuipers e Groeneveld (2013) dizem que em um processo planejado "o papel da liderança é geralmente visto como essencial durante a execução da mudança organizacional." E apesar da atenção ficar, em muitos casos, focada na alta administração ou na equipe de coalizão administrativa da mudança, "supervisores diretos desempenham um papel muito importante durante a implementação da mudança".

Gráfico 2: Visão sobre os responsáveis pelas estratégias traçadas

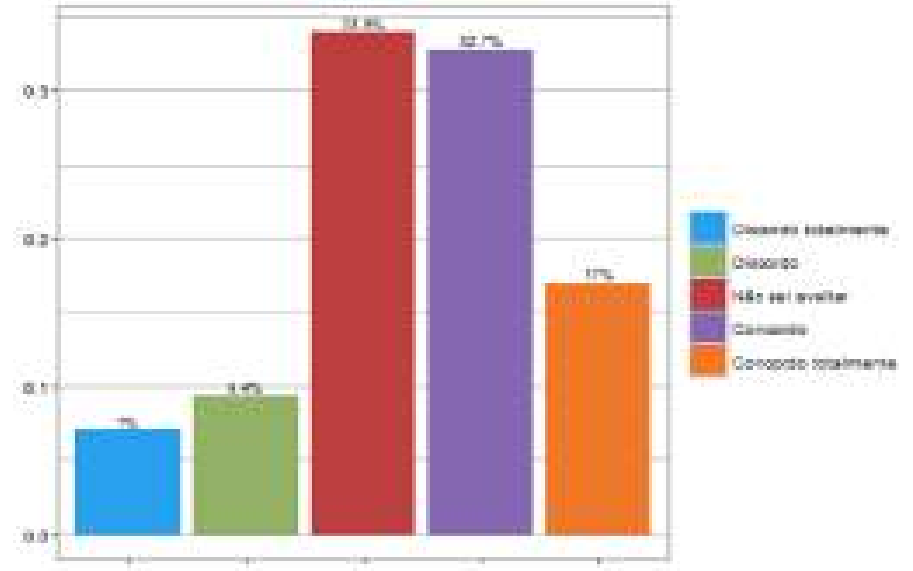

Fonte: o autor, 2016

A afirmação 10 carregou em seu bojo a faculdade de permitir que se procedesse a uma análise do poder de influência dos líderes sobre o grupo. Com apenas $19,9 \%(15,8 \%+4,1 \%)$ de discordâncias, os resultados mostraram que $52,1 \%$ dos respondentes concordaram que a 
conduta dos líderes/gestores foi influenciadora nas reações à mudança, ratificando o observado por Yukl (2009).

Gráfico 3: Influência dos gestores nas reações às mudanças

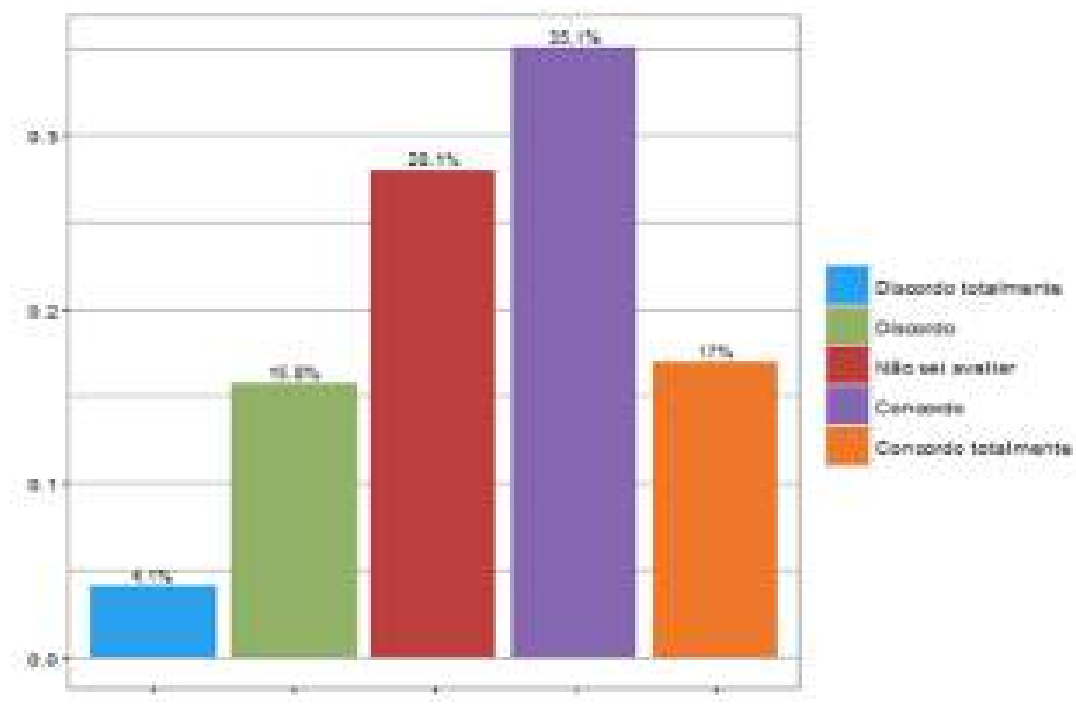

Fonte: o autor, 2016

Na afirmação 18 checou-se a ocorrência de uma estratégia comum no exercício da liderança: a concessão de benefícios para estimular o engajamento dos servidores. Entendendose aqui benefício como qualquer ação que favoreça ou recompense o servidor, $73,7 \%$ (52,6\% + $21,1 \%) ;$ dos respondentes concordou que tais benefícios se revertem em um maior engajamento de todos os servidores nos processos de trabalho.

Gráfico 4: Resultado de benefícios concedidos pelos líderes

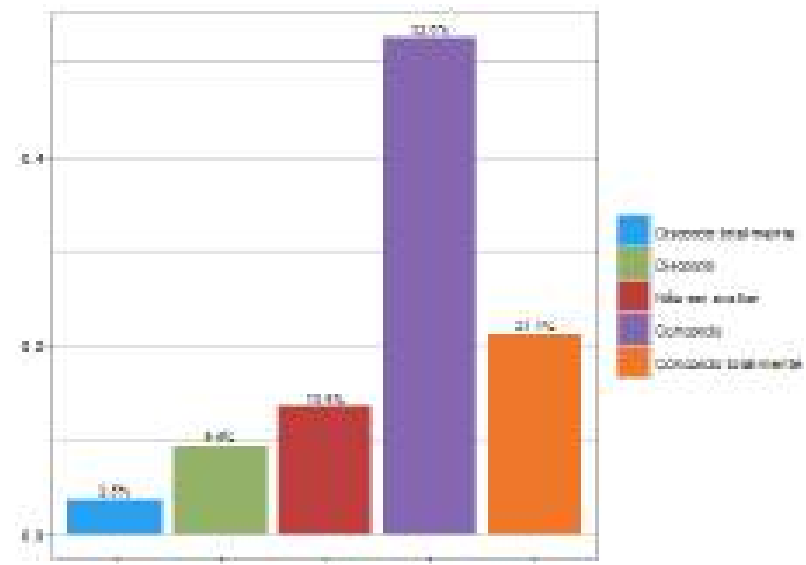

Fonte: o autor, 2016

Essa questão merece observações outras que dizem respeito à conduta geral adotada pela organização que anulou a importância da cessão de benefícios e seguiu por caminho contrário. Desta forma, vale destacar o depoimento do servidor que disse que para o processo 
ter sido bem sucedido "Não [deveria] mexer no bolso das pessoas! Veja, como é que você vai trabalhar mais, muito mais, tendo os seus incentivos pecuniários retirados ou diminuídos?! (...) Mas o que ocorreu mesmo, é que ótimos funcionários perderam suas gratificações com a fusão e aí rolou uma inversão, pois os funcionários foram punidos por trabalharem bem."

Schein (2009) lembra que "a natureza das recompensas e punições conduzem as mensagens. Os líderes podem, rapidamente, conduzir com sucesso suas prioridades, valores e suposições ao vincular conscientemente as recompensas e punições ao comportamento que os afeta." Desta forma, percebe-se que no processo de fusão estudado a decisão de cortes de gratificações, que veio pronta da administração superior, demostrou que a alta administração não se atentou para mecanismos básicos, como os efeitos das punições e recompensas, nas relações de liderança.

$\mathrm{Na}$ afirmação 19, verificou-se a existência de "empoderamentos" no exercício dos gestores. Percebeu-se pelo resultado que uma relativa maioria dos respondentes $(35,7 \%+8,8 \%)$ disse concordar que os gestores souberam delegar autoridade a fim de que os servidores se sentissem mais participativos e responsáveis. Segundo Hassan et al. (2013) "a ética e o empoderamento" de membros da organização são comportamentos suscetíveis de serem associados com a alta qualidade de relacionamentos de troca entre líder e membro.

Gráfico 5: Delegação de autoridade pelos gestores a outrem

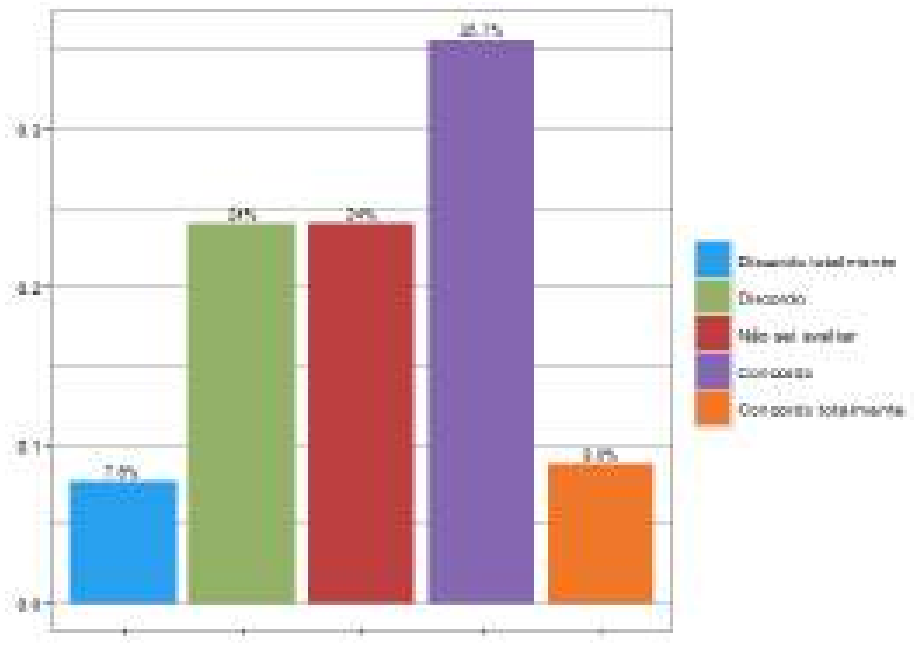

Fonte: o autor, 2016

Na afirmação 21, a lealdade do gestor à organização é o ponto central. Pelos resultados percebe-se que a grande maioria dos respondentes, $73,7 \%(46,8 \%+26,9 \%)$, concorda que essa lealdade do gestor à organização é um fator determinante para o envolvimento das equipes com 
as mudanças. Conforme HASSAN et al. (2013), no cenário atual mundial, marcado por crises morais, as relações de lealdade e compromisso dos membros com as organizações vem sendo cada vez mais valorizadas. Tse, Ashkanasy e Dasborough (2012) colocam como postulado que o relacionamento de alta qualidade demanda lealdade, afeto, contribuição e respeito profissional.

Gráfico 6: Lealdade do gestor à instituição é determinante

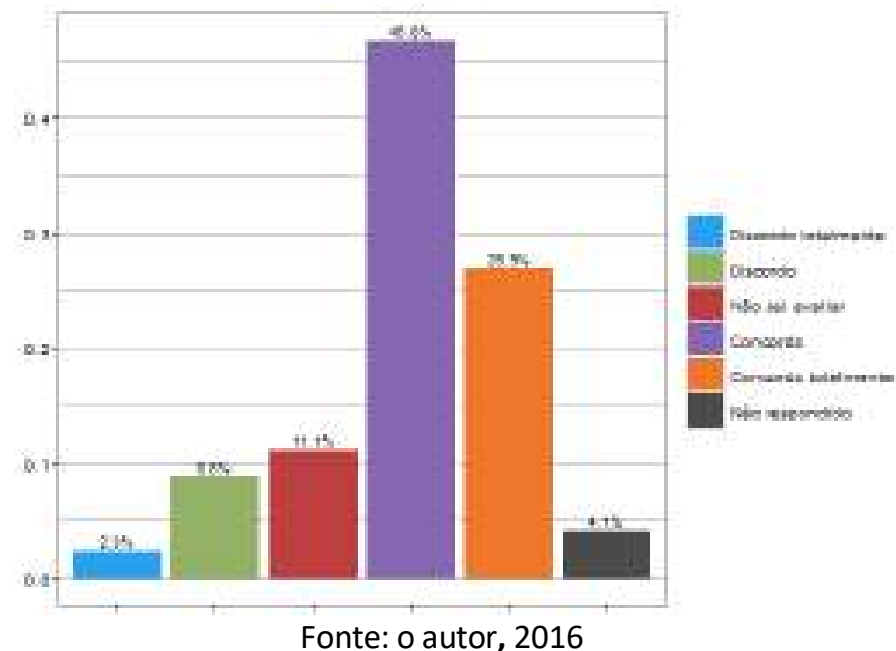

Ao ser analisada em conjunto com a afirmação 22 , a afirmação 13 , averiguou-se o gestor de órgãos públicos enfrenta pressões de diferentes grupos de interesse, tornando sua atuação vulnerável aos interesses pessoais. $75 \%$ dos respondentes concordou que eles estão suscetíveis a isso, fato que reflete um quadro crítico do funcionalismo público brasileiro marcado pelas práticas das nomeações políticas. O professor Matias-Pereira, expressando-se sobre o sistema estabelecido na Administração Pública, comenta que "quando loteiam cargos no governo, o critério não é de competência nem de postura ética. O critério é político". Esse fato é sem dúvida um empecilho à boa administração e um dos dificultadores nos processos de reestruturações, quando implicam na nomeação de novos gestores.

$\mathrm{Na}$ afirmação 22 foi possível ver que a maior parcela dos respondentes, 78,9\% (38\% + 40,9\%), concorda que os cargos em comissão da gestão pública, beneficiando, por vezes, pessoas despreparadas para ocupá-los, é uma realidade e eles podem atrapalhar as mudanças organizacionais. 
Gráfico 7: Despreparo em cargos em comissão podem obstaculizar

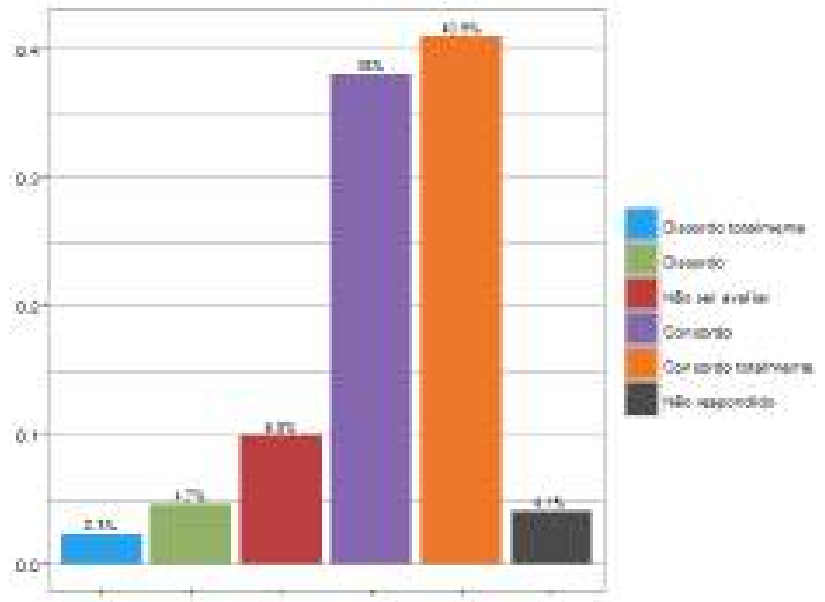

Fonte: o autor, 2016

Moreira (2009) lembra que a livre contratação para cargos em comissão deveria rigorosamente respeitar os princípios constitucionais da legalidade, impessoalidade, moralidade, publicidade e eficiência. Teixeira, Bassotti e Santos (2014) e Coelho e Barros (2021), destacam que na administração pública brasileira, os apadrinhamentos são grandes dificultadores na busca por gestões mais eficazes.

$\mathrm{Na}$ afirmação 25, tentou-se detectar se os gestores haviam desenvolvido boas soluções para minimizar os conflitos interpessoais que surgiram no processo de fusão. A maior parte dos respondeu afirmativamente. Segundo o ponto de vista de Schein (2009), diante das crises o papel das lideranças ganha visibilidade. É quando se pode perceber como líderes lidam com a necessidade de se criar novas regras, valores e procedimentos.

Gráfico 8: Ações para minimizar conflitos

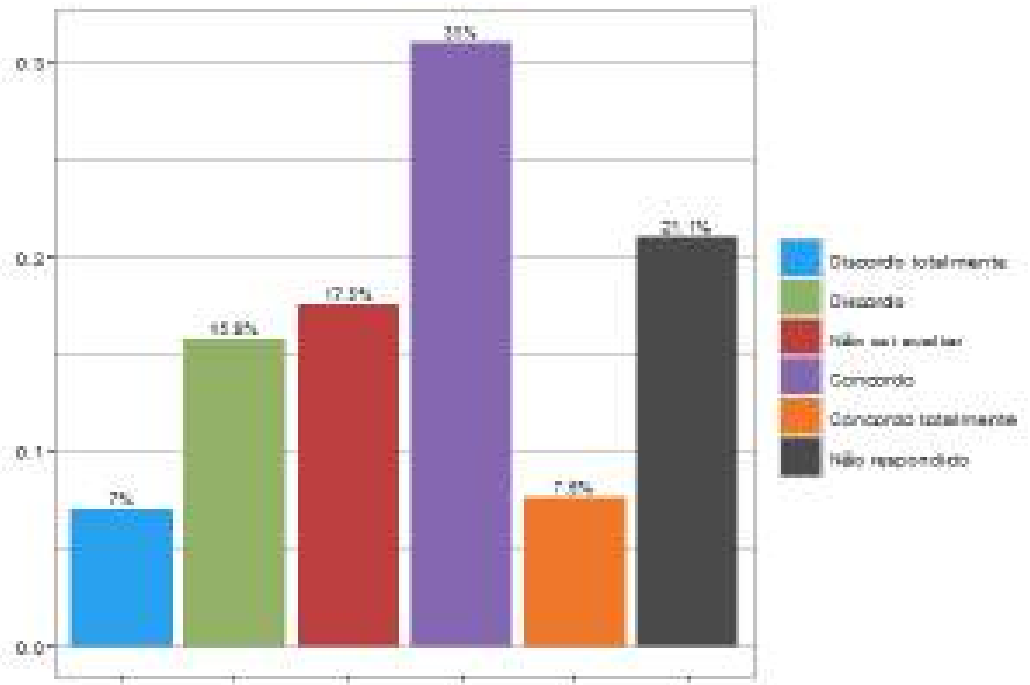


Fonte: o autor, 2016

Em síntese, no tocante à "questão (i)", o que se pode perceber a partir da correlação entre a prática e as concepções teóricas é que apesar da existência de estudos sugerindo formas para se conduzir um processo de fusão, não se pode desconsiderar o que cada caso demanda e o contexto social em que ocorrem, assim como as singularidades de cada grupo (ou organização) envolvido no processo. Desta forma, não se objetivando que se depreenda da literatura um processo padronizador para as práticas das lideranças no processo de gestão de mudanças, percebe-se, a partir dos comparativos ora construídos que existiu satisfatório alinhamento entre as práticas das lideranças identificadas na pesquisa de campo e a literatura científica sobre o tema.

Kuipers (2014), ao mencionar que a resistência à mudança nas fusões, é um tema recorrente nos estudos sobre aquisições de organizações no âmbito da iniciativa privada, lembrou que a literatura vem mostrando ser esse assunto também é uma questão importante no âmbito da gestão pública e que "não parece haver um consenso sobre o que provoca as resistências e como elas podem ser superadas". Destarte, considerando os resultados das afirmações 13 e 22, assim como a revisão da literatura, e desconsiderando as peculiaridades de cada processo de resistência, mesmo que a atuação das lideranças possa em muitos casos minimizá-las, percebe-se, na tentativa de responder à "questão (ii)", que, no referente ao Brasil, as deficiências das lideranças em processos de mudança administrativa no setor público podem se revelar de múltiplas formas. Mas, é consenso que, é na recorrente supremacia dos critérios políticos sobre os critérios técnicos, que resultam na nomeação de gestores mal preparados para ocupar, principalmente, os cargos de alta liderança nas organizações públicas, onde se pode encontrar o fato motivador de muitas das deficiências que se sucedem nos processos de gestão de mudanças na administração pública.

Dentre os resultados obtidos, destacaram-se então que respeitadas as diferenças contextuais de cada caso onde se processa uma gestão de mudança, a literatura científica serve como um bom parâmetro para conduzi-la; que a resistência às mudanças é traço recorrente nos processos de gestão de mudança, seja na esfera da administração pública ou da privada e ainda que a subestimação da gestão de pessoas é uma falha cometida por muitos gestores no universo da administração pública, a qual pode conduzir fusões ou processos similares ao insucesso. 


\section{CONCLUSÕES}

O que se pode perceber a partir da correlação entre a prática e as concepções teóricas, é que apesar de estudos existentes sugerirem formas para se conduzir em um processo de fusão, não se pode desconsiderar as singularidades de cada caso - sejam as especificidades decorrentes do contexto social em que se dão, sejam as particularidades de cada grupo da organização. Há que sempre se considerar esses fatores como componentes dificultadores para a criação de processos padronizadores para fusões setoriais. A título de complementação, vale ainda considerar o mencionado por Kuipers (2014), que diz que apesar das resistências à fusão ser um tema recorrente nos estudos sobre fusões de organizações no âmbito da iniciativa privada, deve-se lembrar que a literatura vem mostrando ser esse um assunto importante no âmbito da gestão pública. Entretanto, "não parece haver um consenso sobre o que provoca as resistências e como elas podem ser superadas". Desta forma, pode-se concluir que encontrar modelos que avaliem inteiramente um processo de integração entre culturas organizacionais distintas ainda se apresenta como um importante desafio para os estudiosos do tema.

Sena Neto (2019) e Agune (2014) destacam que os processos decisórios no mundo corporativo tornaram-se, necessariamente, cada vez mais velozes e as organizações governamentais estão tendo que evoluir sob a pena de se tornarem obsoletas e não conseguirem atender, minimamente, o público em tempos razoáveis e com qualidades aceitáveis. É fato imperativo na modernização da administração pública, que planejamentos estratégicos, reestruturações setoriais e aperfeiçoamentos de processos de trabalho, venham sendo comumente promovidos a fim de se alcançar melhores resultados nos modelos de governança. Apesar das abordagens de Voet, Kuipers e Groeneveld (2013), Kuipers e Groeneveld (2014), Hassan et al. (2013), dentre outras fontes citadas, ressaltarem a importância de as lideranças estarem atentas para o bem estar de seus seguidores e destacarem a importância do engajamento dos colaboradores, ainda se percebe que a subestimação da gestão de pessoas é uma falha cometida por muitos gestores no universo da administração pública e que pode levar fusões e processos similares ao insucesso.

Assim, se a organização não tem, dentre as suas prioridades, o bem-estar dos funcionários e a satisfação profissional, ela tende a experimentar uma alta taxa de 
rotatividade dentre seus colaboradores e, em decorrência, perdas de capital intelectual e mais gastos com novas contratações e treinamentos. Quando se fala em 'rotatividade' de funcionários, raramente se associa diretamente o termo ao universo do serviço público, visto que a estabilidade acaba sendo considerada como um atrativo imperativo para a manutenção dos vínculos empregatícios na administração pública. Isto é fato, mas insatisfações com processos mal geridos podem levá-los comumente a trocarem de setores dentro da organização, a buscarem transferências para outros órgãos ou até mesmo fazerem outros concursos públicos, em busca de carreiras públicas mais satisfatórias.

Esse fato deve ser também complementado sobre a ótica de Bastos e Rowe (2015), que mencionam, que a falta de perspectiva daqueles servidores que não desejam ou não conseguem se lançar em busca de uma carreira nova, principalmente por já se encontrarem no final de uma carreira funcional, gera o discutido entrincheiramento, um comportamento marcado pela acomodação, pois o empregado necessita se manter na organização para garantir os benefícios adquiridos com o decorrer do tempo, assim como a sua própria sobrevivência. Essa acomodação pode ser vista então como o prenúncio de uma resistência às mudanças. Destarte, os servidores entrincheirados podem vir a se tornar o maior desafio para gestores do setor público, pois o que estes esperam de suas equipes de trabalhos é que os indivíduos estejam engajados e demonstrem comprometimento na realização das metas e objetivos da organização, motivações raras quando na condição de entrincheirados. Logo, o entrincheiramento pode, assim, se configurar como um fator representativo em mudanças malfadas contribuindo para as avaliações deficitárias das lideranças abordadas na 'questão (i)'.

Diagnosticadas as deficiências em processos de mudanças administrativas em instituições públicas, tendo como base o alinhamento entre as práticas apuradas no trabalho de campo e as teorias existentes, percebe-se que a pesquisa desenvolvida poderá trazer contribuições futuras na apuração de muitas outras questões correlacionadas aos fluxos relacionais entre lideranças e colaboradores assim como possibilitar o desenvolvimento de investigações visando a produção de estudos preventivos para minimizar impactos e conduzir as fusões a melhores resultados. 


\section{REFERÊNCIAS}

AGUNE, Roberto. Governo no Século XXI. In: Dá pra fazer - Gestão do conhecimento e inovação em governo. (autores Roberto Agune ... [et al.]). São Paulo: Secretaria de Planejamento e Desenvolvimento Regional, p.23-33, 2014.

ARISTOS, D; GEORGIOS, S.; MILTIADIS, C; GRIGORIOS, K. The impact of mergers and acquisitions on corporate culture and employees: the case of aegean \& olympic air, Academy of Strategic Management Journal, v. 17, Issue 1, 2018

ALVES, Paulo Vicente. Gestão Pública Contemporânea. Rio de Janeiro: Editora Alta Books, 2015.

Banks, G. C., Fischer, T., Gooty, J., Stock,G. (2021). Ethical leadership: Mapping the terrain for concept cleanup and a future research agenda, The Leadership Quarterly, 32(2), 1-14

BASTOS, Antonio Virgílio Bittencourt; SOUZA, Janice Janissek de; COSTA, Vânia Medianeira Flores; PEIXOTO, Adriano de Lemos Alves. A Adoção de Novas Práticas de Gestão: explorando o esquema cognitivo dos atores em empresas com diferentes padrões de inovação. Revista de Ciência da Administração, v. 15, n. 31, p. 243-268, set/dez. 2011

BEER, M.; NOHRIA, N. Cracking the code of change. Harvard Business Review, May/June, p. 133-41, 2000.

BURKE, W. W. Organization change: theory and practice. Thousand Oaks: Sage publications, 2010.

BERGUE, Sandro Trescastro. Gestão estratégica de pessoas no Setor Público. 2. ed. Belo Horizonte: Fórum, 2020. p. 15

CAMERON, K. A process for changing organizational culture. In: CUMMIINGS, T. G. (Org.), Handbook of Organizational Development. California: Sage Publications, 2008.

Carson, K. D.; Bedeian, A. G. Career commitment: construction of a measure and examination of its psychometric properties. Journal of Vocational Behavior, v. 44(3), p. 237-262, 1994 Coelho, C.C.; Barros, A. Padrinhos e caciques: o lado sombrio da atividade corporativa na captura do Estado. Curitiba: Revista Eletrônica de Ciência Administrativa, v.20, n.1, p. 14-42, Jan-Abr, 2021

COLLINS, J. Level 5 Leadership: The triumph of Humility and Fierce Resolve. In: On leadership. Boston: Harvard Business Review Press. P.115 - 136, 2011.

CONGER, J. A.; KANUNGO, R. N. The empowerment process: Integrating theory and practice, Academy of Management Review, v.13, pp. 471-182, 1988. 
DAM, van K. OREG, S.; SCHYNS, B. Daily work contexts and resistance to organizational change: The role of leaders-member exchange, development climate, and change process characteristics. Applied Psychology, v. 57(2), p. 313-334, 2007.

DEDA, R. Elevado número de cargos em comissão facilita o nepotismo. A Gazeta do Povo, Curitiba, 14. set. 2008. Disponível em: <http://www.gazetadopovo.com.br/vidapublica/elevado-numero-de-cargos-em-comissao-facilita-o-nepotismob6e2yaib0y6ggk5lykri4cy1a> Acesso em 29. out. 2015.

Dîrvă, C., Rădulescu, A. S. (2018). Managing resilience to change in merger and acquisitions. Romanian Economic Journal, 21(68), 145-160.

Dom F. R., Ahmad A. (2019). An impact of cultural change on employees engagement and organization performance: a literature review, ICBEISS 2019: International Conference on Business, Education, Innovation \& Social Sciences, Kuala Lumpur, Malaysia, 29 June

DRUCKER, P. F. Fator humano e desempenho. 1. ed., São Paulo: Cengage Learning, 1981.

FAGANELLO, Cláudia Piccoli. Balanço do Gerencialismo: análise da influência do modelo de administração pública gerencial no período de 1995 a 2017. Dissertação (Mestrado) - Instituto de Filosofia e Ciências Humanas, Universidade Federal do Rio Grande do Sul, Porto Alegre, 2017

HAMEED, I KHAN, A. K.; SABHARWAL, M.; ARAIN, G. A,; Irfan HAMEED, I. Managing Successful Change Efforts in the Public Sector: An Employee's Readiness for Change Perspective. Review of Public Personnel Administration, USA, v. 39, Issue 3, 1-24, 2019

HASSAN, S.; MAHSUD, R.; YUKL, G.; PRUSSIA, G. E. Ethical and empowering leadership and leader effectiveness, Journal of Managerial Psychology, v. 28, p.133-146, 2013.

HOFSTEDE, G. Cultures and Organizations: Software of the Mind. 1. ed., USA: McGrawHill, 1991.

HOLT, D. T.; ARMENAKIS, A. A.; FEILD, H. S.; HARRIS, S. G. Readiness for organizational change: The systemic development of a scale. The Journal of Applied Behavioral Science, v. 43(2), p. 232-241, 2007.

HOGG, M; VAN KNIPPENBERG, D.; RAST, D. Intergroup leadership in organizations: Leading across group and organizational boundaries. Academy of Management Review v. 37(2), p. 232-255, 2012.

KAVANAGH M. H.; ASHKANASY N. M. The Impact of Leadership and Change Management Strategy on Organizational Culture and Individual Acceptance of Change during a Merger. British Journal of Management, v. 17, p. 81-103, mar. 2006.

KOTTER, J. P. Leading change. Boston: Harvard Business Review Press, 1996. 
KUIPERS, Ben; GROENEVELD, Sandra. De kracht van High Performance Teams - Zes ingrediënten voor excellent presteren in de publieke sector. Amsterdam: Mediawerf Uitgevers, 2014

KUIPERS, B. S.; HIGGS, M. J.; KICKERT, W. J. M.; TUMMERS, L. G.; GRANDIA, J.; VAN DER VOET, J. The management of change in public organisations: A literature review. Public Administration, v. 92, n. 1. P. 1 - 20, Newcastle, 2014.

LUBIS, Fitri \& HANUM, Farida. (2020). Organizational Culture. YICEMAP 2019: International Conference on Educational Management/Administration and Pedagogy, Yogyakarta, Indonesia.

MATIAS-PEREIRA, José. Curso de Administração Pública: foco nas instituições e ações governamentais. 4. ed. São Paulo: Atlas, 2014. p. 123-135

MEIRELLES, Hely Lopes. Direito administrativo brasileiro. 42. ed. São Paulo: Malheiros, 2016.

MOREIRA, A. M. F. A arte de prevaricar na designação de ocupantes de cargos em comissão. jul. 2009. Disponível em:<http://jus.com.br/artigos/13179/a-arte-de-prevaricar-na-designacao-deocupantes-de-cargos-em-comissao> Acesso em 29. out. 2015.

NADLER, D. A.; THIES, P. K.; NADLER, M. B. Culture Change in the Strategic enterprise: Lessons from the Field. In: COOPER, C. L.; Carwright, S.; EARLY, P. C. The International Handbook of Organizational Culture and Climate. Chichester: John Wiley\& Sons Ltda, 2001.

NOGUEIRA, José Marcelo Maia; OLIVEIRA, Kátia Michelle Matos de; VASCONCELOS; Alan Pereira de; OLIVEIRA, Leonel Gois Lima. Estudo exploratório da eficiência dos Tribunais de Justiça estaduais brasileiros usando a Análise Envoltória de Dados (DEA). Rio de Janeiro: Revista de Administração. Pública, v.46(5), p.1317 - 1340, set. - out. 2012.

OLIVEIRA, A. F. Identificação organizacional. In: Siqueira, Mirlene Maria Matias (org.). Medidas do comportamento organizacional: Ferramentas de diagnóstico e de gestão. Porto Alegre: Artmed, p.181 - 190, 2008.

OREG, S. Personality, context, and resistance to organizational change. European Journal of Work \& Organizational Psychology, (2006).

Perides, M. P. N., Vasconcellos, E. P. G., Vasconcellos, L. (2020). A gestão de mudanças em projetos de transformação digital: estudo de caso em uma organização financeira. Revista de Gestão e Projetos, 11(1), 54-73. doi:http://dx.doi.org/10.5585/gep.v11i1.16087

PIDERIT, S.K. Rethinking resistance and recognizing ambivalence. Academy of Management Review, v. 25, n. 4, p. 783-94, 2000.

PIETERSE, Jos H.; CANIELS, Marjolein C. J. HOMAN, Thijs. Professional discourses and resistance to change. Journal of Organizational Change Management, v. 25, n. 6, p. 798-818, 2012. 
PINHO, Ana Paula Moreno; BASTOS, Antônio Virgilio Bittencourt; ROWE, Diva Ester Okazak. Diferentes Vínculos Indivíduo-Organização: Explorando Seus Significados entre Gestores, 3. ed. especial, Rio de Janeiro: RAC, v. 19, art. 3, pp. 288-304, Out. 2015.

PUHL, C.; PROCÓPIO M. L. Burocracia ou gerencialismo: um estudo de caso sobre a administração do Poder Judiciário Federal. XXXVIII Encontro da AMPAD: Rio de Janeiro, set. 2014.

RODRIGUES, Ana Paula Grillo; BASTOS, Antônio Virgílio Bittencourt. Os vínculos de comprometimento e entrincheiramento presentes nas organizações públicas. Revista de Ciência da Administração, v. 15, n. 36, p.143-158, ago. 2013.

ROUSE, T.; HARDING, D. Due diligence humana. Harvard Business Review - Brasil, jan.2012. Disponível em http://hbrbr.com.br/due-diligence-humana/. Acesso em: 02. fev. 2021.

Salem, M., Van Quaquebeke, N., Besiou, M., Meyer, L. (2019). Intergroup Leadership: How leaders can enhance performance of humanitarian operations. Production and Operatons Management, 28(11), 2877-2897.

SAMPAIO, J. Suspensão ameaça serviço público. Diário do Nordeste, Fortaleza, 20.set.2015. Disponível em:

<http://diariodonordeste.verdesmares.com.br/cadernos/nacional/suspensao-ameacaservico-publico-1.1390994>. Acesso em: 30. set. 2015.

SCHEIN, E. H. Cultura Organizacional e Liderança. São Paulo: Atlas, 2009.

SENA NETO, B. G. Governo eletrônico e-Gov. Natal: IFRN, 2019.

SILVA JUNIOR, Domingos da; COSTA, Francisco José. Mensuração e Escalas de Verificação: uma Análise Comparativa das Escalas de Likert e Phrase Completion. São Paulo: Revista Brasileira de Pesquisas de Marketing, Opinião e Mídia, v. 15, p. 1-16, out. 2014.

SCHOONENBOOM, Judith; Designing Mixed Methods Research by Mixing and Merging Methodologies: A 13-Step Model. American Behavioral Scientist, v. 62(7), p. 998-1015, 2018

TEE, E.; ASHKANASY, N. M.; PAULSEN, N. The influence of follower mood on leader mood and task performance: An affective, follower-centric perspective of leadership. The Leadership Quarterly, v.24, p. 496-515, ago. 2013.

TEIXEIRA, H. J.; BASSOTTI, I. M.; SANTOS T. S. (org.). Mérito, desempenho e resultados: ensaios sobre gestão de pessoas para o setor público. São Paulo: FIA/USP, p. 16, 2014.

TROMPENAARS, F.; HAMPDENTURNER, C. Riding the Waves of Culture: Understanding Cultural Diversity in Business. London: Nicholas Brealey Publishing, 2000.

TSE, H. H. M.; ASHKANASY, N. M.; DASBOROUGH, M T, Relative leader-member exchange, negative affectivity and social identification: $A$ moderated-mediation examination, The Leadership Quarterly, v.23, p. 354-366, jun. 2012. 
VAGARINHO, J. P. Como identificar a originalidade num artigo científico ou numa tese de doutoramento? (How to identify originality in a scientifi c manuscript or in a doctoral thesis?) Educar em Revista, Curitiba, Brasil, v. 35, n. 73, p. 181-207, jan./fev. 2019

VAN KNIPPENBERG, D. and HOGG, M. A. A social identity model of leadership effectiveness in organizations. In: STAW, B.; KRAMER, R. M. (eds.), Research in Organizational Behavior, Greenwich: JAI Press, v. 25, p. 245-297, 2003.

VOET, Joris van der; KUIPERS, Ben; GROENEVELD, Sandra. Implementing change in public organizations: The relationship between leadership and affective commitment to change in a public sector context. Paper presented at the 11th Public Management Research Conference, Madison, Wisconsin, June 20-22 2013.

WEBER, Y. The effects of top management culture clash on the implementation of mergers and acquisitions. Tese de doutorado. University of South Carolina, 1989.

WEBER, Y.; SCHWEIGER, D. M.; LUBATKIN, M. H. Cultural clash in mergers and acquisitions: a longitudinal study on the acquired top management turnover. Trabalho não publicado apresentado na Reunião Anual da Academy of Management, Las Vegas, Nevada. 1992.

WEBER, Y. Corporate Culture Fit and Performance in Mergers and Acquisitions, Human Relations, v. 49(9), p. 1181-1202, 1996.

WEBER, Y. Development and Training at Mergers and Acquisitions. Procedia - Social and Behavioral Sciences, v. 209, p. 254 - 260, dez. 2015.

YUKL, Gary. Leadership in organizations. Global Edition, Harlow:Pearson Education Limited, 2013. 


\title{
O CONSUMO DE MEMES COMO FORMA DE MINIMIZAÇÃO DA ANSIEDADE EM JOVENS ADULTOS NO BRASIL
}

\author{
Mariane Nascimento Reis
}

UNISANTOS

\begin{abstract}
RESUMO
Este trabalho tem como objetivo compreender como os memes humorísticos da internet, compartilhados por jovens adultos (adultos emergentes) podem contribuir para a amenização do sentimento ansioso vivenciado por esta população, especialmente no momento pandêmico de Covid-19. Para esse fim, a metodologia empregada foi a de pesquisa qualitativa de cunho exploratório, por meio de dados bibliográficos e levantamento documental, de memes na internet, e uma análise qualitativa de cunho psicanalítico. Com a iminência pandêmica, a coleta de dados sobre o tema se tornou mais ampla. Os resultados apontam que o jovem adulto está propenso a sentir-se ansioso pela percepção do que seria a vida adulta e das exigências da sociedade. As redes sociais e os laços que se formam, podem contribuir para que encontrem um espaço de compartilhamento de suas vivências e angústias, que podem ser sintetizadas por meio da linguagem dos memes. Os memes têm como característica a utilização do humor para retratar a mensagem vinculada. O humor pode ser entendido como um meio de expressão e sua função, psicanaliticamente, de amenizar uma situação sofrível, assim, como em uma pandemia. Consequentemente, o humor nos memes e seu compartilhamento evidencia um processo de afastamento do sofrimento e demonstra experiências e significados compartilhados de um grupo social.
\end{abstract}

Palavras-chave: Jovem Adulto; Ansiedade; Humor; Internet. 


\section{ABSTRACT}

\section{MEMES CONSUMPTION AS A FORM OF MINIMIZING ANXIETY IN YOUNG ADULTS IN BRAZIL}

This work aims to understand how the humorous memes of the internet, shared by young adults can contribute to the easing of the anxious feeling experienced by this population. For this purpose, the methodology used was that of qualitative research of an exploratory nature, through bibliographic data and documentary survey, of memes on the internet, and a qualitative analysis of a psychoanalytical nature. The results indicate that the young adult is prone to feel anxious about the perception of what adult life would be and the demands of society. Social networks and the bonds that are formed can contribute to finding a space for sharing their experiences and anxieties, which can be synthesized through the language of memes. Memes are characterized by the use of humor to portray the linked message. Humor can be understood as a means of expression and its function, psychoanalytically, to alleviate a suffering situation. Consequently, the humor in memes and their sharing shows a process of moving away from suffering and demonstrates shared experiences and meanings of a social group.

Keywords: Young Adult; Anxiety; Humor; Internet. 


\section{INTRODUÇÃO}

O cenário da sociedade moderna atual se caracteriza pelas exigências sociais, transformações em ritmo acelerado e um futuro incerto. Diante disso, muitos jovens adultos vivem este estágio da vida como um momento de inconstâncias, de explorações e exigências. Logo, os sentimentos de insuficiência, desamparo e ansiedade tendem a surgir. Segundo o estudo da Organização Pan-Americana de Saúde (2017) os jovens estão entre a população mais ansiosa e alerta que pode a vir a aumentar ao longo dos anos.

Os meios tecnológicos de comunicação podem ser um meio para compreender, conhecer e acessar os sentimentos despertados nos jovens. A internet é um veículo de livre expressão e uma forma de comunicação encontrada é por meio de compartilhamentos de materiais digitais como os memes. Os memes transmitem uma mensagem que muitas vezes, estão embutidos de humor visto como uma outra forma de expressar, compreender a realidade e, psicanaliticamente, pode ser um meio de alívio e leveza diante das angústias.

Desse modo, a pesquisa tem como objetivo compreender como o consumo de memes humorísticos na internet, podem ser um meio de minimização do sentimento de ansiedade em jovens adultos, visto que, os jovens são a população que mais estão conectados na internet e consomem os materiais vinculados a ela, segundo a Pesquisa Nacional por Amostra de Domicílios Contínua (2017). Sendo assim, a internet pode ser o veículo que estes utilizam para expressar, compreender sua realidade e uma busca de alívio diante de uma sociedade acelerada e atravessada por muitas transformações e exigências.

\section{METODOLOGIA}

A produção partiu de uma pesquisa de natureza exploratória, que segundo Gil (2008) tem como finalidade esclarecer e desenvolver conceitos, com o objetivo de prover uma visão geral, com riqueza de informações, acerca de um determinado fato. Na primeira etapa, foi realizado o método bibliográfico, desenvolvido a partir do levantamento de dados a partir de artigos científicos e livros. Para o levantamento de dados foram utilizados palavras-chaves e seus sinônimos, entre elas: "jovem adulto", "ansiedade”, "humor", "internet”, "redes sociais", "memes", com abrangência de vinte anos, a partir da atualidade; partindo de bancos de dados eletrônicos, como Google Scholar, SciELO, ScienceDirect, Portal Capes, e em livros impressos e digitais que versam o cenário dos objetos da pesquisa. 
A segunda etapa foi realizada a partir do método documental, que é o levantamento de materiais que ainda não foram analisados, como filmes, gravações, fotografias, entre outros, neste caso, os memes da internet. A seleção dos memes foi constituída por conveniência, que segundo Gil (2008) é a seleção de materiais das quais se tem acesso, em que se admite que esses possam, de alguma forma, demonstrar ou representar a pesquisa. A busca do material se realizou durante todo o processo de elaboração do trabalho, de fevereiro a outubro de 2020 em redes sociais virtuais como Instagram, Twitter, Facebook e Google Imagens.

Foram selecionados 4 memes em sites, realizado de forma aleatória de forma como apareciam nas redes; categorizados em temas: (1) sentimento em relação ao início da vida adulta; (2) sentimento em ser adulto; (3) sentimento de ansiedade e amparo; e (4) o sentimento em relação à realidade pandêmica. A análise dos memes orientou-se pelo modelo indiciário proposto por Carlo Ginzburg, que por meio de materiais, "dados aparentemente negligenciáveis, remontar a uma realidade complexa não experimentável diretamente" (GIL, 2008, p.152). É como um detetive, como a figura do caçador, em que a partir de detalhes, muitas vezes, despercebidos que, quando decifrados e analisados, podem mostrar algo revelador.

\section{RESULTADOS}

O início da vida adulta costuma oferecer para muitos jovens uma "moratória", ou seja, um prolongamento do tempo, para que se possa ingressar na vida adulta. Nesta moratória, o jovem pode experimentar papéis sociais, estilos e formas de vida diferentes até encontrar o seu próprio e assumir suas responsabilidades e compromissos da vida adulta. Sociologicamente, um relacionamento estável e a formação de uma família, a entrada no mercado de trabalho ou a profissionalização, a independência financeira, são marcadores que definem a entrada na vida adulta. Contudo, deve-se considerar que o caminho para a vida adulta seja influenciado por diversos fatores, como o contexto social e cultural em que esse jovem está inserido, que podem adiantar ou atrasar a entrada na vida adulta (GRIFFA; MORENO, 2001; PAPALIA, FELDMAN, 2013).

Jeffrey Arnett (2004) propôs o conceito de "adultez emergente", em que abarcaria o momento da sociedade atual com o adiamento das responsabilidades adultas; seriam os marcadores sociais, juntamente com a compreensão do que é ser adulto pelos jovens. As 
características do jovem nessa fase, seriam: (1) exploração da identidade, o jovem se sente desprendido para experimentar as possibilidades identitárias; (2) instabilidade, em que muda as estratégias e os planos de vida em consequência das explorações de identidade; (3) auto centramento, antes do jovem assumir a vida adulta, aproveita para aprender sobre si e ser autossuficiente, um momento necessário antes de se comprometer; (4) sentimento de transição, o sentimento ambíguo de não ser adolescente e nem adulto, é o momento em que se dá o processo a vida adulta; (5) possibilidades, em que o jovem tem a oportunidade de se construir e transformar seu futuro, mesmo que tenha passado dificuldades anteriores (PONCIANO; SEIDL-DE-MOURA, 2017).

As exigências sociais e pessoais, os compromissos e responsabilidades da vida adulta, este momento de exploração e transição podem gerar angústia nos jovens que estão ingressando na vida adulta. Andrade et al (2019) caracterizam o termo "Ansiedade", com sua origem no latim anxius, anseio, por sua vez é derivada de agere, com a significação de agitação, angústia, e sufocamento, respectivamente. Segundo uma pesquisa da Organização Mundial da Saúde (OMS) realizada em 2015 e publicada em 2017, aponta um crescimento de 14,9\% entre 2005 e 2015 da população ansiosa; a Organização considera, que a ansiedade é uma das causas principais de incapacitação no mundo e, a Organização Pan-Americana de Saúde, alertou em 2018 sobre a incapacitação de jovens causada pela ansiedade.

Freud propôs, em 1926, com a publicação de “Inibições, sintomas e ansiedade", uma teoria sobre a ansiedade. Compreende o autor que o ser humano nasce com capacidade de reagir ao meio ambiente por meio de manifestações físicas e psicológicas, a qual denominase ansiedade. Para Freud (1926/1976), a ansiedade se encontra na instância do ego, que tem como função dominar e descarregar estímulos, que manifesta a ansiedade a fim de reagir a uma situação de perigo. Surgiria a partir da criação de sintomas, a fim de se livrar ou evitar uma situação de perigo, por isso, também, se relaciona a expectativa de um perigo, para estar preparada a ela. Sempre quando houver a possibilidade de a situação de perigo ocorrer, a ansiedade será acionada, para o autor, "a ansiedade é um produto do desamparo mental (...)" (FREUD, 1926/1976, p. 162).

Há três formas de situação de perigo que Freud (1926/1976) propõe, a situação de perigo em que se constituiu a separação de uma pessoa que é importante como fonte de satisfação é lidada como o perigo da perda de objeto, a que se segue o perigo de não ser 
amado por ela; mesmo a pessoa estando presente pode temer a perda de seu amor, a qual se refere perda do amor de objeto. A situação proveniente do perigo de castração, refere ao medo, a ansiedade de ser separado, de perder um objeto de grande valor, de brilho fálico. A ansiedade de castração conduz aos processos defensivos nas neuroses, a situação de perigo que provém do superego que repousa na ansiedade moral e social, no medo de ser punido, desaprovado, culpado ou perder o amor do superego.

Na sociedade moderna, Bauman (2007) considera que os indivíduos vivem uma vida liquida, ou seja, numa sociedade em constante transformação e rapidez em seus processos, os indivíduos vivem à mercê dessa sociedade, seguindo seu fluxo e permeada de modernização, transformação, velocidade; o que provoca nos indivíduos o sentimento de ansiedade, por se sentirem pressionados pelas exigências de acompanhar a sociedade em evolução. Por isso, segundo o autor, a vida é precária, sendo vivida em condições de incerteza; vive-se em uma "sociedade de valores voláteis, descuidada do futuro, egoísta e hedonista, onde a velocidade e não a duração é o que importa" (BAUMAN, 2007, p.10).

Macêdo (2012), aponta que na sociedade moderna há um processo de fragmentação do tecido social; que pode ser visualizada pelo abandono do Estado (referencial simbólico), que potencializa a vivência de desamparo pelos indivíduos que buscam no consumo uma estratégia de sobrevivência e preenchimento do vazio existencial, dando algum sentido em sua vida. Para a autora, o desamparo é a causa primeira dos sofrimentos, que faz emergir as psicopatologias, como ansiedade, pânico, psicossomatizações; pelos laços frágeis e descartáveis, pela dissimetria entre as exigências sociais e os meios para cumpri-las, pela falta de um referencial simbólico, pelo consumismo exacerbado.

Desse modo, para os jovens, cada um encontrará alguma forma para lidar com os sentimentos angustiantes e de estresse, que são comuns neste período de mudanças; que podem ir de comportamentos saudáveis para os não saudáveis, podendo afetar a saúde física e mental. Uma das formas em que o jovem pode lidar com as situações estressoras que Ihe surgem seria por meio das relações sociais, que apresentam benefícios a saúde e bem-estar, sendo um relacionamento face a face ou através de redes virtuais, que aparentam ter os mesmos benefícios e onde a maioria dos jovens também se encontram (ELLISON, STEINFIELD e LAMPE, 2007; COHEN, 2004 apud PAPALIA, FELDMAN, 2013). 
As tecnologias de comunicação interligadas por meio de redes permitiram que, através do virtual, pessoas distantes se aproximassem em espaços curtos de tempo, facilitou na produção, compartilhamento e acesso de informações; ou seja, modificou a forma de interação com o meio, com a realidade (MORAN, 1996). A comunicação via computadores foi definida por Lévy como ciberespaço, é “um espaço de comunicação aberto pela interconexão mundial dos computadores e das memórias dos computadores" (MORAN, 1999, p.92). É uma forma de explorar todos os recursos oferecidos por essas infraestruturas de modo inventivo, coletivo e interativo, a exemplo, os vários modos de comunicação, do correio eletrônico a realidade virtual, estimula uma comunicação e um estilo de relacionamento que independe da localização e do tempo.

A comunicação que é expressa na internet está relacionada a livre expressão, em todas as formas (CASTELLS, 2003). A ferramenta utilizada para a comunicação e expressão são os sites de redes sociais, como Facebook, Twitter, Blogs, entre outros. Segundo Recuero (2009), os sites de redes sociais foram definidos por Boyd \& Ellison (2007) como aqueles sistemas que permitem a construção de uma persona através dos perfis da página pessoal do site, a exposição pública do indivíduo e a interação com outros indivíduos através de comentários, curtidas, entre outros. A interação, segundo a autora, é um reflexo comunicativo influenciada pelo contexto e pelas motivações, como por exemplo, o suporte social, quando alguém escreve que está triste pode receber apoio através de comentários e se sentir melhor. O que contribui para que a interação seja geradora e/ou mantedora das relações sociais e de laços sociais.

A interação e os laços formados por meio da internet podem proporcionar aos indivíduos, um sentimento de pertencimento e de comunidade. Assim como nos espaços sem mediação digital, os indivíduos na internet buscam conexões com outros indivíduos, a partir de seus interesses, desejos e aspirações (RECUERO, 2009). A definição mais comum de comunidade mediada pelo computador, a chamada comunidade virtual é a de Barry Wellman (2008, p. 228): “comunidades são redes de laços interpessoais que proporcionam sociabilidade, apoio, informação, um senso de integração e identidade social". Entretanto, Castells (2003) aponta que as comunidades são dinâmicas na internet, construídas a partir da escolha dos indivíduos, fundamentadas na seleção do tempo, lugar e parceiros de interação. 
Os sujeitos personalizam suas redes de pertencimento de acordo com seus projetos, valores, afinidades e interesses que se modificam ao longo do tempo.

\subsection{MEMES E HUMOR}

O conceito de meme surge no livro "O Gene Egoísta", publicado em 1976 pelo etólogo Richard Dawkins. Para o autor, existe uma unidade de transmissão de informação cultural semelhante ao gene, ao que nomeou por meme. A palavra meme é a abreviação de mimeme, de raiz grega que significa imitação. Como exemplo, têm-se as melodias, os slogans, os comportamentos, as ideias, os padrões culturais, as crenças, os preconceitos. A ideia do autor é que a transmissão do meme aconteça de cérebro para cérebro de forma seletiva, ou seja, a partir de todos os acontecimentos, comportamentos ou memes que é possível imitar. Alguns serão imitados e outros não, sendo esquecidos, além dos cérebros para a transmissão dos memes, há outras formas como placas, fotografias, roupas, gestos, livros, entre outros, ou seja, qualquer artefato que possa sustentar, transportar e transmitir o meme (RECUERO, 2009; HORTA, 2015; JESUS, 2020).

Desse modo, o termo meme também denomina o fenômeno na internet, caracterizado pela propagação de informações, comportamentos, conceitos entre outros, e pela sua repetição nas redes e sites da internet. Os memes na internet, assim como na biologia de Dawkins, representam a cultura e a cosmovisão de um grupo na internet. Refletem a dinamicidade e a velocidade que a internet apresenta, com o acesso a diversas fontes de informações, o alcance global dessas informações e a forma rápida de acessá-las. A partir da ação humana de transmitir os memes por meio de sua difusão e compartilhamento, estes alcançam muitos usuários, que repetindo a ação, alcançam muitos outros. Os veículos dos memes na internet são imagens estáticas ou em movimento, vídeos, frases, brincadeiras; sua propagação ocorre em sua forma original, sendo replicada diversas vezes, ou recriadas pelos usuários, sendo este o caráter mais simbólico do meme (RECUERO, 2009; SHIFMAN, 2013; HORTA, 2015; JESUS, 2020).

O meme potencializa a vontade dos indivíduos de se expressar, de entender sua realidade, de pertencer a uma comunidade. A pesquisa, com mil entrevistados, revela que $46 \%$ dos usuários compartilham memes que traduzem seus problemas pessoais; $75 \%$ atribuem ao meme como uma forma de aliviar o estresse do dia a dia; e $64 \%$ se sentem incluídos no grupo quando entendem um meme. Na mesma pesquisa, evidencia-se que 
quanto mais jovem, mais interação há com os memes, mais de $90 \%$ dos entrevistados entre 16 a 29 anos utilizam e gostam dos memes; mas não se restringe a uma comunicação do público jovem, mas estende-se para outros públicos, entre $75 \%$ a $89 \%$ dos usuários de memes, abrange as idades de 30 a 66 anos (CONSUMOTECA, 2019).

Para Shifman (2007) atualmente a internet é o porta voz do humor. Através das ferramentas de produção e a facilidade de distribuição, é a nova fonte de expressão do humor. Pode-se encontrar na internet diversas formas e formatos do humor, mesclando fontes antigas, como charges e piadas, quanto novas, por meio de vídeos, imagens, memes. Segundo a pesquisa da Consumoteca (2019) com mil entrevistados, $85 \%$ dos brasileiros costumam gostar dos memes na internet; $57 \%$ participam de redes para acompanhar os memes; $63 \%$ procuram os memes para se distrair e $45 \%$ usam os memes para iniciar uma conversa.

Para Horta (2015) o meme apresenta a intenção de levar ao riso, através da presença do cômico e do humor. Seria uma nova forma de se entender a realidade, que demonstra um novo olhar a realidade de maneira divertida, com a liberdade de criação e associações, sem padrões rígidos. O humor propõe brincar com as experiencias e significados culturais compartilhados, cada usuário poderá se sentir representando como pode inserir e compartilhar suas experiencias. Para a autora "os memes acabaram se tornando a válvula de escape moderna para expressar a perplexidade em relação aos fatos do mundo, operando também como uma maneira de compreender esses fatos" (HORTA, 2015, p.159-60).

O significado do humor é amplo e diverso; pode ser encontrado na literatura com diversas nomenclaturas, as investigações sobre o humor são extensas e com contribuição de diversas disciplinas; que podem vir a se complementar ou se destoar. O humor é considerado um fenômeno social, com o riso partilhado no processo de comunicação; sendo, muitas vezes, definidos e partilhados dentro de uma fronteira espacial e temporal. Nas investigações sobre o humor, três teorias se destacam na explicação e na sua definição. Essas teorias tentam explicar o fenômeno do humor e na produção do riso a partir de determinadas perspectivas e técnicas. São elas, as teorias da incongruência, da superioridade e do alívio (JERÓNIMO, 2015; SALIBA, 2017).

Na teoria da incongruência, o humor está ligado à dualidade entre a percepção e a representação, ou seja, seria derivado da incongruência dessa dualidade. O humor ocorre, 
portanto, quando os indivíduos percebem que a relação entre o objeto real e seu conceito se tornaram, a partir de um ponto de vista, incongruentes. A teoria da superioridade deriva da ideia de que o humor e o riso são formas de ridículo e expressão de superioridade e hierarquia. A premissa básica dessa teoria é de grupos de mais poder ou numa posição hierárquica superior tendem a fazer piadas, a rir de grupos marginalizados, excluídos ou considerados inferiores. Na teoria do alívio, encabeçada pelos estudos de Freud (1905), o riso é uma descarga de energia psíquica que ocorre quando há uma elaboração, através da piada, de uma situação conflituosa. As piadas funcionariam como uma forma de diluir a tensão quando se trata de temas reprimidos e controversos, com o riso sendo uma forma de liberação dos desejos e pensamentos reprimidos (JERÓNIMO, 2015; SALIBA, 2017).

Freud gostava de ouvir e contar piadas, em 1905 escreveu a obra "Os chistes e sua relação com o inconsciente". O chiste é um meio de manifestar a vida psíquica, os pensamentos sexuais ou agressivos. Uma forma encontrada pelo ego para manifestar conteúdos latentes que estão inconscientes e não poderiam ser expressos por vias normais, onde seriam reprimidos; ou seja, o chiste suspende a repressão para proporcionar a descarga do conteúdo e promover prazer. O prazer deriva da economia de energia despendida para a repressão do pensamento; com o montante de energia poupado através do chiste, ela fica disponível para ser descarregada na forma do riso (BRENNER, 1975; MEZAN, 2005). Segundo Mezan (2005), o humor no chiste seria o movimento de converter o desprazer em prazer, em que os pensamentos ou afetos penosos seriam substituídos; seria como se o ego dissesse "sou bom demais, ou grande demais, para me sentir atingido pelo que está me acometendo" (MEZAN, 2005, p.171-2).

Em vista disso, em 1927, Freud escreveu um ensaio intitulado "O Humor", em que retoma a discussão do prazer humorístico do chiste de 1905. Para Freud (1927/1974), o humor apresenta sua grandeza através dos processos de evitar o desprazer e sofrimento, a partir do triunfo do narcisismo e do princípio do prazer, o qual o ego se recusa a ser assolado por uma realidade opressora. $\mathrm{O}$ autor salienta que o humor seria o processo saudável que a mente encontrou para afastar os sofrimentos, dando ênfase na invulnerabilidade do ego diante da realidade e sustentar o princípio do prazer. Pode se apresentar em relação a própria pessoa (humorista) em que o outro (espectador) deriva o prazer, ou em relação a duas pessoas, em que o outro é objeto do prazer humorístico. Supõe que o ouvinte das piadas do humorista 
compartilha ou concorda com ele para que, assim se produza o humor, o riso. $\mathrm{O}$ fato mais importante do humor é sua intenção, de jogar com a realidade.

\section{DISCUSSÃO}

Ao analisar os resultados dos objetos que compõem o fenômeno pesquisado, percebese que o ciberespaço permite a comunicação e a expressão dos indivíduos e que traduz um momento histórico e cultural de um grupo ou comunidade. Assim, um meio de comunicação e expressão cultural na internet são os memes, muitos com teor humorístico. Desse modo, os sentimentos expressos pelos jovens podem ser visualizados através dos memes compartilhados nas redes sociais da internet. Muitos jovens compartilham memes que traduzem sua realidade, como os sentimentos em relação ao início da vida adulta; os sentimentos em ser adulto, sentimento de ansiedade e amparo, e o sentimento em relação a realidade que experimenta, como a pandemia. Categorias analisadas com memes a seguir.

\subsection{SENTIMENTO EM RELAÇÃO AO INÍCIO DA VIDA ADULTA}

Sociologicamente, os marcadores do início da vida adulta são a entrada no mercado de trabalho ou profissionalização, a independência financeira e afetiva, um relacionamento estável ou formação de uma família. Para uma sociedade, como a atual, que está em transformações em ritmos acelerados, a precarização do Estado e as exigências para desempenhar os papéis designados para o adulto, vide os marcadores sociais, exerce uma pressão sobre os jovens que podem gerar sentimentos angustiantes e de incerteza sobre si e o seu futuro.

Figura 1 - Sentimentos em relação ao início da vida adulta

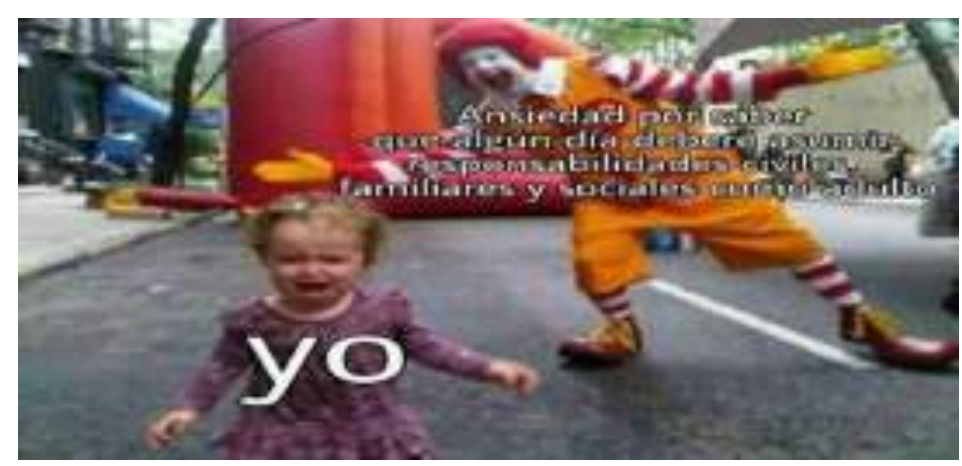

Fonte 1 - Google Imagens "Vida adulta responsabilidades memes"

O meme acima demostra através de um palhaço, que tem o papel de despertar alegria e diversão, mas em suas formas estranhas e desproporcionais podem causar espanto e medo, 
tanto que há indivíduos que têm medo de palhaço. Nesse meme, o palhaço representa a vida adulta e que não traz alegrias, mas medos de assumir as responsabilidades que lhe cabem, "responsabilidades civis, familiares e sociais" e que despertam o choro; pode ser da ameaça que estar por vir, o desamparo que sentem ao se deparar com os deveres e sentir que não conseguirá concretizá-los.

\subsection{SENTIMENTO EM SER ADULTO}

Do imaginário da vida adulta para o ser adulto. O meme que representa o estágio adulto vai de encontro com o conceito de adultez emergente, de Jeffrey Arnett (2004), em que parece que há o sentimento de não se sentir um adulto, muitas vezes, marcado pelo próprio ritmo da sociedade, como cita Bauman (2007), que se transforma de maneira tão rápida, que não oferece tempo para a consolidação do ser, da identidade do indivíduo e conseguir embarcar na vida adulta, como seria na concepção de desenvolvimento erickisiano.

Figura 2 - Sentimentos em ser adulto

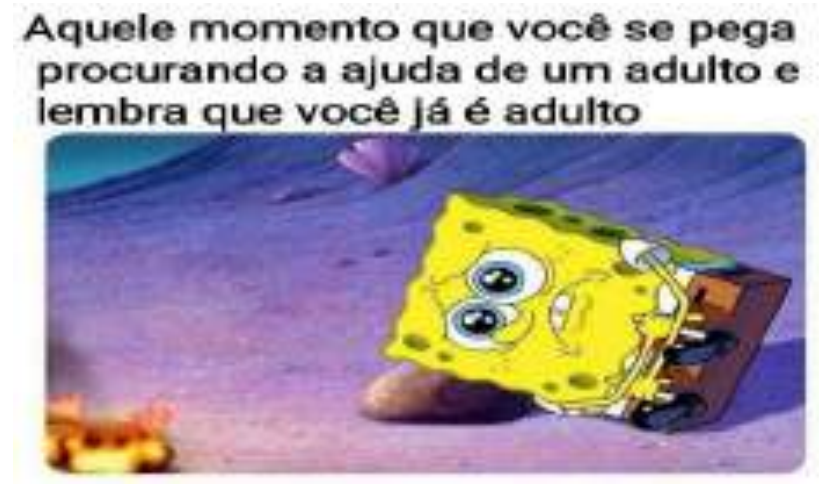

Fonte 2 - Google Imagens "Frases tristes do Bob Esponja

O meme acima demonstra a característica da adultez emergente do sentimento de transição, ou seja, o sentimento de não ser adolescente e nem adulto. Aquele momento que percebe que deverá se responsabilizar por seus atos, terá que tomar decisões por si mesmo; sem que outra pessoa, como, por exemplo, os pais se responsabilizem por seus atos. Perceber que deverá "tomar as rédeas" da própria vida, pode trazer reações, como se deduz na imagem, de apreensão e a sensação de que não conseguirá "dar conta" de suas responsabilidades, de sua vida. É a sensação de desamparo, de se ver responsável por seus fracassos e derrotas, somado com a percepção de dever de agir com a autonomia, dever de ser sozinho. A imagem associada ao texto, pode remeter, também, ao desejo do outro; para atender suas necessidades. Pode-se recordar a situação de um bebê (na posição fetal) que 
não consegue se satisfazer sozinho, necessitando do auxílio da mãe, e sem ela há a sensação do desamparo e as reações de ansiedade.

\subsection{SENTIMENTO DE ANSIEDADE E AMPARO}

Essa categoria visa demonstrar os sentimentos de desejo e expansão que os jovens sentem, os seus anseios e como uma rede de apoio se torna importante para aliviar as preocupações em torno da realização dos seus desejos. Entende-se que o jovem está em meio a possibilidades diversas que podem se transformar em exigências e lhe causar ansiedade. É a faixa etária que mais sofre com sintomas ansiosos. Mas, ao mesmo tempo, busca concretizar as suas realizações a partir de atitudes que visam para um futuro esperançoso.

Figura 3 - Sentimento de ansiedade e amparo

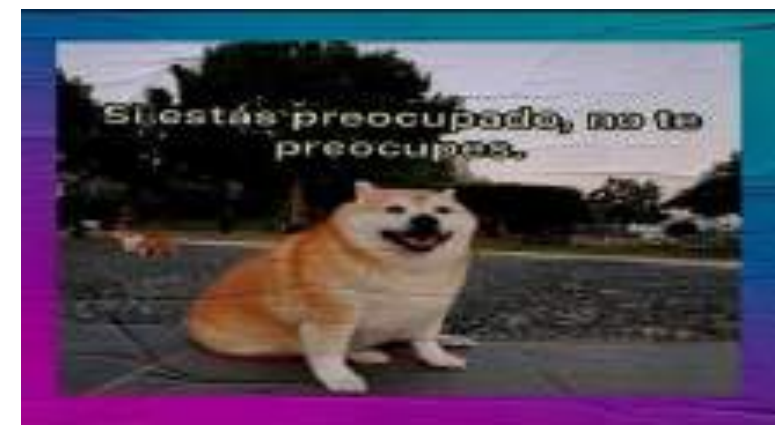

Fonte 3 - Instagram memeawards

O meme acima ilustra um animal, um cachorro, com o dizeres "se está preocupado, não te preocupes", em tradução livre. Pode-se perceber com esse meme duas teorias do humor, a incongruência e a do alívio, da psicanálise. A incongruência por usar um animal não falante, sorrindo e desejando uma despreocupação, é a dualidade entre o que é real e o que está sendo passado no meme. Na teoria do alívio e nos estudos freudianos sobre o humor, este meme traz uma dimensão libertadora, como um alívio diante de preocupações. O meme oferece, através do humor, a economia de energia. A energia que seria gasta nas preocupações, será usada no relaxamento, através do riso. E é essa a grandeza do humor que Freud se refere, mesmo com as preocupações, o indivíduo consegue não ser tão afetado por elas, rir das preocupações, mas não as negar, elas existem. O humor traz essa sensação de invencibilidade do ego, como uma forma de enfrentamento, que mesmo com as dificuldades, poderá superá-las. 


\subsection{SENTIMENTO EM RELAÇÃO A REALIDADE PANDÊMICA}

O novo coronavírus foi identificado na China, em dezembro de 2019, e logo se espalhou entre diversas pessoas e países. A Covid-19, como denominado, integra uma família de vírus, comuns em muitas espécies de animais e alguns são transmitidos a humanos. A Organização Mundial da Saúde declarou Emergência de Saúde Pública de Importância Internacional em janeiro de 2020 em virtude do surto da doença do coronavírus e alertou os a adotarem medidas para interrupção e contenção do espalhamento do vírus. Uma das medidas foi a adoção da política da quarentena, isso que significa que as pessoas tiveram seus movimentos restritos.

Brooks, et al (2020) elaboraram uma revisão sobre os efeitos psicológicos causados pela quarentena, a partir de estudos em surtos pandêmicos anteriores, apresentando como um sentimento desagradável e que provoca efeitos psicológicos negativos, como incertezas sobre a doença e duração da quarentena, sentimentos de isolamento, ansiedade, raiva, estresse, frustração e tédio. Esses sentimentos podem ser reduzidos através da ativação das redes sociais, ao contatar e se comunicar com familiares e amigos permite o apoio social, atualização de informações sobre a situação e garantam que estão bem, o que vem a reduzir esses sentimentos. A ativação da rede social, mesmo que remotamente, está associada a redução da ansiedade imediata e do sofrimento ao longo prazo.

Figura 4 - Sentimentos em relação a pandemia

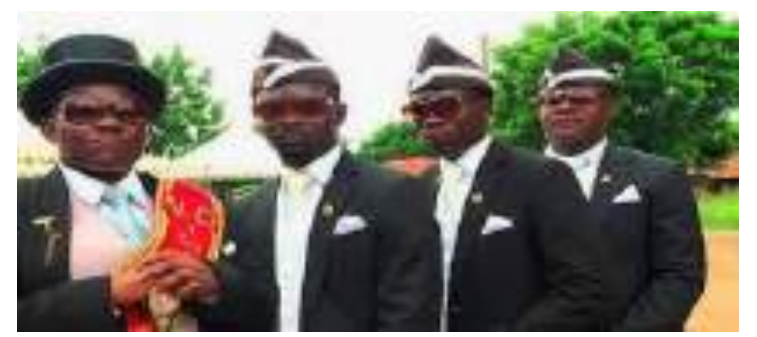

Fonte 4-Google Imagens - Meme do Caixão

O meme acima foi compartilhado durante a pandemia nas redes sociais para ilustrar os sentimentos gerados com a pandemia. Esse meme, denominado como o meme do caixão, popularizou durante a quarentena, mas, circula nas redes desde 2015 quando um vídeo de carregadores de caixão ganeses aparece dançando num funeral, a dança é uma tradição de Gana, na África. O meme é uma simbolização, ou seja, reflete, os efeitos e acontecimentos 
trágicos, a morte, que podem acontecer por meio da contaminação do vírus (MUSEU DE MEMES, 2020).

Segundo a Diretoria de Análise de Políticas Públicas da Fundação Getúlio Vargas (FGVDAPP), órgão que promove pesquisas sociais no campo de políticas públicas no Estado brasileiro, aponta que $42 \%$ das postagens nas redes sociais em fevereiro deste ano, foram referentes ao coronavírus embutidos de humor (RESENDE, 2020). Os memes seriam uma forma de suportar o estresse provocado pela pandemia, o criador da página de memes Melted Vídeos, Felipe Misale, diz que os memes representam os sentimentos vivenciados pelas pessoas e que buscam neles uma forma de encontrar respostas para o que estão vivendo (GOMES, 2020).

\section{CONSIDERAÇÕES FINAIS}

Este trabalho teve como objetivo compreender a utilização de materiais digitais humorísticos na internet como um meio de redução do sentimento de ansiedade em jovens adultos. Tal objetivo foi cumprido por meio das pesquisas bibliográficas e pela análise documental dos memes selecionados, compartilhados pelas redes sociais de internet. Foi verificado que os memes na internet conectam as pessoas por meio da mensagem que está vinculada, que é compartilhado socialmente pelas pessoas que o consomem, ou seja, elas se identificam com a mensagem.

Os memes, como Horta (2015) sugere são uma válvula de escape moderna, quando as pressões internas ou externas são muito altas, os memes recheados com humor, podem ser um caminho seguro para liberar as tensões, faz com que as pessoas se reconheçam e percebam que também é sentida por outras pessoas, não estão sozinhas, o que pode a vir a contribuir para uma minimização do desamparo, mesmo que seja temporária. Os memes demonstram a força que uma pessoa tem para conseguir enxergar além do que a realidade impõe. É a tentativa de vencer as adversidades da realidade. É a invencibilidade do ego, segundo Freud (1927/1974).

A partir das análises com os memes percebe-se que esta forma de comunicação pode ser uma forma de entender o que se passa com os grupos, com o jovem; o que eles sentem diante dos acontecimentos cotidianos e sociais. Os memes compartilhados retratam comportamentos, atitudes, situações sociais que está em comum com um grupo. Eles 
enxergam esses comportamentos com outros ângulos, utilizando o humor para questionar e refletir, além de divertir. Se tornam uma válvula, um escape de uma realidade massacrante, limitante, desgastante, podendo ser sentida como um refresco para voltar mais forte para a realidade e esperar por um futuro melhor.

Um ponto em questão do humor, além da questão do alívio e do sentimento de comunidade, pois estão compartilhando uma experiencia em comum; é a questão crítica que traz consigo. No humor e nos memes há o seu aspecto reflexivo por ter essa característica de questionar a realidade mostrando um outro aspecto dela. E uma das reflexões que este trabalho despertou é o sentido do consumo. Vemos que a sociedade moderna é baseada no consumo e os altos índices de consumo de memes por jovens e outras faixas etárias, podem estar demonstrando uma forma de preencher um vazio, o sentimento de desamparo.

Entretanto, a pesquisa sofreu limitações pela dificuldade de encontrar estudos que relacionam os memes e os fatores psicológicos. Os memes selecionados não abarcam todo o universo de memes que circulam nas redes e, consequentemente, não foi possível abarcar outros aspectos psicológicos encontrados na literatura. As reflexões não se esgotam, desse modo, se faz necessário que mais pesquisas sejam realizadas a fim de ampliar e compreender os aspectos psicológicos envolvidos no humor e na sua expressão através de conteúdos digitais, como os memes. Novas pesquisas são uma forma de ampliar os conhecimentos do fenômeno estudado, onde estão em abundância nos meios de comunicação, principalmente a internet, e que são estendidos para o cotidiano das pessoas e percebe-se que são expressão da realidade e de afetos, muito mais que apenas divertimento, o que evidencia sua importância, como um tema atual.

\section{REFERÊNCIAS}

ANDRADE, J.V. et al. Ansiedade: um dos problemas do século XXI. Revista de Saúde ReAGES, v.2, n.4, p. 34-39, jul. 2019. Disponível em: http://npu.faculdadeages.com.br/index.php/revistadesaude/article/view/220 Acesso em 27 jul. 2020

BAUMAN, Zygmunt. Vida Líquida. Trad. Carlos Alberto Medeiros. Rio de Janeiro: Jorge Zahar, 2007 
BROOKS, S.K. et al. The psychological impact of quarantine and how to reduce it: rapid review of the evidence. The Lancet v. 395, issue 10227, p. 912-920, 2020 Disponível em https://www.sciencedirect.com/science/article/pii/S0140673620304608?casa_token=HVV5 As-N-8AAAAAA:129mimyAfiTgZwPy8WyAYkfzVOSmx8h-ssaXNwZrVxFsiHaaqG451864ahB3jwwNLKtPSHvrPw Acesso em 11 mai. 2020

CASTELLS, Manuel. A Galáxia Internet: reflexões sobre a Internet, negócios e a sociedade. Trad. Maria Luiza X. de A. Borges. Zahar, 2003

CONSUMOTECA. In meme we trust. GENTE GLOBO, 29 mai. 2019. Disponível em https://gente.globo.com/meme-we-trust/ Acesso em 28 out. 2020

FREUD, S. Inibição, sintoma e ansiedade. In. Obras Completas. Trad. Christiano Monteiro Oiticica. Rio de Janeiro: Imago: 1976, vol. XX (Original de 1926)

FREUD, S. O humor. In. Obras Completas. Trad. José Octávio de Aguiar Abreu. Rio de Janeiro: Imago: 1974, vol. XXI (Original de 1927)

GIL, A.C. Métodos e técnicas de pesquisa social. São Paulo: Atlas, 2008

GOMES, T. Memes reforçam 'capacidade analgésica' do humor em tempos de pandemia. Catraca Livre, 25 mai. 2020. Disponível em https://catracalivre.com.br/saude-bemestar/memes-da-pandemia/ Acesso em 24 jul. 2020

GRIFFA, M.C.; MORENO, J.E.. Chaves para a psicologia do desenvolvimento, tomo 2: adolescência, vida adulta, velhice. Trad. Vera Vaccari. São Paulo: Paulinas, 2001

HORTA, N.B. $O$ meme como linguagem da internet: uma perspectiva semiótica. Orientador: Dr. Sérgio de Sá. 2015. 191f. Dissertação (Programa de Pós-Graduação em Comunicação) Universidade de Brasília, Brasília, 2015.

JERÓNIMO, N.A. Humor na sociedade contemporânea. Orientador: Dr. José Carlos Venãncio. 2015. 268f. Tese para obtenção do Grau de Doutor em Sociologia. (Ciências Sociais e Humanas) - Universidade da Beira Interior, Portugal, 2015.

JESUS, A. M. R. de. Manda memes: a memética e a cultura como discurso. Elemmental, 2020 Disponível em https://elemmental.com/2020/01/21/manda-memes-a-memetica-e-acultura-como-discurso/ Acesso em 31 jan. 2020

LÉVY, P. Cibercultura. Trad. Carlos Irineu da Costa. 1o ed. São Paulo: Editora 34, 1999

MACÊDO, Kátia Barbosa. O desamparo do indivíduo na modernidade. ECOS-Estudos Contemporâneos da Subjetividade, v. 2, n. 1, p. 94-107, 2012. Disponível em http://www.periodicoshumanas.uff.br/ecos/article/view/742 Acesso em 26 set. 2020

MEZAN, R. A "ilha dos tesouros": Relendo a piada e sua relação com o inconsciente. In: SLAVUTZKY, A.; KUPERMANN, D. (Orgs.) Seria trágico... se não fosse cômico. Rio de Janeiro: Civilização Brasileira, 2005. p. 129-198

MORAN, J. Novas tecnologias e o reencantamento do mundo. Tecnologia educacional, v. 23, n. 126, 14 p. 26, 1996. Disponível em http://www.eca.usp.br/prof/moran/site/textos/tecnologias_eduacacao/novtec.pdf Acesso em 29 jun. 2020 
MUSEU DE MEMES. Meme do Caixão. 08 abr. 2020. Disponível em https://www.museudememes.com.br/sermons/meme-do-caixao/ Acesso em 12 ago. 2020

MUSEU DE MEMES. Quando o viral vira meme: a propagação do coronavírus na internet. 11 abr. 2020. Disponível em https://www.museudememes.com.br/quando-o-viral-vira-meme-apropagacao-do-coronavirus-na-internet/ Acesso em 29 jun. 2020

NOGUEIRA, L.C. A pesquisa em psicanálise. Psicologia USP, v.15, n.1-2, p.83-106, 2004 Disponível em https://www.scielo.br/j/pusp/a/nMGDnFmKgySBkGkdshtfzPg/?lang=pt Acesso em 10 abr. 2021

ORGANIZAÇÃO PAN-AMERICANA DE SAUDE. Folha Informativa - Saúde mental dos adolescentes. $2018 . \quad$ Disponível em https://www.paho.org/bra/index.php?option=com_content\&view=article\&id=5779:folhainformativa-saude-mental-dos-adolescentes\&ltemid=839 Acesso em 15 jan. 2020

$\begin{array}{llllr}\text { ORGANIZAÇÃO PAN-AMERICANA DE SAÚDE. Folha Informativa - COVID-19 (doença causada } \\ \text { pelo } & \text { novo } & \text { coronavírus). } & 2020 & \text { Disponível }\end{array}$ https://www.paho.org/bra/index.php?option=com_content\&view=article\&id=6101:covid19 \&ltemid=875\#contagio Acesso em 05 ago. 2020

PNAD Contínua. Pesquisa Nacional por Amostra de Domicílios Contínua. Acesso à Internet e à televisão e posse de telefone móvel celular para uso pessoal 2017. IBGE. 2018. Disponível em https://biblioteca.ibge.gov.br/visualizacao/livros/liv101631_informativo.pdf Acesso em 10 jul. 2020

PAPALIA, D.E.; FELDMAN, R.D. Desenvolvimento Humano [Recurso Eletrônico] Trad. Carla Filomena Marques Pinto Vercesi et al. 12ㅇe ed. Porto Alegre: AMGH, 2013

PONCIANO, E. L. T.; SEIDL-DE-MOURA, M. L. Narrativas sobre si mesmo e o futuro na adultez emergente: critérios subjetivos e marcadores sociais. Psicol. Am. Lat., México, n. 29, p. 128146, dez. 2017.2 Disponível em http://pepsic.bvsalud.org/scielo.php?script=sci_arttext\&pid=S1870$350 \times 2017000300009 \&$ Ing=pt\&nrm=iso. Acesso em 07 ago. 2020

RECUERO, R. Redes sociais na internet. Porto Alegre: Sulina, 2009

RESENDE, L. Avanço do coronavírus faz Twitter diminuir memes sobre o tema e ficar mais sério. CNN Brasil, Rio de Janeiro, 18 mar. 2020. Disponível em https://www.cnnbrasil.com.br/tecnologia/2020/03/18/avanco-do-coronavirus-faz-twitterdiminuir-memes-sobre-o-tema-e-ficar-mais-serio Acesso em 28 set. 2020

SALIBA, Elias Thomé. História cultural do humor: balanço provisório e perspectivas de pesquisas. Revista de História (São Paulo), n. 176, 2017. Disponível em https://www.scielo.br/pdf/rh/n176/2316-9141-rh-a01017.pdf Acesso em 15 set. 2020

SHIFMAN, Limor. Humor in the age of digital reproduction: Continuity and change in internetbased comic texts. International Journal of Communication, v. 1, n. 1, p. 23, 2007. Disponível em https://ijoc.org/index.php/ijoc/article/view/11 Acesso em 13 out. 2020

SHIFMAN, Limor. Memes in a digital world: Reconciling with a conceptual troublemaker. Journal of computer-mediated communication, v. 18, n. 3, p. 362-377, 2013 Disponível em https://academic.oup.com/jcmc/article/18/3/362/4067545 Acesso em 13 out. 2020 
WELLMAN, B. Physical place and cyberplace: The rise of personalized networking. International Journal of Urban and Regional Researsh, v.25, n.2, p.227-252, 2001 Disponível em https://onlinelibrary.wiley.com/doi/abs/10.1111/1468-2427.00309 Acesso em 14 abr. 2021

WORLD HEALTH ORGANIZATION. Depression and other common mental disorders: global health $\quad$ estimates. $2017 . \quad$ Disponível em https://apps.who.int/iris/bitstream/handle/10665/254610/WHO-MSD-MER-2017.2-eng.pdf Acesso em 13 mar. 2020 


\title{
TERRITÓRIOS RELIGIOSOS E SUAS INTERFACES TEMÁTICAS
}

\author{
Valdery Ferreira Zotelli \\ Mestrando em Desenvolvimento Local -PPGDL-UCDB-MS \\ valderyzotelli@gmail.com \\ Michael hideky Kubota \\ Mestrando em Desenvolvimento Local -PPGDL-UCDB-MS \\ arqmhk@gmail.com
}

Arlinda Cantero Dorsa

Doutora em Língua Portuguesa e docente do Programa de Pós-Graduação em Desenvolvimento Local

acdorsa@ucdb.br

\section{RESUMO}

Este artigo focaliza as interfaces temáticas que se relacionam ao descritor "territórios religiosos", a partir do mapeamento de dissertações referentes aos anos de 2013-2020, encontradas na plataforma do banco de dissertações e teses da Capes. Este tema traz relevância em razão dos diferentes enfoques simbólicos culturais e principalmente por propiciar um panorama das produções existentes na pósgraduação stricto sensu em nosso país. Enfatiza-se que o presente trabalho busca a elaboração de uma síntese integrativa do estado de conhecimento sobre a referida temática, objetivando a visibilidade e divulgação cientifica, facilitando assim o acesso, a pesquisa e o aprofundamento desta área de conhecimento, válida para todos os membros os membros da comunidade acadêmica de diferentes áreas de conhecimento, sejam eles alunos de graduação, pós-graduação e docentes pesquisadores e orientadores. Integra-se esta pesquisa em uma discussão mais ampla, desenvolvida pelo "Grupo de Pesquisa em Patrimônio Cultural, Direitos e Diversidade", formado por professorespesquisadores da Graduação e do Mestrado e Doutorado em Desenvolvimento Local, pósgraduandos/orientandos, acadêmicos em iniciação científica, com uma visão interdisciplinar. Os resultados foram obtidos a partir do refinamento dos resultados: Descritor, ano, tipo, grande área de conhecimento, área de avaliação, área de concentração, Instituições e Programas. A partir de uma análise aprofundada dos trabalhos selecionados concluiu-se que se trata de um tema interdisciplinar e multidisciplinar, com abordagens em diversas áreas do conhecimento e diferentemente dos outros processos de ocupação do espaço com óticas econômicas, a visão religiosa não apresenta explicações ligadas ao mundo material, mas sim sagrado e as suas várias manifestações.

Palavras-chave: Territórios; Territorialidades religiosas; Estado da arte. 


\section{ABSTRACT}

\section{RELIGIOUS TERRITORIES AND THEIR THEMATIC INTERFACES}

This article focuses on the thematic interfaces related to the descriptor "religious territories", based on the mapping of dissertations from 2013-2020, found on the platform of the Capes dissertation and thesis database. This theme is relevant because of the different symbolic cultural approaches and mainly because it provides an overview of existing productions in the post-graduation stricto sensu in our country. It is emphasized that the present work seeks to elaborate an integrative synthesis of the state of knowledge on this theme, aiming at the visibility and scientific disclosure, thus facilitating the access, the research, and the deepening of this area of knowledge, valid for all the members of the academic community from different areas of knowledge, whether they are undergraduate or graduate students, and professors, researchers, and advisors. This research is part of a wider discussion, developed by the "Research Group on Cultural Heritage, Rights and Diversity", formed by teacherresearchers from the Undergraduate and the Master's and Doctorate in Local Development, postgraduate students/guidancers, academics in scientific initiation, with an interdisciplinary vision. The results were obtained from the refinement of the results: Descriptor, year, type, major area of knowledge, area of evaluation, area of concentration, Institutions and Programs. From an in-depth analysis of the selected works it was concluded that it is an interdisciplinary and multidisciplinary theme, with approaches in various areas of knowledge and differently from other processes of occupation of space with economic optics, the religious view does not present explanations linked to the material world, but to the sacred and its various manifestations.

Keywords: Territories; Religious Territorialities; State of art.art. 


\section{CONSIDERAÇÕES INICIAIS}

É relevante afirmar que na formação territorial dos territórios religiosos, os processos de domínio e ocupação são responsáveis pela modificação do espaço e são fundamentalmente simbólicos no contexto cultural, político e econômico, tendo como principal agente da configuração territorial a religião.

A importância científica desta temática relaciona-se à discussão nos meios acadêmicos acerca das interfaces temáticas que se relacionam aos descritores "territórios religiosos" tema este de relevante importância por envolver diferentes enfoques simbólicos culturais e por entendermos ser relevantes para a comunidade científica em razão de poder propiciar um panorama do que se produz em nível de pós-graduação stricto sensu em nosso país, relacionados a esta temática.

Objetiva, portanto, esta pesquisa analisar as interfaces temáticas relacionadas ao descritor "territórios religiosos", nas dissertações referentes aos anos de 2013-2020, encontradas na plataforma do banco de dissertações e teses da Capes.

Enfatiza-se, neste contexto, o papel fundamental da plataforma CAPES por desempenhar frente à comunidade científica, a visibilidade para o intercâmbio acadêmico e enriquecimento de conhecimentos das diversas áreas do conhecimento e gerando assim, a divulgação científica para a sociedade em geral.

Com relação à metodologia utilizada, a pesquisa pautou-se em duas fases: a primeira destinou-se à revisão bibliográfica relativa às questões e às temáticas concernentes ao tema, com a apropriação e amadurecimento de referenciais teóricos e uma segunda fase, voltada à elaboração do mapeamento com abordagem quantitativa e análise das interfaces temáticas.

Para a consecução deste objetivo pretende: conceituar território religioso e estado da arte, elaborar um mapeamento dos trabalhos e enfim apresentar uma abordagem quantitativa e análise das interfaces temáticas encontradas nas referidas dissertações. 


\section{PRINCÍPIOS CONCEITUAIS: TERRITÓRIOS E TERRITORIALIDADES RELIGIOSAS}

Para a compreensão do conceito simbólico-cultural de território e territorialidade pela perspectiva da religião e da religiosidade, é necessária a adoção de parâmetros conceituais no âmbito da geografia.

Raffestin (1993) destaca que o território se constitui a partir do espaço, construído através da força e mobilização dos atores locais de desenvolvimento. A transformação de um espaço em território passa pela territorialização, processo em que os atores locais se apropriam do espaço e o transformam, seja na dimensão física ou simbólica.

Na mesma linha de pensamento, Santos (1997) aponta que a territorialidade é o sentimento de pertença, sendo despertado através da participação coletiva na transformação do espaço. A julgar que a noção de território está associada com o sentimento de propriedade, os autores se empenham em um projeto de desenvolvimento coletivo de construção do território.

O território então nesta perspectiva conceitual pode ser visto como uma porção do espaço apropriado/utilizado por um grupo humano na utilização de práticas de garantia utilizadas para a sobrevivência neste espaço. Nas palavras de Haesbaert (2004), o território pode ser visto por alguns em uma perspectiva política e mesmo cultural, contudo em "uma perspectiva geográfica, vê a territorialização como o processo de domínio (políticoeconômico) e/ou apropriação (simbólico-cultural) do espaço pelos grupos humanos".(HAESBAERTH, 2004, p. 16).

Na concepção de território religioso, Rosendahl (2005) define-o como um território demarcado, controlado em seus acessos e ações por um profissional religioso; complementa esta afirmação Weber (1991), ao definir a presença de três agentes neste espaço definido: a) o profeta religioso, dotado de carisma; b) o sacerdote produtor do sagrado, responsável pela difusão da doutrina e da ideologia da instituição religiosa; c) o leigo, consumidor do sagrado.

Outro aspecto importante é reconhecer que para a formação do território religioso, o aspecto simbólico e cultural é mais representativo e as territorialidades são relacionadas ao sagrado e sobre elas, Rosendahl (2005) afirma que se trata: “[...] de um conjunto de práticas desenvolvidas por instituições ou grupos no sentido de controlar um dado território, onde o 
efeito do poder do sagrado reflete uma identidade de fé e um sentimento de propriedade mútuo". (ROSENDAHL, 2005, p.204).

A autora ainda afirma que a visão territorial é um reflexo de uma identidade cultural no qual o sentimento de pertencimento é um sentimento comum e mútuo entre seus integrantes. Isto implica incluir o modo como os espaços e gestão do espaço são distribuídos e inscritos em sua significação na paisagem, com alcance visto de forma coletiva.

Assim, é necessário ressaltar que a territorialização do espaço religioso ocorre de maneira oposta às demais atividades inerentes à vida humana. O território religioso é um espaço de manifestação do sagrado, carregado de uma simbologia própria que não se limita ao mundo tangível, explicável apenas na fé do homem religioso que busca esses espaços como forma de ligação ou proximidade com o sagrado.

Os espaços religiosos são construídos de forma coletiva por uma comunidade através de suas vivências e limitado a seu arcabouço cultural, podendo estar ligado ao território natural, ou contido em objetos e pessoas. Assim sendo, é preciso considerar que um mesmo território pode despertar diferentes sensações em grupos ou comunidades distintas, resultando em conflitos religiosos que marcam a trajetória da humanidade.

Pode-se afirmar que os territórios religiosos são múltiplos e plurais e podem ser reconhecidos nos estudos de territorialidade religiosa, a partir de três comportamentos diferenciados: coexistência pacífica, instabilidade e competição e intolerância e exclusão.

\section{DO ESTADO DA ARTE}

Ao possibilitar as percepções discursivas, que em um primeiro momento se apresenta como descontínuos ou contraditórios, Ferreira (2002) afirma que o interesse dos pesquisadores que se voltam para a realização de mapeamentos é a sensação do não conhecimento acerca da totalidade de estudos e pesquisas e seu crescimento qualitativo e quantitativo. Alguns questionamentos emergem e voltam, segundo a autora, a perceber de que formas e em que condições têm sido produzidas certas dissertações de mestrado, teses de doutorado, publicações em periódicos e comunicações em anais de congressos e de seminários.

Amplia a discussão a referida autora, ao afirmar que: 
Também são reconhecidas por realizarem uma metodologia de caráter inventariante e descritivo da produção acadêmica e científica sobre o tema que busca investigar, à luz de categorias e facetas que se caracterizam enquanto tais em cada trabalho e no conjunto deles, sob os quais o fenômeno passa a ser analisado. (FERREIRA, 2002, p.252)

Neste artigo, o que desafia os autores, é a possibilidade de construção de uma contextualização sobre as temáticas abordadas, assim como análise das possibilidades presentes para a concepção de um novo referencial teórico.

Há que se considerarem dois eixos estruturantes dando sustentação aos estudos do tipo estado da arte ou conhecimento, segundo Slongo (2004) que são: o aspecto quantitativo, ou seja, o significativo crescimento numérico das produções e/ou a variação dessas produções num lapso específico de tempo sem que se considere, nessa vertente de atuação, a qualidade dessas produções e também aponta um importante aspecto qualitativo - a diversidade de enfoques.

De caráter inventariante, o estado da arte propicia uma visão crítica do contexto evolutivo de um assunto ou tema, apontando para novos caminhos a serem trilhados pelos pesquisadores a fim de contribuir para a solução mais efetiva dos problemas sociais. Para mais, presta-se a conferir visibilidade aos avanços científicos, em atenção à função social de disseminação do conhecimento e da informação. (SHIOTA;DORSA, 2019, p. 35)

O desafio então para os pesquisadores consiste a partir do estado da arte de dar conta de determinado saber como também de buscar aquilo que ainda poderá ser feito.

\section{O MAPEAMENTO REALIZADO}

O trabalho inicial consistiu na pesquisa bibliográfica realizada no Banco de Teses e dissertações da Capes entre os anos de 1990-2020, a partir de abordagem quantitativa.

Como segundo passo, foi submetida como descritor a palavra "territórios religiosos", conforme mostra a figura 1, obtendo-se como resultado 12.816 teses e dissertações referente a temática, em busca ampla. 


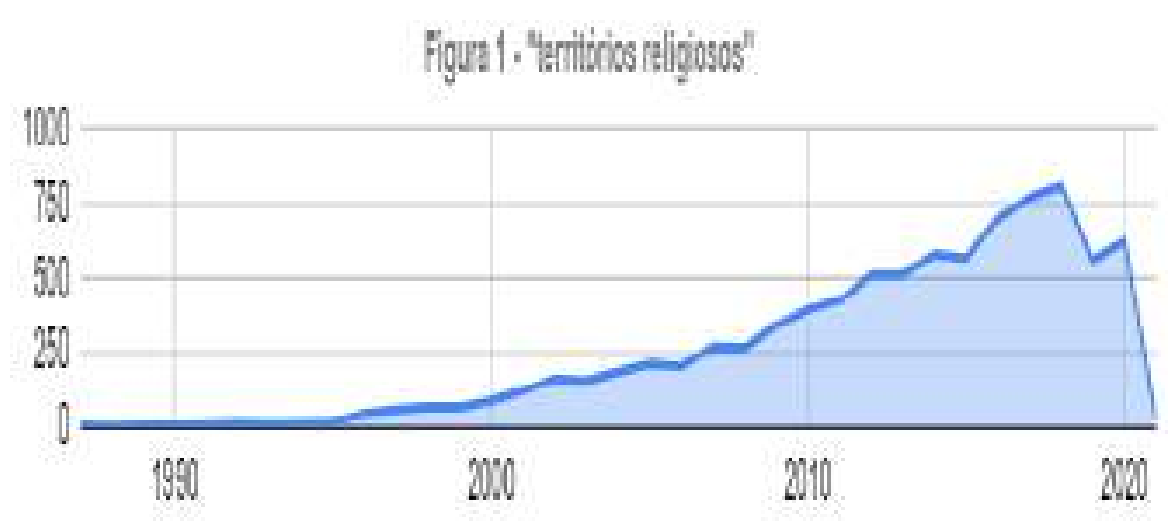

O terceiro passo consistiu no refinamento dos resultados com os seguintes filtros: "Dissertações", com o objetivo de delimitar as buscas apenas entre as produções em âmbito de mestrado, como mencionado nos objetivos deste trabalho. Como resultado foi obtido um total de 8449 dissertações que estão relacionadas com os descritores mesmo que seja em um sentido amplo.

Em seguida foi adicionado a pesquisa o filtro "Anos", selecionando apenas os trabalhos que estavam listados entre 2013-2020. Dentro disso, obtivemos os seguintes resultados:

2013 - foram encontrados 511 trabalhos, em 2014 foram 579, em 2015 foram localizados 567, em 2016 foram encontrados 698 trabalhos, em 2017 foram 771, em 2018 foram localizados 808 trabalhos, em 2019 foram encontrados 559 e em 2020623 trabalhos. Portanto,

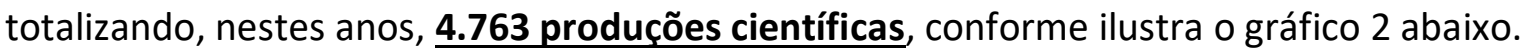

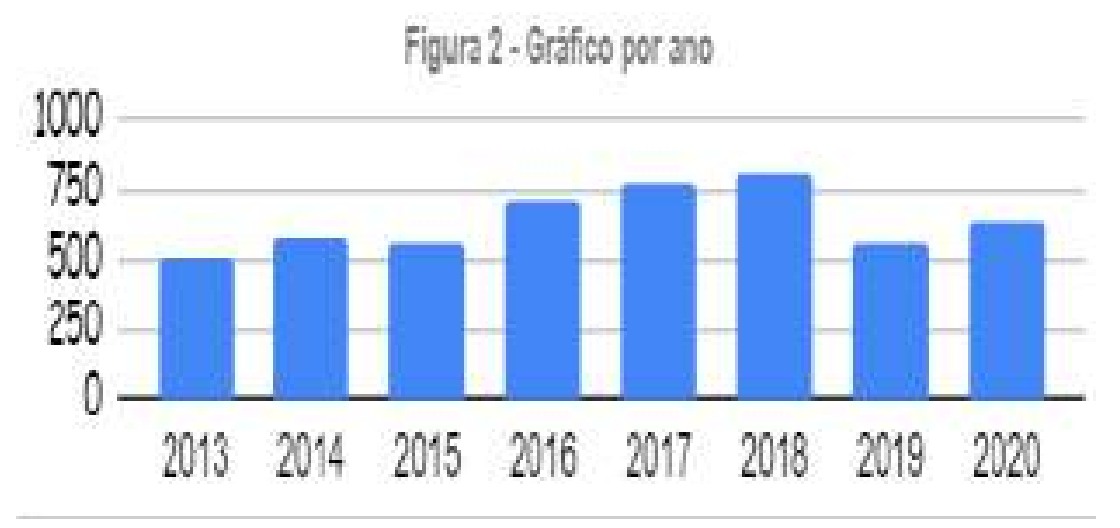


Desta maneira, o quarto passo da pesquisa foi a seleção da área de "Ciências Humanas" como Grande Área Conhecimento e como quinto passo, foram selecionadas as seguintes áreas de conhecimento listadas abaixo.

A primeira área do conhecimento analisada foi Geografia, onde por meio deste refinamento foram encontrados um total de 516 dissertações. A segunda seleção foi feita a partir da área de conhecimento História, onde foram encontrados um total de 452 dissertações referente ao tema proposto. Em sequência ainda foram selecionados trabalhos das áreas de conhecimento relacionados à Comunicação Social e Serviço social, por apresentarem os descritores em seus títulos e resumo.

O sexto passo foi o mapeamento das universidades em suas respectivas regiões, conforme gráfico 2 abaixo. Nesse filtro, chama atenção a região sudeste, onde foram localizados os principais trabalhos selecionados para este trabalho. Da mesma forma, não podemos deixar de mencionar a ausência de trabalhos referente à temática representando a região norte do país, fato que pode ser explicado pelo mapeamento ter sido elaborado após todo o critério de exclusão e seleção das dissertações importantes para o trabalho.

Conforme, aponta a figura 3, abaixo, é possível identificar como estão distribuídos os trabalhos utilizados neste artigo:

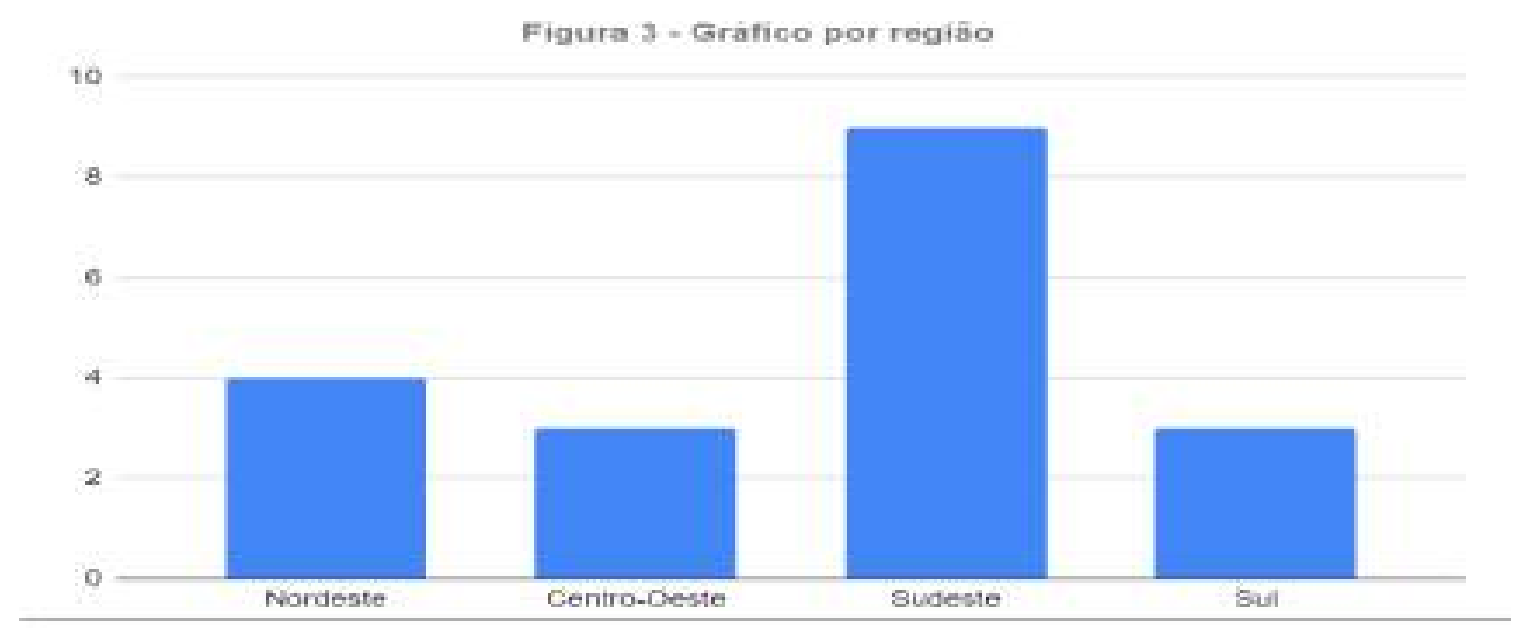

Desta maneira, a presente pesquisa científica apresentou a abordagem quantitativa das 8489 dissertações a partir do descritor "territórios religiosos", de todas as Instituições apresentadas. Para tal investigação, o filtro final foi a análise das interfaces temáticas a partir 
da seleção das dissertações por meio da presença do descritor no título, resumo ou palavraschaves, conforme quadro 1 abaixo

Como passos sequenciais, as referidas dissertações foram agrupadas a partir do programa de mestrado que representam em quadros contendo: título, autor, palavras chave, programa e Universidade.

Ao final do mapeamento e da análise das dissertações encontradas, foram selecionadas cinco (5) dissertações em Ciências da Religião. Em relação a estas dissertações foi possível analisar as diferentes interfaces temáticas:

Quadro 1: Dissertações analisadas segundo o Programa de Ciências da Religião.

\begin{tabular}{|c|c|c|c|c|}
\hline Tituilo: & Autor & Palarras - Chaves & Proginams & Universidade \\
\hline $\begin{array}{l}\text { Embates da Fe: couflitor religiosos entre } \\
\text { congregacioonis e catolicos co sento da } \\
\text { Paraiba (1930-1940) }\end{array}$ & $\begin{array}{l}\text { Buno Cesar } \\
\text { Cordeiro de } \\
\text { Araujo }\end{array}$ & $\begin{array}{l}\text { Estado. Igreji. Poder. } \\
\text { Movimectos de resistibnis. } \\
\text { Congregucionalismo. }\end{array}$ & $\begin{array}{l}\text { Ciencia da } \\
\text { Religiăo }\end{array}$ & $\begin{array}{l}\text { Universidade } \\
\text { Catolien de } \\
\text { Pernambeco }\end{array}$ \\
\hline 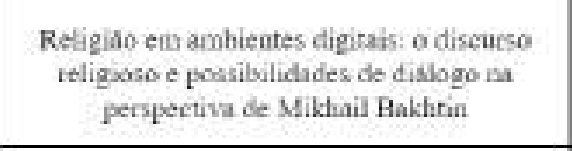 & $\begin{array}{c}\text { Rogerio Tiago } \\
\text { Miguel }\end{array}$ & $\begin{array}{c}\text { Religino, Discrusa Religioso. } \\
\text { Ambisates Digitais Religiosos. } \\
\text { Dialogisma. }\end{array}$ & $\begin{array}{l}\text { Ciencia da } \\
\text { Religino }\end{array}$ & $\begin{array}{l}\text { Pontificia } \\
\text { thaiversidade } \\
\text { Catolice de } \\
\text { Minas Genais }\end{array}$ \\
\hline $\begin{array}{l}\text { Maprantivito e Phuralisno; a terniocalidade } \\
\text { religiosa to bairro do pens im Recife }\end{array}$ & $\begin{array}{c}\text { Maria Vacessa } \\
\text { Nuges do Carmo }\end{array}$ & 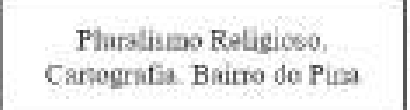 & $\begin{array}{l}\text { Ciencis ds } \\
\text { Roligiân }\end{array}$ & $\begin{array}{l}\text { Uaversidade } \\
\text { Catcica de } \\
\text { Pernambuco }\end{array}$ \\
\hline $\begin{array}{l}\text { Cabolicos: "Falsos" versus "verdideiros": } \\
\text { observado relaçdes de poder entre deis grupos } \\
\text { religiosos ma cidade de Capanema-PA }\end{array}$ & $\begin{array}{l}\text { Alne Ellen dos } \\
\text { Samtos Mata }\end{array}$ & $\begin{array}{c}\text { Catolicismos, Capanemin, "Fnleos } \\
\text { Catolicos", "Vendadeiros } \\
\text { Catolicos". Dissidèncin. Igreja } \\
\text { Cotolica Sepan. }\end{array}$ & $\begin{array}{l}\text { Cièncin da } \\
\text { Religiño }\end{array}$ & $\begin{array}{l}\text { Universidade do } \\
\text { Estado do Pari }\end{array}$ \\
\hline $\begin{array}{c}\text { A temtorialidade da lgueja Catblica em } \\
\text { Colarima-ES: um olhar a partir de Zeay } \\
\text { Rosendahl }\end{array}$ & $\begin{array}{c}\text { Daniel Louzada } \\
\text { Casteluber }\end{array}$ & $\begin{array}{c}\text { Espaço. Sagrado. } \\
\text { Territorialidade Religiâa. Igreja } \\
\text { Católica }\end{array}$ & $\begin{array}{l}\text { Ciencia da } \\
\text { Rehigiân }\end{array}$ & $\begin{array}{l}\text { Facuidade de } \\
\text { Viterial }\end{array}$ \\
\hline
\end{tabular}

Na dissertação de Casteluber (2014), foi feito um estudo procurando dar uma visão sobre o processo de construção do território relacionado à questão do poder e dominação religiosa da cidade de Colatina-ES, singularizando a contribuição das Instituições religiosas no processo de construção do espaço geográfico da cidade.

Já, Mota (2016), realizou um estudo onde foram observadas as relações divergentes entre dois grupos religiosos católicos. Para isso, foram observados como exemplo das classificações impostas pela comunidade aos recém-chegados e aos que por ela foram "convertidos" como "falsos católicos", visto que os primeiros se intitulam como "verdadeiros católicos". 
Carmo (2017), em seu trabalho, buscou a delimitação da área baseando-se num espaço amostral de 55 núcleos religiosos, em que os cenários atuais do bairro do Pina indicam uma perspectiva de transformações do ambiente por meio das atividades religiosas, mostrando que essa diversidade é convertida num processo de demarcação de territórios, provocando uma reconstrução do espaço.

Já a dissertação de Miguel (2017), destaca que as religiões se deparam com um novo cenário de modelo comunicacional, na qual devem admitir que não podem permanecer no modelo tradicional. Com isso, as tecnologias digitais podem ser aliadas às práticas religiosas onde a prática religiosa adquire novos significados ampliando o diálogo entre os fiéis.

Por fim, o trabalho de Araujo (2020), objetivou demonstrar os conflitos entre a igreja católica em relação aos protestantes congregacionais entre as décadas de 1930 e 1940. Vários documentos foram examinados para explicar que tipo de ameaça esse movimento ofereceria no sentido de reconstruir a história dos conflitos religiosos e das comunidades envolvidas no Sertão da Paraíba.

Em relação ao Programa de Geografia, foram levantadas 8 dissertações, que possibilitaram a verificação dos seguintes pontos:

Quadro 2: Dissertações analisadas segundo o Programa de Geografia. 


\begin{tabular}{|c|c|c|c|c|}
\hline Tinalo & Autor & Palawres - Chaves & Prograna & Universidade \\
\hline $\begin{array}{c}\text { Estralégias de difukgo espacial do } \\
\text { Protestantisuno no Estado do Rio de Janeiro: } \\
\text { o caso da lgreja Projeto Vida Nowa }\end{array}$ & $\begin{array}{l}\text { Robenta Criste } \\
\text { Martius Dias }\end{array}$ & $\begin{array}{l}\text { Difusfo espacial da fs. } \\
\text { Território religioso. Espaçoz } \\
\text { publicos. }\end{array}$ & Geografia & $\begin{array}{l}\text { Universidade do } \\
\text { Estado do Rio de } \\
\text { Janeire }\end{array}$ \\
\hline 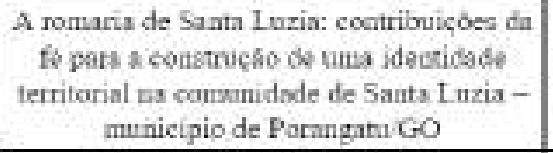 & $\begin{array}{l}\text { Matcos Roberto } \\
\text { Pereira Moum }\end{array}$ & $\begin{array}{l}\text { Tecritocio religioso. } \\
\text { Eatolicismo Romaria } \\
\text { Identidade. Communidade de } \\
\text { Santa Luzia }\end{array}$ & Geogratia & $\begin{array}{l}\text { Uaiversidade } \\
\text { Federal de Goias }\end{array}$ \\
\hline 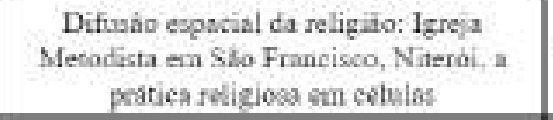 & $\begin{array}{l}\text { Rosana Jardim } \\
\text { Madureina }\end{array}$ & $\begin{array}{c}\text { Difusio Espacial. Território } \\
\text { Religioso. Geognafia da } \\
\text { Religiấ }\end{array}$ & Goografia & $\begin{array}{l}\text { Universidade do } \\
\text { Estado do Rie de } \\
\text { Janeifo }\end{array}$ \\
\hline 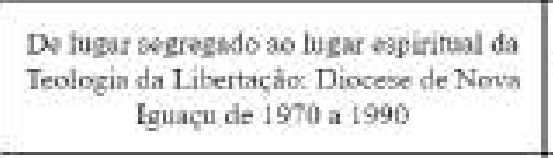 & $\begin{array}{l}\text { Supilen Sautigo } \\
\text { das Reis }\end{array}$ & 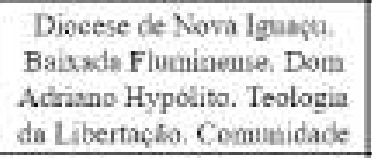 & Geografia & $\begin{array}{l}\text { Universidade do } \\
\text { Estado do Rio de } \\
\text { Jaueiro }\end{array}$ \\
\hline 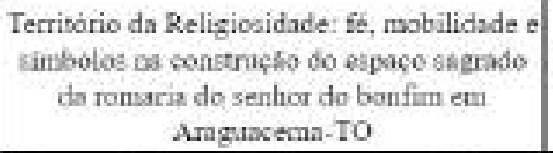 & $\begin{array}{l}\text { Jose Rodhgues } \\
\text { de Carvalho }\end{array}$ & $\begin{array}{l}\text { Territórioa religiocos. } \\
\text { Bathdaitos vintes. } \\
\text { Territorialidades simbólicas. } \\
\text { Simbolismo. Trajetorias. }\end{array}$ & Geogratia & $\begin{array}{l}\text { Uaimorsidade } \\
\text { Federal de Goias }\end{array}$ \\
\hline $\begin{array}{l}\text { Campo da Fè territorio e territorialidades } \\
\text { dos peregribos sergipanos a Jocrada } \\
\text { Mumdial da Juvenode: Rio de Janviro/2013 }\end{array}$ & $\begin{array}{l}\text { ELiete Furtado } \\
\text { Cecilio E Silva }\end{array}$ & $\begin{array}{c}\text { Territorialidades. Peregnos. } \\
\text { Jocnada Musdial da } \\
\text { frventude }\end{array}$ & Geografia & $\begin{array}{l}\text { Fundocto } \\
\text { Uaiversidade } \\
\text { Fodecal de Sergip? }\end{array}$ \\
\hline 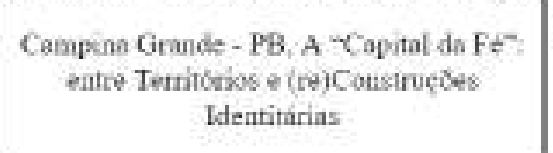 & $\begin{array}{l}\text { Debom Vatessa } \\
\text { Regis Ferreira } \\
\text { Sampaio }\end{array}$ & $\begin{array}{l}\text { Gecgrafia Culnural. } \\
\text { Idvertidikle. Evwatos } \\
\text { Retigiosos. Territorio. } \\
\text { Territorialidade }\end{array}$ & Geogratia & $\begin{array}{l}\text { Universidode } \\
\text { Estadual do Oeste } \\
\text { do Parana }\end{array}$ \\
\hline $\begin{array}{c}\text { "Dai pra ca e meu"t territorialidades aa } \\
\text { courexto da tosta do divino pai eterno om } \\
\text { Triadide-Go }\end{array}$ & $\begin{array}{l}\text { Locrana Laila } \\
\text { Stlva de Almeida }\end{array}$ & $\begin{array}{c}\text { Festa religiosa. Territorio. } \\
\text { Petegrimastô. Religiło. }\end{array}$ & Geografia & $\begin{array}{l}\text { Uberlandis-MG } \\
\text { Universidade } \\
\text { Federal de } \\
\text { Lberiandia - MG }\end{array}$ \\
\hline
\end{tabular}

Na Dissertação de Reis (2013), a pesquisa consistiu em esclarecer sobre as ações no processo histórico e geográfico da Diocese de Nova Iguaçu, localizada na Baixada Fluminense, buscando entender o papel que a igreja teve para a sociedade iguaçuana nas décadas de 1970 a 1990 e de como a relação da dimensão política e religiosa interagem e intervém na sociedade.

No que diz a respeito à dissertação de Carvalho (2014), a pesquisa procurou conhecer o mundo religioso de forma peculiar, através de experiências de fé, romarias, dos símbolos, tradições e da influência dos valores simbólicos que tornam os santuários significativos para o ser religioso e para a geografia cultural.

A dissertação "Difusão espacial da religião: Igreja Metodista em São Francisco, Niterói, a prática religiosa em células, (2014), segundo a autora Rosana Jardim Madureira mostra a dimensão da política religiosa da igreja Metodista e a sua organização territorial, onde a gestão religiosa incentiva à organização da Igreja em Célula. 
No que tange à dissertação de Moura (2015), foi possível identificar que a festa religiosa é considerada além de um ato de devoção dos peregrinos, um patrimônio da comunidade local, o que contribuiu para a formação de uma identidade territorial, tradições e ritos vinculados à festa, demarcando a configuração dos territórios religiosos da igreja católica no município de Porangatu.

Segundo Silva (2016), em sua dissertação, foi feito um estudo durante a Jornada Mundial da Juventude (JMJ, 2013), buscando analisar os territórios e as territorialidades construídas durante o evento. Foi observado a importância para os peregrinos sergipanos e como se mobilizaram, congregaram e construíram as redes de amizades, possibilitando uma organização missionária em nível local e o encontro de comunidades de várias partes do Brasil e do mundo.

Já para Roberta Cristina Martins Dias ( 2016 ) em “Estratégias de difusão espacial do Protestantismo no Estado do Rio de Janeiro: o caso da Igreja Projeto Vida", foi feita uma pesquisa analisando as estratégias de difusão espacial do protestantismo e o crescimento de grupos evangélicos através do exemplo empírico da igreja projeto vida nova no Estado do Rio de Janeiro.

Na dissertação de Sampaio (2018), a pesquisa buscou verificar os processos que influenciaram a (re)construção identitária em Campina Grande-PB, buscando informação e compreensão sobre fenômenos religiosos, e verificou-se a formação de territórios e territorialidades religiosas e os processos que influenciaram esta (re)construção identitária nesta cidade.

Por fim, na dissertação de Almeida (2020), o objetivo do trabalho foi analisar como se configura a territorialidade no contexto da Festa do Divino Pai Eterno em Trindade-GO. Foi observado no contexto da peregrinação, a atuação principalmente de comerciantes no trajeto da romaria e o domínio da igreja e do poder público como os detentores de controle e disputas territoriais.

Já em relação ao Programa de História, foram levantadas 3 dissertações, que possibilitaram a verificação dos seguintes pontos: 
Quadro 3: Dissertações analisadas segundo o Programa de História.

\begin{tabular}{|c|c|c|c|c|}
\hline Titulo & Auten & Pslavrns - Chuves & Programa & Vniversidade \\
\hline 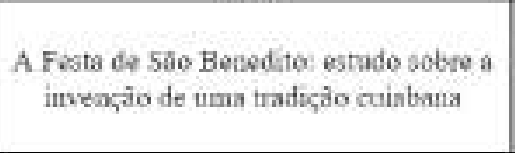 & $\begin{array}{l}\text { Sibole Corren } \\
\text { Perrassolo Siluz }\end{array}$ & $\begin{array}{l}\text { Historia e Historiografia. } \\
\text { Roligiác Cuiaba-MII. } \\
\text { Festrvidsole retigiosa. } \\
\text { Cultura Cuisbaza. }\end{array}$ & Hisioria & $\begin{array}{l}\text { Universidade } \\
\text { Federal de Mato } \\
\text { Grosso }\end{array}$ \\
\hline $\begin{array}{l}\text { Levantes Religiosos e combate ao diabo: } \\
\text { concepches e praticas sociais no norte da } \\
\text { Africa entre os séculos TV e V }\end{array}$ & $\begin{array}{c}\text { Juliana Marques } \\
\text { Morais }\end{array}$ & $\begin{array}{l}\text { Notte da Africa. } \\
\text { Perseguiçào Conflitos } \\
\text { religosos. Praticas sociais } \\
\text { Antiguxdade Tardis }\end{array}$ & Histócia & $\begin{array}{l}\text { Lniversidade } \\
\text { Estadzial de } \\
\text { Lotdrita }\end{array}$ \\
\hline $\begin{array}{l}\text { As relaços entre os confiontos religiesos } \\
\text { eos bigares cristoes des cidades do norte } \\
\text { da África darante a antiguidade tardia }\end{array}$ & $\begin{array}{c}\text { Giosas do } \\
\text { Nascimento }\end{array}$ & $\begin{array}{l}\text { Conflito Religioso; Culnura } \\
\text { Marerial Norte da Africa. } \\
\text { Antizuidade Tardia }\end{array}$ & História & $\begin{array}{l}\text { Uaiversidade } \\
\text { Esradual de } \\
\text { Londrina }\end{array}$ \\
\hline
\end{tabular}

Na dissertação de Silva (2014), a origem da festa de São Benedito ocorreu junto com a fundação da vila, no século XVIII, referência na construção da tradição e sendo visto como a maior festa religiosa de devoção ao santo negro. Ela é realizada no mês de julho, contribuindo para a historiografia da igreja Católica da Capital e refletindo o papel do cenário das manifestações culturais.

Concluindo, a dissertação de Nascimento (2015), destaca que os confrontos entre as diferentes facções religiosas, ocorreram, pelo controle das basílicas cristãs, e foi constatado que essas basílicas sustentaram e mantiveram diversos níveis de atrito entre as comunidades religiosas, incentivando as suas concorrências oferecendo durabilidade aos confrontos.

Por fim, em relação ao Programa de Serviço Social, foram levantadas 3 dissertações, que possibilitaram a verificação dos seguintes pontos:

\section{Quadro 4: Dissertações analisadas segundo o Programa de Serviço Social.}

\begin{tabular}{|c|c|c|c|c|}
\hline Titrilo & Autar & Palmvras - Chaves & Programa & Universidade \\
\hline $\begin{array}{l}\text { Cepuchinhos lombardos no } \\
\text { Maranbào: suas praticas } \\
\text { eommicarivas aa Cidade de } \\
\text { Imperatriz (1922-1979) }\end{array}$ & $\begin{array}{c}\text { Valdalia Alves } \\
\text { de Andrade }\end{array}$ & $\begin{array}{l}\text { Capnchinbos. Missðes } \\
\text { Comnticaçio. Aspectos } \\
\text { religiosos. Igreja Carolics. } \\
\text { Memória coletiva. }\end{array}$ & $\begin{array}{c}\text { Commacaçấo e } \\
\text { Semiótica }\end{array}$ & $\begin{array}{c}\text { Pontificia } \\
\text { Universidade } \\
\text { Catolica de } \$ 3.50 \\
\text { Paulo }\end{array}$ \\
\hline $\begin{array}{l}\text { Os valores religiosoc e seus } \\
\text { desdobramentos no cotidiano dos } \\
\text { jovens: }\end{array}$ & $\begin{array}{c}\text { Elisa Botri } \\
\text { Vidal }\end{array}$ & $\begin{array}{l}\text { Valores religiosos. } \\
\text { Conservadorismo. } \\
\text { hrventude. }\end{array}$ & Serviço Social & $\begin{array}{c}\text { Pontificis } \\
\text { Universidade } \\
\text { Catolica de Sto } \\
\text { Paulo }\end{array}$ \\
\hline $\begin{array}{c}\text { A comumicaçăo da igreja católica no } \\
\text { Brasil: rendéncias conumicacionais } \\
\text { da Conferéncia Nacional dos Bispos } \\
\text { do Brasil Sajo Bemardo }\end{array}$ & $\begin{array}{l}\text { Ricardo Costa } \\
\text { Alvarenga }\end{array}$ & 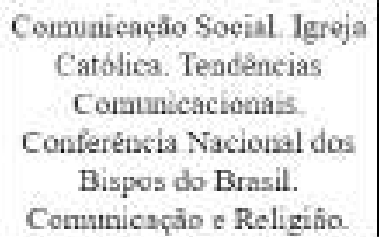 & $\begin{array}{l}\text { Comunicactós } \\
\text { Social }\end{array}$ & $\begin{array}{c}\text { Universidade } \\
\text { Metodista de Sto } \\
\text { Paulo }\end{array}$ \\
\hline
\end{tabular}


No que diz respeito à dissertação de Vidal (2016), esta tem por objetivo analisar a representatividade destes valores conservadores na vida de jovens vinculados a diferentes religiões, por meio de pesquisas bibliográficas e de campo, de questionários semi estruturados, em pesquisas científicas, possibilitando a compreensão da relação entre conservadorismo, juventude e religião.

A dissertação de Alvarenga (2016), buscou identificar as tendências comunicacionais por contribuir com os estudos relacionados à interface Comunicação e Religião no Brasil. Assim, a pesquisa foi desenvolvida com base em levantamentos bibliográficos, análise documental e entrevistas, que levaram às conclusões de que a CNBB foi influenciada por aspectos sociais, eclesiais, políticos e econômicos.

Concluindo, a dissertação de Andrade (2017), busca entender a articulação da comunicação utilizada pelos missionários italianos para difundir o catolicismo romano. Para a realização desta pesquisa foram utilizadas de fontes sistematizadas em documentos e periódicos ilustrados e fontes orais. Por fim, a pesquisa percorre os desejos de renovação, definidos pelo Concílio Vaticano II.

\section{CONSIDERAÇÕES FINAIS}

A partir do estudo realizado foi possível relacionar através do mapeamento realizado, as várias concepções de territórios religiosos, tendo como base os principais autores que são referência na discussão do tema em âmbito acadêmico. Ainda, por meio do levantamento quanti/qualitativos das produções na plataforma CAPES, foi possível identificar e analisar as principais produções que traziam em seus títulos, resumos ou palavras chaves algum dos descritores pesquisados.

A pesquisa representou um grande desafio para os autores principalmente por se tratar de um tema novo e principalmente por utilizar de novas metodologias de estudo, como foi o caso do levantamento quantitativo e qualitativo das produções. Desta forma, compreende-se que sua importância vai bem além da simples produção apresentada até aqui, mas sim nas infinitas possibilidades de estudo que foram descobertas ao longo de sua elaboração.

Por fim compreende que o processo de construção dos territórios religiosos é um 
processo social que está diretamente associado ao ideário do homem religioso. Diferentemente dos outros processos de ocupação do espaço com óticas econômicas, a visão religiosa não apresenta explicações ligadas ao mundo material, mas sim ao sagrado e as suas várias manifestações.

\section{REFERÊNCIAS}

ALMEIDA, Lorrana Laila Silva de. "DAÍ PRA CÁ É MEU”: Territorialidades no contexto da Festa do Divino Pai Eterno em Trindade-GO. 28/04/2020. Mestrado Geografia do Pontal - PPGEP. Instituição de Ensino: Universidade Federal de Uberlândia, Uberlândia-MG. Disponível em: <https://repositorio.ufu.br/bitstream/123456789/29386/1/DaiPraCaEMeu.pdf>. Acesso em: 13 jul. 2021.

ALVARENGA, Ricardo Costa. A Comunicação da Igreja Católica no Brasil: tendências comunicacionais da Conferência Nacional dos Bispos do Brasil São Bernardo. 22/11/2016 232 f. Mestrado em Comunicação Social. Instituição de Ensino: Universidade Metodista de São Paulo, São Bernardo do Campo. Biblioteca Depositária: UMESP. Disponível em: $<$ https://sucupira.capes.gov.br/sucupira/public/consultas/coleta/trabalhoConclusao/viewTr abalhoConclusao.jsf?popup=true\&id_trabalho=4162973>. Acesso em: 13 jul. 2021.

ANDRADE, Valdalia Alves de. Capuchinhos lombardos no Maranhão: suas práticas comunicativas na Cidade de Imperatriz (1922-1979). 25/05/2017 undefined f. Mestrado em Comunicação e Semiótica. Instituição de Ensino: Pontifícia Universidade Católica de São Paulo, São Paulo. Biblioteca Depositária: PUC/SP. Disponível em: <https://sapientia.pucsp.br/bitstream/handle/20139/2/Vald\%c3\%a1lia\%20Alves\%20de\%20 Andrade.pdf>. Acesso em: 13 jul. 2021.

ARAUJO, Bruno Cesar Cordeiro de. Embates da fé: conflitos religiosos entre congregacionais e católicos no sertão da Paraíba (1930-1940). 30/06/2020 138 f. Mestrado em Ciências da Religião. Instituição de Ensino: Universidade Católica de Pernambuco, Recife. Biblioteca Depositária: Biblioteca Central da UNICAP. Disponível em: <http://tede2.unicap.br:8080/bitstream/tede/1324/5/Ok_bruno_cesar_cordeiro_araujo.pdf >. Acesso em: 13 jul. 2021.

CARMO, Maria Vanessa Nunes do. Mapeamento e Pluralismo: A Territorialidade Religiosa no Bairro do Pina em Recife. 20/03/2017 176 f. Mestrado em Ciências da Religião. Instituição de Ensino: Universidade Católica de Pernambuco, Recife. Biblioteca Depositária: Biblioteca Central da UNICAP (O trabalho não possui divulgação autorizada).

CASTELUBER, Daniel Louzada. A Territorialidade da Igreja Católica em Colatina-ES: Um olhar a partir de Zeny Rosendahl. 09/12/2014 87 f. Mestrado Profissional em Ciências das Religiões Instituição de Ensino: Faculdade Unida de Vitória, Vitória. Biblioteca Depositária: Biblioteca Central Faculdade Unida de Vitória (O trabalho não possui divulgação autorizada). Disponível em: 
<http://bdtd.faculdadeunida.com.br:8080/jspui/bitstream/prefix/147/1/Disserta\%c3\%a7\%c 3\%a3o\%20-\%20Daniel\%20Louzada\%20Casteluber.pdf>. Acesso em: 13 jul. 2021.

CARVALHO, José Rodrigues de. Território da Religiosidade: Fé, Mobilidade e Símbolos na Construção do Espaço Sagrado da Romaria do Senhor do Bonfim em Araguacema, Tocantins. 14/03/2014 156 f. Mestrado em Geografia. Instituição de Ensino: Universidade Federal de Goiás, Goiânia. Biblioteca Depositária: Biblioteca Central da UFG. Disponível em: $<$ https://sucupira.capes.gov.br/sucupira/public/consultas/coleta/trabalhoConclusao/viewTr abalhoConclusao.jsf?popup=true\&id_trabalho=1538349>. Acesso em: 13 jul. 2021.

DIAS, Roberta Cristina Martins. Estratégias de difusão espacial do Protestantismo no Estado do Rio de Janeiro: o caso da Igreja Projeto Vida Nova. 13/09/2016 106 f. Mestrado em Geografia. Instituição de Ensino: Universidade do Estado do Rio de Janeiro, Rio de Janeiro. Biblioteca Depositária: Biblioteca CTC/C Rede Sirius UERJ. Rua São Francisco Xavier 524, 4은 andar, sala 4014, bloco C (O trabalho não possui divulgação autorizada).

FERREIRA, Norma Sandra de Almeida. As pesquisas denominadas "estado da arte". Educ. Soc. [online]. 2002, vol.23, n.79, pp.257-272. Disponível em: <https://www.scielo.br/j/es/a/vPsyhSBW4xJT48FfrdCtgfp/?lang=pt\&format=pdf>. Acesso em: 27 jul. 2021.

FILIPE, Rosana Jardim Madureira. Difusão espacial da religião: Igreja Metodista em São Francisco, Niterói, a prática religiosa em células, (2014). 29/04/2014 129 f. Mestrado em Geografia. Instituição de Ensino: Universidade do Estado do Rio de Janeiro, Rio de Janeiro. Biblioteca Depositária: Biblioteca CTC/C - Rede Sirius, UERJ. Rua São Francisco Xavier 524, 4은 andar, sala 4014, bloco C. (O trabalho não possui divulgação autorizada). Disponível em: <https://www.bdtd.uerj.br:8443/bitstream/1/13339/1/Dissertacao\%20completa.pdf>.

Acesso em: 23 jul. 2021.

HAESBAERT, R. O mito da desterritorialização. Do "fim dos territórios" à multiterritorialidade. Rio de Janeiro:Bertrand Brasil, 2004

MIGUEL, Rogerio Tiago. Religião em Ambientes Digitais: o discurso religioso e possibilidades de diálogo na perspectiva de Mikhail Bakhtin. 22/05/2017 123 f. Mestrado em Ciências da Religião. Instituição de Ensino: Pontifícia Universidade Católica de Minas Gerais, Belo Horizonte. Biblioteca Depositária: Pe. Alberto Antoniazzi. Disponível em: $<$ https://sucupira.capes.gov.br/sucupira/public/consultas/coleta/trabalhoConclusao/view Tr abalhoConclusao.jsf?popup=true\&id_trabalho=5068456>. Acesso em: 13 jul. 2021.

MOURA, Marcos Roberto Pereira. A romaria de Santa Luzia: contribuições da fé para a construção de uma identidade territorial na comunidade de Santa Luzia - município de Porangatu/GO. 17/11/2015 206 f. Mestrado em Geografia. Instituição de Ensino: Universidade Federal de Goiás, Goiânia. Biblioteca Depositária: Biblioteca Central da UFG. Disponível em: <https://sucupira.capes.gov.br/sucupira/public/consultas/coleta/trabalhoConclusao/viewTr abalhoConclusao.jsf?popup=true\&id_trabalho=3452159>. Acesso em: 13 jul. 2021. 
MORAIS, Juliana Marques. Levantes Religiosos e Combate ao Diabo: Concepções e Práticas Sociais no Norte da África entre os séculos IV e V. 28/08/2014 104 f. Mestrado em História Social. Instituição de Ensino: Universidade Estadual de Londrina, Londrina. Biblioteca Depositária: Biblioteca Central da Universidade Estadual de Londrina (UEL). Disponível em: $<$ https://sucupira.capes.gov.br/sucupira/public/consultas/coleta/trabalhoConclusao/viewTr abalhoConclusao.jsf?popup=true\&id_trabalho=2090150>. Acesso em: 13 jul. 2021.

MOTA, Aline Ellen dos Santos. Católicos: "Falsos" Versus "Verdadeiros": Observando relações de poder entre dois grupos religiosos na cidade de Capanema-PA. 14/10/2016 151 f. Mestrado em Ciências da Religião. Instituição de Ensino: Universidade do Estado do Pará, Belém Biblioteca Depositária: Biblioteca Paulo Freire - Centro de Ciências Sociais e Educação da UEPA (O trabalho não possui divulgação autorizada).

NASCIMENTO, Giovan do. As relações entre os confrontos religiosos e os lugares cristãos das cidades do Norte da África durante a Antiguidade Tardia (Séculos IV - VI D.C.). 07/07/2015 95 f. Mestrado em História Social. Instituição de Ensino: Universidade Estadual de Londrina, Londrina. Biblioteca Depositária: BC-UEL. Disponível em: $<$ https://sucupira.capes.gov.br/sucupira/public/consultas/coleta/trabalhoConclusao/viewTr abalhoConclusao.jsf?popup=true\&id_trabalho=3106906>. Acesso em: 13 jul. 2021.

RAFFESTIN, Claude. O que é o Território? In: Por uma geografia do poder. São Paulo: Ática, 1993. p. 144-220.

REIS, Suellen Santiago dos. De lugar segregado ao lugar espiritual da Teologia da Libertação: Diocese de Nova Iguaçu de 1970 a 1990. 07/02/2013 135 f. Mestrado em Geografia. Instituição de Ensino: Universidade do Estado do Rio de Janeiro, Rio de Janeiro Biblioteca Depositária: CTC/C (O trabalho não possui divulgação autorizada). Disponível em: <https://www.bdtd.uerj.br:8443/bitstream/1/13342/1/Dissertacao\%20completa.pdf>.

Acesso em: 13 jul. 2021.

ROSENDAHL, Z. (Orgs.) Geografia Cultural: um século (3). Rio de Janeiro: EdUERJ, 2002.

SAMPAIO, Debora Vanessa Regis Ferreira. Campina Grande (PB). A "Capital da Fé": entre Territórios e (re)Construções Identitárias. 09/08/2018 165 f. Mestrado em Geografia Instituição de Ensino: Universidade Estadual do Oeste do Paraná, Marechal Cândido Rondon. Biblioteca Depositária: Unioeste - Campus de Marechal Cândido Rondon. Disponível em: $<$ https://sucupira.capes.gov.br/sucupira/public/consultas/coleta/trabalhoConclusao/viewTr abalhoConclusao.jsf?popup=true\&id_trabalho=6592402>. Acesso em: 13 jul. 2021.

SANTOS, M. O espaço: sistema de objetos, sistemas de ação. In: A natureza do espaço: técnicas e tempo - razão e emoção. 2.ed. São Paulo: Hucitec, 1997.

SHIOTA, Hanae Caroline Quintana; DORSA Arlinda Cantero.O estado da arte e as técnicas de análise de conteúdo segundo Laurence Bardin. In: As Interfaces da Diversidade, do Patrimônio e da Globalização a partir das Produções Científicas. Org. Arlinda Cantero Dorsa e Antonio Henrique M. Lima. - Campo Grande, MS: Life Editora, 2021 
SILVA, Eliete Furtado Cecilio e. Campo da Fé: Território e Territorialidades dos peregrinos sergipanos na Jornada Mundial da Juventude: Rio de Janeiro/2013. 22/06/2016 204 f. Mestrado em Geografia. Instituição de Ensino: Fundação Universidade Federal de Sergipe, São Cristóvão Biblioteca Depositária: undefined. Disponível em: <https://ri.ufs.br/handle/riufs/5517>. Acesso em: 13 jul. 2021.

SILVA, Silbene Correa Perassolo da. A Festa de São Benedito: Estudo sobre a invenção de uma tradição cuiabana. 30/05/2014 238 f. Mestrado em História. Instituição de Ensino: Universidade Federal de Mato Grosso, Cuiabá. Biblioteca Depositária: Biblioteca Central da Universidade Federal de Mato Grosso. Disponível em: $<$ https://sucupira.capes.gov.br/sucupira/public/consultas/coleta/trabalhoConclusao/viewTr abalhoConclusao.jsf?popup=true\&id_trabalho=1695250>. Acesso em: 13 jul. 2021.

SLONGO, lône Inês Pinsson. A produção acadêmica em ensino de biologia: um estudo a partir de teses e dissertações. Florianópolis : UFSC, 2004. Disponível em: $<$ https://repositorio.ufsc.br/xmlui/bitstream/handle/123456789/88012/205538.pdf?sequen ce=1\&isAllowed=y>. Acesso em: 27 jul. 2021.

VIDAL, Elisa Borri. Os Valores Religiosos e seus Desdobramentos no Cotidiano dos Jovens. 11/03/2016 106 f. Mestrado em Serviço Social. Instituição de Ensino: Pontifícia Universidade Católica de São Paulo, São Paulo Biblioteca Depositaria: PUCSP. Disponível em: $<$ https://sucupira.capes.gov.br/sucupira/public/consultas/coleta/trabalhoConclusao/viewTr abalhoConclusao.jsf?popup=true\&id_trabalho=3690798>. Acesso em: 13 jul. 2021. 


\title{
A DIMENSÃO HUMANA DO HERÓI NA GUERRA DO PARAGUAI (1864-1870)
}

\author{
Gustavo Ribeiro Capibaribe \\ Doutorando em Desenvolvimento Local- PPGDL-UCDB-MS \\ gustavocapibaribe@outlook.com \\ Luiz Jeha Pecci de Oliveira \\ Mestrando em Desenvolvimento Local- PPGDL-UCDB-MS \\ luizpecci97@gmail.com \\ Wilson Cardoso de Sá \\ Doutorando em Desenvolvimento Local- PPGDL-UCDB-MS \\ Wilson_cardoso@hotmail.com \\ Heitor Romero Marques \\ Doutor em Desenvolvimento local. PPGDL-UCDB-MS \\ heiroma@ucdb.br
}

\begin{abstract}
RESUMO
O presente trabalho tem o objetivo de analisar um novo conceito sobre o herói e o heroísmo, inserindo-o na análise da Guerra do Paraguai (1864-1870), pontuando a dimensão humana da figura sobre a qual se aplica esse conceito. Valendo-se de bibliografia diversa, estabelecer-se-á a definição de "herói" como sendo o indivíduo que, impelido pela virtude na busca e defesa de um sentido para sua vida, sacrifica-se sob um ideal de serviço ao próximo, reabsorvendo e transcendendo as suas circunstâncias. Então, será trazido o contexto da Guerra do Paraguai, mostrando-a como um importante conflito sul-americano, de modo a compreendê-la também como um grande berço de indivíduos com características heroicas. Por fim, será feita uma análise sobre a dimensão humana da figura construída, e como ela se insere no contexto bélico do conflito narrado. $O$ artigo conclui que os heróis na Guerra do Paraguai foram pessoas comuns que, diante de grande sofrimento, apresentaram um comportamento acima da média esperada para a sociedade, realizando atos extraordinários, de modo que se identifica o heroísmo na pessoa capaz de apresentar à coletividade a esperança e o amor desejados em caso de situações adversas, como nesse exemplo histórico. Quanto à metodologia, este artigo se valeu do método hipotético-dedutivo do procedimento histórico.
\end{abstract}

Palavras-chave: Herói; heroísmo; circunstâncias; Guerra do Paraguai; dimensão humana. 


\section{ABSTRACT}

\section{THE HERO'S HUMAN DIMENSION AT THE PARAGUAYAN WAR (1864-1870)}

The current work has the objective of analyze a new concept about the hero and heroism, inserting it in the analysis of the Paraguayan War (1864-1870), pointing the human dimension of the figure that this concept applies itself. Utilizing diverse bibliography, it will be established the definition of "hero" as being the individual which, impelled by virtue in the search and defense for a meaning for his life, sacrifice himself under an idea of serving the others, reabsorbing and transcending his circumstances. Then, it will be brought the context of the Paraguayan War, showing it as an important South American conflict, to comprehend it also as a big cradle of individuals with heroic characteristics. Lastly, it will be made an analysis about the human dimension of the figure built, and how it inserts itself in the martial context of the narrated conflict. The paper concludes that the heroes of the Paraguayan War were common people that, in the face of great suffering, presented an above average behavior, in the sense that the heroism in the person capable of presenting the collectivity the hope and love desired in adverse situations identifies himself, as in this historical example. As for the methodology, this work utilized the hypothetical-deductive method, with historical proceeding.

Keywords: Hero; heroism; circumstances; Paraguayan War; human dimension. 


\section{INTRODUÇÃO}

A história da humanidade se alicerça nos feitos dos homens enquanto parte de seus respectivos grupos. Esses feitos são observáveis e classificáveis por envergadura, sobre eles recaindo também o juízo de valores para definir se são proveitosos ou deletérios para a memória conjunta desses grupos. A partir desse juízo, com uma avaliação positiva, surge, inescapavelmente, a figura do herói.

Ao se trabalhar com a ideia de herói, é compreensível que se recorram às imagens das figuras mitológicas deixadas por gregos e romanos ou aos grandes líderes políticomilitares que preenchem os livros de história. Porém, a questão é mais profunda: a noção sobre o que é e como se manifesta o heroísmo vai além das figuras já capturadas por esse senso imediato.

Aqui, atinge-se o propósito deste trabalho, ao se pretender apresentar uma nova concepção sobre essa figura, permitindo entender como ela pode alcançar mesmo os indivíduos aparentemente mais ordinários, a ponto de identificá-la e inseri-la num episódio histórico importante para o Brasil: a Guerra do Paraguai (1864-1870).

Dessa forma, a estrutura do artigo se alicerçará, em um primeiro momento, na apresentação do conceito tradicional da figura heroica, e na construção de um novo, que embasará a tese central. Então, será apresentada uma síntese dos eventos e fatos ocorridos durante a Guerra do Paraguai, para que se compreenda como a figura construída no primeiro capítulo pode nela se encaixar. Esse encaixe será completado diante da apresentação da dimensão humana que cerca a imagem heroica, e como ela se insere no contexto bélico.

Para a consecução desta pesquisa, valeu-se no método hipotético-dedutivo, mediante revisão bibliográfica, vez que se construiu um conceito para se moldar uma hipótese para análise de um caso particular, diante do encaixe da definição apresentada logo ao início do trabalho no fato histórico descrito. O procedimento de pesquisa foi, naturalmente, o histórico. 


\section{HERÓI}

Todas as civilizações se encaixam na esfera de uma determinada cultura. Essa cultura se alicerça sobre uma memória coletiva, que pode ser definida como a lembrança dos feitos realizados em comum. Esses feitos, agrupados em um todo unívoco, perfazem a trajetória de cada nação por eles representada. Nessa trajetória, é natural que se evidenciem atos individuais de maior envergadura, voltados para o bem ou para o mal. O caso dos primeiros abarca o surgimento da figura que se conhece como herói.

Os dicionários não trazem uma única assertiva para esse conceito. Entre os significados trazidos, pode-se encontrar: 1) "aquele que se distingue por seu valor ou por suas ações extraordinárias"; 2) "Pessoa que se destaca em relação aos demais"; 3) "Aquele que é condecorado por suas ações corajosas, pelo seu caráter magnânimo, por comportamentos altruístas"; e 4) "Quem é capaz de suportar situações adversas sem se abater" (DICIO, 2021). Todas essas assertivas são válidas dentro de seus respectivos limites conceituais, mas este trabalho propõe um passo a mais: a construção de um novo conceito de herói, que se possa amoldar adequadamente dentro da interpretação desta figura na Guerra do Paraguai (18641870).

\subsection{A VIVÊNCIA DAS CIRCUNSTÂNCIAS - A VISÃO HEROICA A PARTIR DE ORTEGA Y GASSET}

A vida impõe a todos os seus limites. As situações de fato em que eles se verificam podem ou não ser limitantes para o desenvolvimento das potencialidades de uma pessoa. Porém, sobre elas, o filósofo espanhol José Ortega Y Gasset (1883-1955) exprime uma de suas antológicas citações: "Yo soy yo y mi circunstancia, y si no la salvo a ella no me salvo yo" (ORTEGA Y GASSET, 1914, p. 43-4).

Para que se entenda esse comentário, faz-se necessária a compreensão do conceito de circunstância dentro da filosofia de Ortega, o que vem elucidado por Carvalho $(2009$, p. 335-6), nos termos:

O conceito de circunstância contempla o entorno que não se resume à paisagem representada pelo ambiente social ou o nós. Este ponto é marcante no

\footnotetext{
1 “Eu sou eu e minha circunstância, e se não salvo a ela, não salvo a mim mesmo" (tradução livre).
} 
raciovitalismo, o entorno ao eu inclui a intimidade representada pelos mecanismos fisiológicos da vida, das leis que regem a alma e pelas expressões do pensamento ou espírito, tudo isto histórico e escondido em cada homem. [...] A intimidade ou o lado de dentro que representa a parcela oculta da vida também circunscreve o eu, como também o envolve a situação exterior, a realidade social, econômica, política, temporal, em resumo cultural onde vivemos. O lado de fora do indivíduo, aquilo que se manifesta para os outros, é expressão do interior que se deixa ser conhecido pelo que aparece fora. $\mathrm{O}$ homem tem, pois um lado de fora e um de dentro e ambos circunscrevem o eu, sendo que o corpo põe à mostra a alma [...]

Sumarize-se, portanto: o ser humano incorpora em si uma série de particularidades, que acabam constituindo a forma como ele se percebe e identifica perante si mesmo e no mundo. Essas particularidades tais como classe social ou local de nascença, podem representar fatores que limitam o homem na vivência de suas capacidades.

O filósofo espanhol, contudo, ensina a amar essas circunstâncias, ao estabelecer que sua reabsorção é o destino concreto do homem (ORTEGA Y GASSET, 1914). Seu raciocínio se completa com interessante observação (ORTEGA Y GASSET, 1914, p. 44-5):

Nada impide el heroísmo-que es la actividad del espíritu-, tanto como considerarlo adscrito a ciertos contenidos específicos de la vida. Es menester que donde quiera subsista subterránea la posibilidad del heroísmo, y que todo hombre, si golpea con vigor la tierra donde pisan sus plantas, espere que salte una fuente ${ }^{2}$.

Chega-se, então, à primeira parte do conceito buscado: o herói é a pessoa que, fundamentalmente, transcende suas circunstâncias, golpeando a terra à espera da fonte, de modo a imprimir uma marca no presente com os seus atos. A compreensão da segunda parte vem a partir do entendimento do porquê desse ato de transcendência.

\subsection{O SENTIDO DA VIDA E O SERVIÇO AO PRÓXIMO - A CONTRIBUIÇÃO DE VIKTOR FRANKL}

Defende-se neste trabalho que a superação das circunstâncias individuais não é um ato que se deve entender isoladamente por si, mas sim uma atitude que precisa vir acompanhada de

\footnotetext{
${ }^{2}$ Nada impede o heroísmo - que é a atividade do espírito -, tanto como considerá-lo apegado a certos conteúdos específicos da vida. É necessário, onde quer que exista a subterrânea possibilidade de heroísmo, que todo homem, se golpeia com vigor a terra em que se pisam as plantas, espere que salte uma fonte (tradução livre).
} 
um sentido intrínseco dado pelo sujeito que a concretiza. Para isso, deve-se compreender a natureza dessa característica.

O psiquiatra austríaco Viktor Frankl (1905-1997) desenvolveu uma abordagem psicoterapêutica chamada logoterapia. Nas palavras de Rodrigues e Barros (2009), essa abordagem se baseia na ideia de que a vida possui um sentido, fundamentando-se no respeito ao ser humano, que seria um ente responsável e capaz de se posicionar perante os condicionamentos da vida.

No que diz respeito não apenas à busca desse sentido, mas seu direcionamento, Frankl (1987, p. 75) assim se manifesta:

\begin{abstract}
Ao declarar que o ser humano é uma criatura responsável e precisa realizar o sentido potencial de sua vida, quero salientar que o verdadeiro sentido da vida deve ser descoberto no mundo, e não dentro da pessoa humana ou de sua psique, como se fosse um sistema fechado. Chamei esta característica constitutiva de "a autotranscendência da existência humana". Ela denota o fato de que ser humano sempre aponta e se dirige para algo ou alguém diferente de si mesmo - seja um sentido a realizar ou outro ser humano a encontrar. Quanto mais a pessoa esquecer de si mesma - dedicando-se a servir uma causa ou a amar outra pessoa - mais humana será e mais se realizará. $O$ que se chama de auto-realização não é de modo algum um objetivo atingível, pela simples razão de que quanto mais a pessoa se esforçar, tanto mais deixará de atingi-lo. Em outras palavras, auto-realização só é possível como um efeito colateral da auto-transcendência-
\end{abstract}

Note-se que a procura advogada por Frankl se encontra atrelada ao serviço dedicado ao próximo. Uma existência humana plena não se resumiria, portanto, à simples satisfação egoísta de suas próprias necessidades. Frankl (1987) defende que a descoberta de sentido para a vida pode se dar de três formas: (1) criando um trabalho ou praticando um ato; (2) experimentando algo ou encontrando alguém; e (3) pela atitude que tomamos em relação ao sofrimento inevitável.

Em relação a esse terceiro aspecto, pode-se dizer que a concepção de Frankl sobre a carga do sofrimento serve como um apontamento de caminho em busca da redenção do sujeito que dele padece. Assim, o indivíduo converte o sofrimento em sacrifício. Veja-se:

Não devemos esquecer nunca que também podemos encontrar sentido na vida quando nos confrontamos com uma situação sem esperança, quando enfrentamos uma fatalidade que não pode ser mudada. Porque o que importa, então, é dar testemunho do potencial especificamente humano no que ele tem de mais elevado, 
e que consiste em transformar uma tragédia pessoal num triunfo, em converter nosso sofrimento numa conquista humana. Quando já não somos capazes de mudar uma situação - podemos pensar numa doença incurável, como um câncer que não se pode mais operar - somos desafiados a mudar a nós próprios (FRANKL, 1987, p. 76).

Complemente-se, pois, o conceito que se pretende trabalhar neste artigo: o herói é aquele que transcende suas circunstâncias por meio do sacrifício, o que faz como forma de dedicar serviço ao próximo. E é nessa transcendência que ele encontra o sentido para a sua vida. Completar essa definição dependerá da fixação do alcance sobre quem é esse "próximo".

O "próximo" a quem e por quem se concretizam os atos do herói é uma figura ampla. Ele pode representar desde um ente querido até o próprio país. Recorde-se aqui que o heroísmo enquanto fenômeno está ligado, fundamentalmente, ao cumprimento de um dever, ato que evidencia um último elemento em sua constituição.

Esse elemento é aquele que abastece a busca de sentido e a superação das circunstâncias do indivíduo: a virtude. Sobre ela, considerada a importância dessa concepção, devem-se dedicar algumas linhas, optando-se por adotar como fundamento a base conceitual que lhe é fornecida pelo ensinamento da Igreja Católica.

\subsection{A VIRTUDE COMO ELEMENTO FINAL DO CONCEITO HEROICO - A PERSPECTIVA DO CATECISMO DA IGREJA CATÓLICA}

O elemento final para a construção do conceito de herói que aqui se pretende defender é dado pelos ensinamentos da Igreja Católica, em virtude não apenas da importância desta instituição, mas também da pertinência e precisão com que trata o tema. A ideia final, portanto, reside na noção de virtude.

De início, recorde-se sua definição trazida pelo Catecismo da Igreja Católica (2017, p. 485): “A virtude é uma disposição habitual e firme para fazer o bem. Permite à pessoa não só praticar atos bons, mas dar o melhor de si. Com todas as suas forças sensíveis e espirituais, a pessoa virtuosa tende ao bem, o procura e o escolhe na prática". 
Não se cingindo ao elemento teológico desse conceito, amplie-se aqui a noção do destinatário do citado "bem". A figura beneficiada pelos atos da pessoa virtuosa varia da família à pátria, em outro conceito amplo. Prossegue o compêndio:

As virtudes humanas são atitudes firmes, disposições estáveis, perfeições habituais da inteligência e da vontade que regulam nossos atos, ordenando nossas paixões e guiando-nos segundo a razão e a fé. Propiciam, assim, facilidade, domínio e alegria para levar uma vida moralmente boa. Pessoa virtuosa é aquela que livremente pratica o bem (CIC, 2017, p. 485-6).

O indivíduo virtuoso é, portanto, aquele que tem as paixões ordenadas. Isso lhe permite a aquisição de uma resistência suficiente para poder superar as adversidades do meio à sua volta. Portanto, conclua-se este-tópico apresentando o conceito definitivo cuja defesa será contextualizada no decorrer do artigo: o herói é aquela pessoa que, impelida pela virtude na busca e defesa de um sentido para sua vida, sacrifica-se sob um ideal de serviço ao próximo, reabsorvendo e transcendendo as suas circunstâncias.

O surgimento desse tipo de personagem é propiciado pela existência de fatos extraordinários, nos quais residem os momentos historicamente propícios para o aparecimento de figuras heroicas, particularmente se esses episódios perfazem acontecimentos históricos importantes na trajetória de uma nação como um todo. No contexto latino-americano, um desses momentos mais determinantes é a Guerra do Paraguai (1864-1870), episódio com importância vital para os países participantes, e no qual a existência e amplitude do heroísmo levam a debates sobre a dimensão humana das figuras de seus participantes com esses atributos. A seguir, será recordada a história do desenvolvimento do conflito, de forma a embasar a tese central.

\section{EVENTOS HISTORICOS DA GUERRA DO PARAGUAI}

A Guerra do Paraguai, somente conhecida por este toponímico no Brasil, visto ser conhecida por Guerra da Tríplice Aliança na Bacia do Prata e por Guerra Grande no Paraguai, foi o maior conflito armado em que as Forças Armadas Brasileiras participaram diretamente, seja pela quantidade de mortos, tempo de duração dos embates e pelas consequências geopolíticas decorrentes. 
A Historiografia, durante o tempo, evocou diversos matizes para compreender o desenrolar dos fatos e explicar as razões para a deflagração do conflito em apreço. Estas visões históricas foram influenciadas pelas tendências acadêmicas dos pesquisadores que as formularam, enfatizando determinado aspecto ou pretendendo apresentar a visão intelectual do autor.

A primeira que apresentamos é aquela descrita logo após a Proclamação da República, período em que militares, veteranos do conflito, estavam no comando da nação ou tinham participação proeminente nas decisões. Esta corrente procurou enaltecer as virtudes heroicas dos combatentes, atribuindo ao expansionismo paraguaio o estopim pela deflagração das hostilidades.

Esses autores enfatizam a nação guarani, um país com características mediterrâneas no coração sul-americano, almejando uma saída para o mar e que, alegando interferências do Brasil no Uruguai, teria tomado medidas de cunho bélico. Tais medidas levaram o Império Brasileiro, a República da Argentina e o Uruguai a unirem esforços para derrotar as intenções de Solano López, o ditador paraguaio, herdeiro político de seu pai, Carlos López, que controlava seu território com mão de ferro.

Essas ideias estão fundadas em acontecimentos plenamente documentados, sendo, portanto, muito fiéis aos ensinamentos positivistas, em voga na época. Esses acontecimentoschave seriam o aprisionamento do navio Marquês de Olinda, a Invasão de Mato Grosso e o ataque a Uruguaiana. Assim, entenderíamos que foram os paraguaios os causadores da guerra.

O aprisionamento do navio Marquês de Olinda ocorreu no dia 12 de novembro de 1864. Este vaso, então sob o comando de Manoel Luiz da Silva Souto, foi capturado no Rio Paraguai, a montante de Assunção, antes de cruzar a fronteira com o então Mato Grosso. Entre os capturados, estava o nomeado presidente desta província brasileira. Entre os motivos alegados estão a tentativa de Solano López em distrair os brasileiros da campanha destes contra o Uruguai e a informação, não confirmada, que a embarcação transportava armas e tesouros valiosos. 
Os tripulantes, passageiros e oficiais foram capturados e encarcerados. Os últimos sofreram torturas, fome e falta de cuidados, o que acarretou na morte de todos, menos dois, libertados em 1869, com o avanço das tropas aliadas sobre o Paraguai.

Por sua vez, a invasão de Mato Grosso ocorreu entre dezembro de 1864 e abril de 1868, ou seja, na fase inicial do conflito, embora antes da declaração oficial de guerra, ocorrida em 13 de dezembro de 1864. Feita por um Corpo de Exército paraguaio, realizou-se quase simultaneamente com a invasão da província argentina de Corrientes e do Rio Grande do Sul. Pela superioridade numérica e a fraca defesa brasileira, teve fácil sucesso (TOLENTINO, 1986).

Esse avanço foi dividido em duas colunas. A primeira, chamada de Ocidental, subiu o Rio Paraguai, ocupando o Forte Coimbra, após luta, em 20 de dezembro de 1864. Corumbá, abandonada por sua guarnição, que se dirigira para Cuiabá, foi ocupada em 02 de janeiro de 1865. Esta cidade foi reconquistada em 13 de junho de 1867 após campanha conduzida pelo General Antônio Maria Coelho. Essa reconquista foi efêmera, pois uma epidemia de varíola assolou a tropa brasileira, obrigando-a a, novamente, deixar a localidade, reocupada pelos paraguaios em 23 de julho de 1867, ali permanecendo até o desfecho da Batalha de Humaitá, em 1868, ocasião em que Solano Lopez determinou o abandono do Mato Grosso, incluindo o Forte Coimbra e o Morro da Marinha, ponto artilhado (TOLENTINO, 1986).

A outra coluna, a Oriental, iniciou a campanha por terra, partindo de Concepcion em 26 de dezembro de 1864, atacando a Colônia Militar de Dourados, onde enfrentaram heroica defesa por parte do Tenente Antônio João Ribeiro, e seguiram em direção à Cuiabá, passando por Miranda, Nioaque e Coxim. Digna de nota é a participação indígena nessa ocupação. Enquanto Kadiweos, Terena e Quiniquinaus apoiaram os brasileiros, protegendo os refugiados, proporcionando-Ihes comida, apoio logístico e de inteligência, os Guató, do Pantanal, aliaram-se, ainda que temporariamente, aos paraguaios. Também relacionada com a invasão ao Mato Grosso, especificamente a Coluna Oriental, está a célebre "Retirada da Laguna", evento ensejador do livro homônimo escrito por Alfredo D’Escragnole Taunay, onde é relatada a campanha conduzida por uma força brasileira, que partira de São Paulo (CAMPESTRINI e GUIMARAES, 1991).

A invasão ao Rio Grande do Sul e da província argentina de Corrientes ocorreu entre 10 de junho e 18 de setembro de 1865, quando Solano López, tentando forçar os brasileiros a 
se retirarem da guerra em condições favoráveis ao Paraguai, determina a incursão. A tropa paraguaia estava sob o comando de Antônio Estigarribia e de Pedro Duarte. As colunas guaranis seguiram o curso do Rio Uruguai durante a incursão. Duarte conquista Paso de los Libres em 02 de agosto de 1865 e, dois dias depois, Estigarribia ocupa Uruguaiana. Contudo, problemas logísticos e falta de reforços ocasionaram a rendição paraguaia ao Conde de Porto Alegre, Manoel Marques de Souza, encerrando a campanha no sul do Brasil (VASCONSELLOS, 1962).

Este entendimento da História sobre a Guerra do Paraguai encontrou oposição quando Chiavenato (1979) escreveu uma obra intitulada "Genocídio Americano: A Guerra do Paraguai". Para esse autor, a guerra teria razões de controle hegemônico mundial, na medida em que o Paraguai apresentaria condições socioeconômica, como baixas taxas de analfabetismo, condições industriais autônomas e liderança política soberana, capazes de proporcionar mecanismos de enfrentamento ao centro do poder mundial à época, a Inglaterra vitoriana.

A Historiografia nacional teria sido abalada com essa publicação. Queiróz (2011, p. 12), enfatiza que;

O livro causou grandes discussões sobre a historiografia nacional da guerra do Paraguai, desagradando os militares, principais representantes da história oficial sobre aquele conflito. Afinal, Chiavenato superava a descrição factual das batalhas; discutiu a formação histórica, social e econômica do Paraguai; denunciou os interesses da guerra; impugnou pontos cruciais das narrativas oficiais e oficiosas; desconstruiu os grandes heróis militares nacionais; mostrou o sofrimento do povo como outro lado da guerra; denunciou a ação das tropas imperiais no Paraguai, o excesso de violência, os crimes de guerra, as deserções. Desconstruiu a retórica sobre os Voluntários da Pátria e os grandes feitos do exército imperial, apresentou um novo Duque de Caxias, um novo Conde d 'Eu, e apresentou ao Brasil, sobretudo, um novo Paraguai, muito diferente da visão nacional- patriótica [...]

Ainda segundo Queiróz (2011), o trabalho teria sofrido grande rejeição por parte da historiografia tradicional, cuja produção seria capitaneada pelo Exército, pela Academia Brasileira de Letras e por parte da imprensa. Segundo ela, a censura impedia novos olhares históricos sobre assuntos ligados ao poder mundial, referenciando outra obra de Chiavenato, "A Guerra do Chaco". Este posicionamento teria dominado a produção científica histórica ao longo da década de 80 do século XX até sofrer oposição. Este questionamento à essa corrente 
se dá por diversas questões, que na essência fogem ao objetivo deste trabalho, mas de grande importância para a compreensão de como a guerra aflige as pessoas mais que as instituições. Doratioto (2002) enfoca sua produção mais em relatórios estatísticos do que em interesses políticos. Contudo, o próprio Doratioto $(2009$, p. 8) continua afirmando que toda produção intelectual está contextualizada no meio político onde foi redigida:

A Nueva Historiografia sobre la Guerra de la Triple Alianza ou Interpretação Sistêmica Regional está isenta de ideologia? Claro que não. Sabe-se, muito bem, que toda produção intelectual carrega consigo valores da época em que foi escrita e do seu autor. A Nueva Historiografia emerge no contexto do fim das ditaduras no Cone Sul e, no plano mundial, do término da Guerra Fria. Esses acontecimentos levaram à abertura de arquivos; a maior liberdade acadêmica e à oxigenação ideológica, criando as condições para a ousadia intelectual por parte dos historiadores, que passaram a estudar novos objetos e questionar antigas interpretações que se apoiavam em precária base documental. Foi a redemocratização dos países que vivenciaram a Guerra do Paraguai que permitiu superar o revisionismo simplificador.

O primeiro aspecto desse revisionismo seria a constatação de que Solano López efetivamente expôs sua população a um conflito com um gigante 22 vezes maior do que ele, em especial quando o torno uma "Guerra Total", ocasião quando toda a população está envolvida, não apenas as forças militares.

Continuando nessa nova forma interpretativa, outro viés polêmico é a percepção de que o subdesenvolvimento paraguaio não poderia ser atribuído exclusivamente à guerra, que por óbvio causa a ruína de nações, mas encerrada há 150 anos. Mesmo antes do conflito a nação tinha característica rurais, com fraca liberdade econômica. Desta forma, sua pobreza não seria somente decorrência dos embates, mas também da forte instabilidade política que por lá vigorou durante o século XX.

Também a influência decisiva para a deflagração do conflito atribuída à Inglaterra não parece se confirmar. Edward Thornton, representante inglês da época, até tentou intervir para o apaziguamento da situação, e que os eventos se resolvessem de forma diplomática. Importante ser dito que, no momento da deflagração do conflito, Brasil e o Reino Unido viviam momentos diplomáticos tensos, culminando com a Questão Christie (DORATIOTO, 2002).

A própria situação brasileira não melhorou em nada com a guerra. 0 país ficou endividado, o movimento abolicionista foi intensificado, minando as bases da oligarquia rural 
escravagista, e a indenização exigida ao Paraguai como reparação nunca foi paga. A moderna História Demográfica também questiona os dados da guerra, alegando não existir base estatística para se afirmar números, o que refutaria um projeto de genocídio perpetrado pela Tríplice Aliança. Ao certo, é que as guerras são feitas por pessoas e que a Guerra do Paraguai forneceu personagens para o panteão heroico republicano, composto, sobretudo por militares participantes deste embate.

Das fileiras imperiais, o Exército tirou aquele que seria seu patrono, cujo nome representa a própria grandeza da força terrestre nacional: Caxias. Nascido Luís Alves de Lima e Silva, no atual município de Duque de Caxias, então chamado Porto Estrela, província do Rio de Janeiro, em 25 de agosto de 1803, tem no seu aniversário comemorado o Dia do Soldado. Assentou praça aos cinco anos de idade e lutou em diversos conflitos internos, destacando-se na Balaiada, no Maranhão, onde recebeu a alcunha de "O Pacificador". Comandou as forças da Tríplice Aliança após a saída de Bartolomé Mitre, reorganizando a tropa e dando-lhe novo ânimo. Foi o único brasileiro a receber o título nobiliárquico de duque, o mais alto na nobreza. Outros nomes aparecem também em destaque no meio castrense, como o de Osório, o Marquês do Herval, vencedor da Batalha de Tuiuti, e do Conde de Porto Alegre, que derrotou os paraguaios no Rio Grande do Sul (ALMEIDA, 1961).

A Armada Imperial, antigo nome da Marinha do Brasil, também extraiu da Guerra do Paraguai aquele que simbolizaria o poder naval: Tamandaré, notável estrategista, que observara do perigo que avizinhava o Mato Grosso nos prelúdios da guerra.

Nome de batismo de diversas embarcações brasileiras ao longo da História, o Almirante Barroso é mais um dos heróis nacionais ligados à Guerra do Paraguai. Vencedor da Batalha Naval do Riachuelo, marco divisor do conflito, evento definidor do controle fluvial indispensável para a consecução das atividades em terra por parte dos aliancistas, em especial pela quase inexistência de estradas na região conflituosa, Barroso é visto como objetivo a ser alcançado pelos marinheiros.

Do aqui apresentado até agora, percebemos que a Guerra do Paraguai foi um nascedouro de heróis nacionais, e que essas personalidades foram pessoas, seres humanos. Daí a importância de vermos qual a dimensão humana destes expoentes. 


\section{A DIMENSÃO HUMANA DO HERÓI}

O conceito de humanidade vem sendo discutido ao longo da História humana por diversas áreas: filosofia, biologia, antropologia, teologia e etc. Pelo conceito do Dicionário de filosofia, define-se a humanidade pela História e pela cultura, aspectos abrangentes que estabelecem valor à formação do ser humano enquanto ser histórico que é. Diante disso, temos:

\footnotetext{
Humanidade. Hist. Cult. 1) Termo usado sobretudo em quatro sentidos: a) essência ou natureza humana, isto é, aquilo que faz que um homem seja homem; b) solicitude do homem pelo seu semelhante, ou filantropia em sentido amplo, abrangendo vasta gama de formas; c) processo de formação do homem, de humanização (a Paideia dos Gregos); d) gênero humano, ou conjunto de todos os homens [sic] (DICIONÁRIO DE FILOSOFIA, s/d)
}

Estabelecido o conceito de humanidade segundo o Dicionário de Filosofia, nos voltamos à dimensão humana segundo Alvarenga (2016), que considera o desenvolvimento do ser humano abrangente quanto à sua complexidade. Segundo ele, as dimensões humanas física, afetiva, social, intelectual e espiritual, "tendem a ser o conjunto de elementos que possibilitam as pessoas se sentir felizes, tornando necessário buscar garantir o desenvolvimento integral do ser humano" (ALVARENGA, 2016, s/p), o que nos leva à reflexão acerca das características de um ser humano comum que realiza feitos extraordinários, recebendo, com isso, o título de herói.

Pela perspectiva de Alvarenga (2016), as dimensões humanas podem ser mais ou menos desenvolvidas em cada indivíduo, o que leva certas pessoas a se tornarem excepcionalmente empáticas em determinadas situações. Nas palavras do autor:

A dimensão afetiva e a dimensão social envolvem diretamente as relações que se estabelecem com os outros circunstancialmente na rua, na escola, no parque, na praça, no shopping, no trabalho, numa viagem, na comunidade religiosa. (ALVARENGA, 2016, s/p)

Ao abordarmos o contexto bélico em que se insere o herói da vida real, podemos afirmar que, de acordo com a reflexão de Alvarenga (2016), suas dimensões afetiva e social são superdesenvolvidas, fornecendo ao ser humano comum o impulso à realização de grandes feitos para beneficiar seus companheiros, os inocentes que são atingidos por situações hostis ou, até mesmo, em prol da causa pela qual se luta. 
Ainda conforme a análise do autor, as situações a que está sujeito o indivíduo que se destaca, estão diretamente relacionadas à sua natureza, no entanto, no extremo oposto do desenvolvimento de suas dimensões sociais e afetivas. Alvarenga (2016, s/p ) afirma que:

Não é possível ignorar que muitas expressões de violência, preconceitos e discriminação, geralmente ocorrem em relações sociais estabelecidas sem o desenvolvimento da dimensão afetiva, de modo que julgamentos desrespeitosos e incompreensão tornam-se infelizmente comuns.

Acerca dessa premissa, a dimensão humana do herói já havia sido desenvolvida no homem comum, estando latente em sua personalidade, o que nos leva à observação de Frankl (1991, s/p ) de que "o heroísmo está na atitude, por assim dizer". O herói em contexto de guerra se vê, a partir da situação vivenciada, em posição de enfrentá-la a partir de sua formação humana individual, se colocando a favor do coletivo devido à sua reação interior diante dos acontecimentos.

Frankl (1991) ressalta que o ser humano em sofrimento se vê diante de dois caminhos: sofrer e silenciar ou aprender a sofrer. Para melhor compreensão, nos voltemos sobre a concepção do autor acerca do significado do sofrimento, conforme segue:

[...] a prioridade permanece com a mudança criativa da situação que nos faz sofrer. Mas realmente superior é o saber como sofrer, quando se faz necessário. E há evidências empíricas de que - literalmente - o "homem comum" é exatamente da mesma opinião. Pesquisas de opinião pública da Áustria revelaram recentemente que aqueles que atraíam a maior estima e consideração entre a maioria dos entrevistados não eram os grandes artistas, cientistas, estadistas ou esportistas, mas aqueles que eram capazes de atravessar experiências difíceis com suas cabeças erguidas (FRANKL, 1991, s/p).

Destaca ainda o referido autor (1991) que o sofrimento não é motivo de orgulho para o ser humano, mas sim, como vimos anteriormente, a atitude diante do sofrimento faz do homem comum, extraordinário. A admiração coletiva que alcança este homem que adapta suas reações, evidenciando suas principais dimensões humanas no enfrentamento das situações adversas, é aquele que será tido como um herói sob os olhares da opinião pública.

Observa também que, "na verdade, as oportunidades de agir de modo apropriado, as potencialidades para realizar um sentido, são afetadas pela irreversibilidade das nossas vidas" (FRANKL, 1991, s/p), ou seja, em ambiente bélico, não há nenhuma mudança quanto 
ao contexto em que o homem se encontra, há apenas atitudes a serem modificadas para que seja possível minimizar os efeitos causados pelas circunstâncias vivenciadas.

\subsection{TERRITORIALISMO E A REPRESENTAÇÃO DO HERÓI}

Para abranger a essência do herói, as ações daqueles que lutaram durante a Guerra do Paraguai serão observadas, delineando as principais características do ser humano extraordinário que, a partir do anseio que o move para o auxílio do outro em ambiente bélico, passa a ser reconhecido com o título. No entanto, pretendendo compreender a dimensão humana do herói, entenda-se, primeiramente, o contexto.

A Guerra do Paraguai, segundo Silva (2018), tem suas causas centradas no processo de formação das nações platinas no contexto da segunda metade do século XIX. Cada nação possuía seus interesses econômicos e políticos, e a defesa desses interesses causou o choque entre o Paraguai e Brasil, Argentina e Uruguai. Segundo o autor:

[...] o Brasil tinha como grande interesse garantir o seu direito de livre navegação pelos rios da Bacia Platina, sobretudo pelo Rio Paraguai, por ser a única forma de o Rio de Janeiro manter contato com a capital de Mato Grosso, Cuiabá (não havia naquela época estradas por terra que ligavam Cuiabá ao restante do Brasil) (SILVA, $2018, s / p)$

Contextualizando, dessa forma, os motivos da Guerra do Paraguai, pode-se identificar, no excerto retirado do texto de Silva (2018), que as defesas de território eram fundamentais para cada uma das nações envolvidas, independente do interesse individual destas. Por território, entretanto, não se compreenda apenas o espaço concreto. A territorialidade é complexa e aprofunda-se nas necessidades humanas.

O conceito de territorialidade é atribuído à etologia animal no "sentido da ênfase da força de apropriação exclusiva do espaço" (BARCELLOS, 1995, p 46). Na concepção de Sodré (1988, p. 13) , concebe-se os "regimes de relacionamento, relações de proximidade e distância". Na perspectiva das ciências humanas, a noção de território é ampliada pela incorporação da dimensão simbólica do espaço físico e concreto, gerando o sentimento de posse e necessidade de defesa. 
Para Mesquita (1995), as pessoas vivem a territorialidade sem ter clara consciência da sua territorialidade individual, já que esta não assume limites visíveis no território concreto e tampouco contornos definidos nos sentimentos de indivíduos e grupos. A territorialidade pode ser entendida como projeção de nossa identidade sobre o território.

Mesquita (1995) distingue várias formas de territorialidade, sendo que destaca: territorialidade familiar, quando no território atualizamos pela identidade, antigos sentimentos de emulação, competição ou solidariedade vividos no território familiar; de senhoril, quando se atualizam e se expressam raízes de posse e poder autoritário ou manipulador, fundamentando o sentimento de pertença territorial e as condutas direcionadas a um uso político do território; e territorialidade cultural, que, por sua vez, é aquela que emerge das manifestações de usos, costumes e linguagem.

Na concepção analisada por Hall (1966), a territorialidade se define como o comportamento característico adotado por um organismo para tomar posse de um território, defendendo-o contra os membros da sua própria espécie. Ela existe também entre os seres humanos, que inventaram numerosas maneiras de defenderem aquilo a que chamam a sua terra, o seu solo ou seu espaço, entre elas, a própria guerra. A territorialidade constitui um sistema de comportamentos fundamentais próprios de todos os organismos vivos, incluindo o homem.

A reflexão acerca do territorialíssimo nos leva a outro aspecto deste estudo: o surgimento do herói em tempos de guerra. Para esta análise, é necessário o retorno aos principais conceitos sobre a figura do herói, sua função na sociedade e suas características específicas, que o tornam especial, inspirador e fundamental para a configuração social. Dito isto, a exposição da dimensão humana do herói se torna passível de investigação.

\subsection{A DIMENSÃO HUMANA DO HERÓI FRENTE À GUERRA}

O herói pode ser visto como um homem de grandes qualidades, cujos atributos se destacam dos demais e suas ações justificam a alcunha de herói. Sendo assim, será traçado o perfil do herói e sua composição, além de expor a análise da contribuição da figura do herói como representação de esperança, amor e virtudes. 
Segundo Galindo (2019), na sociedade grega, cuja filosofia serviu de alicerce para o desenvolvimento do conhecimento ocidental, o herói situava-se na posição intermediaria entre os deuses e os homens, sendo, em geral, filho de um Deus e de uma mortal (como por exemplo, Hércules e Perseu), ou vice-versa (Aquiles). Em decorrência deste fato, curiosamente, para os gregos antigos o herói tinha uma dimensão semidivina. Ou seja, ele era um ser que carregava em si atributos divinos e terrenos ao mesmo tempo. Galindo (2019, s/p) destaca ainda:

[...] o propósito maior de suas ações procurava atuar no sentido de unificar estes dois planos. Resulta daí a origem dos seus poderes extraordinários e dos seus feitos épicos com reflexos no mundo terreno; e, consequentemente na psiquê humana.

Diante da explanação do autor, os feitos épicos do herói mitológico são decorrentes de grande poder que sua constituição lhe concede, que é a filiação de um deus e uma mortal e vice-versa. No entanto, quando falamos de personagens históricos que se tornaram representações dos heróis terrenos, Eliade, (1991, s/p) apud Gomes; Andrade (2009, s/p) ressaltam:

[...] que essa retomada dos diversos simbolismos não é uma descoberta inédita do mundo moderno, tendo em vista que o símbolo, enquanto instrumento de conhecimento, era uma orientação presente na Europa até o século XVIII, além de se fazer presente em culturas extra-européias, mesmo naquelas consideradas arcaicas e primitivas.

Gomes e Andrade (2009) afirmam ainda que os simbolismos estão relacionados ao inconsciente pessoal, uma vez que estes inserem conteúdos mentais adquiridos durante a vida do indivíduo e que foram esquecidos ou reprimidos, enquanto que o inconsciente coletivo é uma estrutura herdada comum a toda a humanidade composta dos arquétipos. Uma elaboração derivada destes arquétipos povoa todos os grandes sistemas mitológicos e religiosos do mundo. Sobre a existência do arquétipo, refletindo seus impactos na sociedade, Jung (2000, p.53) afirma:

O conceito de arquétipo, que constitui um correlato indispensável da idéia do inconsciente coletivo, indica a existência de determinadas formas na psique, que estão presentes em todo tempo e em todo lugar [sic]. 
Desta forma, temos a figura do herói como representação da necessidade de expressão de esperança e amor em situações adversas do seu tempo. Segundo Campbell (1997), a primeira tarefa do herói consiste em retirar-se da cena mundana dos efeitos secundários e iniciar uma jornada pelas regiões causais da psique, onde residem efetivamente as dificuldades, para torná-las claras, erradicá-las em favor de si mesmo (isto é, combater os demônios infantis de sua cultura local) e penetrar no domínio da experiência e da assimilação, diretas e sem distorções, daquilo que Jung (2000) denominou "imagens arquetípicas" .

O herói em contexto de guerra enquadra-se na imagem arquetípica, uma vez que desafia o horror da guerra em defesa de sua pátria, seus conterrâneos e o próprio território. A figura do herói representa esperança e inspira àqueles que não possuem as habilidades e capacidade dos heróis no enfrentamento das situações adversas, a se manterem confiantes e, em grande parte, se convencerem de que podem contribuir com ações heroicas igualmente válidas para a sociedade.

As ações de heroísmo incluem virtudes como a persistência, a resiliência, a fé, a força de vontade, a determinação, a paciência, a justiça, a empatia, o altruísmo, e a capacidade de auto sacrifício. Galindo (2019) lembra que, além das virtudes, é importante mencionar que o verdadeiro herói deverá sempre ser guiado por ideais nobres e altruístas.

Os feitos do herói sempre demonstram sendo de coletividade, coragem, fraternidade, liberdade, sacrifício, justiça, moral; e, finalmente, a paz em todo o planeta. Segundo Galindo (2019), seus horizontes de atuação estão sempre pautados em ações voltadas para o bem de toda a humanidade e não para os próprios interesses. Essa representatividade dos anseios da sociedade é fundamental para que, individualmente, não se perca a esperança de dias melhores.

\section{CONSIDERAÇÕES FINAIS}

O Trabalho foi realizado com a finalidade de se identificar o que seria um herói; como a Guerra do Paraguai apresentou pessoas para montar o arquétipo deste conceito; e qual seria a dimensão humana destes. Para tanto, foi realizada revisão bibliográfica, procurando visualizar, inicialmente, como a literatura científica entende aqueles que, de uma forma ou outra, realizam atos incomuns. Passado este aspecto, buscaram-se, no material histórico já 
produzido sobre o conflito em comento, as diversas formas abordadas pela História com relação ao tema, procurando identificar quais suas tendências. Por fim, investigou-se o que é e qual o entendimento de dimensão humana em situações conflituosas.

Ficou patente que as situações podem estimular diferentemente as pessoas, apresentando situações nas quais alguém, por suas qualidades pessoais, se sobressai e tornase exemplo para a sociedade em que está inserido. Esta pessoa, cuja definição não pode se encontrar facilmente em dicionários com verbetes, é o herói, cuja particularidade principal é a de observar um obstáculo e transpô-lo. Mas essa virtude em superar dificuldades, per si, não tornaria alguém uma pessoa com características heroicas. Para se atingir este patamar, o empreendedor deve dedicar este esforço em prol do coletivo, podendo este ser a pátria.

Deste modo, um momento no qual se verifica a ocorrência do heroísmo neste viés é a guerra, quando cidadãos envidam todas as suas forças para a vitória de sua nação no campo de batalha. Como demonstrado, a Guerra do Paraguai, no caso da História Brasileira, é um exemplo bem contundente. Do apresentado, a primeira corrente historiográfica apresentaria os militares combatentes de forma mais próxima deste conceito de herói, ao enaltecer a participação destes na defesa nacional contra um invasor. Por sua vez, a corrente mais vinculada ao envolvimento inglês na deflagração do conflito apresenta os brasileiros como algozes e os paraguaios como vítimas, numa inversão de papéis. Por sua vez, os estudiosos mais recentes não apontam culpados e inocentes nessa contenda.

De qualquer forma, independente do lado de observação, os heróis na Guerra do Paraguai foram pessoas comuns, que diante de grande sofrimento apresentaram um comportamento acima da média esperada para a sociedade, realizando atos extraordinários, tendo-se em mente sempre que este embate bélico refletiu a disputa de territorialidades, ocasião em que os seres humanos enfrentam seus iguais para deter o controle sobre algum território considerado seu por grupos rivais. Assim, o sofrimento forjaria a identificação do herói como uma pessoa capaz de apresentar à coletividade a esperança e o amor desejados em caso de situações adversas.

Do anteriormente descrito, observamos que o herói é todo aquele personagem que possui virtudes incomuns à sociedade e que, em momentos de extrema dificuldade, atende 
ao entendido como humanidade no sentido de auxiliar o próximo, ajudando-o, pondo sua vida em função dos demais.

\section{REFERÊNCIAS}

ALMEIDA, Antônio da Rocha. Vultos da pátria: os brasileiros mais ilustres de seu tempo. Rio de Janeiro: Globo, 1961.

ALVARENGA, Mary. Dimensões humanas. SlidShare, 2016. Disponível em <https://pt.slideshare.net/Alvarenga-48/dimenses-humanas> Acesso em 02 jul.2021.

BARCELLOS, Jorge A. S. Territórios do cotidiano: introdução a uma abordagem teórica contemporânea. In :MESQUITA, Z ; BRANDÃO, C.R. (Orgs) Territórios do cotidiano: uma introdução a novos olhares e experiências. Porto Alegre Ed. Universidade/UFRGS, Santa Cruz do Sul Ed. Umversidade/UNISC, 1995 p 40-48

CAMPBELL, Joseph. O herói de mil faces. Tradução Adail Ubirajara Sobral. São Paulo: CULTRIX/ PENSAMENTO, 1997, Edição 10a․ Disponível em $<$ https://projetophronesis.files.wordpress.com/2009/08/joseph-campbell-o-heroi-de-milfaces-rev.pdf> Acesso em 20 mai.2021.

CAMPESTRINI, Hildebrando e GUIMARÃES, Acyr Vaz. História de Mato Grosso do Sul. Campo Grande: Assembleia Legislativa de Mato Grosso do Sul, 1991.

CARVALHO, José Mauricio de. O conceito de circunstância em Ortega y Gasset. Revista de Ciências Humanas, v. 43, n. 2, p. 331-45, 2009.

CATECISMO DA IGREJA CATÓLICA. 19.ed. São Paulo: Loyola, 2017.

CHIAVENATO, Júlio José. Genocídio americano: a Guerra do Paraguai. São Paulo: Brasiliense, 1979.

DORATIOTO, Francisco. História e Ideologia: a produção brasileira sobre a Guerra do Paraguai, Nuevo Mundo Mundos Nuevos [En ligne], Colloques, mis en ligne le 13 janvier 2009, consulté le 20 mai 2021. URL : http://journals.openedition.org/nuevomundo/49012 ; DOI : https://doi.org/10.4000/nuevomundo.49012. P. 1 - 9.

DORATIOTO, Francisco. Maldita Guerra; nova história da Guerra do Paraguai. São Paulo: Companhia das Letras, 2002.

Dicionário de Filosofia. Humanidade. $\mathrm{s} / \mathrm{d}$. Disponível em $<$ https://sites.google.com/view/sbgdicionariodefilosofia/humanidade> Acesso em 01.07.2021.

FRANKL, Viktor Emil. Em busca de sentido: um psicólogo no campo de concentração. Tradução de Walter O. Schlupp e Carlos C. Aveline. São Leopoldo: Sinodal, 1987.

FRANKL, Viktor Emil. Em busca de sentido: um psicólogo no campo de concentração. Petrópolis: Vozes, 1991. RAFAEL, Z. A. Disponível em <https://files.cercomp.ufg.br/weby/up/58/o/Em_Busca_de_Sentido_-_Viktor_Frankl.pdf> Acesso em 02 jul.2021. 
GALINDO, Toni. Precisamos de heróis ou de referências? Revista administradores.com, publicação online, 2019. Disponível em <https://administradores.com.br/artigos/precisamosde-her\%C3\%B3is-ou-de-refer\%C3\%AAncias> Acesso em 25 mai.2021.

GOMES, Vinícius Romagnolli Rodrigues. ANDRADE, Solange Ramos de. Mitos, símbolos e o arquétipo do herói. Cesumar, v. 11, n. 2, 2009, p. 139-147. Disponível em $<$ https://periodicos.unicesumar.edu.br/index.php/iccesumar/article/view/1271> Acesso em 20 mai.2021.

HALL, Edward T. A dimensão oculta. Lisboa Relógio D’Água, 1966.

HERÓI. In: DICIO, Dicionário Online de Português. Porto: 7Graus, 2021. Disponível em <https://www.dicio.com.br/heroi/>. Acesso em 12 jul.2021.

JUNG, Carl Gustav. Os arquétipos e o inconsciente coletivo. Tradução Maria Luíza Appy, Dora Mariana R. Ferreira da Silva. - Petrópolis, RJ : Vozes, 2000. Disponível em $<$ https://conexoesclinicas.com.br/wp-content/uploads/2015/05/jung-c-os-arquetipos-e-oinconsciente-coletivo.pdf> Acesso em 21mai.2021.

MESQUITA, Zilá. Do território à consciência territorial. In: MESQUITA, Z.; BRANDÃO, C.R. (Orgs). Territórios do cotidiano: uma introdução a novos olhares e experiências Porto Alegre Ed. Universidade/UFRGS, Santa Cruz do Sul. Ed. Universidade/UNISC, 1995. p. 76-92.

ORTEGA Y GASSET, José Ortega y. Meditaciones del Quijote. Madrid: Imprenta Clásica Española, 1914

QUEIRÓZ, Silvânia de. História e historiografia: revisando a obra "Genocídio americano: a guerra do Paraguai", de J.J. Chiavenato. Anais do XXVI Simpósio Nacional de História ANPUH • São Paulo, julho 2011, p. 1 - 16.

RODRIGUES, Larissa Assunção; DE BARROS, Lúcio Alves. Sobre o fundador da logoterapia: Viktor Emil Frankl e sua contribuição à psicologia. Revista EVS-Revista de Ciências Ambientais e Saúde, v. 36, n. 1, p. 11-31, 2009.

SILVA, Daniel Neves. Causas da Guerra do Paraguai. Revista Mundo Educação, 2018. Disponível em <https://mundoeducacao.uol.com.br/historiadobrasil/causas-guerraparaguai.htm> Acesso em 26 jun.2021.

SODRÉ, Muniz. O terreiro e a cidade. Petrópolis: Vozes, 1988.

TOLENTINO, Teresinha Lima. Ocupação do Mato Grosso antes e depois da Guerra da Tríplice Aliança. São Paulo: Fundação Escola de Sociologia e Política da São Paulo, 1986.

VASCONSELLOS, Victor Natalicio. Lecciones de Historia Paraguaya. Assunção: Livraria Freitas Bastos, 1962. 


\title{
O IMIGRANTE E O RESPEITO ÀS SUAS LIBERDADES INSTRUMENTAIS NO BRASIL
}

Tânia Regina Silva Garcez Mestra em Direito - PPGD-UFMS taniarsgarcez@gmail.com

Ana Paula Martins Amaral Docente do Programa de Pós Graduação -Mestrado em Direito. PPGD-UFMS anapaulamartinsa@yahoo.com.br

\begin{abstract}
RESUMO
O objetivo do presente artigo foi trazer a visão sobre as liberdades instrumentais do imigrante no Brasil. Os objetivos específicos foram: conhecer a migração e a cidadania frente ao direito do desenvolvimento e o respeito à sua liberdade instrumental. A pesquisa usou o método dedutivo com pesquisa exploratória, bibliográfica, documental e descritiva, visando destacar o direito ao desenvolvimento do imigrante no Brasil. Em razão do princípio de respeito à dignidade da pessoa humana, dos instrumentos internacionais de proteção de Direitos Humanos e da vasta normatização brasileira voltada ao imigrante apontada nesse trabalho, verificou-se que toda pessoa deve ter seus direitos respeitados pelo simples fato de pertencer à humanidade, independentemente de qualquer outra circunstância.
\end{abstract}

Palavras-Chave: Cidadania; Migração Internacional; Liberdade. 


\section{ABSTRACT}

\section{THE IMMIGRANT AND RESPECT FOR THEIR INSTRUMENTAL FREEDOMS IN BRAZIL}

The aim of this article was to bring the view on the instrumental freedoms of immigrants in Brazil. The specific objectives were to know migration and citizenship in the face of the right of development and respect for their instrumental freedom. The research used the deductive method with exploratory, bibliographic, documentary and descriptive research, aiming to highlight the right to immigrant development in Brazil. Due to the principle of respect for the dignity of the human person, the international instruments of protection of human rights and the vast Brazilian norms aimed at the immigrant pointed out in this work, it was found that every person should have his rights respected by the mere fact of belonging to humanity, regardless of any other circumstance.

Keywords: Citizenship; International Migration; freedom. 


\section{INTRODUÇÃO}

Com a globalização, os movimentos migratórios ocorreram e ainda ocorrem maciçamente em escala mundial e, apesar de, ao longo de toda sua história, o Brasil ter recebido fluxos migratórios das mais diversas partes do mundo, atualmente, oriundos, na maioria, de seus vizinhos da América do Sul, apenas recentemente, em 2017, com a aprovação da Lei de Migração (Lei no 13.445/2017), os direitos humanos, que são princípios fundamentais constitucionais brasileiros desde 1988, quando foi promulgada a Constituição Federal de 1988, foram adotados como marco legal sobre a política migratória brasileira.

A demora em se reformular a legislação migratória, apesar das iniciativas nesse sentido, decorreu, segundo Silva (2015), de uma falta de vontade política e de consenso entre os diferentes atores políticos, pelo menos, desde o início da década de 1990.

A Lei no 13.445/2017, nova Lei de Migração, pode ser considerada um avanço no campo dos direitos humanos, cujo texto mostra o interesse da reversão de pontos arenosos, como a personalidade militarista, ainda identificável no Estatuto do Estrangeiro, Lei no 6.815/1980, reflete, também, um movimento de atualização e de aproximação às pautas de direitos e questões humanitárias mundialmente consolidadas.

A nova Lei no 13.445/2017 sinaliza seus interesses a partir de uma própria e interna renovação conceitual, não mais se refere ao termo estrangeiro, mas sim, migrante. Inova no ordenamento jurídico, ao trazer os direitos humanos como tema central da política migratória que, até então, era permeada pela ideologia de segurança nacional. Busca a proteção para o migrante e, para isso, tem-se a necessidade de constante diálogo com as Leis já vigentes no país e com os tratados e documentos internacionais, os quais o Brasil ratificou.

Essa norma, que teve vacatio legis de 180 dias, entrou em vigor em 21 de novembro de 2017 e, ao substituir a Lei no 6.815/1980, Estatuto do Estrangeiro, visou interligar a política migratória brasileira, de acordo com a Constituição de 1988. Introduz em seu Art. 3ํa a base principiológica dessa nova política, que é regida pela "universalidade, indivisibilidade e interdependência dos direitos humanos" (BRASIL, 2017, online). Desse modo, ao situar topograficamente os princípios de direitos humanos, destaca-os como parâmetros hermenêuticos da Lei e alinha, axiologicamente, a política migratória ao regime jurídicoconstitucional de prevalência dos direitos humanos. Nessa perspectiva, se faz necessário 
verificar, primeiramente, a compatibilidade da Lei de Migração e das demais normas brasileiras, numa concepção ampla de cidadania, se está a promover ou não o direito ao desenvolvimento do imigrante no país.

A questão do presente artigo resumiu-se em saber qual a visão sobre as liberdades instrumentais do imigrante no Brasil?

O objetivo do presente artigo foi trazer a visão sobre as liberdades instrumentais do imigrante no Brasil. Os objetivos específicos foram: conhecer a cidadania do migrante e seu direito ao desenvolvimento e apresentar o desenvolvimento do imigrante no ordenamento jurídico brasileiro, as liberdades políticas e as facilidades econômicas ao imigrante no Brasil.

A pesquisa usou o método dedutivo com pesquisa exploratória, bibliográfica, documental e descritiva.

\section{MIGRAÇÃO E CIDADANIA DIANTE DO DIREITO AO DESENVOLVIMENTO}

O atual conceito de cidadania tem significado dinâmico e deve ser considerado em suas dimensões mais amplas e conectado com a permanente evolução dos direitos humanos. Isso acontece não somente por causa das regras de nacionalidade que definem quem tem ou não cidadania, mas por causa dos diferentes direitos que marcam o cidadão em cada Estado e perante a comunidade internacional. Assim, cidadania hoje engloba direitos civis, políticos, econômicos, sociais, difusos e está interligada aos valores como liberdade, justiça, igualdade e solidariedade.

O processo de globalização e a constante imigração propiciaram profundas transformações nas relações entre indivíduos e Estado, especialmente, no campo do direito internacional dos direitos humanos, no qual as necessidades humanas passaram a ser manifestadas regional e internacionalmente, visando concretizar o princípio da dignidade humana e investigar o elo entre cidadania e direitos humanos (MEZZAROBA; SILVEIRA, 2018).

As notáveis transformações no cenário mundial, desencadeadas a partir de 1989, pelo fim da guerra fria e a irrupção de numerosos conflitos internos, caracterizaram os anos noventa como um momento na história contemporânea marcado por uma profunda reflexão, em escala universal, sobre as próprias bases da sociedade internacional e a formação gradual da agenda internacional do século XXI. Seu denominador comum tem sido a atenção especial 
às condições de vida da população, em particular dos que integram os grupos vulneráveis, que têm necessidade especial de proteção. Com efeito, os grandes desafios desse século, -a proteção do ser humano e do meio ambiente, a superação das disparidades alarmantes entre os países e dentro deles, assim como da exclusão social, a erradicação da pobreza crônica e o fomento ao desenvolvimento humano e o desarmamento-, têm incitado à revitalização dos próprios fundamentos e princípios do Direito Internacional contemporâneo, tendendo a fazer abstração de soluções jurisdicionais e espaciais (territoriais) clássicas, deslocando a ênfase para a noção de solidariedade (TRINDADE, 2006).

As poucas pesquisas que já foram realizadas sobre a Nova Lei de Migração, nesse sentido, conforme. Dupas (2018), Vedovato (2018) e, Amaral e Costa (2017), indicam que ao facilitar a inclusão dos imigrantes na sociedade brasileira e tratar a migração como tema de direitos humanos e não mais de segurança nacional, o Brasil posiciona-se na contramão de muitos países na atualidade.

Numerosos países continuam a fazer vista grossa para a migração ilegal ou legal, aceitando trabalhadores estrangeiros temporários porque almejam se beneficiar de sua energia, talento e seu trabalho barato, e acabam se recusando a legalizar o status dessas pessoas, alegando que não querem imigração, gerando, assim, sociedades hierárquicas, onde uma classe de "cidadãos" explora uma subclasse de "estrangeiros impotentes", como acontece hoje no Qatar e em diversos outros Estados do Golfo (HARARI, 2018).

Vedovato (2018, p. 19), explica que, a necessidade do Brasil e dos demais países do globo, em pensar a migração como tema sobressalente de direitos humanos é urgente e improrrogável já que:

A liberdade total do Estado para definir quem entra no seu território desapareceu com o surgimento dos tratados de direitos humanos. Ou seja, os Estados estão inseridos em um contexto de tratados internacionais, aos quais necessariamente devem reportar-se e que chamamos de sistema internacional de proteção aos direitos humanos.

O atual significado de cidadania é dinâmico, devendo ser pensada em dimensões mais amplas, estando imbricada com a constante evolução dos direitos humanos. Ambos, cidadania e direitos humanos, configuram um conceito histórico, o que faz com que seus sentidos se 
modifiquem no tempo e no espaço, acompanhando o progresso da humanidade (CAMPELLO; SILVEIRA, 2010).

Santos (2006) propõe a combinação de formas individuais com formas coletivas de cidadania, apontando para ampliação do conceito de cidadania tanto quanto para além da ideia de reciprocidade e equivalência entre direitos e deveres. Nesse sentido, pode-se compreender que a condição jurídica do estrangeiro está, eminentemente, fadada a sofrer uma reestruturação, vez que carece de controles quanto à constitucionalidade das normas limitadoras dos direitos humanos, tidos como fundamentais.

O Direito Trabalhista, os Estatutos regulatórios e o próprio Direito Civil elevam os nacionais a nível garantidor superior aos dos estrangeiros, mantendo certa proteção aos primeiros, de toda sorte ilusória, em face de uma visão transcendental, principalmente histórica, tanto ao se considerar o berço da colonização, quanto à transitoriedade que o instituto da nacionalidade contempla (SALERNO; BERTACO, 2007).

Quanto à proteção aos migrantes ressalta-se que, não são apenas a vida e a saúde, bens passíveis de serem protegidos, mas tudo aquilo que seja digno de proteção, a partir do ponto de vista dos direitos fundamentais como, por exemplo, a dignidade, a liberdade, a família, a propriedade, o seu desenvolvimento como pessoa humana. São diversas as formas de viabilizar a proteção, como a proteção por meio de normas de direito penal, de responsabilidade civil, de direito processual, por meio de atos administrativos e ou por meios de ações fáticas.

\subsection{O DESENVOLVIMENTO DO IMIGRANTE NO ORDENAMENTO JURÍDICO BRASILEIRO}

O desenvolvimento do ser humano pressupõe liberdade. A partir do presente subtítulo verifica-se a adequação das normas brasileiras à garantia do desenvolvimento do imigrante no país. Como Baeninger (2013) aponta, as migrações internacionais vêm adquirindo papel cada vez mais importante no cotidiano social, na mobilidade da força de trabalho, no mercado de trabalho, nas sociedades de chegada e partida, no fluxo financeiro, na vida dos imigrantes e o desenvolvimento do país que escolhem como destino. É parte integrante do desenvolvimento, reflete e é refletido na divisão do trabalho. 
A fim de responder se as normas do direito brasileiro são adequadas à promoverem o desenvolvimento do imigrante no Brasil e se estão efetivamente cumprindo sua função de resguardar esse desenvolvimento por meio de liberdades instrumentais, como apresentadas por Sen (2010), propôs-se fazer um estudo mais legalista que doutrinário, levando em conta as cinco liberdades instrumentais diante do ordenamento jurídico brasileiro, quais sejam, liberdades políticas; facilidades econômicas; oportunidades sociais; garantias de transparência e segurança protetora.

As liberdades instrumentais são meios importantes que se fortalecem mutuamente $e$ auxiliam, de modo geral, a implementação de políticas públicas e de leis que se fazem decisivas para o exercício da liberdade global, além do que, o papel instrumental da liberdade se relaciona com os diversos tipos de direitos, oportunidades e habilitações que colaboram para o aumento da liberdade humana geral, e assim, são essenciais para as capabilidades das pessoas e do desenvolvimento social. Elas possuem valor próprio, mas é por meio da intensidade, com que acontecem a interação e a complementaridade, que o desenvolvimento se fortalece. A inter-relação entre as liberdades instrumentais é necessária, percebida e sedimentada nos encadeamentos empíricos, que se processam no interior das relações sociais, reforçando-se umas às outras (ZAMBAM, 2009).

Zambam (2009) faz um minucioso estudo sobre as liberdades instrumentais de Sen (2010), trazendo sua importância e características específicas: 1 As liberdades políticas dizem respeito à participação do indivíduo nas ações que se referem ao governo e suas organizações, interesses e meios que permitem ao povo como um todo, exercer a cidadania, a exemplo do direito de participar das eleições, liberdade para escolher, liberdade de imprensa, a seleção e a inspeção dos governantes, entre outros.

2. As facilidades econômicas tratam dos recursos econômicos necessários, sejam eles naturais ou não, inclusive incluem as oportunidades imprescindíveis e satisfatórias para comercializar, para trabalhar, distribuição de renda e riqueza, acesso ao crédito, dentre outros (ZAMBAM, 2009).

3. Oportunidades sociais são as chances que os governos propiciam para uma melhor qualidade de vida da população, a exemplo da saúde, educação, dentre outras, como erradicar o analfabetismo, notadamente, entre mulheres que vivem em sociedades nas quais são 
discriminadas, e os planos de saúde de abrangência coletiva são extraordinários meios para desempenho das liberdades (ZAMBAM, 2009).

4. Segurança protetora diz respeito aos instrumentos organizacionais, que permitem a proteção da população em situação de extrema pobreza, garantindo que nenhuma pessoa em situação de risco fique sem condições de obter seguridade social, em casos de desastres ambientais, épocas de seca, dentre outros; do mesmo modo, prevenir situações especiais, a exemplo, desemprego, vacinação em massa ou aplicação recursos para moradia, saneamento básico ou obras de infraestrutura (ZAMBAM, 2009).

5. As garantias de transparência dizem respeito ao direito de se ter relações límpidas, claras, tanto em relação aos indivíduos como, também, desses com a coletividade, incluindo organismos controladores organizacionais. A transparência assegura que tudo que é realizado pode ser conhecido por todos, livremente, sem que nada fique escondido, ou seja, confidencial e é protegida juridicamente, tendo função de eliminar a corrupção, a falta de responsabilidade financeira e atos ilícitos (ZAMBAM, 2009).

\subsubsection{O BRASIL E AS LIBERDADES POLÍTICAS DO IMIGRANTE}

A Constituição Federal de 1988 não positivou expressamente os objetivos da política migratória no Brasil, entretanto, desde o seu preâmbulo, o constituinte originário expressou os valores de "uma sociedade fraterna pluralista e sem preconceitos" e dispôs como objetivo fundamental República Federativa do Brasil: “Art. 3 [...] IV - promover o bem de todos, sem preconceitos de origem, raça, sexo, cor, idade e quaisquer outras formas de discriminação" (BRASIL, 1988, online, grifo nosso).

Posteriormente o texto constitucional retrata os princípios que vigoram nas relações internacionais do Brasil: "Art.4으...] II - prevalência dos direitos humanos" e a busca pela "[...] integração econômica, política, social e cultural dos povos da América Latina, visando à formação de uma comunidade latino-americana de nações" (BRASIL, 1988, online).

Além do que, o constituinte, implicitamente, assentiu a importância da participação dos braços migrantes na construção do país, ao estabelecer, no Art. $242, \S 1$, que: “[...] ensino da História do Brasil levará em conta as contribuições das diferentes culturas e etnias para a formação do povo brasileiro" (BRASIL, 1988, online). 
Seria, então, possível deduzir que uma política migratória restritiva, não acolhedora e xenófoba não poderia ser compatível com o ordenamento constitucional do país, porém, a Carta não rompe em definitivo com a política migratória de Estado Nacional Soberano e não Cooperativo (HÄRBELE, 2007), já que limita o conceito de cidadania ao direito de votar e ser votado e institui expressamente o conceito de soberania popular somente aos seus nacionais natos ou naturalizados. Como demonstra o Artigo 14, da Constituição Federal de 1988, online, in verbis:

[...] a soberania popular será exercida pelo sufrágio universal e pelo voto direto e secreto, com valor igual para todos, e, nos termos da lei, mediante: [...] $\S 100$ alistamento eleitoral e o voto são: I - obrigatórios para os maiores de dezoito anos; II - facultativos para: a) os analfabetos; b) os maiores de setenta anos; c) os maiores de dezesseis e menores de dezoito anos [...] § 20 Não podem alistar-se como eleitores os estrangeiros e, durante o período do serviço militar obrigatório, os conscritos. § 3오ão condições de elegibilidade, na forma da lei: I - a nacionalidade brasileira (grifo nosso).

Reis (2008, p. 4), enfatiza que, ainda que a pessoa ou candidato se torne inelegível, o mais importante, em termos de soberania, é o direito ao voto, visto que seja esse ato, um ato fundamental para a cidadania. Veja-se,

De fato, embora o exercício da soberania implique tanto, de um lado, o direito a escolher os governantes quanto, de outro, o direito de candidatar-se aos cargos eletivos, é o primeiro que é mais definitivo, visto que uma restrição que impeça um cidadão de integrar o eleitorado implica uma exclusão mais forte do que uma restrição que o torne inelegível (o direito de votar, nas democracias modernas, é mais fundamental do que o de candidatar-se, de modo que, perdendo o primeiro, perde-se algo mais básico, perde-se uma condição mais fundamental para o exercício da cidadania).

Essa negativa de participação política aos imigrantes limita o conceito de uma soberania popular, de uma cidadania ampla, que visa respeitar, por meio de sua Constituição Federal de 1988, características de um Estado Nacional Cooperativo, criando um déficit democrático e, também, descontextualizando a imagem de um povo-uno, em uma sociedade que objetiva fundamentalmente promover o bem de todos, sem preconceitos de origem, raça, sexo, cor, idade e quaisquer outras formas de discriminação (Art. 3 IV , CF/1988). Demonstra Costa $(2018$, p. 84),

A Constituição coloca a igualdade de tratamento e a vedação à discriminação entre brasileiros e estrangeiros como regra, mas seu texto reserva alguns direitos aos 
nacionais, como o acesso a cargos estratégicos (art. 12, §3으) e confere direitos de cidadania apenas aos brasileiros quando veda ao estrangeiro o alistamento eleitoral no art. $14, \S 2$.

Esse é, também, o entendimento de Mendes e Branco (2014), quando afirmam que os estrangeiros não dispõem de direitos políticos, não podendo votar ou ser eleitos para cargos políticos. Não podem exercer outros direitos de cidadania, como a propositura de ação popular e a subscrição de projetos de lei de iniciativa popular. Destacam, assim, Marin e Bartarello (2010, p. 166):

A ação na esfera pública ou, em outras palavras, a participação na decisão acerca das políticas públicas é condição primeira da existência da sociedade democrática, para que a imagem do povo-Uno se concretize, o que não ocorre na democracia que elide a participação cidadã nas políticas públicas.

Desde o ano de 2007, no Brasil, vem se discutindo o direito à participação popular do imigrante ao voto nas eleições municipais e, também, o direito a se eleger como vereador, desde que domiciliados no país.

Foi por meio do Projeto de Emenda Constitucional (PEC) no 14/2007, arquivada em 23/12/2014, que se iniciou a discussão; veio depois a PEC 88/2012, arquivada em 21/12/2018 e, recentemente, a PEC 09/2019, que se encontra, até a data do presente estudo, tramitando no Senado Federal com o mesmo objetivo, sendo que em 06/06/2019 se deu o último andamento ao Projeto, enviando para a Comissão de Constituição, Justiça e Cidadania - CCJ para que o senador relator Veneziano Vital do Rêgo emita relatório. A Lei no 13.445/2017, online, traz em seu Art. 4ㅇ que:

Ao migrante é garantida no território nacional, em condição de igualdade com os nacionais, a inviolabilidade do direito à vida, à liberdade, à igualdade, à segurança e à propriedade, bem como são assegurados: I - direitos e liberdades civis, sociais, culturais e econômicos (grifo nosso).

Direitos civis são aqueles relacionados às liberdades individuais. O Art. 50, da Constituição Federal de 1988, foi o responsável por garanti-los em seu caput e nos demais 78 incisos. A Lei Maior do país embasou-se na Declaração Universal dos Direitos Humanos e em ambos os Pactos Internacionais (Direito Civis e Políticos e de Direitos Econômicos, Sociais e Culturais), todos ratificados e internalizados pelo Brasil, constituindo um rol, não só de direitos 
e garantias fundamentais a todos os cidadãos brasileiros, mas também aos migrantes que escolhem esse país como destino e são recebidos dentro dos trâmites legais.

Piovesan (2004, p. 26) citando os ensinamentos de Sem (2010), quando trata dos direitos civis, sociais, econômicos e culturais evidencia que:

O pleno exercício dos direitos políticos pode implicar o "empoderamento" das populações mais vulneráveis e o aumento de sua capacidade de pressão, articulação e mobilização políticas. Para Amartya Sem, os direitos políticos (incluindo a liberdade de expressão e discussão) são não apenas fundamentais para demandar respostas políticas às necessidades econômicas, mas também centrais para a própria formulação dessas necessidades econômicas.

Como o presente estudo tem a finalidade de trazer a visão do direito ao desenvolvimento do imigrante na concepção das liberdades instrumentais de Sem (2010, p. 55-6), não se pode deixar de trazer a opinião desse autor, no que tange ao não reconhecimento do direito à participação popular do indivíduo na sociedade em que vive:

\begin{abstract}
Nas visões mais estreitas de desenvolvimento (baseadas, por exemplo, no crescimento do PNB ou da industrialização) é comum indagar se a liberdade de participação e dissensão política é ou não "conducente ao desenvolvimento". A luz da visão fundamental do desenvolvimento como liberdade, essa questão pareceria mal formulada, pois não considera a compreensão crucial de que a participação e a dissenção política são partes constitutivas do próprio desenvolvimento. Mesmo uma pessoa muito rica que seja impedida de expressar livremente ou de participar de debates e decisões públicas está sendo privada de algo que ela tem motivos para valorizar. O processo de desenvolvimento, quando julgado pela ampliação da liberdade humana, precisa incluir a eliminação da privação dessa pessoa. Mesmo se ela não tivesse interesse imediato em exercer a liberdade de expressão ou de participação, ainda assim seria uma privação de suas liberdades se ela não pudesse ter escolha nessas questões. O desenvolvimento como liberdade não pode deixar de levar em conta essas privações. A relevância da privação de liberdades políticas ou direitos civis básicos para uma compreensão adequada do desenvolvimento não tem de ser estabelecida por meio de sua contribuição indireta a outras características do desenvolvimento (como o crescimento do PNB ou a promoção da industrialização). Essas liberdades são parte integrante do enriquecimento do processo de desenvolvimento.
\end{abstract}

No que tange à liberdade de debates e discussões públicas, a Lei da Migração, em seu artigo 3o, inciso XIII, garante "[...] o diálogo social na formulação, na execução e na avaliação de políticas migratórias e promoção da participação cidadã do migrante [...]" (BRASIL, 2017, online), ao mesmo tempo em que resguarda, no inciso XIV, o fortalecimento da integração econômica, política, social e cultural dos povos da América Latina, mediante constituição de espaços de cidadania e de livre circulação de pessoas. 
A Lei da Migração garante o direito de discussões e debates públicos visando à integração política, econômica, social e cultural dos migrantes que aqui chegam, já que a força dessas discussões é um dos correlatos da democracia de grande alcance e esses direitos podem fazer com que a própria democracia funcione melhor.

Desde 2007, está em pauta no Congresso Nacional, a discussão sobre direito de votar e ser votado do imigrante domiciliado no Brasil nas eleições municipais, por meio do Projeto de Emenda Constitucional (PEC 09/2019) em trâmite. Por mais valiosa que a democracia seja e sirva de fonte fundamental para oportunidade social, segundo Sen (2010), existe ainda a necessidade de examinar os caminhos e os meios para funcionar bem e realizar seus potenciais.

Os direitos políticos dos migrantes internacionais constituem um tema central da agenda de direitos humanos (CHELIUS, 2011) e fazem parte da discussão dos países onde há uma democracia pluralista, onde o conceito de soberania e cidadania ultrapassam as fronteiras geográficas e o tipo sanguíneo do indivíduo.

Härbele (2007 e 2009) traz a necessidade de substituir o pensamento jurídico e político de um Estado Constitucional Nacional fechado, para um Estado Constitucional Cooperativo aberto, que não prioriza a soberania nacional, mas a relativiza para conceder verdadeiro sentido à dignidade humana, como um direito público subjetivo fundamental do indivíduo contra o Estado e contra a sociedade, um dever do Estado em proteger, não somente seus nacionais, mas todo aquele que o escolhe como destino e participa de seu desenvolvimento.

No plano regional, o Brasil é o único Estado-Parte do MERCOSUL que não concede o direito ao voto ao migrante, pois Paraguai e Bolívia permitem o voto na esfera municipal; Venezuela e Argentina nas esferas estaduais e municipais; Chile e Uruguai permitem o pleno exercício do voto, em todos os âmbitos, seja no municipal, estadual e federal. As Constituições do Paraguai, da Argentina, do Chile, da Venezuela e do Uruguai concedem o direito de voto aos migrantes em seus artigos 120, 20, 14, 64 e 78, respectivamente.

O direito à participação política do imigrante no Brasil deve ser efetivado tanto no plano jurídico constitucional quanto no direito material e processual, e parece estar caminhando nessa direção, com a Lei de Migração trazendo as liberdades civis, sociais, 
econômicas e culturais como garantia à população migrante, o direito de se associar, os projetos de emenda constitucional para estabelecer o direito de votar e ser votado nas eleições municipais, Leis Municipais que trazem uma política migratória mais participativa como, por exemplo, a Lei Municipal da cidade de São Paulo no 16.478/2016, que visa garantir aos imigrantes daquela cidade uma efetiva participação social, por meio de Conselhos Municipais de Imigrantes, que dentre diversos objetivos, visa fomentar a participação social e desenvolver ações coordenadas com a sociedade civil, são prováveis exemplos de um direcionamento ao respeito à liberdade política dos imigrantes que chegam no Brasil.

\title{
2.1.2 FACILIDADES ECONÔMICAS AO IMIGRANTE NO BRASIL
}

O acesso ao mercado de trabalho por meio da oportunidade de escolha de uma determinada profissão amplia o exercício da liberdade, portanto, o imigrante quando chega ao país de destino, precisa ter a oportunidade de trabalhar e escolher a atividade que atende suas capacidades anteriores, adquiridas em seu país de origem, pois essas condizem com suas aptidões e possibilitam sua melhor participação e integração na sociedade. Segundo Sen (2010, p. 59):

\begin{abstract}
Facilidades econômicas são oportunidades que os indivíduos têm para utilizar recursos econômicos com propósito de consumo, produção e troca. Os intitulamentos econômicos que uma pessoa tem dependerão dos seus recursos disponíveis, bem como das condições de troca, como os preços relativos e o funcionamento dos mercados. À medida que o processo de desenvolvimento econômico aumenta a renda e a riqueza de um país, estas se refletem no correspondente aumento de intitulamentos econômicos da população.
\end{abstract}

Para o economista, o significado de intitulamento originado do verbo latino, intitulare, representa um conjunto de pacotes alternativos de bens que, podem ser adquiridos mediante o uso de vários canais legais disponíveis para uma pessoa, formados pelo pacote original de bens que ela possui e pelos vários pacotes alternativos que ela pode adquirir por meio do comércio e produção, denominados intitulamento de troca (SEM, 2020, grifo do autor).

Nessa parte do presente estudo se analisam os intitulamentos de troca do imigrante no Brasil, no que tangem às facilidades que possuem, em exercer sua profissão de origem por 
meio da revalidação de seu diploma, de poder ter seu próprio negócio como microempresário e de trabalhar de forma digna no mercado de trabalho (grifo nosso).

O trabalho é um dos maiores bens (intitulamentos) que possui o ser humano, pois a organização da vida desse, é, nitidamente, identificada pela sua vida laboral, da qual depende sua família, sua integração social e sua vida pessoal. Determinada profissão ou trabalho contribui para que o indivíduo integre seus objetivos, sonhos e metas, que são dependentes dos rendimentos dessa atividade.

A Lei de Migração (no 13.445/2017) traz em seu Art. 3ํㅡ, sua base principiológica ao direito do migrante no Brasil: "A política migratória brasileira rege-se pelos seguintes princípios e diretrizes: [...] X - inclusão social, laboral e produtiva do migrante por meio de políticas públicas [...]"; e ainda "[...] XXI - promoção do reconhecimento acadêmico e do exercício profissional no Brasil, nos termos da lei" (BRASIL, 2017, online);

O exercício de atividade remunerada é vedado ao imigrante que se encontre no Brasil sob amparo do visto de visita (Art. 13 da Lei no 13.445/2017), podendo apenas receber pagamento de governo, de empregador brasileiro ou de entidade privada, a título de diária, ajuda de custo, cachê, pró-labore ou outras despesas com a viagem, bem como concorrer a prêmios, inclusive em dinheiro, em competições desportivas e em concursos artísticos ou culturais. Nas demais espécies de vistos como, por exemplo, temporário, oficial, cortesia e diplomático, ao residente fronteiriço e aos apátridas, são concedidos o direito de exercerem atividades remuneradas como traduzem os artigos 14 a 18, 23, 24 e 26 respectivamente da supracitada Lei de Migração.

No Brasil, a conjectura do trabalho do imigrante está prevista especificamente na Lei de Migração (no 13.445/2017), na Lei no 9.474/97 (Lei do Refúgio), e na Lei trabalhista (Consolidação das Leis Trabalhistas- Decreto-Lei no 5.452 de 1ㅇ de maio de 1943), Lei essa bastante antiga, que não privilegiava direitos aos imigrantes que adentravam ao país, todavia, com a reforma trabalhista instrumentalizada pela Lei no 13.467 de 13 de julho de 2017, que entrou em vigor em 11 de novembro do mesmo ano e a própria Lei de Migração, que entrou em vigor 21/11/2017, portanto, 10 dias após a Lei da reforma trabalhista, houve um aumento significativo na procura por vistos de trabalho por imigrantes no país, isso porque lhes foi conferido um tratamento igualitário ao dos trabalhadores brasileiros (pela Lei de Migração), 
possibilidade de os empregados imigrantes se filiarem aos sindicados e federação, os mesmos direitos trabalhistas concedidos aos brasileiros natos e naturalizados e, ainda, a desburocratização do acesso do imigrante aos serviços públicos e ao mercado de trabalho por meio da emissão de Carteira de Trabalho e Previdência Social (CTPS).

A Lei no 13.445/2017 e o Decreto no 9.199/2017 passaram a reger a condição do imigrante no país e estabeleceram a competência legal da Coordenação-Geral de Imigração Laboral (CGIL) para emitir autorizações de residências para fins laborais, nos termos das Resoluções Normativas editadas pelo Conselho Nacional de Imigração (CNIg). Nesse contexto, o imigrante para trabalhar no Brasil, com vínculo empregatício ou não, salvo exceções, necessita de autorização de Residência para fins laborais. São várias Resoluções Normativas que mudam ao longo do tempo e se alteram facilmente por meio de outras, que surgem causando insegurança jurídica aos imigrantes que procuram adentrar no mercado de trabalho. De dezembro de 2017 a julho de 2020 foram mais de 42 resoluções normativas tratando somente da autorização de residência no país.

\section{CONSIDERAÇÕES FINAIS}

As autorizações de residência prévia a imigrantes são exigidas pelas autoridades consulares brasileiras, para efeito de concessão de visto temporário aos imigrantes que desejem vir ao Brasil a trabalho. Por sua vez, a categoria de autorização de residência, é utilizada quando a pessoa já se encontra no Brasil, não necessitando mais sair do país para receber outro visto.

O imigrante que aqui se estabelece, tem como amparo de seus direitos uma Constituição Federal Cidadã que o resguarda, uma Lei de Migração capaz de trazer princípios e garantias revolucionários de direito e acolhimento, portarias, resoluções de órgãos da Administração Pública que visam defender o direito a saúde, educação, ao pleno emprego, a benefícios assistenciais e a clareza das informações a todos imigrantes no país, porém, não há proteção efetiva a esses direitos conquistados por meio de políticas públicas que os assegure.

A falta de acolhimento por parte do Estado e da sociedade brasileira por meio de políticas públicas e a falsa ideia de que imigrantes são "estranhos" que batem à porta são os 
empecilhos para o melhor desenvolvimento social e econômico desses braços que escolheram o Brasil como destino transitório ou final de sua jornada.

Durante o transcorrer do século passado aos dias atuais, não deixaram de surgir Leis e estudos filosóficos, sociológicos, antropológicos e jurídicos, visando à proteção desses direitos aos imigrantes, todavia, se a vontade política não assumir o protagonismo dessa luta por meio de políticas públicas que os promova, o desenvolvimento do país deixará de ter um compromisso sério com as possiblidades de liberdade.

\section{REFERÊNCIAS}

AMARAL, Ana Paula Martins; COSTA, Luiz Rosado. A (não) criminalização das migrações e políticas migratórias no Brasil: do Estatuto do Estrangeiro À Nova Lei de Migração. Justiça do Direito, v.31, n.2, 2017.

BAENINGER, Rosana et al. (orgs.). Migrações sul-sul. Campinas: Nepo/Unicamp, 2018. BRASIL. Constituição da República Federativa do Brasil de 1988. Disponível em: <http://www.planalto.gov.br/ccivil_03/Constituicao/Constituicao.htm>. Acesso em: 10 set. 2020.

BRASIL. Decreto no 9.199, de 20 de novembro de 2017. Regulamenta a Lei no 13.445, de 24 de maio de 2017, que institui a Lei de Migração. Disponível em: <http://www.planalto.gov.br/ccivil_03/_ato2015-2018/2017/decreto/d9199.htm>. Acesso em 20 nov. 2020.

BRASIL. ESTADO DE SÃO PAULO. Lei no 16.478 de 8 de julho de 2016. Institui a Política Municipal para a População Imigrante, dispõe sobre seus objetivos, princípios, diretrizes e ações prioritárias, bem como sobre o Conselho Municipal de Imigrantes. $<$ http://legislacao.prefeitura.sp.gov.br/leis/lei-16478-de-08-de-julho-de-2016>. Acesso em 01/10/2020.

BRASIL. Lei no 5.452 de 1o de maio de 1943. Aprova a Consolidação das Leis do Trabalho. Disponível em: <http://www.planalto.gov.br/ccivil_03/decreto-lei/del5452.htm>. Acesso em 10 nov. 2020.

BRASIL. Lei $n$ 0 9.474/97, de 22 de julho de 1997. Define mecanismos para a implementação do Estatuto dos Refugiados de 1951, e determina outras providências. Disponível em: <http://www.planalto.gov.br/ccivil_03/leis/l9474.htm>. Acesso em 10 nov. 2020.

BRASIL. Planalto. Lei $\mathbf{n} \mathbf{0}$ 13.445, de 24 de maio de 2017. Institui a Lei de Migração. Disponível em: <http://www.planalto.gov.br/ccivil_03/_ato2015-2018/2017/lei/l13445.htm>. Acesso em 31 jul. 2020. 
BRASIL. PORTAL DA TRANSPARÊNCIA. Legislação. 2020. Disponível em: <http://www.portaltransparencia.gov.br/sobre/legislacao>. Acesso em: 10 nov. 2020.

CAMPELLO. Lívia Gaigher Bosio; SILVEIRA, Vladmir Oliveira da. Dignidade, Cidadania e Direitos Humanos. In: Anais do XIX Encontro Nacional do CONPEDI em Fortaleza. 2010. Disponível <htttp://www.publicadireito.com.br/conpedi/Manaus/arquivos/anais /fortaleza/3914.pdf>. Acesso em 01 out. 2017.

CHELIUS, Leticia Calderón. O que há por trás do direito ao voto dos emigrantes internacionais? Teoria, história e cidadania demandante. Contexto int., Rio de Janeiro, v. 33, n. 1, p. 231-250, june 2011. Disponível: <http://www.scielo.br/scielo.php?script=sci_ arttext\&pid=S0102$85292011000100010 \&$ Ing=en\&nrm=iso>. Acesso em 05 out. 2020.

COSTA, Luiz Rosado. A construção de uma fase de direitos humanos na política migratória brasileira. 2018. 116 f. Dissertação (programa de pós-graduação em direito) - Universidade Federal de Mato Grosso do Sul.

DUPAS, Elaine. Nova lei de migração: a possibilidade de reconhecimento do imigrante como sujeito de Direitos Humanos no Brasil. 2018. 138 f. Dissertação (programa de pós-graduação em Fronteiras e Direitos Humanos) - Faculdade de Direito e Relações Internacionais, Universidade Federal da Grande Dourados.

HARARI, Yuval Noah. 21 lições para o século 21. Trad. Paulo Geiger. 1ạ ed. São Paulo: Companhia das Letras, 2018.

HÄRBELE, Peter. A dignidade humana como fundamento da comunidade estatal. In: SARLET, Ingo Wolfgang (Org.). Dimensões da Dignidade: Ensaios de Filosofia do Direito e Direito Constitucional. 2a ed. Porto Alegre, RS: Livraria do Advogado, 2009.

HÄRBELE, Peter. Estado Constitucional Cooperativo. Trad. Marcos Augusto Maliska e Elisete ANTONIUK. Rio de Janeiro: Renovar, 2007.

MARIN, Jeferson Dytz; BERTARELLO, Marina. A realização da democracia por meio da participação nas políticas públicas: a afirmação democrática do programa nacional de direito humanos (PNDH-3). Revista Estudos Jurídicos UNESP, Franca, A. 14 n.19, 2010. p. 163-178.

MENDES. Gilmar Ferreira; BRANCO, Paulo Gustavo Bonet. Curso de Direito Constitucional. 9a ed. São Paulo: Saraiva: 2014.

MEZZAROBA, Orides; SILVEIRA, Vladmir Oliveira da. O princípio da dignidade da pessoa humana: uma leitura da efetividade, da cidadania e direitos humanos por meio dos desafios frente à globalização. Revista de Investigações Constitucionais, Curitiba, vol.5, n.1, p.273-293, jan./abr. 2018. 
PIOVESAN, Flavia. Direitos sociais, econômicos e culturais e direitos civis e políticos. Sur, Rev. int. direitos humanos. São Paulo, v. 1, n. 1, p. 20-47, 2004. Disponível em <http://www.scielo.br/scielo.php?script=sci_arttext\&pid=S180664452004000100003\&lng=e $\mathrm{n} \& \mathrm{nrm}=\mathrm{iso}>$. Acesso em 05 de out de 2020.

REIS, Claudio Araújo Constituição de 1988: O Brasil 20 Anos Depois. Os Alicerces da Redemocratização. Todo Poder Emana do Povo: o exercício da soberana popular e a Constituição de 1988. Disponível em <https://www12.senado.leg.br/publicacoes/estudoslegislativos/tipos-deestudos/outras-publicacoes/volume-i-constituicao-de-1988/principios-edireitosfundamentais-todo-o-poder-emana-do-povo-o-exercicio-da-soberania-populare-aconstituicao-de-1988>. Acesso em 03 out.2020.

SALERNO, Marília; BERTACO, Luciana Marques. A Condição Jurídica do Estrangeiro a Trabalho no Brasil. Revista do Direito Privado da UEL, volume 2, número 2. 2007. Disponível: <http://www.uel.br/revistas/direitoprivado/artigos/Marilia_e_Luciana_A__ condi\% C3\%A7\%C3\%A3o_jur\%C3\%ADdica_estrangeiro_trabalho_Brasil.pdf>. Acesso em 11 nov 2020.

SANTOS, Heloisa Souza dos; MEDEIROS, André Aparecido. Migração e Acesso a Serviços de Saúde: A necessidade da Pauta intercultural para o cumprimento dos direitos humanos. Disponível em: <http://www.inscricoes.fmb.unesp.br/upload/trabalhos/20177311134.pdf>. Acesso em 22 out 2020.

SARLET, Ingo Wolfgang (Org). Direitos Fundamentais Sociais, Estudo de Direito Constitucional Internacional e Comparado. Rio de Janeiro e São Paulo: Renovar, 2003.

SEN, Amartya. Desenvolvimento como liberdade. Tradução de Laura Teixeira. São Paulo: Companhia das letras, 2010.

SILVA, César Augusto S. da. A política migratória brasileira para refugiados (1998-2014). Curitiba: Íthala, 2015.

TRINDADE, Antônio Augusto Cançado. A humanização do direito internacional. Belo Horizonte: Del Rey, 2006.

VEDOVATO, Luís Renato; ASSIS, Ana Elisa Spaolonzi Queiroz Assis. Os vetos à nova lei de migração brasileira: a interpretação como um passo necessário. In: BAENINGER, Rosana et al. (orgs.). Migrações sul-sul. Campinas: Nepo/Unicamp, 2018. p. 597-608.

ZAMBAM, Neuro José. A teoria da justiça de Amartya Sen: liberdade e desenvolvimento sustentável. 2009. 189 f. Tese (Doutorado em Filosofia e Ciências Humanas) - Pontifícia Universidade Católica do Rio Grande do Sul, Porto Alegre, 2009. 


\title{
A MIGRAÇÃO CONTEMPORÂNEA EM MATO GROSSO DO SUL
}

\begin{abstract}
Arlinda Cantero Dorsa
Doutora em Língua Portuguesa, docente do Mestrado e Doutorado em Desenvolvimento Local, Universidade Católica Dom Bosco (UCDB), Campo Grande, MS, Brasil. acdorsa@uol.com.br

Michele Nakazato

Doutoranda em Desenvolvimento Local, Universidade Católica Dom Bosco (UCDB), Campo Grande, MS, Brasil. michelenakazato@hotmail.com.

Thiago Henrique Conde Britts Mestrando em Desenvolvimento Local, Universidade Católica Dom Bosco (UCDB), Campo Grande, MS, Brasil. thiago_britts@hotmail.com.
\end{abstract}

\begin{abstract}
RESUMO
As reflexões produzidas sobre os problemas sociais contemporâneos, com relação aos estudos migratórios nos últimos anos é uma realidade que vem inspirando muitos pesquisadores ao aprofundamento dessa discussão. Neste prisma, este artigo apresenta um estudo sobre a migração contemporânea em Mato Grosso do Sul, partindo-se da questão norteadora sobre qual é a realidade da migração no estado do MS. Objetiva, portanto, a partir de um estudo exploratório, bibliográfico e documental, aprofundar a realidade vivida no MS sobre esta temática. Com relação aos estudos bibliográficos, apresenta uma tipologia conceitual sobre migração, refugiados, suas implicações no território e territorialidade e possibilidades do receber e acolher. Infere-se dessa pesquisa que há uma necessidade de se promover a possibilidade de redução do preconceito e discriminação em relação aos imigrantes, desenvolvendo um equilíbrio humanitário no novo território que o acolhe para a formação de uma nova territorialidade e que contribua para o desenvolvimento local.
\end{abstract}

Palavras-chave: Migrações; Refugiados; Território e territorialidade; MS 


\section{ABSTRACT}

\section{CONTEMPORARY MIGRATION IN MATO GROSSO DO SUL}

The reflections produced on contemporary social problems, with respect to migration studies in recent years is a reality that has inspired many researchers to deepen this discussion. In this perspective, this article presents a study on contemporary migration in Mato Grosso do Sul, starting from the guiding question of what is the reality of migration in the state of MS. It aims, therefore, from an exploratory, bibliographical, and documental study, to deepen the reality experienced in MS on this theme. Regarding the bibliographical studies, it presents a conceptual typology about migration, refugees, their implications on the territory and territoriality and possibilities of receiving and welcoming. It is inferred from this research that there is a need to promote the possibility of reducing prejudice and discrimination against immigrants, developing a humanitarian balance in the new territory that receives them for the formation of a new territoriality and that contributes to local development.

Keywords: Migrations; Refugees; Territory and territoriality; MS

Recebido em: 23/09/2021. Aceito em: 16/12/2021 


\section{INTRODUÇÃO}

A presença dos migrantes no Estado de Mato Grosso do Sul é uma realidade que inspira reflexões sobre problemas sociais contemporâneos. Uma das questões prementes é a relação da migração para refúgio nos últimos anos. A pessoa que sai de seu país e não tem como retornar por motivos políticos, de guerras, conflitos, perseguição, entre outras razões, é considerada "refugiada".

Conforme Almeida (2017, p. 25), “a palavra 'refúgio' tem um sentido cada vez mais significativo para o momento contemporâneo, pois retrata que o mundo ainda não conseguiu resolver seus problemas mais primários do passado". Com isso, a pesquisadora reafirma que a temática refúgio é um problema social que o mundo está enfrentando pois segundo seu pensamento "são milhões de pessoas fugindo, buscando abrigo e necessitando de ajuda" (ALMEIDA, 2017, p. 25). Nesse prisma, essa é a realidade de muitos que vivem no estado sulmato-grossense.

Assim como existe aquele que está em fuga, existe aquele que recebe, que acolhe o que vive a triste realidade da fuga de seu território para viver em território com uma cultura totalmente diferente. Para analisar esta realidade, este estudo traz uma discussão inicial sobre migração, refugiados, suas implicações no território e territorialidade a partir de uma abordagem quantitativa e qualitativa e pesquisa bibliográfica e documental.

\subsection{AS TIPOLOGIAS CONCEITUAIS SOBRE MIGRANTES E REFUGIADOS}

Os exercícios na elaboração de fronteiras conceituais de definição de determinados temas é uma tarefa difícil que muitas vezes pendem para tarefas inclusivas ou exclusivas, principalmente quando os exercícios se voltam às definições relacionadas a Migrações e Refugiados. Há dois polos extremos que variam entre definição ampla que inclui diferentes formas de mobilidade e do outro restrita, excluindo determinados movimentos, pois de acordo com Peixoto (1998, p.13), "apesar de ser fácil distinguir, em certos contextos, um 'migrante' de um 'não migrante', a quantidade de situações 'mistas' coloca problemas inesperados a uma definição do termo".

O estudo das Migrações implica uma cronologia retomando o ano de 1925, quando Fairchild, clarificando as diferentes formas de deslocação humana, apresentou quatro tipos de mobilidade: i) invasão - exemplificando os Visigodos durante o império romano; ii) 
conquista - resultante da iniciativa dos povos com cultura superior; iii) colonização descoberta e submissão dos povos mais débeis; iv) imigração - deslocamento pacífico dos indivíduos entre países. Segundo o autor "as causas para estes distintos movimentos migratórios têm que ser muito poderosas, porque a tendência do ser humano é permanecer no local ao qual pertence". (FAIRCHILD, 1925: 2 e 9).

Já em 1958, Petersen apresenta cinco tipos de migrações i) primitiva - suscitadas pelas condições ecológicas; ii) forçada - determinismo do estado ou outra instituição social; iii) impelida - a decisão do ato migratório cabe aos indivíduos; iv) livre - decisão ainda dependente da vontade individual ainda que de forma reduzida; v) massiva - pela condução coletiva expressa por vontade migratória.(PETERSEN, 1958)

Um terceiro estudo foi feito em 1991 por Appleyard, ao elaborar uma tipologia migratória internacional compreendendo seis tipos: i) migrantes permanente - fixação definitiva no local a que se destinou; ii) trabalhadores contratados temporários-, limitação de permanência podendo se converter em permanente; iii) profissionais qualificados de circulação temporária - mobilidades pertencentes a empresas transnacionais; iv) trabalhadores clandestinos ou ilegais; v) migrantes demandantes de asilo político; vi) refugiados circunstanciais relacionados a fatos políticos ou ambientais.

Uma conceituação mais recente foi elaborada por Portes em 1998, ao desenvolver três diferentes tipos de níveis de incorporação do migrante nas comunidades, a qual se destinou: i) política imigratória desenvolvida pelo governo; ii) atitude da sociedade relativamente à recepção de migrantes; iii) comunidade étnica de pertença no país de destino.

Amplia esta concepção, Cohen, em 2005, quando afirma que ainda que tenha havido as restrições, controles e formas seletivas de migrações, estas tiveram um sensível aumento, podendo atualmente serem distinguidos cerca de oito tipos migratórios:

migrações de trabalhadores legais; migração de trabalhadores ilegais ou indocumentados; migração de refugiados e de pessoas deslocadas; migração feminina independente; trabalhadores migrantes especializados passageiros; trabalhadores migrantes especializados de longa duração; movimentos internos em grande escala; turismo (COHEN, 2005: 33-37).

A partir dessas diferenciações, percebe-se então, um sensível aumento de possibilidades migratórias que abrem um leque de tipologias implicando assim não só em adaptações aos países que os recebe como também nas amplas condições de trabalho nesses países. 
Desde as recomendações em 1953, da Organização das Nações Unidas (ONU), ser migrante portanto, deveria atender à permanência de no máximo um ano no estrangeiro; em 1998, a entidade passou a estabelecer uma diferenciação entre migrante de longa data e de curta duração, diferença estabelecida pelo limite dos 12 meses de permanência ou não no estrangeiro.

Dada à dificuldade de conceituação de forma clara e objetiva, é importante que possamos apresentar uma definição das expressões que permeiam o universo das Migrações e Refugio com o objetivo de clarear estas distinções, já com um olhar mais contemporâneo e cima de tudo elucidativo.

Apoiamo-nos então no Relatório intitulado "Percursos, percalços e perspectivas: a jornada do projeto Atuação em Rede: capacitação dos atores envolvidos no acolhimento, na integração e na interiorização de refugiados e migrantes no Brasil, organizado pela Escola Superior do Ministério Público da União (ESMPU) e Alto comissariado das Nações Unidas para os Refugiados (ACNUR) publicado em 2020. Serviu também de embasamento teórico o Relatório mensal do OBMigra de 2020, Observatório das Migrações Internacionais de autoria de Cavalcanti (et al, 2020).

De acordo com os referidos relatórios e artigo publicado, podemos utilizar as seguintes tipologias para conceituar o universo que envolve as Migrações e Refugiados, de acordo com o Quadro 1 abaixo:

Quadro 1 - Tipologias conceituais (ESMPU/ACNUR)

\begin{tabular}{|l|l|}
\hline Tipologia & Conceito \\
\hline Migrante & $\begin{array}{l}\text { qualquer pessoa que está se movimentando, ou já se movimentou, através de } \\
\text { uma fronteira internacional ou dentro de um Estado, saindo do seu lugar habitual } \\
\text { de residência, independentemente da situação jurídica da pessoa; se o } \\
\text { deslocamento foi voluntário ou involuntário; quais foram os motivos para esse } \\
\text { deslocamento; ou a duração de sua estada. }\end{array}$ \\
\hline Imigrante: & $\begin{array}{l}\text { pessoa nacional de outro país ou apátrida que trabalha ou reside e se estabelece } \\
\text { temporária ou definitivamente em um país. }\end{array}$ \\
\hline Emigrante & pessoa que se estabelece temporária ou definitivamente no exterior \\
\hline
\end{tabular}




\begin{tabular}{|l|l|}
\hline $\begin{array}{l}\text { Residente } \\
\text { fronteiriço }\end{array}$ & $\begin{array}{l}\text { pessoa nacional de país limítrofe ou apátrida que conserva a sua residência } \\
\text { habitual em município fronteiriço de país vizinho. }\end{array}$ \\
\hline Visitante & $\begin{array}{l}\text { pessoa nacional de outro país ou apátrida que vão a um país para estadas de } \\
\text { curta duração, sem pretensão de se estabelecer temporária ou definitivamente } \\
\text { no território nacional. }\end{array}$ \\
\hline Refugiado & $\begin{array}{l}\text { pessoa que está fora de seu país de nacionalidade devido a fundados temores de } \\
\text { perseguição relacionados a questões de raça, religião, nacionalidade, } \\
\text { pertencimento a um determinado grupo social ou opinião política, como também } \\
\text { devido a grave e generalizada violação de direitos humanos e conflitos armados. }\end{array}$ \\
\hline $\begin{array}{l}\text { Solicitante da } \\
\text { condição } \\
\text { refugiado }\end{array}$ & $\begin{array}{l}\text { de } \\
\text { pessoa que solicita às autoridades competentes ser reconhecida como refugiada, } \\
\text { mas que ainda não teve seu pedido avaliado definitivamente pelas autoridades } \\
\text { competentes. }\end{array}$ \\
\hline Apátrida & $\begin{array}{l}\text { pessoa que não é considerada como seu nacional por qualquer Estado, segundo a } \\
\text { sua legislação, seja por discriminação contra determinados grupos étnicos ou } \\
\text { religiosos ou com base no gênero; surgimento de novos Estados e transferências } \\
\text { de território entre Estados existentes; e lacunas nas leis de nacionalidade. }\end{array}$ \\
\hline
\end{tabular}

Fonte: ESMPU; ACNUR; OBMigra, 2020. Reelaboração dos autores

De acordo com o Relatório do Observatório das Migrações Internacionais (OBMigra), de autoria de Cavalcanti (et al, 2020), algumas definições como imigrante, emigrante, residente fronteiriço, visitante e apátrida, seguidas pelo referido órgão, segue o estabelecido no Art,10 da Lei n. 13.445/2017, que dispõe sobre os direitos e os deveres do migrante e do visitante, regula a sua entrada e estada no País e estabelece princípios e diretrizes para as políticas públicas para o emigrante.

$\S 1$ O Para os fins desta Lei, considera-se:

I - (VETADO);

II - imigrante: pessoa nacional de outro país ou apátrida que trabalha ou reside e se estabelece temporária ou definitivamente no Brasil;

III- emigrante: brasileiro que se estabelece temporária ou definitivamente no exterior;

IV -residente fronteiriço: pessoa nacional de país limítrofe ou apátrida que conserva a sua residência habitual em município fronteiriço de país vizinho;

V - visitante: pessoa nacional de outro país ou apátrida que vem ao Brasil para estadas de curta duração, sem pretensão de se estabelecer temporária ou definitivamente no território nacional;

$\mathrm{VI}$ - apátrida: pessoa que não seja considerada como nacional por nenhum Estado, segundo a sua legislação, nos termos da Convenção sobre o Estatuto dos Apátridas, de 1954, promulgada pelo Decreto o 4.246, de 22 de maio de 2002, ou assim reconhecida pelo Estado brasileiro. 
Segundo a Lei no 9.474, de 22 de julho de 1997, na condição de refugiados segundo o Art. 1으, será reconhecido como refugiado todo indivíduo que:

\footnotetext{
I - devido aos fundados temores de perseguição por motivos de raça, religião, nacionalidade, grupo social ou opiniões políticas encontre-se fora de seu país de nacionalidade e não possa ou não queira acolher-se à proteção de tal país;

II - não tendo nacionalidade e estando fora do país onde antes teve sua residência habitual, não possa ou não queira regressar a ele, em função das circunstâncias descritas no inciso anterior; III - devido a grave e generalizada violação de direitos humanos, é obrigado a deixar seu país de nacionalidade para buscar refúgio em outro país.
}

O estudo das Migrações, seus movimentos e sua complexidade política, cultural, ambiental e econômica, requer, portanto, análises de outras áreas da pesquisa, como aquelas que buscam no contexto geográfico o entendimento de territórios e territorialidades e suas implicações no desenvolvimento local.

\subsection{TERRITÓRIO E TERRITORIALIDADE}

Os deslocamentos humanos sempre ocorreram e são diversos os motivos pelos quais os indivíduos decidem mudar: catástrofes naturais, problemas econômicos ou políticos, guerras ou motivações pessoais. Nessas mudanças, fatores culturais são transportados e passam a circular em outros territórios.

O geógrafo Rogério Haesbaert (2020) traz em seus estudos o conceito de território, o pesquisador vai buscar na etimologia da palavra e nos apresenta territorium em latim, derivada do vocábulo latino terra. Segundo o autor, a palavra terra, no século IV "era utilizada pelo sistema jurídico romano dentro do chamado jus terrendi", concepção esta trazida por Di Méo (1998, p. 47) e se "confundia com o 'direito de aterrorizar' (terrifier, em francês)" (Ibdem). Conforme Haesbaert, (2020) território era a porção apropriada de terra estabelecida dentro de uma determinada jurisdição político-administrativa. De acordo com o referido autor, das várias noções de território pode-se agrupar as concepções em quatro vertentes:

Vertente 1 - política: refere-se às relações espaço-poder ou jurídico-política (relacionada ao espaço-poder institucional). É a vertente mais difundida, onde o território é um espaço delimitado e controlado, que exerce um determinado poder, muitas vezes relacionado ao poder político do Estado. 
Vertente 2 - cultural ou simbólico-cultural: refere-se a dimensão simbólica e mais subjetiva de território; e é entendida como um produto da apropriação/valorização de um grupo em relação ao espaço vivido.

Vertente 3 - econômica: é a vertente menos difundida aonde a dimensão espacial das relações econômicas e o território são vistos como fonte de recursos e/ou embates de classes sociais e na relação capital-trabalho, como a divisão territorial do trabalho.

Vertente 4 - natural: a mais antiga e pouco veiculada nas Ciências Sociais. Refere-se às relações entre sociedade e natureza, especialmente ao comportamento do homem em relação ao seu ambiente físico.

Ao apontar as quatro dimensões de análise de território, o pesquisador destaca que existem outras definições para análise. Assim, também traz em seus estudos a perspectiva materialista de território, aquela que "tem uma conotação fortemente vinculada ao espaço físico, à terra" (HAESBAERT, 2020, p. 42). Enfatizando as características materiais e imateriais, Radomsky, et al. (2016, p. 114), destaca que "os territórios são estabelecidos a partir das características materiais e imateriais, ou seja, com base em seus recursos biofísicos e humanos, suas relações sociais, e seus modos de produção e cultura".

Santos (2020, p. 96), define território como "chão e mais a população, isto é, uma identidade, o fato e o sentimento de pertencer àquilo que nos pertence". Para o autor, território é mais do que um composto de sistemas naturais e de coisas produzidas pelas pessoas; é "a base do trabalho, da residência, das trocas materiais e espirituais e da vida, sobre os quais ele influi" (SANTOS, 2020, p. 96).

A partir do conceito de território, tem-se reflexões sobre territorialidade. Segundo Saquet (2008), a territorialidade representa a qualidade que o território adquire conforme sua utilização ou apreensão pelo ser humano. De acordo com o autor, "corresponde às ações humanas, ou seja, à tentativa de um indivíduo ou grupo para controlar, influenciar ou afetar objetos, pessoas e relações numa área delimitada" (SAQUET, 2008, p. 86). Nos estudos de Bomtempo e Sposito (2008), questões sobre a territorialidade são descritas a partir de observações dos fluxos migratórios entre o Japão e o Brasil.

Os estudos demonstram sobre como os migrantes japoneses e brasileiros deixaram seu território de origem e o consequente "contato com outro território e a formação de novas territorialidades como condição e meio para a sua permanência no Brasil" (BOMTEMPO e SPOSITO, 2008, p. 230). Trazem em seu bojo as relações sociais da territorialidade e o ganho 
adquirido em uma área limitada, que é o território e como podemos perceber a presença e inserção dos refugiados em seus processos migratórios. Neste sentido, busca-se aprofundar os estudos e compreender os fluxos migratórios sob o olhar jurídico-administrativo.

\section{O RECEBER E ACOLHER NAS MIGRAÇÕES E REFUGIADOS SOB A ÓTICA DOS DADOS E LEGISLAÇÕES}

$\mathrm{Na}$ atualidade, segundo relatório do Alto Comissariado das Nações Unidas para Refugiados, no ano de 2017, mais de 68 milhões de pessoas no mundo todo foram forçadas a se deslocar de seus países de origem, por diferentes motivos, como guerras, conflitos armados, perseguições e desastres; considerando-se como um problema mundial que carece de medidas imediatas.

Essas pessoas denominadas de refugiados, que segundo o artigo 1으 da Lei 9.474/1997, são caracterizadas como pessoas que se encontram fora de seu país de nacionalidade, e que não podem ou não querem acolher-se à proteção de tal país; ou em decorrência de violação dos direitos humanos de forma generalizada, são obrigadas assim a deixar seu país de origem para buscar refúgio em outros países.

No Brasil, a legislação tem como base a Convenção de Genebra, ocorrida no ano de 1951 pela ONU (Organização das Nações Unidas), assim como pela Declaração de Cartagena, publicada em 1984, acrescentando os temos "grave e generalizada" violação dos direitos humanos, possibilitando muitas interpretações sobre seu conceito, e sua proteção no país de acolhimento.

Desse modo, considera-se que os refugiados saem de seu país de origem em busca de proteção contra os motivos supracitados, em cinco áreas apontadas pela legislação: religião, nacionalidade, raça, grupo social e opinião política. Além disso, também existem os tipos de violência generalizada e perseguições que podem se combinar à questões de cunho social e econômico, denominados de "migrações internacionais mistas" e também de "migrações internacionais multicausais".

O Brasil, por suas dimensões continentais e suas diversas fronteiras com a maioria dos países da América do Sul, acaba recebendo uma grande quantidade de imigrantes por suas fronteiras secas, especialmente na região Centro-Oeste do país e no estado de Mato Grosso 
do Sul (MS), tendo como principais municípios de entrada as regiões de Corumbá, Dourados, Ponta Porã, Mundo Novo e outros, que se localizam nas fronteiras com Bolívia e Paraguai.

Assim, nessas regiões do MS, já existe uma dinâmica de mobilidade humana principalmente nas cidades da região fronteiriça, que recebem imigrantes da América Latina, como bolivianos, haitianos e paraguaios, que são os maiores solicitantes de refúgio do país. Nessa perspectiva, o Brasil e o estado do MS, na atualidade fazem parte do fenômeno internacional das migrações, com enorme relevo no sistema internacional de Estados.

A partir desse contexto, foi construído o Comitê Estadual para Refugiados, Migrantes e Apátridas (CERMA-MS), que busca consolidar as diretrizes de defesa dos direitos humanos, para a construção de políticas de proteção a essas pessoas. Em razão do exposto, considerase que por ser um local de passagem de imigrantes e refugiados, a região de fronteira do Estado do Mato Grosso do Sul, configura-se como espaço para a criação de instituições de políticas públicas, caracterizando-se como um potencial para o país, no sentido de solucionar os problemas atuais para os migrantes internacionais.

Da mesma forma, outra estratégia para solucionar as demandas atuais, seria a busca pela realização de diagnósticos e levantamento de dados, como os de atendimento em postos de saúde, matrícula de estudantes migrantes, refugiados, bem como de solicitantes de refúgio nas escolas do MS, no sentido de identificar os municípios e regiões do país com maior e menor concentração, para assim planejar-se estratégias específicas e diretas considerando as características e especificidades de cada contexto populacional.

\subsection{REALIDADE DOS REFUGIADOS: DA REALIDADE MUNDIAL A MATO GROSSO DO SUL}

O ato de migrar corresponde à movimentação espacial da população. O migrante troca de país, de Estado, região, ou até de domicílio e este processo de migração ocorre desde o início da história da humanidade, sendo que a categoria de migração de refugiados está ligada a pessoas que escaparam de conflitos armados ou perseguições.

Esses conflitos colocam em uma situação muito perigosa e intolerável a vida das pessoas que devem cruzar fronteiras internacionais para buscar segurança nos países mais próximos e então se tornarem um 'refugiado' reconhecido internacionalmente, com o acesso à assistência dos Estados, do ACNUR (Alto Comissariado das Nações Unidas para Refugiados) e de outras organizações. 
O direito internacional define e protege os refugiados. Nesse sentido, atuam a Convenção da ONU de 1951 sobre o Estatuto dos Refugiados e seu protocolo de 1967, assim como a Convenção da OUA (Organização da Unidade Africana) - pela qual se regularam os aspectos específicos dos problemas dos refugiados na África em 1969 - ou a Declaração de Cartagena de 1984 sobre os Refugiados, que continuam sendo a chave da atual proteção dos refugiados (ACNUR).

Segundo o Instituto de Pesquisa Econômica Aplicada (IPEA) existe um crescente fluxo de imigrantes haitianos, sírios e congoleses que passam a ter diariamente seu futuro e sua vida ameaçados pelo aumento da violência e desrespeito aos direitos humanos, sendo forçados a deixarem o seu país e buscarem refúgio no Brasil. Para PEREIRA JUNIOR (2020, p. 09):

[...] o Brasil mantém registros históricos da presença de refugiados, ainda que não se apresente como destino preferencial de refúgio, tornando-se, entretanto, um destino possível diante das barreiras cada vez mais consolidadas para o ingresso de deslocados com baixa qualificação laboral em países tradicionalmente recipiendários desses fluxos de imigrantes.

Vale ressaltar que o território brasileiro é composto e formado por imigrantes, um país de misturas étnicas e culturais. Existe na atualidade um novo fluxo migratório de pessoas que buscam melhores condições de vida, fugindo de crises econômicas, guerras civis e buscando emprego. Nas últimas décadas, o Brasil passou a ser procurado por diversos grupos migratórios do Haiti, Venezuela, Senegal, República Democrática do Congo e da Síria.

De fato, os últimos anos foram marcados por um crescente número de solicitações e concessões de refúgio no Brasil. Em janeiro de 2019, havia um total de 161.057 solicitações de refúgio em trâmite e, até dezembro de 2018, um acumulado de 11.231 refugiados reconhecidos no país, sendo que em 2014 esse número somava 7.262 pessoas (BRASIL, 2018).

Quadro 2 - Panorama mundial do deslocamento forçado em 2019

\begin{tabular}{|c|c|}
\hline \multicolumn{2}{|c|}{$\begin{array}{c}\text { Deslocados forcados no mundo } \\
79,5 \text { milhós do pessoas }\end{array}$} \\
\hline Deslocados intemes (iDPla) & A5.7 milhöes de pessoas \\
\hline Refugiados sob o mandato do ACNUR & 20.4 milhões de pessoas \\
\hline Refugiados sob o mandato do UNRWA & 5.6 milhò̀ de pessoas \\
\hline Solicitartes de refugio & 4.2 milhobs de pessoas \\
\hline Venezuelanos desiocados no exterior & 3.6 milhōes de pessoas \\
\hline
\end{tabular}


Fonte: elaborado pelo OBMigra a partir dos dados do Alto Comissariado das Nações Unidas para os Refugiados (ACNUR, 2020).

A partir da análise da movimentação de trabalhadores solicitantes de reconhecimento da condição de refugiados se verifica uma mudança de inserção desses trabalhadores no mercado de trabalho formal no Brasil ao longo da década. A geografia do refúgio no Brasil passou por muitas transformações importantes com a distribuição de pessoas solicitantes de reconhecimento da condição de refugiados no território brasileiro segundo a grande capacidade de atração do mercado de trabalho nas áreas de maior dinamismo do país. (SILVA, G.J - OBMigra, 2020).

Quadro 3 - Número de solicitantes de reconhecimento da condição de refugiado, segundo principais países de nascimento, Brasil - 2019.

\begin{tabular}{|l|c|}
\hline \multicolumn{1}{|c|}{ Pais de nascimento } & 2019 \\
\hline Total & $\mathbf{8 2 . 5 5 2}$ \\
\hline Venezuela & 53.713 \\
\hline Haiti & 16.610 \\
\hline Cuba & 3.999 \\
\hline China & 1.486 \\
\hline Bangladesh & 738 \\
\hline Angola & 603 \\
\hline Siria & 429 \\
\hline Colómbia & 381 \\
\hline Senegal & 363 \\
\hline Nigérie & 331 \\
\hline India & 312 \\
\hline Marrocos & 229 \\
\hline Guiné Bissau & 205 \\
\hline Libano & 196 \\
\hline R.D. Congo & 167 \\
\hline Paquistäo & 165 \\
\hline Gana & 155 \\
\hline Outros & 2.470 \\
\hline
\end{tabular}

Fonte: Elaborado pelo OBMigra, a partir dos dados da Polícia Federal, solicitações de reconhecimento da condição de refugiado - Brasil, 2019.

No quadro 3 , verifica-se que o maior número de solicitação de reconhecimento da condição de refugiado, em 2019, é de venezuelanos com 82.552 pedidos; seguido dos haitianos com 16.610 pedidos; dos cubanos com 3.999; e dos chineses com 1.486 solicitações. Depois tem-se pedidos de pessoas de Bangladesh, Angola, Síria, Colômbia, Senegal, entre outros países. 


\section{Gráfico 1 - Número de solicitações de reconhecimento da condição de refugiado, segundo} ano, Brasil, 2011 - 2019.

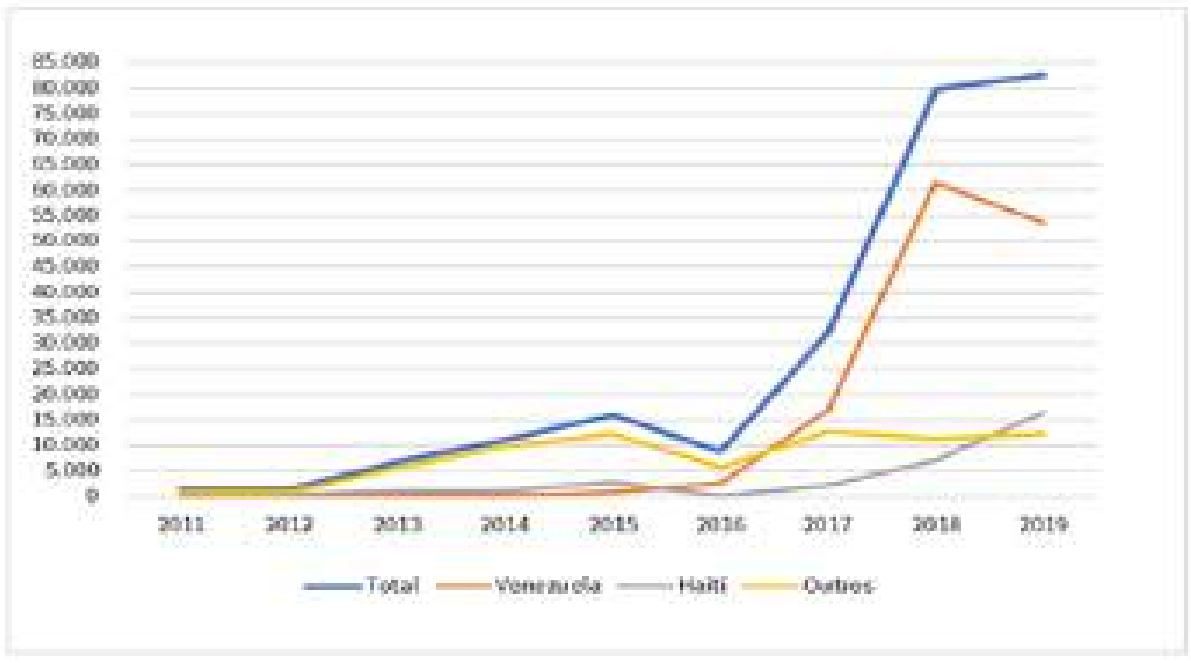

Fonte: Elaborado pelo OBMigra, a partir dos dados da Polícia Federal, solicitações de reconhecimento da condição de refugiado.

O Gráfico 1 aponta o número de solicitações de reconhecimento da condição de refugiado, no Brasil de 2011 a 201, com destaque para a Venezuela que teve um aumento acentuado nos ano de 2016 a 2018, chegando a 60 mil pedidos.

O Estado de Mato Grosso do Sul apresenta uma grande faixa de fronteira com outros países da América do Sul, como Paraguai e Bolívia. Essa faixa tem 150 quilômetros de largura e soma 143 mil quilômetros quadrados, ou $40 \%$ dos 357,1 mil quilômetros quadrados, que formam o território sul-mato-grossense. (IBGE, 2019).

O Mato Grosso do Sul representa para alguns imigrantes o destino final de uma jornada em busca de uma vida melhor, porém, para outros é apenas um corredor de passagem para outros grandes centros urbanos do Brasil como São Paulo e Rio de Janeiro. (NICOLAU, 2016, p. 03). A maioria dos imigrantes presentes no referido estado tem origem do Paraguai e Bolívia e em uma escala menor haitianos, venezuelanos, colombianos, bengalis e africanos. (IPEA, 2015, p. 90).

Tal estado também apresenta uma modalidade de migração que retardou a ser reconhecida pelo Brasil, a chamada migração humanitária. Essa migração, estabeleceu uma grande entrada de bengalis (oriundos de Bangladesh), que entram pela Bolívia e adquirem documentos falsos, sendo atravessados pelos "coiotes" até o Brasil. (NICOLAU, 2016, p. 05). 
Os municípios do estado de Mato Grosso do Sul, como Campo Grande, Ponta Porã, Corumbá e Dourados apresentaram diversas dificuldades nas políticas públicas estaduais e nas interações dos agentes de fronteira, como a insuficiência dos recursos humanos para trabalhar com o fluxo migratório, falta de orientação para a população sobre a problemática das migrações internacionais no âmbito nacional para evitar a violência e a discriminação contra os migrantes refugiados. (IPEA, 2015).

Quadro 4 - Movimentação de trabalhadores solicitantes de reconhecimento da condição de refugiado e refugiados no mercado de trabalho formal, segundo Brasil, Grandes Regiões e Unidades da Federação, 2011 - 2019.

\begin{tabular}{|c|c|c|c|}
\hline \multirow{2}{*}{$\begin{array}{c}\text { Grandes Alegbles } \\
\text { Unictades dis Federacbo }\end{array}$} & \multicolumn{3}{|c|}{ Total } \\
\hline & Admissoes & Deslitementios & Salete \\
\hline Brasill & 69.131 & 43.560 & 25.571 \\
\hline Norte & 9.028 & 5.037 & 3.991 \\
\hline Rendonita & 643 & 375 & 268 \\
\hline Acre & 46. & 28 & 18 \\
\hline Amatonas & 3.176 & 1530 & 1.638 \\
\hline Bortime: & 4.926 & 2.939 & 1.907 \\
\hline pars & 181 & 133 & 68 \\
\hline Amapa & 26 & 17. & 9 \\
\hline Tocantins: & 30 & 27 & 3 \\
\hline Nordeste & 3.201 & 6.0 & 491 \\
\hline Maranha & 49 & 22 & 27 \\
\hline Placil & 31 & 18 & 13 \\
\hline Crari & 450 & 296 & 160 \\
\hline Dio Crapnate do Norte & 0.4 & 33 & 31 \\
\hline Peraibs & $10 R$ & 42 & 60 \\
\hline Pernamberso & 159 & 77 & 82 \\
\hline Alacoes & 12 & 5 & 7 \\
\hline Serape & 28 & 15 & 23 \\
\hline Eahia & 200 & 102 & 98 \\
\hline Suctente & 16.520 & 10.6.86 & 5.9.4.4. \\
\hline Minas Gerais & 2004 & 1.177 & 907 \\
\hline Espirito Santo. & 192 & 120 & 72 \\
\hline hio de Ianeiro. & 3.195 & 2,631 & $76-4$ \\
\hline Sto paulo & 11.050 & 6. $95 \pi$ & 4,201 \\
\hline Swal & 36.965 & 23.820 & 13,145 \\
\hline Parand & 9.268 & 6,120 & 3.148 \\
\hline Sante Catarima & 13.113 & 6.907 & 6.206 \\
\hline Alo Grande do Skal & 14584 & 10.733 & 3.791 \\
\hline Centro-Oeste & 5.507 & 3,407 & 2,200 \\
\hline Mato Grosio do Sul & 1.207 & 478 & 629 \\
\hline Mato Crosso & 1.514 & 807 & 707 \\
\hline Cooids & 920 & $5 / 20$ & 371 \\
\hline Dictrito Tederal & 1 acen & 1531 & 433 \\
\hline
\end{tabular}

Fonte: Elaborado pelo OBMigra, a partir dos dados do Ministério da Economia, base harmonizada RAIS-CTPS-CAGED, 2020.

O século XXI marca o aumento do fluxo migratório, de povos da América Latina em sua maioria, para o Brasil, apresentando uma certa alteração no perfil dos imigrantes que já constavam inseridos na sociedade brasileira. Observa-se, no quadro 4, que as regiões Sul e Sudeste são as que mais admitem trabalhadores refugiados. Estes imigrantes que passaram a entrar no território brasileiro são em sua maioria imigrantes pobres e trabalhadores, que 
dependem de acolhimento e políticas públicas para ter respostas às suas necessidades básicas.

Existe um grande fluxo de haitianos e africanos que estão se deslocando dentro de Mato Grosso do Sul, da capital Campo Grande para municípios do interior como Porto Murtinho, Aquidauana e Rio Brilhante, sobretudo atraídos pelo trabalho em áreas rurais e subempregos informais. (IPEA, 2015 p. 91).

Para atuar no combate a exploração dos imigrantes refugiados trabalhadores em áreas remotas do estado, foi criado o Comitê Estadual para Refugiados, Migrantes e Apátridas do Mato Grosso do Sul que está ligado à Secretaria de Estado de Direitos Humanos e à Assistência Social e Trabalho (Sedhast). O objetivo é amparar os imigrantes que chegam ao estado através das fronteiras e especializar um padrão de atendimento a essas pessoas, além de criar outros comitês locais nas diversas áreas de fronteira. (NICOLAU, 2016, p. 09).

\section{CONSIDERAÇÕES FINAIS}

A questão das migrações é um fenômeno recorrente no Mato Grosso Sul. A chegada dos migrantes é uma preocupação das autoridades brasileiras e estaduais, no sentido de acolher e evitar explorações dos trabalhadores refugiados, mas ainda esta situação não é o suficiente.

Deve-se analisar e compreender os contextos em que se dão às pessoas a condição de refugiadas, levando em consideração sua cultura, sua identidade e a sua adaptação a uma nova realidade e a um novo território, de modo que se faz necessário um maior incentivo a criação de novos comitês estaduais e regionais no Brasil e no estado de Mato Grosso do Sul, para intensificar o diálogo com a sociedade.

Para Da Silva (2012, p.88), "a realidade destas pessoas ainda está marcada por uma situação carente, do ponto de vista da inclusão em políticas públicas e oportunidades básicas necessárias para a reconstrução de uma vida". A dificuldade da inclusão do migrante em condição de refúgio nas vertentes básicas de território descritas por Haesbaert (2020) política, cultural, econômica e natural - é a causa de graves problemas sociais no território que recebe/acolhe essas pessoas.

Dessa forma, se faz necessário a criação e intensificação das discussões entre os órgãos responsáveis por receber os refugiados e a sociedade civil. Assim, promovendo-se a 
possibilidade de redução do preconceito e discriminação em relação aos imigrantes, desenvolvendo um equilíbrio humanitário no novo território que o acolhe para a formação de uma nova territorialidade e que contribua para o desenvolvimento local.

Dada à complexidade implícita dessa temática, este entendimento simples revela-se insuficiente nas movimentações migratórias. $\mathrm{O}$ aumento substancial do volume das atividades migratórias pelas diferentes motivações que têm ocorrido, pela história de vida narradas, pelo seguimento das rotas, pela imposição das determinações globais, as migrações internacionais podem ser visto em sua multifacetada visão, em constante metamorfose seja na adaptabilidade, seja nas situações circunstanciais do mundo em que acontecem.

\section{REFERÊNCIAS}

ACNUR. Global Trends 2020: Forced Displacement in 2019. Jun. 2020. Disponível em: <https://www.unhcr.org/globaltrends2019/>. Acesso em: 11 mai. 2021.

ALMEIDA, L. P. (Org.). Migrações, fronteira e refúgio: Mato Grosso do Sul na rota das migrações transnacionais. Campo Grande-MS: UCDB, 2017.

Appleyard, R. International Migration: Challenge for the Nineties. Genebra: IOM, 1991.

BRASIL. Ministério da Justiça e Segurança Pública. Refúgio em números. 3. ed. Brasília: MJSP, 2018.

Disponível

em: <https://portaldeimigracao.mj.gov.br/images/dados/Ref\%C3\%BAgio\%20em\%20n\%C3\%BAm eros/REF\%C3\%9AGIO\%20EM\%20N\%C3\%9AMEROS.pdf>. Acesso em: 11 mai. 2021.

BRASIL. Ministério da Justiça e Segurança Pública. Projeto de Cooperação. Disponível em: <https://app.powerbi.com/view?r=eyJrljoiNTQ4MTUONGItYzNkMi00M2MwLWFhZWMtMDB iM2I1NWVjMTY5liwidCI6ImU1YzM3OTgxLTY2NjQtNDEzNC04YTBjLTY1NDNkMmFmODBiZSIsI mMiOjh9>. Acesso em: 11 mai. 2021.

BOMTEMPO, D. C.; SPOSITO, E. S. Entre o Japão e o Brasil: a territorialidade dos migrantes, isseis e dekasseguis. In: SAQUET, M. A.; SPOSITO, E. S. (Org.). Territórios e territorialidades: teorias, processos e conflitos - 1.ed. São Paulo: Expressão Popular: UNESP. Programa de PósGraduação em Geografia, 2008.

CAVALCANTI, L; OLIVEIRA, FURTADO, A; DICK, P; QUINTINO, F; MACEDO, M. Acompanhamento de fluxo e empregabilidade dos imigrantes no Brasil: Relatório Mensal do OBMigra Ano 1, Número 1, janeiro de 2020/ Observatório das Migrações Internacionais; Brasília, DF: OBMigra, 2020. Disponível em:

<https://portaldeimigracao.mj.gov.br/pt/dados/relatorios-mensais>. Acesso em: 5 mai. 2021. 
CAVALCANTI, L; OLIVEIRA, T.; MACEDO, M., Imigração e Refúgio no Brasil. Relatório Anual 2019. Série Migrações. Observatório das Migrações Internacionais; Ministério da Justiça e Segurança Pública/ Conselho Nacional de Imigração e Coordenação Geral de Imigração Laboral. Brasília, DF: OBMigra, 2019.

Cohen, R. Globalização, migração internacional e cosmopolitismo quotidiano. In: Barreto A. (org.),Globalização e migrações. Lisboa: Imprensa de Ciências Sociais, 2005.

DA SILVA, César Augusto S. (org.). Direitos Humanos e Refugiados. Dourados: Ed. UFGD, 2012.

DI MÉO, G. Geographie sociale et territoires. Paris: Nathan, 1998. In: HAESBAERT, R. O mito da desterritorialização: do "fim dos territórios" à multiterritorialidade. 12a ed. - Rio de Janeiro: Bertrand Brasil, 2020.

Fairchild, H. P. Immigration: A World Movement and its American Significance New York. Macmillan, 1925

HAESBAERT, R. 0 mito da desterritorialização: do "fim dos territórios" à multiterritorialidade. 12a ed. - Rio de Janeiro: Bertrand Brasil, 2020.

IBGE - Instituto Brasileiro de Geografia e Estatística. Atualização dos dados geográficos de estados e municípios brasileiros. Disponível em: $<$ https://agenciadenoticias.ibge.gov.br/agencia-sala-de-imprensa/2013-agencia-denoticias/releases/27737-ibge-atualiza-dados-geograficos-de-estados-e-municipiosbrasileiros>. Acesso em: 11 mai. 2021.

INSTITUTO DE PESQUISA ECONÔMICA APLICADA (IPEA). Migrantes, Apátridas e Refugiados: subsídios para o aperfeiçoamento de acesso a serviços, direitos e políticas públicas no Brasil. Série Pensando o Direito, n. 57, 2015.

MAGALHÃES, L. F.; ZUBEN, C. V.; PARISE, P.; DEMÉTRIO, N.; DOMENICONI, J. (Org.). Migrações internacionais e a pandemia de Covid-19. Campinas: Núcleo de Estudos de População "Elza Berquó" - Nepo/Unicamp, 2020, 636p.

NICOLAU, P. C. Ausência de políticas de integração legislativas de proteção aos refugiados na região sul-americana a partir do caso do Mato Grosso do Sul, 2016.

PEREIRA JÚNIOR, J. R. et al. Refúgio no Brasil: integração de refugiados e solicitantes de refúgio em Brasília (2019). 2020.

RADOMSKY, G. F. W. et al. Desenvolvimento Rural: do agrícola ao territorial. In: NIEDERLE, P. A.; RANDOMSKY, G. F. W. (Orgs.). Introdução às teorias do desenvolvimento. Porto Alegre: Editora da UFRGS, 2016.

PETERSEN, W. A General Typology of Migration. American Sociological Review, 23(3), 256266, 1958. 
PEIXOTO, J. As migrações dos quadros altamente qualificados em Portugal. Fluxos migratórios inter-regionais e internacionais e mobilidade intra-organizacional. Tese de Doutoramento apresentada ao Instituto Superior de Economia e Gestão da Universidade Técnica de Lisboa, Lisboa, Portugal, 1998.

PORTES, A. Migrações internacionais. Origem, tipos e modos de incorporação. Oeiras: Celta, 1999.

SANTOS, M. Por uma outra globalização: do pensamento único à consciência universal. 31a ed. - Rio de Janeiro: Record, 2020.

SAQUET, M. A. Por uma abordagem territorial. In: SAQUET, M. A.; SPOSITO, E. S. (Org.). Territórios e territorialidades: teorias, processos e conflitos - 1.ed. São Paulo: Expressão Popular: UNESP. Programa de Pós-Graduação em Geografia, 2008.

SILVA, C. A. S.; SERPA, P. F. O fluxo migratório no Estado de Mato Grosso do Sul: recepção dos refugiados e de imigrantes internacionais. R. METAXY, Rio de Janeiro, v.2, n.1, p. 31-55, 2019.

SILVA, G. J; CAVALCANTI, L; OLIVEIRA, T; MACEDO, M. Refúgio em Números, 5a Ed. Observatório das Migrações Internacionais; Ministério da Justiça e Segurança Pública/ Comitê Nacional para os Refugiados. Brasília, DF: OBMigra, 2020. 


\title{
ESTUDOS DOS PADRÕES DE CONSUMO DE ÁLCOOL EM MULTITERRITÓRIOS POR ADOLESCENTES
}

\author{
Maria Romilda da Silva \\ Doutoranda em Desenvolvimento Local, Universidade Católica Dom Bosco (UCDB), \\ Campo Grande, MS, Brasil. \\ mar.romildasilva66@gmail.com \\ Giusepe Favieri \\ Doutorando em Desenvolvimento Local, Universidade Católica Dom Bosco (UCDB), \\ Campo Grande, MS, Brasil. \\ pepefavieri@hotmail.com \\ Maria Augusta de Castilho \\ Doutora em História, docente do Mestrado e Doutorado em Desenvolvimento Local, \\ Universidade Católica Dom Bosco (UCDB), Campo Grande, MS, Brasil UCDB \\ maugusta@ucdb.br
}

\begin{abstract}
RESUMO
Este estudo tem como ponto de partida a problemática sobre o consumo de álcool entre adolescentes. Para explicitar esta problematização tem-se o tema: Estudos dos padrões de consumo de álcool em multiterritórios por adolescentes. Trata-se de uma análise bibliográfica com técnica qualitativa e quantitativa das pesquisas científicas executadas por CEBRID disponíveis na web. A amostragem é um recorte do público pesquisado disposto nas pesquisas estudadas, sendo os adolescentes. O método utilizado foi dedutivo porque permite iniciar os estudos a partir de uma ideia geral para chegar à uma compreensão específica. Para tanto, foram traçados objetivos norteadores, sendo o geral: analisar os padrões de consumo de álcool em multiterritórios de adolescentes no contexto da multiterritorialidade brasileira e específicos: destacar os padrões de consumo de álcool por adolescentes e discriminar as dimensões dos padrões de consumo de álcool por adolescentes entre território brasileiro. Os critérios para filtragem e análise dos dados foram: leituras minuciosas das seções que continham o público adolescente; abstraindo os dados sobre os padrões de consumo de álcool por adolescentes, como: frequências, sinais, sintomas, tolerância, problemas, situações de risco, opiniões nos multiterritórios.
\end{abstract}

Palavras-chave: Álcool; Adolescente; Multiterritórios; Padrão. 


\section{ABSTRACT}

\section{STUDIES OF ALCOHOL CONSUMPTION PATTERNS IN MULTI-TERRITORY BY ADOLESCENTS}

This study starts from the problem of alcohol consumption among adolescents. To clarify this problematization we have the theme: Studies of the patterns of alcohol consumption in multiterritories by adolescents. It is a bibliographic analysis with qualitative and quantitative technique of the scientific research performed by CEBRID available on the web. The sampling is a cut of the researched public disposed in the researches studied, being the adolescents. The method used was deductive because it allows to start the studies from a general idea to arrive at a specific understanding. Therefore, guiding objectives were outlined, the general one being: to analyze the patterns of alcohol consumption in multiterritories of adolescents in the context of the Brazilian multi-territoriality and specifics: to highlight the patterns of alcohol consumption by adolescents and to discriminate the dimensions of the patterns of alcohol consumption by adolescents among Brazilian territory. The criteria for filtering and analyzing the data were: thorough readings of the sessions that contained the adolescent public; abstracting the data on the patterns of alcohol consumption by adolescents, such as: frequencies, signs, symptoms, tolerance, problems, risk situations, opinions in the multiterritories.

Keywords: Alcohol; Adolescent; Multi-territory; Patterns. 


\section{INTRODUÇÃO}

As pessoas, em grupos e/ou individual, procuram formar o seu meio visando garantir condições favoráveis as suas expectativas de vida, uma vez que suas atividades humanas tenham caráter espacial e os resultados dessas atividades também moldam suas interações entre indivíduos ou grupos. As atividades humanas, políticas e econômicas no espaço são localizadas e organizadas especificamente conforme cada local. Dentre essas atividades, o foco deste estudo está voltado para o hábito de beber como uma das territorialidades do adolescente.

A territorialidade humana é uma forma de costumes e hábitos que faz parte da construção cultural de uma sociedade em um lugar, ocasionando o compartilhar da vida individual e social. Independente dos diferentes lugares, línguas, culturas, comunidade, sociedade, política ou fatores naturais, a adolescência é uma fase que todo ser humano vivencia, e a bebida alcoólica é um hábito e/ou costume inserida no meio de cada sociedade.

As características espaciais da superfície terrestre somada as atividades humanas localizadas, moldam os padrões de interação entre indivíduos e grupos. Existem muitos fatores que infligem as interações humanas, como a distância, física, a localização, os socioculturais e políticos e organizações funcionais, mas os hábitos são exemplos que ultrapassam as barreiras físicas por meio das influências, como por exemplo a prática de consumir bebidas alcoólica (comemorações, festividades, alegrias, tristezas sempre cabe a bebida, porque alivia ou eleva o ser humano).

Neste sentido, as ações humanas territoriais são formas de colocar significações nas interações sociais e culturais. As pessoas demarcam seu local físico ou abstrato para atender determinados objetivos. Esses locais são construídos por meio da territorialidade, permitindo que as pessoas tenham a oportunidade de colocar ou extrair potencialidades materiais ou imateriais, no caso da bebida alcoólica, a economia e a cultura, e no caso da adolescência, a necessidade de inserir-se a um grupo, de formar sua identidade grupal e de manifestações de suas alegrias e extravasar suas frustrações. Isto por que, a territorialidade humana pode ser vista em todas as escalas geográficas (locais), como acontece os padrões de consumo de álcool em multiterritórios de adolescentes. 


\section{DESENVOLVIMENTO TEÓRICO}

\subsection{MULTITERRITORIALIDADE}

Para compreender os padrões de consumo de álcool por adolescentes faz-se relevante definir os conceitos de território e multiterritórios. Estes conceitos foram abordados por diferentes correntes de pensamento que envolve pluralidades devido as dimensões em que se encontra esse conceito.

O “território não resultará, obrigatoriamente, em paisagem, sem a intermediação da imaginação condicionada por um mediador peculiar. Há uma utilidade que nem sempre a observação é contemplativa" (RAFFESTIN, 2008, p.17). A exemplo, na ótica agrária o utilitário prevalece sob o estético, o homem supre suas necessidades não pelo que é natural, mas a partir de produtividade no lugar em que se encontra. Seguindo essa ótica o território pode ser entendido como um espaço onde "cada sociedade cria seu próprio espaço em seu tempo, e assim se realiza", vindo a resultar na produção deste espaço em "um movimento constante entre o particular e o geral, entre a ordem próxima e a ordem distante" (HENRI LEFEBVRE APUD LIMONAD E LIMA, 2003, pp.15-23).

Nesse mesmo sentido, Lefebvre, Costa (2011), traz uma compreensão ampla desse conceito por meio da Geografia (materialidade do território), Ciência política (construções das relações de poder), Economia (espaço de produção), Antropologia (dimensão simbólica), Sociologia (relações sociais) e a Psicologia (construção da identidade a partir da subjetividade), visões que ampliam o conceito de território, e sua dinamicidade não acontece de forma individualizada. (Figura 1). 


\section{Figura 1 - Imagem demonstrativa da multiterritorialidade}

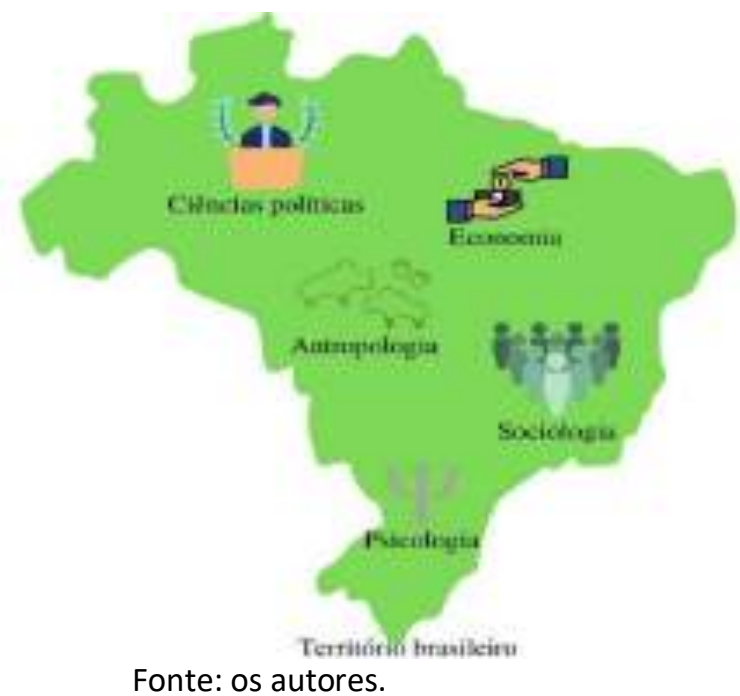

A partir dessa base concreta território brasileiro, Costa (2011) nos leva a entender a dinamicidade de um território como desterritorialização devido à busca constante de identidades, o que aconteceria a reterritorialização, sequencialmente a multiterritorialidade. Pode se afirmar que é um movimento complexo de territorialização, que inclui a vivência concomitante de diversos territórios (o eu - psiquê, os outros - grupal social, o eu e outro em sua construção histórica, enquanto objetiva a economia e as políticas públicas), configurando a multiterritorialidade.

Seguindo essa ótica de reterritorialização, pode se entender que o homem reconhece seu território através das práticas de vida, por seu modo de fazer a vida, das condições vida que se tem, em contrapartida os resultantes dessa relação. No processo múltiplo em dimensão social, há entrelaçamento de influências culturais, educacionais, saúde e econômicas, nos quais estão os adolescentes em processo de desenvolvimento humano, abertos potencialmente para ser e devir a ser pessoa em seu meio. $O$ ser aberto em suas potencialidades interage em seu território porque está em construção de identidade, ao mesmo tempo se encontra em um território de dominação e de apropriação, onde acontece as influências positivas e negativas.

Costa (2011), destaca que a identificação e potencialidade acontece a multirerritorialização, e os costumes e hábitos fazem parte da construção de identidade e dentre muitos está o uso do álcool, inclusive utilizado pelo adolescente, um ser aberto em desenvolvimento. Por isso, faz-se relevante entender brevemente o que é adolescência. 


\subsection{ADOLESCÊNCIA E O USO DO ÁLCOOL}

Caracteriza-se adolescência por vivenciar seu desenvolvimento de forma dinâmica, no qual sua interação com o meio social molda seu eu se estendendo para vida adulta. Conforme Aberastury, Knobel (2004), adolescência é período que se estabelece sentimentos de respeito, fidelidade, valores éticos e morais entre os grupos. Edificam-se desejos pessoais e sociais, buscam-se novos horizontes, novos sentidos. Segundo Quiroga (1998) a adolescência possui diversas interpretações, já que conta com diferentes pontos de vista sobre um ciclo fundamental na vida do indivíduo, onde está envolvido fatores biológicos, psicossociais e influências culturais e históricas que cercam cada um.

Calligaris (2000) nos traz uma percepção da adolescência, como contemplação, onde são fases que nem sempre passageiras, sendo também, um período de grande formação cultural, onde vão se sujeitando a situações delicadas, como familiares e sociais e vão se construindo neste meio. Durante esse processo, a adolescência organizar-se com sobrecarga pulsional, sua modificação corporal causa rejeição, como: trabalho de luto devido a perda da infância, rearranjo defensivo para enfrentar o novo corpo e um eu indefinido, reelaboração narcísica para garantir o amor próprio, sistema de idealização porque chegou a hora de pensar sobre o futuro, procura identificatória dos iguais, adesão ao grupo, acesso a uma nova forma de pensamento.

Durante esta fase, o adolescente adquire recursos físicos, cognitivos, emocionais, sociais e iniciação à economia (por acontecer o primeiro emprego) que são bases para sua saúde de forma sistêmica. Fase que depreende de vários fatores e recursos para seu desenvolvimento que alcança a próxima geração, porque será o adulto de amanhã. Assim, os investimentos na saúde e no bem-estar deste indivíduo em potencial proporcionam benefícios no hoje e no amanhã, (PATTON, SAWYER, SANTELLI, ROSS, AFIFI, ALLEN, 2016).

Para considerar um adolescente saudável, é relevante avaliar sua nutrição desde a infância, sua trajetória educacional qualitativamente, adiar para fase adulta sua formação familiar, inclusive sua iniciação sexual, dentre outras afirmações. Sua territorialidade entendida como fase crítica para alcançar o potencial humano está marcada por um lado, da necessidade de inserção grupal, e por outro da aceitação, fatores que os levam a práticas de grupos já estabelecidos socialmente. É uma fase que expõem o adolescente a estímulos que 
contrapõem ao que lhe é saudável para seu desenvolvimento, no caso deste estudo, o álcool causando transtornos, muitas das vezes irreversíveis.

Os transtornos causados por uso de álcool são heterogêneos de problemas. Sua gravidade pode variar nas fases de vida, em contextos biopsicossociais. A gravidade em estudantes bebedores pesado ocasiona falta à aula, que vivencia sérias consequências sociais e de saúde. Esses problemas atingem qualquer grupo sociodemográfico, racial ou de trabalho/funções. Da perspectiva de problemas com álcool, os profissionais da saúde podem se concentrarem mais claramente nos "padrões de beber, nas consequências negativas que o indivíduo acumulou, nos seus excessos e déficits comportamentais em várias áreas funcionais e nos pontos fortes do bebedor" (McCRADY, 2016, p. 532).

Os fatores mantenedores do padrão ${ }^{1}$ de consumo de bebidas alcoólicas se encontram no hábito de beber individual, ou circunstanciais ambientais, ou das relações interpessoais. Compreender a demanda dos adolescentes por produtos não "saudáveis, inclusive verificando a sensibilidade desta demanda às mudanças nos preços e na renda, é relevante para o desenho de políticas públicas que visem desestimular a procura por eles" (ALMEIDA, ARAÚJO JÚNIOR, 2017, p.88). No Brasil há preocupações com essa prática de beber álcool no público adolescente, tanto que o ECA - Estatuto da Criança e do Adolescente, lei 8069/1990 (2021) art. 79 proíbe publicações que estimulem o menor a consumir bebida alcoólica, já no art. 81 e 243 proíbem a venda. Porém, a relação entre o adolescente e o comércio brasileiro de bebidas alcoólicas não demonstram efetividade dessas proibições, porque os padrões de uso são significativos conforme os dados apresentados na sessão seguinte deste estudo por Carlini (2002 e 2006). A complexidade de relações entre o adolescente, o meio e o comportamento de uso do álcool é um desafio a longo prazo para a sociedade brasileira, para as ciências comportamentais e cognitivas.

A ciência cognitiva comportamental pressupõe antecedentes externos a bebida que tenha relacionamento permissivo pelo hábito de beber com reforços positivos ou negativos ou por meio de expectativas causadas pelo reforço. Pressupõem ainda, que as cognições e os estados afetivos fazem a mediação entre os antecedentes externos e a bebida, e que as

\footnotetext{
1“É importante destacar que o Brasil possui diferentes padrões regionais de consumo para bebidas com teor alcoólico e cigarro. Segundo dados da Pesquisa de Orçamentos Familiares (POF) 2008-2009, as regiões Sul e Sudeste apresentam 14,1\% e 11,5\% de famílias com despesas em bebidas alcoólicas dentro do domicílio", (ALMEIDA, ARAÚJO JÚNIOR, 2017, p.88)
} 
expectativas sobre o valor de reforço do álcool cumprem um papel relevante na determinação de comportamentos posteriores o beber. $\mathrm{O}$ adolescente se encontra sob influências, por um lado de forças internas de seu próprio desenvolvimento, por outras forças interpessoais da família, dos amigos, do momento inicial laboral, entre outros. Então, os padrões de uso do álcool advêm de fontes mantenedoras fisiológicas, psicológicas e interpessoais, ou seja, de vários fatores individuais, familiares e outros fatores interpessoais (McCrady, 2016).

Por isso, o planejamento de intervenção precisa ser multidisciplinar e multidimensional, porque existem vários fatores causadores e vários tipos eficazes para os problemas com álcool devido a variedades de abordagens apoiadas em pesquisas validadas sobre a substância em questão.

\section{METODOLOGIA}

No aporte de Rampazzo (2005), a metodologia nos ensina o caminho a percorrer de um estudo científico por meio de normas e técnicas. Para isso, o homem precisa adentrar nas diversas áreas da realidade para conhecê-la em sua própria verdade e/ou transformá-la satisfazendo suas necessidades. Fato este, conveniente ao presente estudo porque analisar padrões do de consumo de álcool é uma das tantas verdades do ser e devir a ser do público adolescente.

Partindo do princípio das ideias de Marconi e Lakatos (2001), o método de abordagem apresenta graus de abstração, com finalidade explicativa da ação nas etapas da pesquisa. Seguindo esse princípio, a presente pesquisa no primeiro momento foi selecionar as pesquisas que abordassem padrões de álcool com o público adolescente, tais como:

CARLINI, E. A. (supervisão) [et. al.]. I Levantamento domiciliar sobre o uso de drogas psicotrópicas no Brasil: estudo envolvendo as 107 maiores cidades do país: 2001. São Paulo: CEBRID - Centro Brasileiro de Informações Sobre Drogas Psicotrópicas: UNIFESP - Universidade Federal de São Paulo, 2002.

CARLINI, E. A. (supervisão) [et. al.]. II Levantamento domiciliar sobre o uso de drogas psicotrópicas no Brasil: estudo envolvendo as 108 maiores cidades do país: 2005. São Paulo: CEBRID - Centro Brasileiro de Informação sobre Drogas Psicotrópicas: UNIFESP - Universidade Federal de São Paulo, 2006.

Como definições de pesquisas científicas com confiabilidade para dar veracidade no tema investigado, e assim evitar reproduções de ideias já descritas. Neste seguimento foram 
feitas algumas especificações amostrais: o critério de seleção de dados bibliográficos a partir de pesquisas feitas no Brasil pelo Cebrid que continha universo de adolescente e que fosse o tema álcool. O método utilizado foi dedutivo, pois de acordo com Marques et al. (2017), o presente estudo teve como ponto de partida teorias já apresentadas pelo pesquisador Carlini (2001/2002 e 2005/2006²) para entender o fenômeno padrão de consumo do álcool nos multiterritórios (as microrregiões) brasileiro.

\section{RESULTADOS E DISCUSSÕES}

\subsection{PADRÕES DE CONSUMO DE ÁLCOOL POR ADOLESCENTES EM TERRITÓRIO BRASILEIRO}

Em território brasileiro, as políticas públicas traçam diretrizes por meio do poder público nas áreas de educação e saúde, prática objetivada à prevenção, as quais são reforçadas por normas jurídicas já estabelecidas. As propostas preventivas sobre drogas lícitas e ilícitas são via materiais informativos educativos para o público alvo criança e adolescente, (ACSELRAD, 2014). Porém, os dados a seguir demonstram que os padrões de consumo por adolescentes acontecem destoando das políticas públicas, configurando contradições entre práticas de consumo e leis proibitivas.

Apesar de alterada a lei no 8.069 de 13 de julho de 1990 - Estatuto da Criança e do Adolescente, para tornar crime vender, fornecer, servir, ministrar ou entregar bebida alcoólica a criança ou a adolescente; e revogado o inciso I do art. 63 do Decreto-Lei $n=3.688$, de 3 de outubro de 1941 - Lei das Contravenções Penais, os brasileiros têm consumido álcool consideravelmente. Fato que pode ser preocupante para as gestões públicas. Consumo que pode ser comprovado nos resultados territoriais brasileiros dos adolescentes na figura a seguir:

\section{Figura 2 -Imagem ilustrativa elabora no Canva.}

\section{I e Il levantamento domiciliar sobre o uso de drogas psicotrópicas no Brasil.}

CARLINL, E. A. (supervisio) [et. al.], 5 so Paulo : CEBRID - Centro Brasileiro de informaçoes Sobre Drogas Psicotropicas : UNIFESP - Universidade Federal de Săo Paulo, 2002.

CARLINo, E A. (supervisilo) [et. al.]. Săo Paulo : CEBRid - Centro Brasileiro de Informaçốes Sobre Drogas Psicotrópicas : UNIFESP - Universidade Federal de Săo Paulo, 2006.

\footnotetext{
${ }^{2}$ Entende-se pela segunda data como ano de publicação da pesquisa.
} 


\section{Amostra}

Nos dois levantamentos foram entrevistados pessoas de cidades e municipios com populaçăo superior a 200.000 habitantes, totalizando 107 cidades no primeiro levantamento e 108 municipios no segundo.

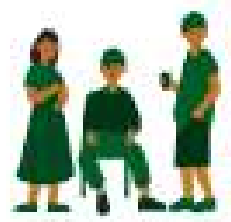

Frequência

- 48,396 da amostra parcial do primeiro levantamento e 54,3\% do segundo afirmam ter usado bebidas alcoólicas na vida.

- 5,246 da amostragem do primeiro levantamento e $7 \%$ do segundo apresentaram dependência de bebidas alcooblicas.

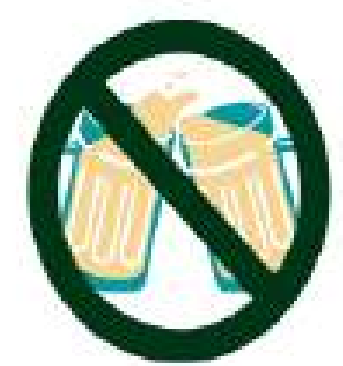

Toletância

- público que apresenta o fenómeno da tolerắncia equivale a $1,2 \%$ dos amostrados do primeiro levantamento e 4,296 do segundo.

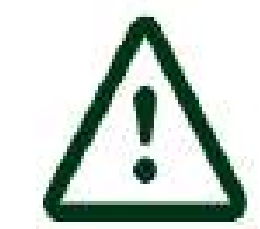

\section{Situaçōes de risco}

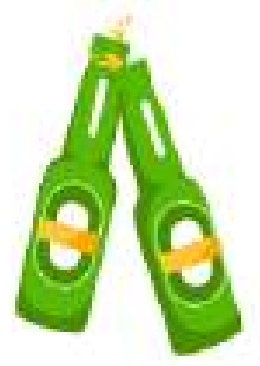

Respostas para os sinais/ sintomas

- $1,6 \%$ da amostragem do primeiro levantamento e $2,6 \%$ do segundo afirmaram gastar tempo para conseguit e usar o álcool.

- 5,2\% da amostragem do primeiro levantamento e 4,3\% do segundo usaram álcool ferequentemente.

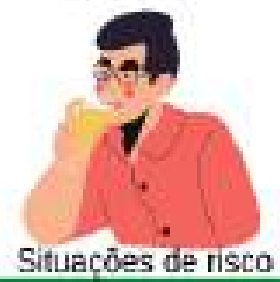

Dirigir, pilotar moto, usar máquinas, nadar entre outros são exemplos de situações de risco. $2 \%$ da amostragem do primeiro levantamento e $3.5 \%$ do segundo estiveram nessas situaçŏes. 


Probiemas pessoais
496 da amostragem do primeiro levantamento
e 5,79 do segundo apresentam problemas
com: Familiares, amigos, trabalho, policia
emocional ou psicológico.

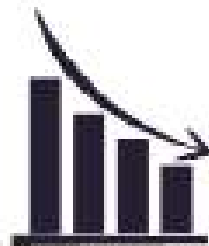

Ver frequentemente alguém bẻbado

$60,1 \%$ da amostragem do primeiro levantamento $e 58,6 \%$ do segundo afirmaram ver frequentemente alguém alcoolizado.

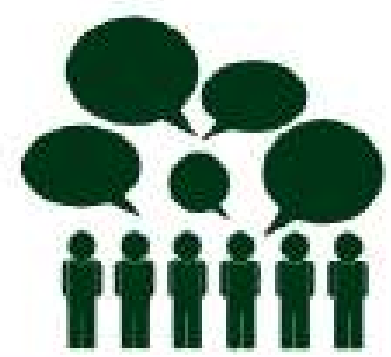

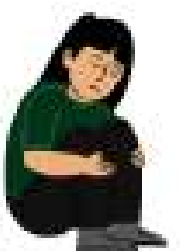

Sinais de diminuiçăo

$8.5 \%$ da amostragem do primeiro levantamento e $7,8 \%$ do segundo apresentaram interesse em diminuir ou parar o usa do álcool.

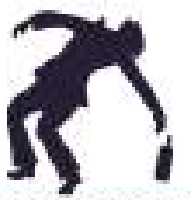

Opinióes da amostracem

- 29,6\% da amostragem do primeiro levantamento e 23,896 do segundo consideram que beber de 1 a 2 drinks por semana é um risco grave.

- 94,4\% da amostragem do primeiro levantamento e $95 \%$ do segundo consideram que o risco grave consiste no beber diariamente.
90 e 68 pessoas da amostragem eram residentes do Norte do país:

- $25,5 \%$ e $25,5 \%$ afirmaram o uso do álcool na vida,

- $9,2 \%$ e 2,9\% são dependentes de álcool.

- 3,2\% e 2,2\% gastararn grande parte do tempo com o álcool.

- $7,2 \%$ e 2,9\% usam álcool com maior frequência.

- $4 \%$ e $0 \%$ apresentam tolerăncia.

- $2 \%$ e $2,2 \%$ estiveram em situaçóes de risco fisico após o uso.

- $7,2 \%$ e $2,9 \%$ enfrentaram problemas pessuais por causa do álcool.

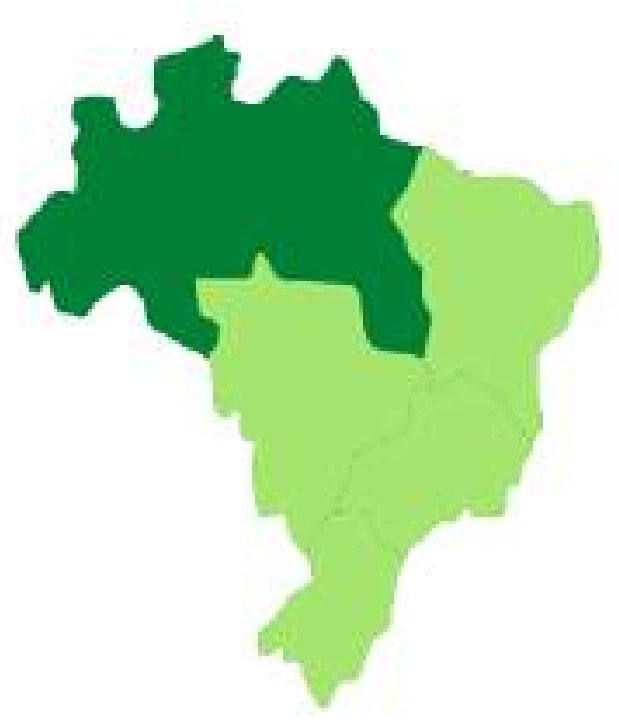


- $11,7 \%$ e 4,5\% desejaram parar ou diminuir o uso.

- $65,8 \%$ e $51 \%$ afirmaram ver frequentemente pessoas alcoolizadas.

- $33,5 \%$ e $17,9 \%$ consideram que beber de 1 a 2 drinks por semana é risco grave.

- $93,5 \%$ e $94,9 \%$ consideram que o risco grave consiste no beber diariamente.

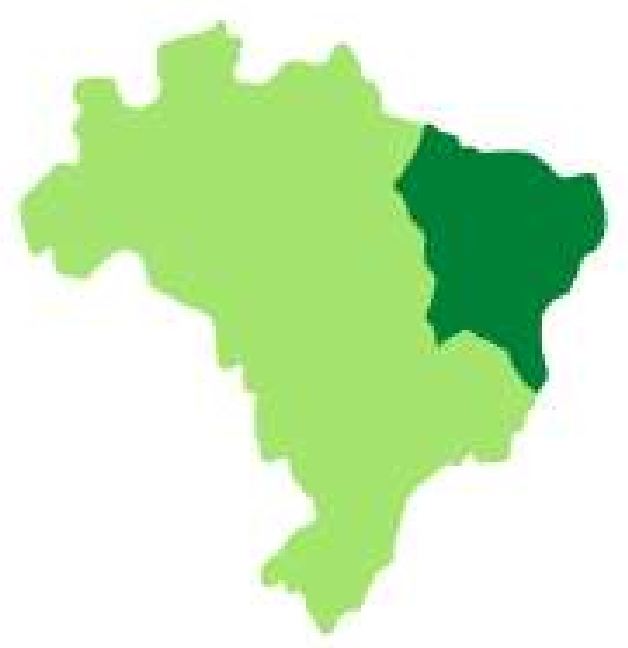

208 e 169 pessoas da amostragem eram residentes no Nortdeste do pais:

- 45,8\% e 43,6\% afirmaram o uso do álcool na vida.

- 9,3\% e 6,5\% são dependentes de álcool.

- $3,7 \%$ e $3,7 \%$ gastaram grande parte do tempo com o álcool.

- $9,8 \%$ e $6,3 \%$ usam álcool com maior frequência.

- $2 \%$ e $5,8 \%$ apresentam toleráncia.

- 1\% e 1,8\% estiveram em situaçōes de risco físico após o uso.

- $3,7 \%$ e $3,6 \%$ enfrentaram probrlemas pessoais por causa do álcool.

- 14,7\% e 9,2\% desejaram parar ou diminuir o uso.

- $64 \%$ e $65,4 \%$ afirmaram ver frequêntemente pessoas alcoolizadas.

- $29 \%$ e $16,9 \%$ consideram que beber de 1 a 2 drinks por semana é risco grave.

- $95,2 \%$ e $\mathbf{9 4 , 9 \%}$ consideram que o risco grave consiste no beber diariamente. 
65 e 87 pessoas da amostragem eram residentes no Centro-Oeste do pais

- 33,3\% e 55\% afirmaram o uso do álcool na vida.

- $1,8 \%$ e $7,7 \%$ são dependentes de álcool.

- $1,8 \%$ e $3,6 \%$ gastaram grande parte do tempo com o álcool.

- $1,8 \%$ e 5,9\% usam álcaol com maior frequência.

- $1,8 \%$ e 5,7\% apresentam tolerância.

- $0 \%$ e 2,1\% estiveram em situaçoes de risco físico após o uso.

- $14,9 \%$ e $6,5 \%$ enfrentaram probrlemas pessoais por causa do Allcool.

- 3,1\% e 8,896 desejaram parar ou diminuir o uso.

- $43,2 \%$ e $44,2 \%$ afirmaram frequêntemente pessoas alcoolizadas.

- 32,59\% e 18,6\% consideram que beber de 1 a 2 drinks por semana é risco grave.

- 94,59 e $100 \%$ consideram que o risco grave consiste no beber diariamente.

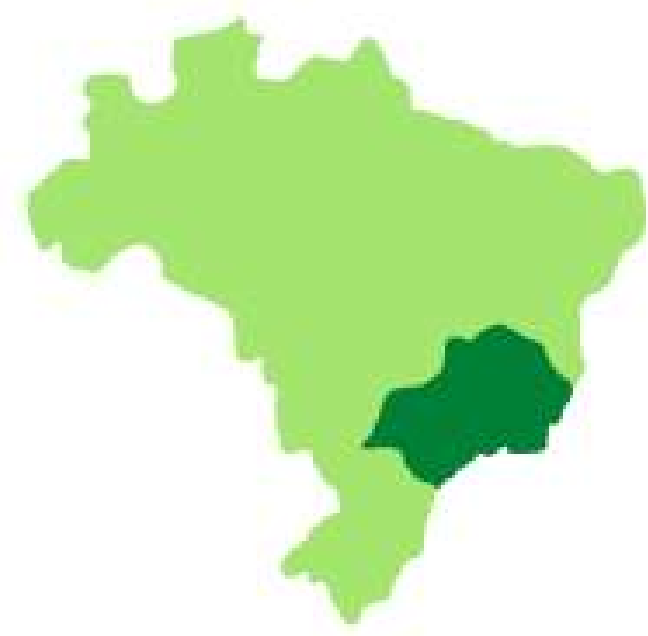

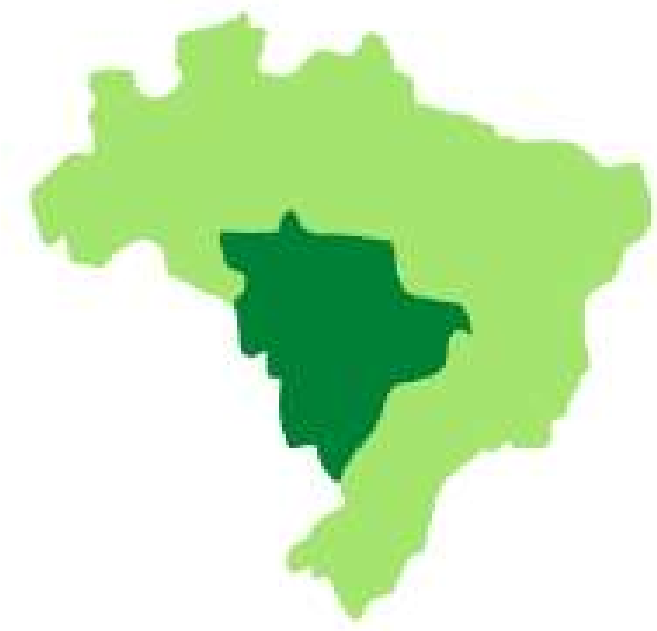

Sudeste

524 e 397 pessoas da amostragem eram residentes no Sudeste do pais:

- $53 \%$ e $60,8 \%$ afirmaram a uso do álcool na vida.

- 3,4\% e 6,3\% săo dependentes de álcool.

- 0,6\% e 2,1\% gastaram grande parte do tempo com o álcool.

- 3,8\% e 3,4\% usam Álcool com maior frequência.

- 1,5\% e 39 apresentam tolerancia.

- 1,1\% e 4,8\% estiveram em situą̧̃es de risco físico após o uso.

- $\mathbf{2 , 7 9}$ e $\mathbf{5 , 4 \%}$ enfrentaram problemas pessoais por causa do álcool.

- 6,5\% e 6,6\% desejaram parar ou diminuir o uso.

- $\mathbf{6 1 , 3} \%$ e $\mathbf{5 9 , 2 \%}$ afirmaram ver frequentemente pessoas alcoolizadas.

- $30,5 \%$ e $\mathbf{2 5 , 5} \%$ consideram que beber de 1 a 2 drinks por semana é risco grave.

- 93,9\% e 95,3\% consideram que o risco grave consiste no beber diariamente. 


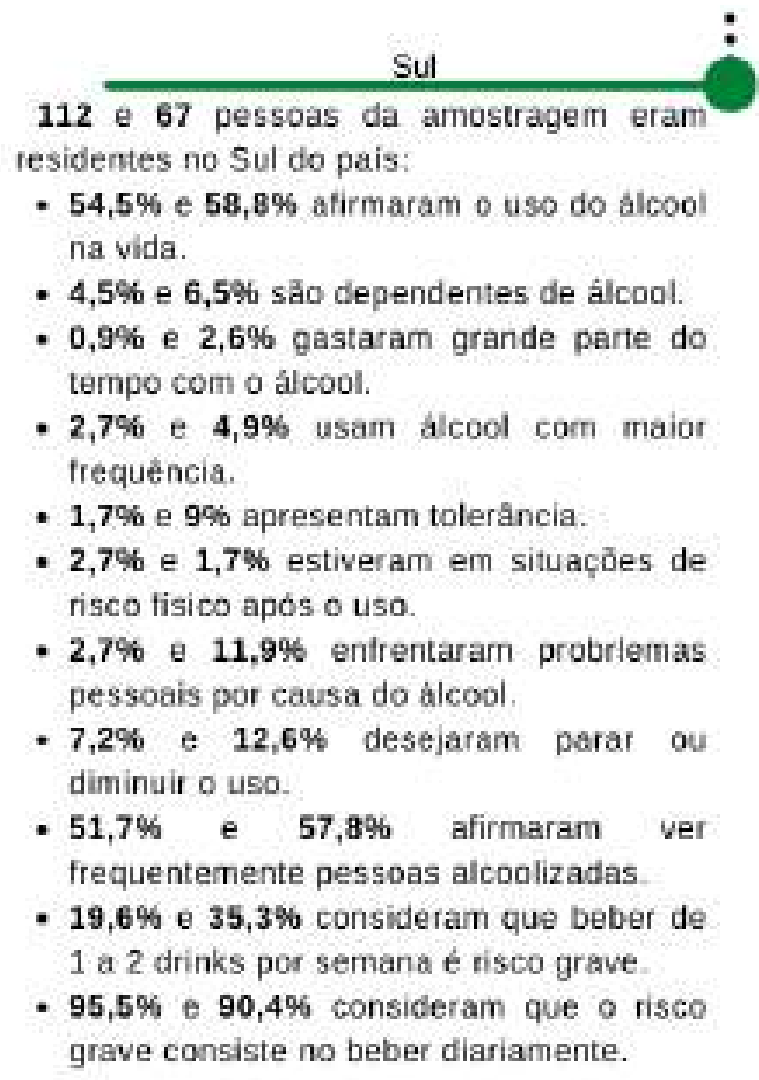

Fonte: descrições dos padrões de álcool por adolescentes - CEBRID

\subsection{ANÁLISE GERAL QUALITATIVA DOS DADOS DE CEBRID}

Ao analisar a frequência entre os dois levantamentos, no tempo de 2002 a 2006, notase que o padrão de usar a bebida alcoólica pelos adolescentes subiu $6 \%$ do primeiro para o segundo levantamento. Nessa mesma ordem crescente, verifica-se a diferença nos dados da dependência de 1,8\%; no gastar tempo para conseguir o álcool é de $1 \%$, no uso frequentemente é de $0,9 \%$ e nas situações de riscos foi de 1,5\%. Já, nos padrões tolerância houve um crescimento de $3 \%$.

Em todos esses padrões - uso, dependência, gastar tempo em busca do álcool, usar frequentemente e riscos - houve um crescimento singelo, mas as políticas públicas precisam repensar em ações efetivas para quebrar a causa do que está mantendo o comportamento dos adolescentes que está perdurando no uso do álcool, o que se pode até afirmar que está tornando hábito. Dessa forma, esses padrões poderão acarretar problemas sociais, educacionais, saúde e psíquico crônicos devido a fase de desenvolvimento ser adolescência. Situação que pode ser comprovado nas respostas de experiências que tiveram com problemas 
familiares, amizade, trabalho, com a polícia, emocionais e/ou psicológico. Problemas que se estendem para o campo perceptual, onde veem frequentemente alguém alcoolizado. No campo das opiniões, estão os critérios de risco grave ao beber 1 a 2 drinks por semana, sendo $23,8 \%$, e no beber diariamente são $95 \%$. Dados preocupante para sociedade, porque se os padrões estão tornando hábitos fortalecendo os adolescentes ao perceberem de forma distorcida sobre os riscos - a maioria pensa que só é grave se beber diariamente - que o álcool possa causar, significando a longo prazo que se pode ter uma sociedade formada por adultos dependentes da referida substância, e/ou alcoólatras.

\section{RESULTADOS ESPECÍFICOS QUANTITATIVO DOS MULTITERRITÓRIOS - REGIÕES BRASILEIRA}

De acordo com Gil (2002), os resultados de um levantamento ocorrem após a coleta e análise dos dados serem concluídas. Nesse contexto, a presente pesquisa analisou os seguintes resultados quantitativos:

Figura 3 - Imagem demonstrativa dos padrões de álcool por adolescentes nos multiterritórios brasileiro - regiões

\section{PADRÕES DE ÁLCOOL NOS MULTITERRITÓRIOS BRASILEIRO - REGIÕES \\ I LEVANTAMENTO CEBRID}

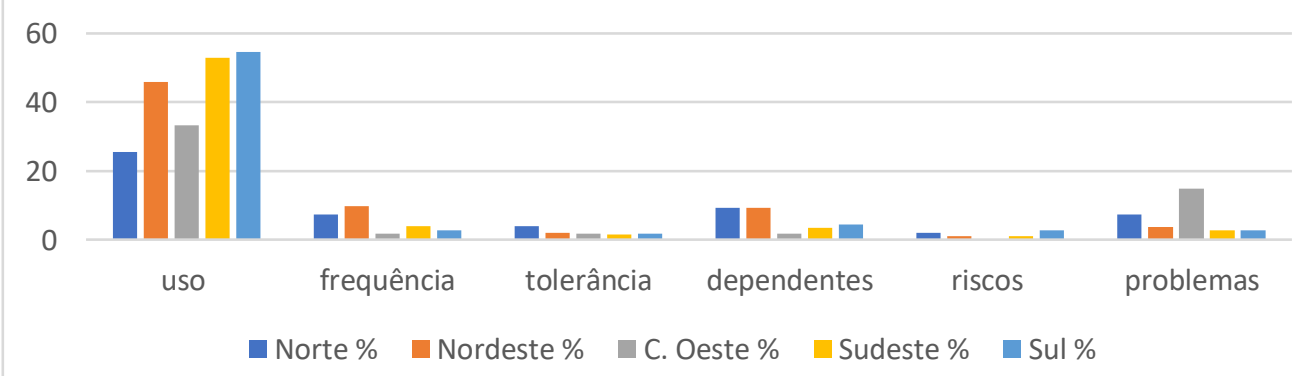

Fonte: CARLINI, E. A. (supervisão) [et. al.]. I Levantamento domiciliar sobre o uso de drogas psicotrópicas no Brasil: estudo envolvendo as 107 maiores cidades do país: 2001. São Paulo: CEBRID - Centro Brasileiro de Informações Sobre Drogas Psicotrópicas: UNIFESP - Universidade Federal de São Paulo, 2002. 
Figura 4 - imagem demonstrativa dos padrões de álcool por adolescentes nos multiterritórios brasileiro - regiões

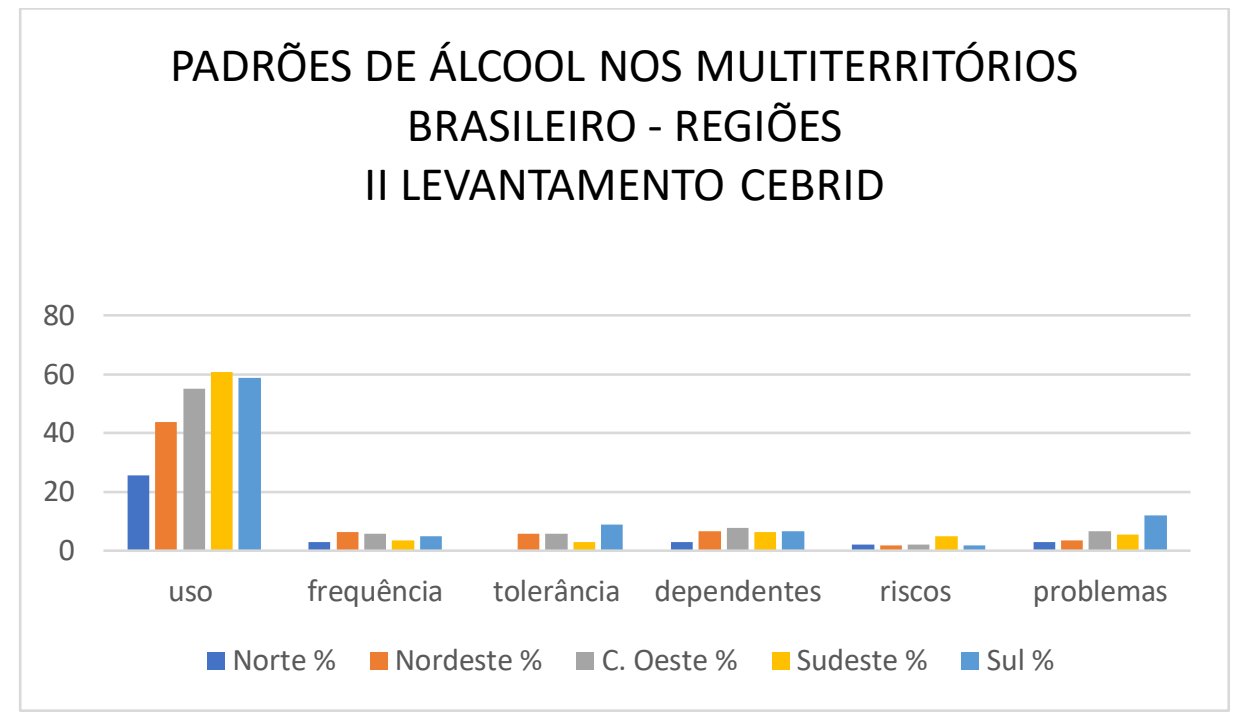

Fonte: CARLINI, E. A. (supervisão) [et. al.]. II Levantamento domiciliar sobre o uso de drogas psicotrópicas no Brasil: estudo envolvendo as 108 maiores cidades do país: 2005. São Paulo: CEBRID - Centro Brasileiro de Informação sobre Drogas Psicotrópicas: UNIFESP - Universidade Federal de São Paulo, 2006.

\subsection{ANÁLISE QUALITATIVA ESPECÍFICAS DOS RESULTADOS DOS MULTITERRITÓRIOS DAS REGIÕES BRASILEIRAS}

Os resultados entre o I e II levantamento CEBRID indicam padrões e crescimento de consumo no grupo adolescentes consideravelmente preocupantes para os gestores públicos. Os padrões: uso, frequência e tolerância podem ser compreendidos como primários, porque as consequências, dependências, riscos são causados por estes primários.

\subsubsection{Região Norte}

Nesta região, o uso do álcool manteve o percentual de $25 \%$ dos amostrados em percurso de tempo dos dois levantamentos, não mudando os comportamentos de uso. O que pode ser influenciador nos padrões da tolerância, porque a constância e aumento do uso do álcool leva o organismo a diminuir respostas de entorpecimento, e consequentemente desenvolverá resistências, levando à dependência da substância. 
Porém, no Norte, mesmo mantendo constância do uso do álcool, os dados sobre gastar parte do tempo de vida em busca do álcool diminuiu de $7,2 \%$ do primeiro para $2,9 \%$ no segundo levantamento, consequentemente a tolerância diminuiria também, de $4 \%$ para $0 \%$. Esta diminuição aconteceu nas situações de riscos, e lógico enfrentariam menos problemas na vida, de 7,2\% para 2,9\% causados pelo uso do álcool. Já nos dados em que os desejos em diminuir ou parar de consumir não foram positivos, porque $11,7 \%$ dos adolescentes do primeiro estudo manifestaram diminuir e/ou parar, enquanto que no segundo levantamento foram apenas $4,5 \%$. O que se pode entender é que as percepções dos adolescentes não sofreram mudanças sobre os malefícios do uso do álcool. Sendo confirmados nos dados do primeiro levantamento, em que 33,5\% consideram 2 drinks por semana é risco grave, enquanto no segundo, apenas $17,9 \%$ os adolescentes consideram que consumir 2 drinks é risco grave. Até porquê, suas percepções são semelhantes no consumo diariamente sendo um risco grave.

\subsubsection{Região Nordeste}

Enquanto no Nordeste as análises dos padrões são demonstrativas de forma comparativa pontuando as quedas do segundo estudo diante do primeiro:

No segundo estudo, houve queda de $2,2 \%$ de no uso do álcool, na dependência a queda foi de $2,8 \%$, no uso frequente caiu $2,5 \%$. Não se sabe os motivos dessa queda, mas pode-se considerar que nas habilidades de enfrentamento desempenham papel essencial no comportamento de beber em excesso ou de diminuir o uso de álcool (COX, CALAMARI E LANGLEY ,2007).

Na tolerância 3,8\% de aumento, nas opiniões aumentaram 0,8\% sobre risco físico ao usar, diante dos problemas pessoais a diferença foi insignificante $0,1 \%$ abaixo. Já no desejo de parar estão demonstrando resistências, porque os adolescentes do segundo apresentaram pouco desejo de parar, 9,2\% em comparação ao primeiro estudo de $14,7 \%$, e o beber só é risco grave se for diariamente, alto percentual do primeiro $95,2 \%$ no segundo $94,9 \%$, praticamente iguais entre os dois estudos. Porém, é um percentual muito próximo dos $100 \%$, dado preocupante, porque sevem de alerta para as políticas públicas aplicarem intervenções preventivas mais efetivas, uma vez que já existe respaldo de leis proibitivas a esse público. 


\subsubsection{Região Centro-Oeste}

Os adolescentes desta região usaram álcool consideravelmente elevado no segundo estudo com a diferença de $21,7 \%$ a mais. O que significa que as regras impeditivas de acesso à substância não estão sendo efetivada. Esse uso contribuirá para a dependência do álcool acontecer, fato que comprova nos dados de 1,8\% para 7,7\% significando um acréscimo de dependência de 5,9\%, alta significativa para prejudicar o desenvolvimento desses consumidores, porque o "alcoolismo é uma enfermidade crônica e progressiva que pode ser detida, mas não curada" (Mccrady, 2016, p. 538). Neste público, quem precisa tomar consciência da problemática são todas os que estão em torno - família, políticas públicas e os próprios adolescentes que usam o álcool. Diante desses dados, consequentemente os adolescentes usam com maior frequência, sendo no primeiro estudo 1,8\% subindo para 5,9\%, padrão que provoca tolerância à substância de $1,8 \%$ para $5,7 \%$. Padrões nocivos de uso são frequentemente criticados por outras pessoas e estão com frequência associados a consequências sociais diversas, (DSM-5, 2014); a exemplo, os problemas enfrentados em situações confirmados pelos amostrados, de $0 \%$ a 2,1\% no segundo. Um dado que contradiz aos descritos, são os problemas pessoais por causa do álcool, 14,9\% para os adolescentes do primeiro, enquanto no segundo estudo afirmam baixo enfretamento de problemas $6,5 \%$, mesmo diante de uso, tolerância e dependência acrescido. Por outro lado, seus desejos em parar ou até diminuir aumentou consideravelmente, sendo de 3,1\% para 6,5\%. Aproximadamente $45 \%$ deles afirmaram ver pessoas alcoolizadas.

Dados preocupantes para sociedade são as percepções sobre o risco grave, porque os que consideram beber dois drinks por semana de $32,5 \%$. para os adolescentes do primeiro estudo, enquanto no segundo são de 18,6 \%. Grave para 100\% deles são os que usam o álcool diariamente. Comportamentos que contrariam o art. 243 do ECA, porque é proibido "vender, fornecer, servir, ministrar ou entregar, ainda que gratuitamente, de qualquer forma, a criança ou a adolescente, bebida alcoólica", (ECA, 2021, p. 119).

\subsubsection{Região Sudeste}

Os adolescentes do sudeste em 2006, segundo estudo afirmaram usar mais álcool do que os adolescentes do primeiro estudo, sendo um acréscimo de 7,8\%. No padrão 
dependência também subiu de 3, $4 \%$ para 6,3\%, tendo um acréscimo de 2,9\%. Consequentemente passaram a gastar mais tempo para com a substância em questão. No padrão frequência houve uma pequena queda de $0,4 \%$ do segundo grupo para com o primeiro, mas $3,4 \%$ deles usam álcool com frequência. Não diferente desses padrões, a tolerância é a sequência, com acréscimo de 1,5\% do primeiro para o segundo, sendo o total de 3,4\% de adolescentes tolerantes ao álcool.

Vale ressaltar sobre afirmações sobre o beber drinks de um a dois por semana é risco grave, porque os dados são baixos, sendo no primeiro $30,5 \%$, vindo baixar um pouco mais no segundo estudo, sendo $25,5 \%$ dos adolescentes entrevistados que consideram risco grave beber até dois drinks. Por outro lado, $95 \%$ consideram que risco grave é beber diariamente. Dados semelhantes a todas as regiões brasileiras. Se as fontes fornecedoras desses padrões são fisiológicas, psicológicas e interpessoais (família, pessoal, grupos, trabalho e sociedade em geral onde circunda o indivíduo), (MCCRADY, 2016). os trabalhos das políticas públicas serão intensos para intervir nessa multiplicidade de fontes envolta ao beber álcool.

Esses padrões de uso, dependência, frequência e tolerância demonstram que o acesso está acontecendo, que os problemas sociais e individuais podem aumentar. fato que exige repensar dos modos interventivos para efetivar o art. 243 da lei 8069/1990 - ECA (2021). Vale repensar sobre as consequências desses padrões na sociedade a longo prazo.

\subsubsection{Região Sul}

Nesta região o percentual se encontra na metade dos adolescentes que afirmaram o uso do álcool, sendo 58,8\% com um acréscimo de $4,3 \%$ do primeiro. Situação que justifica aumentos dos padrões seguintes no segundo estudo para com o primeiro:

A alta de dependentes foi $2 \%$, consequentemente gastaram mais tempo para buscar o álcool $1,7 \%$ a mais, tendo maior frequência $2,2 \%$. Comportamentos de uso de álcool que elevou a tolerância desses adolescentes para com a substância, o que vem a ser uma resistência tanto cognitiva por acreditarem que não embebedam, quanto fisiológica por não se sentirem embriagados. A persistência de uso do álcool evidencia consequências nocivas, tais como danos no fígado por conta do excesso, alterando o humor para depressivo ou agressivo. As intervenções devem ser feitas para conscientizá-los dos danos que possam sofrerem, (DSM-5, 2014). 
Identifica-se que 9,2\% dos adolescentes dessa região enfrentaram mais problemas pessoais por causa do uso do álcool. Possivelmente são fatores que elevaram os desejos em parar ou até diminuir o uso. Mais de $50 \%$ deles afirmaram ver pessoas alcoolizadas. Outro dado preocupante para os gestores de saúde pública é que $90 \%$ dos adolescentes consideram risco grave beber diariamente. Essa habitualização para com o uso do álcool pode ser um estímulo de aprendizagem social para as gerações em desenvolvimento. Segundo Almeida, Araújo Júnior (2017) preocupar com essa demanda seria para desestimulá-los para evitar consequência negativas socialmente.

Adolescente em sua fase de vida, experimenta vulnerabilidade devido período de desenvolvimento de formação cultural, de estar voltado para fora de seu meio familiar, das incertezas profissionais, ainda não definido, e interno vivencia o luto da perda da infância, um novo corpo e um eu indefinido. Os padrões de álcool, tolerância, dependência e os ricos graves devido suas opiniões assinalaram que a gravidade está no uso frequente do álool. Essa situação pode aumentar a vulnerabilidade ou até causar transtornos de desenvolvimento desse público, como por exemplo síndrome de dependência.

A síndrome de dependência se configura por um conjunto de fenômenos fisiológicos, comportamentais e cognitivos, no qual o uso de uma substância alcança prioridade muito maior para um indivíduo que outros comportamentos que antes tinha maior valor (DSM-5). A característica central dessa síndrome é o desejo de consumir, os quais são demonstrados por acreditar que não ficam bêbados, que riscos só quando usar diariamente. São justificativas que reforça a crença de que param na hora que quiserem.

Para entender o fenômeno do uso do álcool é relevante buscar todas as características dos fatores motivacionais do indivíduo que bebe e, em seu entorno. Segundo Cox, Calamari e Langley (2007, p. 64), "embora duas pessoas tenham padrões similares no comportamento de beber, podem ter chegado a esse ponto por caminhos diferentes". Para Laranjeira (2014, p.54), "embora a sociedade brasileira esteja ciente deste importante problema de saúde pública, seu conhecimento acerca dos padrões de consumo, bem como os problemas, ainda são incipientes."

Esse conhecimento incipiente se deve a semelhança de padrões, ao mesmo tempo acontece o uso do álcool a partir da singularidade de cada adolescente. Para Almeida e Araújo Junior (2017), compreender a demanda dos indivíduos por produtos não saudáveis, inclusive 
verificando a sensibilidade desta demanda às mudanças nos preços e na renda, é relevante para o desenho de políticas públicas que visem desestimular a procura do álcool por eles.

\section{CONSIDERAÇÕES FINAIS}

Tem-se que o consumo de álcool por criança e adolescente é um flagelo social afeito a todos os territórios brasileiros e que perdura no tempo, com trágicas consequências orgânicas, comportamentais e na estrutura de desenvolvimento da personalidade dos infantes.

Em que pese os malefícios ocasionados pelo hábito/frequência de uso, tem-se que o combate ao acesso e consumo de bebidas alcoólicas pelos adolescentes, na maioria das vezes, acaba sendo relegado a lei e ao poder público. Não que o tema não mereça a atenção das autoridades e de suas políticas, todavia a luta deve ser de todos, ou seja, ante a relevância do tema, faz-se necessário o engajamento de toda a sociedade civil na sua compreensão e resolução.

Os padrões de consumo/território apresentados neste artigo apontam que há uma perigosa naturalização e permissibilidade acerca do consumo de álcool pelos nossos jovens, potencializado, em muito, pela complacência da mídia, da família e dos seus pares. A facilidade dos jovens em adquirir e fazer uso de bebidas alcoólicas, muitas vezes, franqueados pelos inúmeros estabelecimentos comerciais (bares e lanchonetes), causa uma espécie de terror. Os pontos de comercialização pulverizados em todos os rincões relativizam e/ou minoram os comandos proibitivos trazidos em lei, em aberto descasamento com suas responsabilidades sociais e legais, sob os olhares permissivos de parte da coletividade.

Não se trata de fazer uma cruzada santa ou criminalizar a atividade comercial em lume, todavia, a livre iniciativa e o direito de empreender, afeito a todos os brasileiros, e por que não, aos proprietários de bares, lanchonetes e similares, não pode preponderar sobre os interesses da sociedade. Logo, nenhuma atividade econômica pode colocar em risco a saúde, a vida e o futuro dos jovens.

De toda forma, a comercialização de bebidas alcoólicas para adolescentes é naturalizada por alguns como um desdobramento da atividade econômica. Qual seja, em nome do interesse comercial se aceita, e por que não, estimula, um hábito extremamente prejudicial à saúde dos adolescentes. É o viés financeiro acima da vida. 
Isso se dá não por falta de regramento ou óbice legal, pelo contrário, o Estatuto da Criança e Adolescente (ECA), taxativamente proíbe e criminaliza a prática de vender, fornecer, servir, ministrar ou entregar, ainda que gratuitamente, bebidas alcoólicas a crianças ou adolescentes, numa clara indicação do legislador acerca da antijuricidade desses atos.

Mas nem sempre foi assim. Até a promulgação da lei 13.106, em 17 de março de 2015, pela presidente Dilma Rousseff, a questão era tratada como contravenção penal ou uma simples infração administrativa, o que só servia para trazer sinais invertidos ao tema e a teleologia da lei. Com a alteração da legislação e a nova redação incorporada ao artigo 243 da lei 8.069/90 (ECA) a questão foi resolvida, qual seja, as práticas descritas no mencionado artigo de lei estão afeitas à pena de detenção de 2 (dois) a 4 (quatro) anos, e multa, se o fato não constituir crime mais grave, ou seja, o noveau comando normativo criminaliza quem de alguma forma franqueia as crianças e adolescente o acesso as bebidas alcoólicas.

De toda sorte, a criminalização trazida pelo ECA, bem como as políticas públicas para redução do acesso não tem se mostrado suficiência para minorar o flagelo social do consumo do álcool pelos adolescentes. Infelizmente os números/padrões trazidos pelos estudos apresentados neste artigo indicam, incontroversamente, que os jovens acessam e consomem bebidas alcoólicas cada vez mais cedo e com acentuada frequência, desdobrando-se em dependência física e psíquica.

Nessa ordem, uma nova compreensão sobre o tema urge. Não dá para o problema ficar circunscrito a atenção das autoridades públicas. O engajamento da sociedade contra o acesso e consumo de bebidas alcoólicas pelos jovens é imperativo. Para tanto, paradigmas comportamentais e culturais locais devem ser quebrados e/ou ressignificados ante os malefícios que o álcool provoca nas pessoas, notadamente aos mais jovens.

A aceitação social, inclusive pelos seus pares, também deve ser repudiada e combatida, eis que além do prejuízo à saúde, o uso de álcool na infância e adolescência está associado a outros comportamentos de risco, como o uso de tabaco e drogas ilícitas, atividade sexual sem proteção e acidentes automobilísticos. O consumo de álcool é uma má escolha, não tem nada de glamuroso, saudável e deve ser repudiado por todas as pessoas de bem da sociedade.

\footnotetext{
${ }^{3}$ Art. 243 da Lei 8.079/90 (ECA). Vender, fornecer, servir, ministrar ou entregar, ainda que gratuitamente, de qualquer forma, a criança ou a adolescente, bebida alcoólica ou, sem justa causa, outros produtos cujos componentes possam causar dependência física ou psíquica: (Redação dada pela Lei no 13.106, de 2015)

Pena - detenção de 2 (dois) a 4 (quatro) anos, e multa, se o fato não constitui crime mais grave. (Redação dada pela Lei no 13.106, de 2015)
} 
Nesta seara, insta o engajamento de todos, sem concessões, contra quem insiste em minorar e relativizar a questão, ou pior, não observar o comando normativo, sob a guisa de padrões comportamentais ou tradições arraigadas no local, sob os auspícios do lucro fácil.

Nesta quadra, obstar o acesso e consumo de bebidas alcoólicas pelos jovens é uma luta incessante e inegociável de toda a sociedade. É uma questão de cidadania, e acima de tudo, um compromisso com o nosso tempo e a nossa gente.

\section{REFERÊNCIAS}

ABERASTURY, Arminda e KNOBEL, Mauricio. La adolescência normal: un enfoque psicoanalítico. 26ạ reimpresión. Buenos Aires: Paidós, 2004.

ACSELRAD Gilberta (Org.). Consumo do álcool no Brasil. FLACSO Brasil (da Série Cadernos FLACSO). Rio de Janeiro, 2014. Disponível http://flacso.redelivre.org.br/files/2015/03/58N12-GilbertaAcserlrad.pdf. Acesso dia 15 de abr. de 2021.

ALMEIDA, Aléssio Tony Cavalcanti de, ARAÚJO JÚNIOR, Ignácio Tavares de. Demanda por bebidas alcoólicas e cigarros no brasil: elasticidades, microssimulação e variações no bemestar. Pesquisa e planejamento econômico | ppe | v. 47 | n. 2 | ago. 2017. Disponível em http://repositorio.ipea.gov.br/bitstream/11058/8055/1/PPE v47_n02 Demanda.pdf. Acesso dia 10 de jul. de 2021.

ANDRADE, Arthur Guerra de, ANTHONY, James C., SILVEIRA, Camila Magalhães. Álcool e suas consequências: uma abordagem multiconceitual. Barueri, SP: Minha Editora, 2009. Disponível em https://cisa.org.br/index.php/biblioteca/downloads/artigo/item/180-livroalcool-e-suas-consequencias-uma-abordagem-multiconceitual Acesso dia 4 de abr. de 2021.

BASTOS, Francisco Inácio Pinkusfeld Monteiro; VASCONCELLOS, Maurício Teixeira Leite de; BONI, Raquel Brandini De; REIS, Neilane Bertoni dos; COUTINHO, Carolina Fausto de Souza, (Organizadores). III Levantamento Nacional sobre o Uso de Drogas pela População Brasileira. Ministério da Saúde, FIOCRUZ, Fundação Oswaldo Cruz, 2017. Disponível em https://www.arca.fiocruz.br/bitstream/icict/34614/1/III\%20LNUD PORTUGU\%c3\%8aS.pdf Acesso dia 16 de abr. de 2021.

BRASIL. ECA - Estatuto da criança e do adolescente. Lei no 8.069, de 13 de julho de 1990. 2021. Disponível em https://www.gov.br/mdh/pt-br/assuntos/noticias/2021/julho/trinta-e-umanos-do-estatuto-da-crianca-e-do-adolescente-confira-as-novas-acoes-para-fortalecer-oeca/ECA2021_Digital.pdf. Acesso 2 de agost. de 2021.

CARLINI, E. A. (supervisão) [et. al.]. I Levantamento domiciliar sobre o uso de drogas psicotrópicas no Brasil: estudo envolvendo as 107 maiores cidades do país: 2001. São Paulo: CEBRID - Centro Brasileiro de Informações Sobre Drogas Psicotrópicas: UNIFESP Universidade Federal de São Paulo, 2002. 
CARLINI, E. A. (supervisão) [et. al.]. II Levantamento domiciliar sobre o uso de drogas psicotrópicas no Brasil: estudo envolvendo as 108 maiores cidades do país: 2005. São Paulo: CEBRID - Centro Brasileiro de Informação sobre Drogas Psicotrópicas: UNIFESP - Universidade Federal de São Paulo, 2006.

CARLINI, E. A. (supervisão) [et. al.]. VI Levantamento Nacional sobre o Consumo de Drogas Psicotrópicas entre Estudantes do Ensino Fundamental e Médio das Redes Pública e Privada de Ensino nas 27 Capitais Brasileiras - 2010. São Paulo: CEBRID - Centro Brasileiro de Informações sobre Drogas Psicotrópicas: UNIFESP - Universidade Federal de São Paulo 2010. SENAD - Secretaria Nacional de Políticas sobre Drogas, Brasília - SENAD, 2010. Disponível em https://www.cebrid.com.br/wp-content/uploads/2012/10/VI-Levantamento-Nacionalsobre-o-Consumo-de-Drogas-Psicotr\%C3\%B3picas-entre-Estudantes-do-EnsinoFundamental-e-M\%C3\%A9dio-das-Redes-P\%C3\%BAblica-e-Privada-de-Ensino-nas-27Capitais-Brasileiras.pdf Acesso dia 15 de abr. de 2021.

COSTA, Rogério H. da (Rogério Haesbaert da), 1958. O mito da desterritorialização: do fim dos territórios à multiterritorialidade. 6a ed. Rio de Janeiro: Bertrand Brasil, 2011.

COX, W. Miles, CALAMARI, John E., LANGLEY, Mervin. Habilidades de enfrentamento para o comportamento de beber e assessoria motivacional sistemática: tratamentos cognitivocomportamentais para pessoas que têm problemas com álcool. In.: CABALLO, Vicent $E$. Manual para o tratamento cognitivo-comportamental de transtornos psicológicos da atualidade: intervenções em crise, transtornos da personalidade e do relacionamento e psicologia da saúde. São Paulo: Santos, 2007. Cap. 3.

DSM-5. Manual diagnóstico e estatístico de transtorno. [American Psychiatnc Association, traduç. Maria Inês Corrêa Nascimento, et al.]; revisão técnica: Aristides Volpato Cordioli [et al.]. Porto Alegre: Artmed, 2014.

GIL, Antonio Carlos. Como elaborar projetos de pesquisa. 4ạ Edição. São Paulo: Atlas, 2002. LIMONAD, Ester e LIMA, Ivaldo Gonçalves de. Entre a ordem próxima e a ordem distante: contribuições a partir da obra de Henri Lefebvre.In.: LIMONAD, Ester (org.). Entre a Ordem Próxima e a Ordem Distante: contribuições a partir do pensamento de Henri Lefebvre. Niterói: UFF/GECEL, 2003. Disponível em http://www.biblioteca.clacso.edu.ar/Brasil/ppgeouff/20121204013217/dos.pdf Acesso dia 18 de abr. de 2021.

LARANJEIRA, Ronaldo [et al.]. I Levantamento Nacional sobre os padrões de consumo de álcool na população brasileira. Elaboração, redação e organização: Ronaldo Laranjeira [et al.]. Revisão técnica científica: Paulina do Carmo Arruda Vieira Duarte. Brasília: Secretaria Nacional Antidrogas, 2007.2 Disponível em https://bvsms.saude.gov.br/bvs/publicacoes/relatorio padroes consumo alcool.pdf Acesso dia 04 de abr. de 2021.

LARANJEIRA, Ronaldo (Supervisão) [et al.]. II Levantamento Nacional de Álcool e Drogas (LENAD) - 2012., São Paulo: Instituto Nacional de Ciência e Tecnologia para Políticas Públicas 
de Álcool e Outras Drogas (INPAD), UNIFESP, 2014. Disponível em https://inpad.org.br/wpcontent/uploads/2014/03/Lenad-II-Relat\%C3\%B3rio.pdf Acesso dia 04 de abr. de 2021.

MCCRADY, Barbara S. Transtornos por uso de álcool. In.: BARLOW, David H. (organizador). Manual clínico dos transtornos psicológicos: tratamento passo a passo. Tradução: Roberto Cataldo da Rosa, Elisabeth Meyer. 5a ed. Porto Alegre: Artmed, 2016. Cap. 13.

PATTON, George C, MD; SAWYER, Susan M, MD; SANTELLI, John S, MD; ROSS, David A, PhD; AFIFI, Rima, PhD; ALLEN, Nicholas B, PhD; (et al.). Our future: a Lancet commission on adolescent health and wellbeing. THE LANCET COMMISSIONS | VOLUME 387, ISSUE 10036, P2423-2478,11 DE JUNHO DE 2016. Disponível em https://www.thelancet.com/journals/lancet/article/PIIS0140-6736(16)00579-1/fulltext\# Acesso dia 16 de abr. de 2021.

SAQUET, Marcos Aurelio, SPOSITO Eliseu Savério (organizadores). Territórios e territorialidades: teorias, processos e conflitos. São Paulo: Expressão Popular: UNESP. Programa de Pós-Graduação em Geografia, 2008.

RAFFESTIN, Claude. A produção das estruturas territoriais e sua representação. In.: SAQUET, Marcos Aurelio, SPOSITO Eliseu Savério (organizadores). Territórios e territorialidades: teorias, processos e conflitos. São Paulo: Expressão Popular: UNESP. Programa de PósGraduação em Geografia, 2008.

RAMPAZO, Lino. Metodologia Científica. 3a ed. São Paulo: Loyola, 2005. 


\title{
POLÍTICAS PÚBLICAS (D)E SAÚDE EM CAMPO GRANDE-MS NO CONTEXTO DA PANDEMIA DE COVID-19: APROXIMAÇÕES E DISTANCIAMENTOS COM DESEJOS E EXPECTATIVAS DA POPULAÇÃO
}

\author{
Gustavo Ribeiro Capibaribe \\ Doutorando em Desenvolvimento Local, Universidade Católica Dom Bosco (UCDB), \\ Campo Grande, MS, Brasil. \\ gustavocapibaribe@outlook.com \\ Antônio Henrique Maia Lima \\ Doutor em Ciências Políticas -PUC/SP \\ ahenriquemaia@gmail.com
}

\begin{abstract}
RESUMO
Segundo dados da John Hopkins University, no início de agosto de 2021 o Brasil registra quase 560.000 (quinhentos e sessenta mil mortos) e 20.000.000 (vinte milhões) de casos de COVID19. Assolado por esta pandemia também, o Município de Campo Grande-MS é o locus da pesquisa. Há cerca de um ano e meio depois do início da pandemia busca-se compreender e avaliar se as respostas adotadas pelas instituições encontram eco na opinião pública. Assim o problema básico de pesquisa é "quais as convergências e divergências entre as políticas públicas de saúde adotadas pelo Município de Campo Grande - MS no contexto do combate a pandemia de COVID-19 e aquilo que a população da cidade desejava/esperava?". A instrumentalização da coleta de dados se deu por intermédio de questionário semiestruturado, composto por onze questões objetivas de tipagens distintas e duas abertas ou discursivas. restou demonstrado que a amostra "concorda" com boa parte das medidas implementadas na cidade de Campo Grande como políticas de contenção do contágio da COVID-19 e se mostra "disposta" a segui-las ou cumpri-las, especialmente aquelas mais básicas e, inclusive, pouco mais da metade aprova o uso de medicamentos sem comprovação científica de eficácia no combate à doença. Também restou demonstrado que a maior parte da amostra se posiciona como "discordante" em relação as medidas de fechamento do comércio, bem como da redução de ônibus e fechamento de terminais de transporte coletivo.
\end{abstract}

Palavras-chave: Políticas Públicas; Saúde; Pandemia; Covid-19; Campo Grande - MS. 


\section{ABSTRACT \\ POLICIES AND HEALTH IN CAMPO GRANDE-MS IN THE CONTEXT OF COVID-19 PANDEMIC: APPROACHES AND DISTANCES WITH THE POPULATION'S DESIRE AND EXPECTATIONS}

According to data from John Hopkins University at the beginning of August 2021, Brazil registers almost 560,000 (five hundred and sixty thousand deaths) and 20,000,000 (twenty million) cases of COVID-19. Also affected by this pandemic, the Municipality of Campo GrandeMS is the locus of research. For about a year and a half after the start of the pandemic, an attempt has been made to understand and assess whether the responses adopted by the institutions are echoed in public opinion. Thus, the basic research problem is "what are the convergences and divergences between the public health policies adopted by the Municipality of Campo Grande - MS in the context of combating the COVID-19 pandemic and what the population of the city wanted/expected?". The instrumentalization of data collection took place through a semi-structured questionnaire, consisting of eleven objective questions of different types and two open or discursive. it was shown that the sample "agrees" with most of the measures implemented in the city of Campo Grande as COVID-19 contagion containment policies and is "willing" to follow or comply with them, especially the most basic ones and, in fact, just over half approve the use of drugs without scientific proof of effectiveness in combating the disease. It was also demonstrated that most of the sample is positioned as "disagreeing" in relation to the measures to close the trade, as well as the reduction of buses and the closing of public transport terminals.

Keywords: Public Policies; Health; Pandemic; Covid-19; Campo Grande - MS. 


\section{CONSIDERAÇÕES INICIAIS: CONTEXTO DA PESQUISA, ASPECTOS TEÓRICOS E METODOLÓGICOS}

Segundo o Ministério da Saúde do Brasil, a COVID-19 é a doença causada pelo coronavírus SARS-CoV-2, o qual apresenta um quadro clínico que varia de infecções assintomáticas a síndromes respiratórias agudas graves. De origem ainda obscura, o vírus que passou a ser mais conhecido como Novo Coronavírus fez sua primeira vítima em Wuhan, na China ainda no ano de 2019 e se espalhou pelo mundo rapidamente. No Brasil a partir de fevereiro de 2020 constatou-se o primeiro caso, na primeira quinzena de março 2020 o Brasil registrou a primeira morte dele decorrente. Segundo dados da John Hopkins University o início de agosto de 2021 o país registra quase 560.000 (quinhentos e sessenta mil mortos) e 20.000.000 (vinte milhões) de casos. Em todo o planeta se registra à esta altura 200.000.000 (duzentos milhões) de casos e quase 4.300 .000 (quatro milhões e trezentos mil) mortos.

Tamanhos números sugerem uma realidade sanitária estarrecedora que demandou em praticamente todos os cantos do planeta respostas rápidas e eficientes, tanto de pessoas quanto de governos. Cerca de um ano e meio depois do início da pandemia busca-se compreender e avaliar se essas respostas adotadas pelas instituições encontram eco na opinião pública. Assim o problema básico de pesquisa é "quais as convergências e divergências entre as políticas públicas de saúde adotadas pelo Município de Campo Grande - MS no contexto do combate a pandemia de COVID-19 e aquilo que a população da cidade desejava/esperava?".

Tornou-se relevante pesquisas do tipo, já que as consequências imediatas da pandemia permaneceram por quase um ano meio, a despeito das consequências de longo prazo que certamente atingirão vigorosamente aqueles lugares que, como o Brasil, não souberam lidar e maneira rápida e eficiente com um problema sanitário de tamanha dimensão. Por outro lado, interessa identificar também ou grau de disposição dos atores sociais em colaborar com o combate à doença e tomarem as atitudes ou medidas, positivas ou negativas, que determinam as políticas adotadas pelo município.

É verdade que grande parte das medidas sanitárias adotadas em contextos de crise como estes atingem corpos e comportamentos, redimensionando o espectro do convívio social, práticas corporais, performances, modos de ser e de agir, modos de consumir, modos 
POLÍTICAS PÚBLICAS (D)E SAÚDE EM CAMPO GRANDE-MS NO CONTEXTO DA PANDEMIA DE COVID-19: APROXIMAÇÕES E DISTANCIAMENTOS COM DESEJOS E EXPECTATIVAS DA POPULAÇÃO
Gustavo Ribeiro Capibaribe Antônio Henrique Maia Lima

de comunicar etc. demandando uma disciplina em sentido foucaultiano que outrora, antes da pandemia, não se experienciava pela maioria da população mundial. Por outro lado, todo e qualquer tipo de solidariedade, agora no sentido durkheimiano do termo, se posiciona num limiar só visto em casos extremos e históricos de crises sociais.

O questionário aplicado objetiva identificar correlações positivas (concordâncias) e/ou negativas (discrepâncias) entre as medidas adotadas e aquelas que a população eventualmente não desejasse que fossem adotadas, bem como, entre aquelas que não foram efetivamente adotadas e aquelas que a população desejasse que fossem adotadas. Por exemplo, se se quer descobrir o grau de concordância com as medidas de biossegurança adotadas como objetivo de controlar a pandemia de COVID-19 pela Prefeitura Municipal de Campo Grande, o instrumental ou questionário enumera uma série de medidas e pergunta para a amostra num grau de 1 (um) a 5 (cinco), sendo 5 o grau máximo de concordância e 1 o grau máximo de discordância, a sua opinião. Do mesmo modo, se se quer descobrir o grau de disposição da amostra para a prática das medidas de biossegurança adotadas como objetivo de controlar a pandemia de COVID-19.

Uma pesquisa desse tipo é possível tão somente na sua forma qualitativa, pois, como afirma Minayo (2007, p. 21) e muitos outros ela "trabalha com o universo dos significados, dos motivos, das aspirações, das crenças, dos valores e das atitudes" daqueles que estão em interação durante o processo em análise, o que envolve, naturalmente, também o pesquisador.

A instrumentalização da coleta de dados se deu por intermédio de questionário semiestruturado, composto por onze questões objetivas de tipagens distintas e duas abertas ou discursivas. É possível assim delimitar as tipagens das questões objetivas em 7 (sete) questões objetivas de resposta única e 4 (quatro) de respostas múltiplas.

A amostragem pode ser definida como não probabilística e intencional ou por conveniência, uma vez que a coleta das respostas esteve condicionada ao critério específico de ser domiciliado no município de Campo Grande - MS, havendo, consequentemente uma redução não aleatória do universo de participantes da pesquisa, o que implicou, inclusive, no desprezo (exclusão) das participações que não se enquadravam a esse critério.

Por definição de "amostra" ou "amostragem" tem-se o universo de respostas coletadas por meio da plataforma online Microsoft Forms. Do total destas respostas, 44 
POLÍTICAS PÚBLICAS (D)E SAÚDE EM CAMPO GRANDE-MS NO CONTEXTO DA PANDEMIA DE COVID-19: APROXIMAÇÕES E DISTANCIAMENTOS COM DESEJOS E EXPECTATIVAS DA POPULAÇÃO
Gustavo Ribeiro Capibaribe Antônio Henrique Maia Lima

(quarenta e quatro) foram analisadas por preencherem o requisito do domicílio. Nesse sentido, "amostra" no presente texto faz referência exclusivamente a essas respostas ou sujeitos que vieram a responder ao questionário.

\section{ALGUMAS NOTAS SOBRE POLÍTICAS PÚBLICAS (POLICIES)}

Quando nos defrontamos com algo que altera a situação cotidiana, nos defrontamos com um problema. Brugger (1969, p. 334) diz que nem toda questão pode ser considerada um problema, mas apenas aquelas onde suas dificuldades intrínsecas a tornam impossíveis de serem resolvidas sem especial esforço. A perfeita colocação de um problema seria de importância capital para as ciências porque, assim como a exatidão da identificação das questões que cercam o assunto influenciam nas decisões, a inexatidão pode conduzi-la à medidas danosas.

Nesta toada, ainda afirma que os pseudoproblemas são aqueles que se resolvem sem maiores intervenções ou até por si mesmo. Assim, as ciências devem ocupar-se por identificar, analisar e descrever aqueles onde ação acurada se faz necessária. Dentro desses problemas estão aqueles que demandam enérgicas ações e sua resolução servem para envidar esforços para minorar efeitos de uma futura problematização.

Quando um problema é privado, neste momento entendido como algo exclusivo de alguém, como nos ensina Carnoy (1994), a solução é da alçada do indivíduo afligido, que deve tomar medidas para resolver o dilema sem a participação de terceiros. Existe, contudo, momentos em que problemas privados são de responsabilidade alheia. Podemos enumerar aqueles provocados por outros, onde existe proteção legal; os de natureza obrigacional contratual, quando um se compromete a assumir determinado aspecto desse dilema, a exemplo dos contratos de seguro; e quando a sociedade, representada pelo Estado, tutela alguns bens pessoais e passa a ter obrigação de zelar por eles.

A Constituição Federal de 1988 entendeu que a saúde é um desses bens de tutela coletiva, sendo sua responsabilidade atuar no sentido de prover cuidados a todos os enfermos. Neste ponto, o problema individual passa a ser um problema público, entendido por Secchi $(2013$, p.10) como a diferença entre a situação atual e a situação ideal, quando a 
POLÍTICAS PÚBLICAS (D)E SAÚDE EM CAMPO GRANDE-MS NO CONTEXTO DA PANDEMIA DE COVID-19: APROXIMAÇÕES E DISTANCIAMENTOS COM DESEJOS E EXPECTATIVAS DA POPULAÇÃO
Gustavo Ribeiro Capibaribe Antônio Henrique Maia Lima

quantidade, a qualidade e a espécie daquilo a ser enfrentado está acolhido no ordenamento jurídico.

Quando o Poder Público visualiza algo que ofenda ao legalmente estipulado, estes mesmos mandamentos exigem que providências sejam tomadas, de forma ágil e dentro do princípio constitucional da eficiência. Ou seja, quando a situação vivida não é aquela tida como a ideal, aos governos, das três esferas, cabe a responsabilidade em atuar.

Portanto, ao ser confrontado com um problema público, devem os mandatários formular diretrizes, sejam elas emergenciais ou preventivas, para atender às demandas emergentes. Estas diretrizes são o que Secchi $(2013$, p. 3) chama de políticas públicas. Souza (2006, p. 25), por sua vez, aponta críticos a esta visão, onde existiria um reducionismo teórico quando limitamos o alcance da política pública a solução de problemas.

Estes pensadores entendem que aconteceria o abandono da ideia de jogo de conflitos e interesses sempre que algo está sendo posto em prática pelos Governos, além de focar apenas no papel destes, alijando do cenário político outras formas de participação da sociedade, como instituições privadas e organizações sociais.

Para entendermos este ponto, devemos recorrer ao entendimento do que significaria política para Secchi (2013). Para este autor, a palavra "política", em língua portuguesa, pode não expressar exatamente aquilo entendido quando da formulação do termo em seu idioma materno, 0 inglês.

Neste vernáculo existiriam duas palavras com igual tradução no Português: Politics seria a atividade humana ligada à obtenção e manutenção do poder. Por sua vez, Policy tem o sentido de orientação para a decisão e ação (SECCHI, 2013, p. 1). Neste tipo de estudo o segundo entendimento tem mais sentido e é aquele utilizado.

Este autor enfatiza a participação do Poder Público como majoritária nesse contexto de ações, seja pela exclusividade na formulação de leis e, em sua concepção, de certa forma necessária para corrigir eventuais desníveis que o mercado e a comunidade dificilmente teriam condições de corrigir, e, com isso, reduziriam as desigualdades existentes. Enfatiza que a intervenção estatal é histórica no caso do pensamento político brasileiro (SECCHI, 2013, p. 2).

Souza (2006, p. 22) entende que os Governos são os produtores por excelência das políticas públicas, que como uma das mais importantes instituições do Estado, mereceram 
POLÍTICAS PÚBLICAS (D)E SAÚDE EM CAMPO GRANDE-MS NO CONTEXTO DA PANDEMIA DE COVID-19: APROXIMAÇÕES E DISTANCIAMENTOS COM DESEJOS E EXPECTATIVAS DA POPULAÇÃO
Gustavo Ribeiro Capibaribe Antônio Henrique Maia Lima

especial atenção nos estudos deste ramo das ciências políticas, sempre tentando entender como e porque determinadas atitudes e decisões foram tomadas por aqueles que ocupavam cargos de mando. Para ela, a introdução por parte dos governos de políticas públicas é fruto da Guerra Fria e do crescimento do aparato burocrático estatal para enfrentar suas consequências.

Secchi (2013, p. 3), contudo, disciplina também que os entes não-governamentais, a sociedade civil, também pode ser uma formuladora de políticas públicas porque entendem que uma política é pública quando o problema que ela procura modificar é público, a chamada abordagem multicêntrica. Para isso devemos compreender o que seria público. A simples verificação da personalidade jurídica de uma organização não seria suficiente para esta verificação, visto um ente enquadrado como pessoa privada poderia agir em assuntos públicos, a exemplo da Petrobrás (SECCHI, 2013, p.4).

Neste ponto, Seccchi (2013) diverge dos ensinamentos de Carnoy (1994, p. 9), onde o público é o oposto ao privado. Para este, a superioridade do Estado, aqui entendido como o setor público, é fundamental para a prosperidade da sociedade. O Estado parece deter a chave para o desenvolvimento econômico, para a segurança social, para a liberdade individual e, através da "sofisticação" crescente das armas, para a vida e a morte (CARNOY, 1994, p. 9)

Essa superioridade objetiva do Estado é presente na hora de se impor determinada atitudes à população, ou seja, a imposição do poder de polícia. "A atividade de polícia consiste na imposição de limitações à liberdade e à propriedade dos cidadãos, necessárias para se assegurar a manutenção da ordem pública" (NUNES JR., 2017, p. 3).

O poder de polícia estatal não deve ser confundido com a atividade judiciária de polícia, tampouco com os serviços públicos ou com a exploração direta de atividades econômicas. Atualmente o poder de polícia deve ser visto muito mais como uma "ordenação social e econômica que tem por objetivo conformar a liberdade e a propriedade, por meio de prescrições ou induções, impostas pelo Estado ou por entes não estatais" (BINENBOJM, 2016, p. 71). A melhor questão a se colocar é: qual a razão o poder de polícia? A que ele se destina? A respostas a ser oferecida deve ser algo em torno do gozo ou fruição os direitos fundamentais e o:

[...] alcance de outros objetivos de interesse da coletividade, definidos pela via da deliberação democrática, de acordo com as possibilidades e os limites estabelecidos na Constituição. Cuida-se, assim, de um conjunto de 
regulações sobre a atividade privada, desvinculadas ou complementares a relações especiais de sujeição (estatutárias ou contratuais), dotadas ou não de força coercitiva, conforme o caso, que erigem um sistema de incentivos voltados à promoção de comportamentos socialmente desejáveis e ao desestímulo de comportamentos indesejáveis, de acordo com objetivos político-jurídicos predeterminados. Tem-se aqui o campo do chamado direito administrativo ordenador (grifos nossos) (BINENBOJM, 2016, p. 71).

A pandemia de COVID-19 trouxe novos e frutíferos elementos para a discussão a respeito dos limites da atuação estatal nos usos dados ao poder de polícia em comento. No entanto, conforme nossos grifos da longa citação de Binenbojm, é bastante lógico supor que o interesse da coletividade deve prevalecer sobre o interesse individual, inclusive direcionando a política pública e a atuação estatal em função desse princípio. Isto é, não se pode conceber uma atuação dos entes públicos que destoe dessa busca da defesa dos interesses coletivos. Na fotografia de uma pandemia, portanto, se espera do Poder Público uma atuação nesse sentido, não no contrário.

Trata-se de conceito operacional a ser empregado no exame das atividades de polícia passíveis de delegação ou não. A teoria do "ciclo" de polícia divide em quatro grupos as atividades compreendidas no exercício dessa função: a) ordem de polícia: previsão normativa a partir da qual vai ser exercida a atividade administrativa;

b) consentimento de polícia: ato administrativo que manifesta a aquiescência

da Administração com a conduta do particular, a ser produzido nos casos em que a lei estipula ser necessário;

c) fiscalização de polícia: verificação da observância das regras de polícia administrativa bem como a manutenção das condições que determinaram a manifestação do consentimento de polícia, nos casos em que este for cabível; e

d) sanção de polícia: imposição de medidas punitivas (NUNES JR. et al, 2017, p. 4).

Ocorre que duas faces desse interesse da coletividade foram opostas como antagônicas e como se representassem coisas opostas: de um lado defensores de políticas de cerceamento de determinadas liberdades individuais que tomam como interesse coletivo a saúde pública, o controle da pandemia e a redução do número de mortes e infecções; de outro lado defensores de liberdades individuais como de interesse coletivo, enfatizando abertura da economia e a liberdade de ir e vir. O ápice dessa dicotomia, que aparentemente é pura retórica, foi atingido quando o Governo Federal brasileiro se colocou num lugar de "impedido de atuar" pelo Poder Judiciário, posicionando-se ao lado daqueles que se declaravam contra 
políticas de cerceamento das liberdades comerciais e individuais, apostando numa suposta estratégia de "imunidade de rebanho"

Assim, a política pública seria uma obrigação do Estado agir sempre que um número considerável de pessoas fosse afligida por algo ou quando um pequeno grupo, mais representativo da sociedade, estivesse em perigo de ver seus direitos vilipendiados por algo que, como dito, seria um problema público (SECCHI, 2013, p. 10).

Para Souza (2006, p. 27), o encolhimento da capacidade estatal em promover medidas garantidoras sociais e fatores como globalização, a capacidade intervencionista estatal em promover políticas públicas e de governar, não estão devidamente comprovados de forma empírica. Contudo, é certo que o Estado Keynesiano posterior à 2a Guerra Mundial foi alvo medidas restritivas de gastos, em especial nos países em desenvolvimento, caso do Brasil, onde "[...] do ponto de vista da política pública, o ajuste fiscal implicou a adoção de orçamentos equilibrados entre receita e despesa e restrições à intervenção do Estado na economia e nas políticas sociais" (SOUZA, 2006, p. 20).

Mas essa abordagem positiva não é a única considerada pelas ciências. A omissão seria um componente importante na avaliação de uma política pública. Quando o Estado fica inerte diante de uma demanda, ele estaria agindo naquilo conhecido como comissivo por omissão. Deixando de agir, haveria a demonstração de uma vontade pública em manter o dito status quo, que pode ser entendido como a continuidade de uma determinada situação (SECCHI, 2013, p. 5).

De toda sorte, devemos considerar que a identificação de um problema e a consequente tomada de decisões em nível estratégico para solucionar um determinado dilema depende do ponto de vista do observador e de sua percepção quanto à conveniência ou não do ente público. Ou seja, para que uma demanda deve ensejar atitudes e converterse em política pública dependerá do projeto político e da linha de comportamento do grupo no momento ocupando cargos públicos (SECCHI, 2013, p. 23).

\footnotetext{
${ }^{1}$ Termo que define o momento em que a cadeia de transmissão de uma doença dentro de um grupo populacional é interrompida por se ter atingido um grande percentual de indivíduos já imunizados contra o agente infeccioso. Esta imunidade, ou resistência à infecção, pode ser adquirida pelos indivíduos que se recuperaram, após sofrer a doença, ou foram vacinados contra o agente causador.
} 
POLÍTICAS PÚBLICAS (D)E SAÚDE EM CAMPO GRANDE-MS NO CONTEXTO DA PANDEMIA DE COVID-19: APROXIMAÇÕES E DISTANCIAMENTOS COM DESEJOS E EXPECTATIVAS DA POPULAÇÃO
Gustavo Ribeiro Capibaribe Antônio Henrique Maia Lima

Nesse ponto, ao menos segundo a Ciência Política tradicional, mostraria a dependência das políticas públicas em relação política (politics), entendida como o enfrentamento, disputas de poder e resolução de interesses entre os atores.

Essa percepção mudou quando Theodoro J. Lowi afirmou que a política (politics) influencia políticas públicas (policies) tanto quanto estas influenciam aquelas. Na medida em que uma política pública é implantada, ou está em jogo, a estruturação dos conflitos, dos arranjos e do equilíbrio de poder se modificariam (SECCHI, 2013, p. 23).

Partindo dessa perspectiva, e visando a uma melhor análise das políticas públicas, firmou-se o conceito de tipologias, onde os elementos básicos destas são agrupados para a identificação do tipo a que ela pertenceria. Diversos são os pesquisadores que analisaram as políticas públicas e apresentaram modelos de compartimentação. Neste artigo destacamos as observações formuladas por Theodoro J. Lowi e por Gunnel Gustafsson.

Lowi apresentou inicialmente seu trabalho num artigo de $1964^{2}$, e seu critério de análise é o impacto esperado na sociedade. Existiriam quatro tipos de políticas públicas: Regulatórias, distributivas, redistributivas e constitutivas. Para os objetivos deste estudo as regulatórias e as constitutivas são as mais importantes para análises.

As políticas regulatórias seriam aquelas que determinariam comportamentos e padrões para os agentes públicos e privados. Este tipo de política tem seu desenvolvimento especialmente num contexto pluralista, onde a aceitação estaria vinculada desse gênero seria proporcional às relações de força dos atores e interesses em jogo. Podem ser incluídas neste meio as legislações relacionadas a temas da saúde pública, como aborto, eutanásia, fumo ou qualquer interferência no comportamento humano que se entenda como coletivo (SECCHI, 2013, p. 25).

Por sua vez, as do tipo constitutivas, também chamadas de meta-policies, por estarem supostamente acima dos outros três tipos, são aquelas regras sobre os poderes e sobre as próprias regras, ou seja, são as que definem competências, jurisdições e as regras de disputa política e de formulação das próprias políticas públicas. Mesmo provocando conflitos entre os entes federativos, raramente são notadas pelos destinatários finais dos serviços porque não tratam da execução em si, mas de quem executará.

\footnotetext{
${ }^{2}$ LOWI, T. J. American business, public policy, caso studies, and political theory, World Politics, v. 16, n. 4, p. 677-715, 1964.
} 
Por sua vez, Gustafsson a classificação da política pública se dá na relação existente entre a intenção dos policymakers e a capacidade científica disponível e de pessoal qualificado para realizar a consecução dos trabalhos.

Neste momento de incertezas científicas sobre o contexto pandêmico em que vivemos, onde a ciência ainda procura respostas satisfatórias ao agente patológico, e os agentes públicos devem dar respostas rápidas ao problema. O entendimento do que Gustafsson chama de pseudopolítica é importante. Agum, Riscado e Menezes (2015, p. 22) afirmam que:

A pseudopolítica que Gustafsson apresenta, trata das situações que o policymaker tem intenção de solucionar alguma questão por meio de uma política pública, mas a falta de conhecimento ou corpo técnico especializado inviabiliza seu estabelecimento. Existe a falta de capacidade para estruturar soluções que sejam adequadas ao problema.

Secchi (2013, p. 30), exemplifica que uma prefeitura ao criar um sistema viário para solucionar um problema de trânsito, sem valer-se de critérios técnicos, pautando-se em adequações políticas e "achismos" de seus atores, incorreria na pseudopolítica porque a intenção atenderia os princípios constitucionais da Administração Pública mas, por carência de tecnicidade, ali incorreria em erros. O quadro abaixo mostra bem esse envolvimento (SECCHI, 2013, p. 29).

Tabela 1 - Tipologia de Gustafsson

\begin{tabular}{|c|l|l|l|}
\hline \multicolumn{2}{|c|}{} & \multicolumn{2}{|c|}{ Disposição de implementar a política pública } \\
\cline { 3 - 4 } \multicolumn{2}{|c|}{} & \multicolumn{1}{|c|}{ Sim } & Não \\
\hline $\begin{array}{c}\text { Conhecimento para a } \\
\text { elaboração e implementação }\end{array}$ & Disponível & Política real & Política simbólica \\
\cline { 2 - 4 } & Indisponível & Pseudopolítica & Política sem sentido \\
\hline
\end{tabular}

A Constituição Federal de 1988 estipulou que os entes federativos, bem como toda administração direta e indireta destes seriam regidas por princípios administrativos, dentre os quais está o da eficiência.

É importante vermos que um agente estatal, diante de um problema público, não está apenas vinculado pela lei em sua atuação, mas também a um componente subjetivo, que é envidar esforços no sentido de que suas ações tenham um resultado concreto perante a demanda social em vista. 
Isto porque este princípio constitucional assim o exige. Os pensadores entendem que ser eficiente é um fazer/acontecer concreto, calcado em profissionalismo, onde governos legítimos e democraticamente eleitos traduzem suas promessas eleitorais em mudanças no mundo fenomênico (SOUZA, 2006, p. 26).

Quanto ao princípio da eficiência podemos dizer que o ordenamento jurídico censura a atuação amadorística do agente público, que, no exercício de sua função, deve imprimir incansável esforço pela consecução do melhor resultado possível e o máximo proveito com o mínimo de recursos humanos e financeiros (PINTO, 2008, p. 135).

Os problemas públicos são, desta forma, a vitrine de um determinado grupo no poder. Ao atender demandas sociais, cumpre sua função legal e garante, em tese, suporte político para se sustentar. Ao agir de forma preventiva e corretiva de acordo com as necessidades pode angariar frutos, em especial se realizar suas ações em momento de colapso.

Doenças são momentos muito especiais da vida na sociedade porque envolvem talvez o mais elementar dos direitos - o da vida. Nossos constituintes, em meados dos anos 80 do século $X X$, entenderam que o amparo nas moléstias é assegurado a todos. $O$ texto da Constituição Federal assim descreve esta obrigação:

Art. 196. A saúde é direito de todos e dever do Estado, garantido mediante políticas sociais e econômicas que visem à redução do risco de doença e de outros agravos e ao acesso universal e igualitário às ações e serviços para sua promoção, proteção e recuperação. (grifo nosso)

A crise sanitária provocada pela disseminação pandêmica de um vírus de fácil contágio, onde a eficiência médica foi posta à prova, é um ambiente de estudo capaz de apresentar como o Poder Público encarou o dilema e quais foram as respostas dadas. A característica da transfronteiricidade do patógeno levou os poderes locais, regionais, nacionais e globais a engajarem uma campanha de prevenção e tratamento, não ficando Campo Grande, no Mato Grosso do Sul fora deste conjunto. 


\section{CARACTERIZAÇÃO AMOSTRAL E PANORAMA GERAL DA RELAÇÃO QUESTIONÁRIO/ RESPONDENTES/RESPOSTAS}

O questionário inicia a série de perguntas solicitando a declaração de residência do respondente. Ao se declarar residente e domiciliado na cidade de Campo Grande automaticamente considera-se o respondente como apto a participar da pesquisa, tendo em vista que ele passa a ser considerado sujeito passivo da política pública implementada pela esfera de governo local. 93,61\% dos respondentes declararam preencher tal requisito. As demais respostas foram desprezadas para fins de análise dos dados, permanecendo um saldo de 44 (quarenta e quatro) respostas a serem analisadas.

É importante para fins de cruzamento dos dados determinar características estratégicas da amostra, ainda que não tenha sido em nenhum momento coletada qualquer informação que permitisse individualizá-la ou identificar os respondentes. Essas características consideradas estratégicas permite uma série de inferências no que diga respeitos às preferências, às sinergias, às semelhanças ou discrepâncias entre os grupos característicos, bem como o seu isolamento para fins de análise. Nesse sentido, questões menores, porém não menos importantes, podem ser respondidas, como, por exemplo, a discrepância (caso haja) entre os grupos etários quanto à determinada medida sanitária exigida pelo Poder Público para fins de controle da pandemia de COVID-19. Esses cruzamentos secundários serão feitos em trabalhos posteriores, uma vez que, no presente, busca-se identificar tão somente se a amostra aprovou ou desaprovou as medidas tomadas até o momento no contexto daquilo que chamamos de "políticas públicas de saúde no combate à COVID-19 na cidade de Campo Grande - MS.

Uma primeira caracterização estratégica da amostra pode ser feita quanto a idade dos respondentes. Conforme a Figura 1 (abaixo) as faixas etárias foram divididas em 6 (seis) grupos com extensões distintas de idade. O grupo mais estreito é o que se estende dos 19 (dezenove) aos 25 (vinte e cinco) anos de idade e abarcando 7 (sete) anos, enquanto os mais largos são os que se estendem entre 61 (sessenta e um) anos ou mais e os entre 46 (quarenta e seis) e 60 (sessenta) anos, compreendendo este último um lastro de 15 (quinze) anos. As faixas intermediárias reúnem extensões etárias de 10 (dez) anos cada. A distribuição do total de respostas válidas entre esses grupos se encontra detalhada abaixo. 
POLÍTICAS PÚBLICAS (D)E SAÚDE EM CAMPO GRANDE-MS NO CONTEXTO DA PANDEMIA DE COVID-19: APROXIMAÇÕES E DISTANCIAMENTOS COM DESEJOS E EXPECTATIVAS DA POPULAÇÃO
Gustavo Ribeiro Capibaribe Antônio Henrique Maia Lima

Figura 1: Gráfico: Distribuição da amostra por faixas-etárias

\begin{tabular}{|c|c|}
\hline Faixas etárias & Respostas \\
\hline - Oa. 78 anos: & 3. \\
\hline () 19.25 anos: & 2 \\
\hline - 26,35 anos; & 6 \\
\hline - $36 \mathrm{~s} 45$ anos & 9 \\
\hline - 46 a 60 anas & 16 \\
\hline (-) mas de 00 aros. & 8 \\
\hline
\end{tabular}

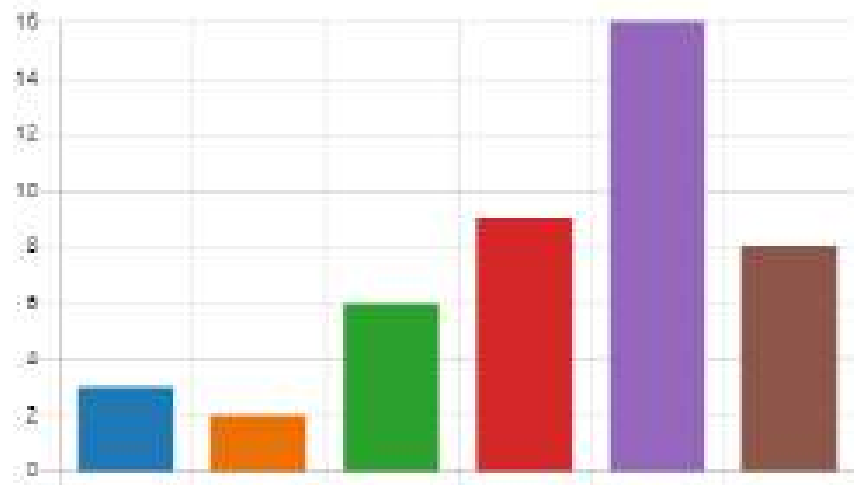

A segunda característica estratégica considerada é a faixa de renda dos respondentes. Ela permite o entrecruzamento de questões socioeconômicas e de classe relevantes e pertinentes ao contexto da pandemia no município sob análise. Embora haja uma distribuição mais proporcional entre as faixas de renda (figura 2) que a distribuição entre as faixas etárias, é notável que cerca de $57 \%$ da amostra se enquadra na faixa de renda superior a cinco salários-mínimos mensais. Com isso, é possível associar, pelo menos numa análise preliminar, esse dado com o dado do recorte anterior de que $55 \%$ dos respondentes têm mais de 46 (quarenta e seis) anos de idade, o que sugere que pouco mais da metade se encontra num momento de relativa maturidade e estabilidade financeiras. Tal conclusão possibilita um recorte imediato da amostra em dois grupos principais e próximos em números: um com faixa etária de até 45 (quarenta e cinco) anos e renda média inferior a 5 (cinco) salários-mínimos e outro com faixa etária de mais de 45 (quarenta e cinco) anos de idade e renda média superior a 5 (cinco) salários-mínimos.

Figura 2: Gráfico: Distribuição da amostra por faixas de renda

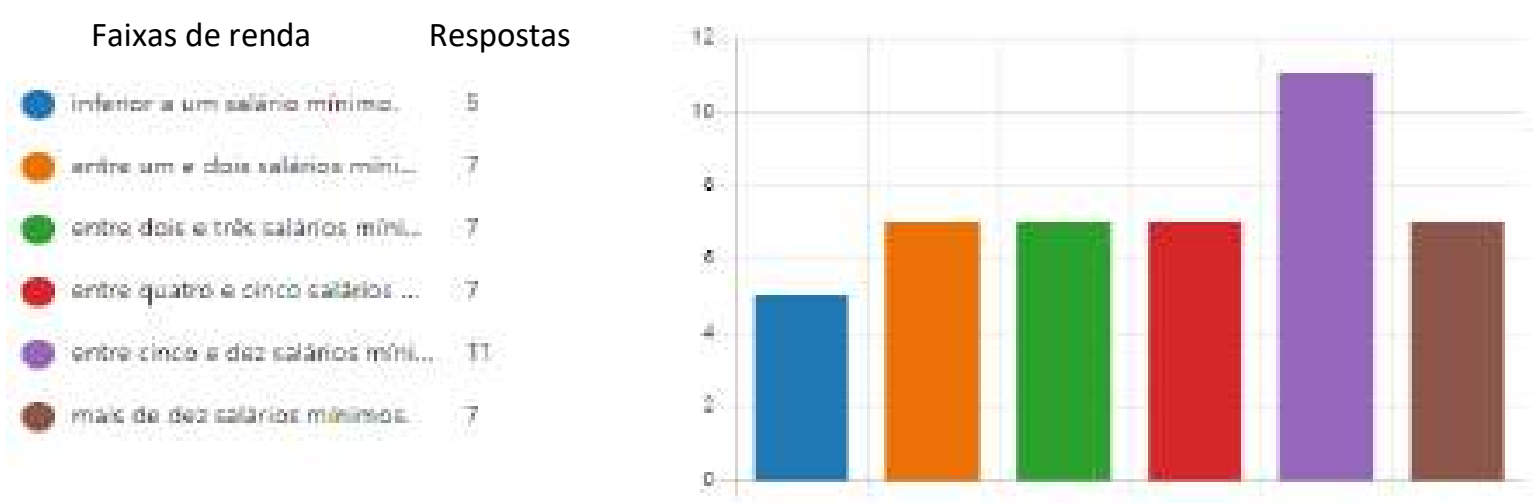


POLÍTICAS PÚBLICAS (D)E SAÚDE EM CAMPO GRANDE-MS NO CONTEXTO DA PANDEMIA DE COVID-19: APROXIMAÇÕES E DISTANCIAMENTOS COM DESEJOS E EXPECTATIVAS DA POPULAÇÃO
Gustavo Ribeiro Capibaribe Antônio Henrique Maia Lima

Como já dito, com essas duas características consideradas estratégicas, idade e renda, será possível pormenorizar à razão das mesmas os dados brutos coletados numa série de recortes de interesse. Por enquanto os dados serão afunilados e direcionados para o objetivo deste artigo. Porém, algumas informações parecem ser fundamentais e dignas de publicidade, ainda que não profundamente analisadas nesta oportunidade. Uma dessas informações é a relação da amostra com a própria doença - COVID-19: 25\% ou 1/4 (um quarto) dela declarou ter sido contaminado ao menos uma vez pelo SARS/COV-2 e contraído COVID-19. Se comparada às estatísticas municipais, Campo Grande - MS possui registro até 18/07/2021 de 124.060 (cento e vinte e quatro mil e sessenta) casos confirmados. Com uma população de 906.092 (novecentos e seis mil e noventa e dois) (IBGE, 2020) habitantes, a proporção de contaminados em relação à população do município é de pouco mais que $13,69 \%$, o que implica em uma diferença de quase $50 \%$, sugestiva de subnotificação da doença. Tal inferência é fortalecida pelo fato de que absolutamente todos os respondentes conhecem ao menos uma pessoa que foi oficialmente diagnosticada com a doença nos últimos 12 (doze) meses.

A Figura 3 apresenta pormenorizadamente quantas pessoas diagnosticadas com COVID-19 cada um dos participantes conheceu. É da ordem de $75 \%$ a quantidade de respondentes que conhece no mínimo 6 (seis) diagnosticados. E de 29,5\% a quantidade que conhece mais de 20 (vinte) diagnosticados, apontando ainda mais para a subnotificação de casos no município.

Figura 3: Gráfico: Número de diagnosticados por COVID-19 que os respondentes afirmam conhecer

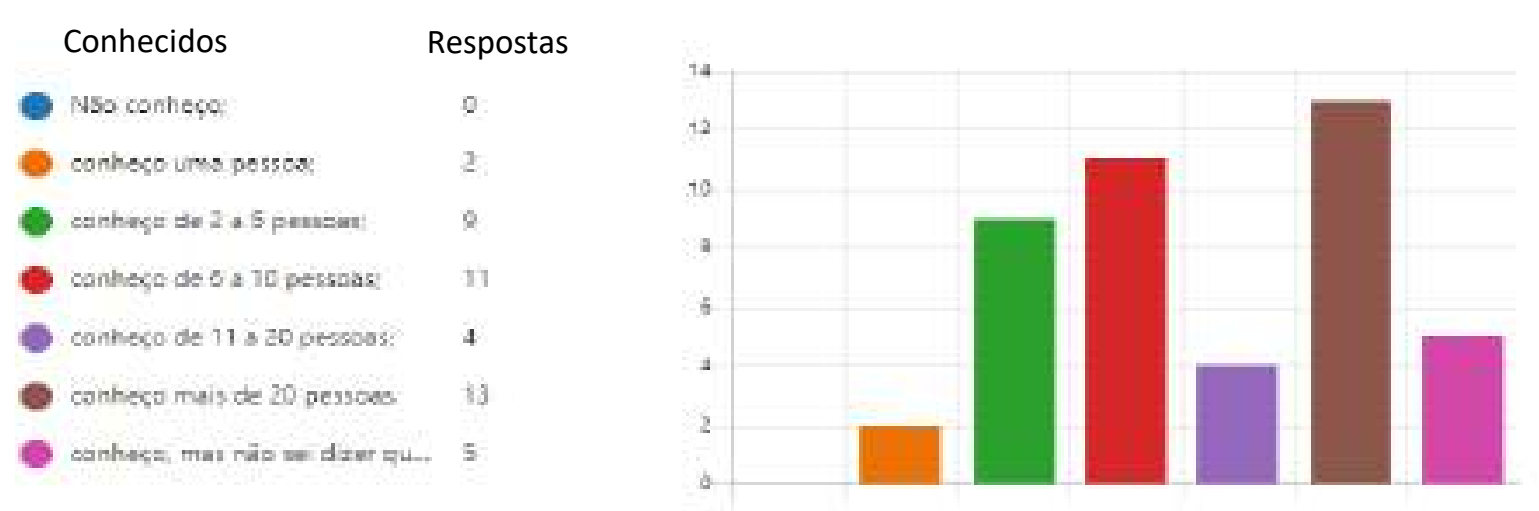


POLÍTICAS PÚBLICAS (D)E SAÚDE EM CAMPO GRANDE-MS NO CONTEXTO DA PANDEMIA DE COVID-19: APROXIMAÇÕES E DISTANCIAMENTOS COM DESEJOS E EXPECTATIVAS DA POPULAÇÃO
Gustavo Ribeiro Capibaribe Antônio Henrique Maia Lima

Dando continuidade à caracterização amostral, mostrou-se relevante também ao menos mensurar a realidade dos participantes quanto à sua proximidade de pessoas que vieram a óbito por COVID-19. Não foi especificado no instrumento de pesquisa, no entanto, se o óbito em questão se referia tão somente as mortes diretas por essa doença ou a chamada "COVID tardia" ou ainda "COVID persistente". No primeiro caso os pacientes graves de COVID19 vêm a óbito por complicações derivadas da doença, estando, a rigor, curados dela. No segundo caso sintomas prolongados por semanas ou meses que se agravam, tais como síndromes respiratórias agudas, problemas de ordem neurológica, fadiga crônica etc. 0 instrumental se referia a mortes pela doença ou "complicações relacionadas a ela". Do universo de respondentes, apenas 4,25\% não conhece nenhuma pessoa que tivesse morrido em tais circunstâncias. Na Figura 4 (abaixo) é possível observar de forma detalhada e por faixas quantitativas essa relação. Ressalta-se que não foi possível por intermédio do instrumental de pesquisa detalhar se as pessoas conhecidas pelos participantes da pesquisa que vieram a óbito ou foram diagnosticados positivamente se sobrepunham, isto é, se em algum momento mais de um respondente se referia a um mesmo conhecido. No entanto, dadas as dimensões da cidade de Campo Grande - MS, é possível que tenha ocorrido em alguma medida tal coincidência.

Figura 4: Gráfico: Quantidade de mortes por COVID-19 que os respondentes afirmam conhecer
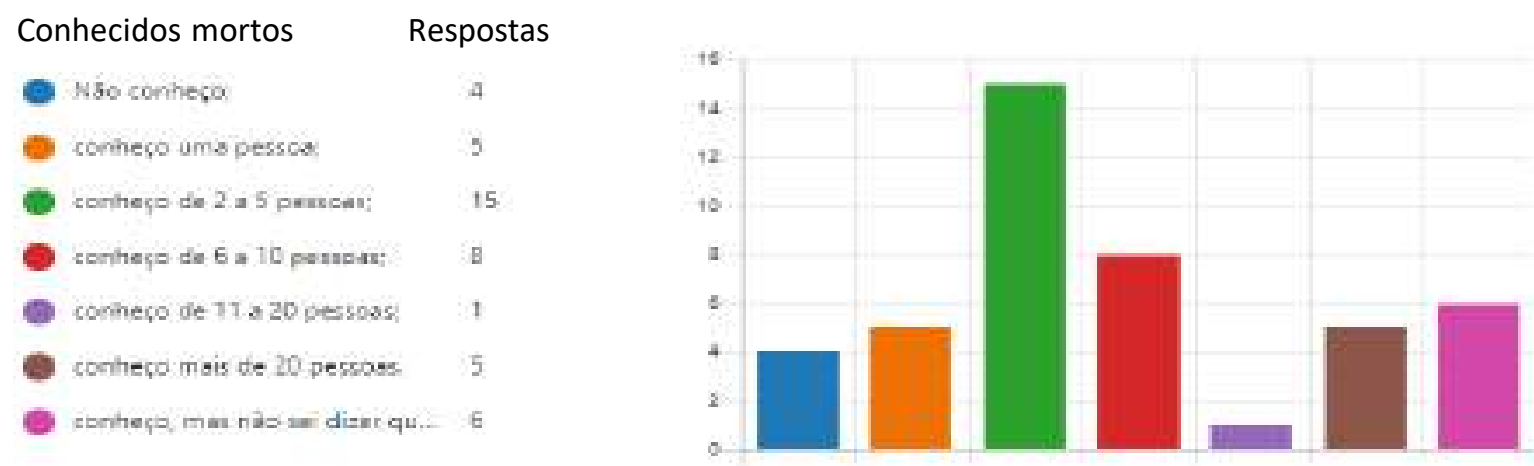

Conforme demonstrado a amostragem é multifacetada, no entanto, é possível traçar pelo menos dois perfis distintos (aproximadamente duas metades) a partir de cada um dos dois primeiros critérios. Uma parcela de renda média elevada, outra de renda média mais baixa. Uma parcela de idade média acima de 45 (quarenta e cinco) anos, outra de idade média 
POLÍTICAS PÚBLICAS (D)E SAÚDE EM CAMPO GRANDE-MS NO CONTEXTO DA PANDEMIA DE COVID-19: APROXIMAÇÕES E DISTANCIAMENTOS COM DESEJOS E EXPECTATIVAS DA POPULAÇÃO
Gustavo Ribeiro Capibaribe Antônio Henrique Maia Lima

abaixo. No que toca aos demais critérios (Figuras 3 e 4) vê-se uma constante na relação da amostra com diagnosticados e com mortos por COVID-19.

\section{CONVERGÊNCIAS E DIVERGÊNCIAS ENTRE POLÍTICAS ADOTADAS/IMPLEMENTADAS E A OPINIÃO DA AMOSTRA}

Em determinado momento o instrumental se volta para a tentativa de diagnosticar as concordâncias ou discordâncias entre as opiniões proferidas pela mostra e as medidas efetivamente adotadas/implementadas pelo município com vistas ao combate à pandemia de COVID-19. Com esse objetivo em mente foram apresentadas 17 (dezessete) medidas tomadas ao longo de março de 2020 e março de 2021. Assim, inquiriu-se os participantes: "Com as questões abaixo gostaríamos de saber seu grau de concordância com as medidas de biossegurança adotadas como objetivo de controlar a pandemia de COVID-19 pela Prefeitura Municipal de Campo Grande. Sendo 5 o grau máximo de concordância e 1 o grau máximo de discordância. O "índice 3" é o ponto intermediário, onde não há concordância nem discordância, mas há uma disposição em concordar.

É digno de destaque que as medidas mais rejeitadas pelos respondentes são o fechamento do comércio (seja parcial, seja total) e as medidas de restrição de locomoção por transporte público, tais como a diminuição da quantidade de ônibus em circulação e o fechamento dos terminais de transporte coletivo nos finais de semana e feriados. Nas questões abertas, inclusive, a principal recomendação da amostra é justamente a ampliação dessa quantidade, com fins a maior dispersão dos usuários, diminuindo assim a concentração e aglomeração. Segundo os respondentes essa medida é excludente, na medida que as pessoas de classe social mais alta, por se locomoverem em veículos particulares ou utilizarem serviços privados de transporte, como aplicativos ou táxi, não têm maiores restrições a sua locomoção. Nesse aspecto, nos meses em que houve a adoção dessas práticas por parte da concessionária de transporte coletivo público sob endosso da Prefeitura Municipal de Campo Grande, os respondentes entendem que houve certo oportunismo por parte do serviço em "economizar" às custas dessas restrições, bem como uma espécie de segregacionismo social, segundo o qual, a população mais pobre, dependente de transporte coletivo público, se via 
forçada a permanecer sem a possibilidade de deslocamento, enquanto a população mais rica não.

No outro extremo, isto é, dentre as medidas que mais contam com a concordância da amostra verifica-se a separação nos pontos de atendimento de saúde dos casos suspeitos e confirmados de COVID-19, uso de máscara, distanciamento social, diminuição de lotação máxima em ambientes de uso coletivo e a vacinação. É salutar também que, embora a Organização Mundial de Saúde e diversos profissionais e órgãos de saúde não recomendem ou mesmo proíbam o uso de medicamentos para tratamento preventivo ou precoce da COVID-19, tais como os que compõem o chamado "Kit Covid", como, cloroquina, ivermectina, azitromicina, zinco, dentre outros, $54,5 \%$ dos respondentes concorda com o uso desses medicamentos que não possuem nenhuma comprovação científica de efetiva atuação positiva no combate à doença.

Figura 5: Gráfico: Escala de concordância/discordância com relação as medidas adotadas pelo município

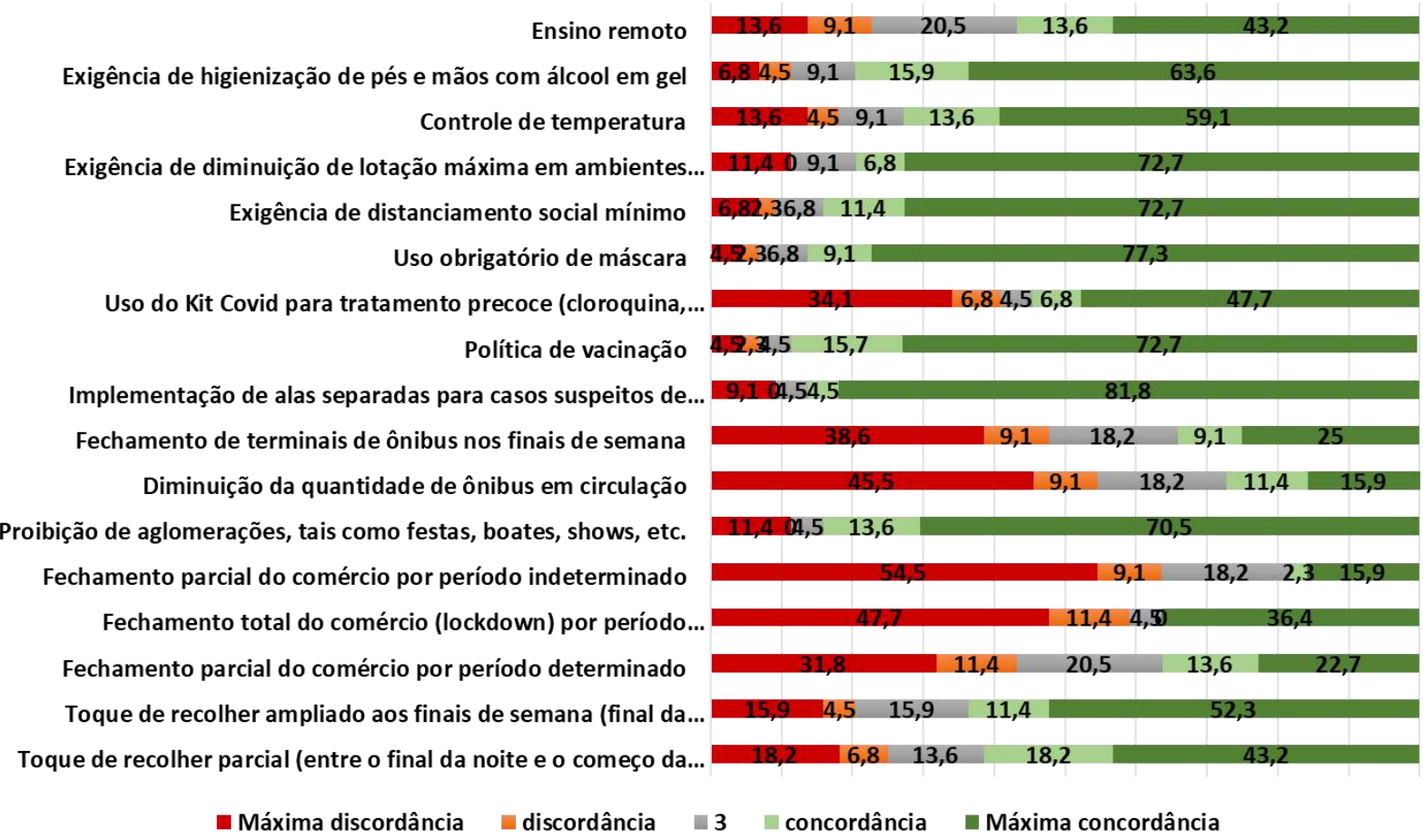

Inquiriu-se também os participantes da pesquisa o sobre grau de disposição para a prática das medidas de biossegurança adotadas como objetivo de controlar a pandemia de COVID-19. Foram listadas no instrumental as medidas adotadas como política pública de 
combate à pandemia no contexto de uma dupla atuação que se entrelaçaram ao longo do período de análise, uma do Estado de Mato Grosso do Sul e outra da Prefeitura Municipal de Campo Grande. Ao longo dos últimos meses uma crise institucional se fez sentir no Brasil, dizendo respeito ao papel de cada ente federativo na adoção de medidas de controle e combate a pandemia de COVId-19, que foi sentida em todo território nacional. Isto porque, o Supremo Tribunal Federal (STF) reconheceu em abril de 2020 a competência concorrente de estados, Distrito Federal, municípios e União no combate à COVID-19.

De modo bastante resumido e talvez não tão preciso, com a decisão acima relatada o Governo Federal posicionou-se como impedido ou desobrigado de adotar efetivas medidas de combate a pandemia, indo contra a própria orientação da suprema corte de que caberia à União organizar, dirigir e protagonizar as ações de combate, respeitando a autonomia aos demais entes federativos estabelecida pela Constituição Federal. Nesse sentido, os ministros do STF se referiram ao fato de que, dada a configuração jurídico-política do Brasil como Federação, sua dimensão e a multifacetada distribuição da doença pelo território nacional, municípios, estados e o Distrito Federal poderiam adotar medidas mais duras dentro dos limites de sua atuação institucional e jurisdicional.

No Mato Grosso do Sul , foi estabelecido o Sistema Prosseguir Decreto № 15.462, de 25 de junho de 2020:

[...] Nesta direção, o Governo do Estado do Mato Grosso do Sul, com o apoio técnico da Organização Pan-Americana de Saúde (OPAS/OMS), criou o Programa de Saúde e Segurança na Economia (PROSSEGUIR), com o objetivo de estruturar um método baseado em dados, informações e indicadores capazes de nortear os diversos agentes da sociedade, principalmente os entes públicos, a tomarem suas decisões e tornarem suas ações mais eficientes no combate à propagação e aos impactos da COVID 19 em nosso Estado. [...] Para contribuir nesta direção, o Programa Prosseguir trata simultaneamente diferentes áreas afetadas pela pandemia. Aqui se verá a abordagem sanitária - de saúde - associada diretamente à segurança das atividades econômicas, não apenas para mitigar a doença, mas também e especialmente evitar a todo custo medidas ainda mais drásticas e restritivas, como o lockdown. [...] (PROSSEGUIR, 2021).

O Sistema Prosseguir vincula odos os municípios do Estado de Mato Grosso do Sul e classifica-os em "faixas de cores" a depender o grau de risco que cada um experimenta no período em análise. Cada uma dessas faixas de cor possui sua própria lista de atividades que podem ou não podem ser desempenhadas, bem como as medidas que devem ser tomadas 
para fins de proteção da doença. Nesse sentido, a classificação de risco da macrorregião e do município é atribuída da seguinte forma: a) Bandeira Preta: funcionamento unicamente das atividades essenciais; b) Bandeira Vermelha: atividades citadas no subitem 4.2.2.1.1, adicionada das atividades não essenciais de baixo risco; c) Bandeira Laranja: atividades citadas no subitem 4.2.2.1.2, adicionada das atividades não essenciais de médio risco; d) Bandeira Amarela: atividades citadas no subitem 4.2.2.1.3, adicionada das atividades não essenciais de alto risco; e) Bandeira Verde: atividades citadas no subitem 4.2.2.1.4 adicionada das atividades não recomendadas ${ }^{3}$.

Figura 6: Gráfico: grau de disposição para a prática das medidas de biossegurança adotadas como objetivo de controlar a pandemia de COVID-19 Permanecer em casa, saindo dela apenas para atividades
essenciais, tais como, trabalhar, ir ao médico, farmácia ou
mercado

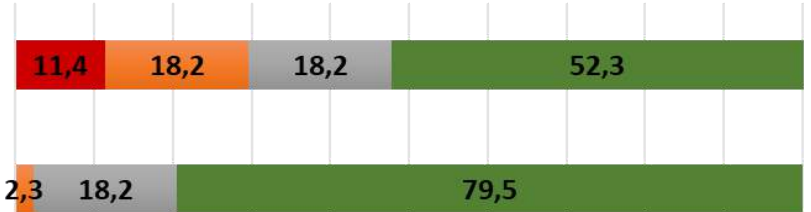

Uso de álcool em gel.

Distanciamento social.

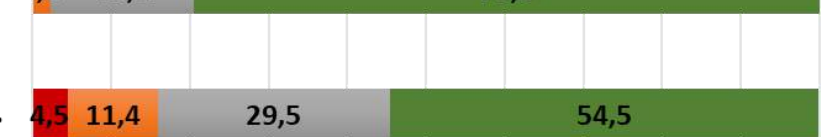

Uso de máscara.

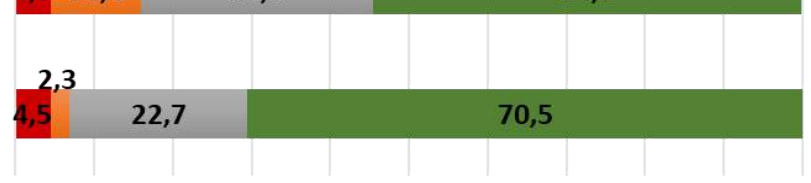

não estou disposto(a) $\quad$ Pouco disposto(a) $\quad$ Disposto(a) $\square$ Muito disposto(a)

De acordo com a figura acima, as chamadas "medidas básicas" para a prevenção e combate a disseminação da COVID-19 foram amplamente defendidas pela amostra, dado que para todas elas a maioria dos respondentes se disse disposta a praticar. As duas que, no entanto, obtiveram menos índice de disposição foram, justamente, as que impõem limitação à locomoção ou interação, como a permanência em casa por períodos maiores que o habitual e o distanciamento social.

\footnotetext{
${ }^{3}$ Os itens referenciados pelas faixas são da DELIBERAÇÃO DO COMITÊ GESTOR DO PROGRAMA DE SAÚDE E SEGURANÇA DA ECONOMIA (PROSSEGUIR) Nº 1, DE 2 DE JULHO DE 2020
} 
POLÍTICAS PÚBLICAS (D)E SAÚDE EM CAMPO GRANDE-MS NO CONTEXTO DA PANDEMIA DE COVID-19: APROXIMAÇÕES E DISTANCIAMENTOS COM DESEJOS E EXPECTATIVAS DA POPULAÇÃO
Gustavo Ribeiro Capibaribe Antônio Henrique Maia Lima

\section{CONSIDERAÇÕES FINAIS}

Este trabalho abordou iniciativas e ações públicas como uma obrigação do Estado, diferenciando o termo política das políticas públicas, entendidas estas como as decisões governamentais destinadas a algum objetivo específico, estando estas influenciadas por diversões elementos, sendo eles ideológicos, interesses individuais e a possibilidade ou não de determinada medida ser eficazmente implantada, o que torna a política pública como algo central de determinada gestão governamental.

As questões de saúde, por suas características transpessoais, ensejam a atuação do Estado em sua função de poder de polícia com o propósito de, sobretudo nos momentos pandêmicos como os vivenciados na confecção do artigo, resguardar os direitos coletivos à redução do perigo de contágio e possibilitar o incremento de medidas terapêuticas eficientes.

A pesquisa realizada apresentou uma diversidade de situações, tendo participantes de várias faixas etárias e renda. Foi perceptível que, a despeito da condição pessoal de cada entrevistado, o alcance social da moléstia não foi por igual. Durante o cotejamento dos dados apurados com o questionário proposto, e tendo como objetivo investigar a concordância ou não das medidas implementadas pelos governos em termos de controle da disseminação da doença, as respostas não foram absolutamente coesas, apresentando opiniões diversas. No entanto, restou demonstrado que a amostra "concorda" com boa parte das medidas implementadas na cidade de Campo Grande como políticas de contenção do contágio da COVID-19 e se mostra "disposta" a segui-las ou cumpri-las, especialmente aquelas mais básicas e, surpreendentemente, pouco mais da metade aprova o uso de medicamentos sem comprovação científica de eficácia no combate à doença. Também restou demonstrado que a maior parte da amostra se posiciona como "discordante" em relação as medidas de fechamento do comércio, bem como da redução de ônibus e fechamento de terminais de transporte coletivo.

Com esses dados em tela outros vieses de análise certamente se justificam, bem como outras questões ou problemas de pesquisa futuras. O material é rico e possibilita o entrecruzamento enfoques e de dados coletados em outras pesquisas, abrindo um fértil campo de pesquisa para o futuro pós-pandemia. 


\section{REFERÊNCIAS}

AGUM, Ricardo; RISCADO, Priscila e MENEZES, Monique (2015). Políticas Públicas: Conceitos e Análise em Revisão. Revista Agenda Política, Vol. 3, n. 2, jul/dez 2015, ISSN: 2318-8499, p. $12-42$.

BINENBOJM, Gustavo. Poder de polícia, ordenação, regulação: transformações políticojurídicas, econômicas e institucionais do direito administrativo ordenador. Belo Horizonte: Fórum, 2016.

BRUGGER, Walter. Dicionário de Filosofia. Tradução de Antônio Pinto de Carvalho. 2a a ed. São Paulo: Editôra Herde, 1969.

CARNOY, Martin. Estado e teoria política. Tradução equipe de tradutores do Instituto de Letras da Puccamp. 4a ed. Campinas: Papirus, 1994.

FREY, Klaus. Políticas públicas: um debate conceitual e reflexões referentes à prática da análise de políticas públicas no Brasil. Planejamento e Políticas Públicas (IPEA). 2009 Disponível EM: https://www.ipea.gov.br/ppp/index.php/PPP/article/view/89 Acesso em: 07/2021.

IBGE (Instituto Brasileiro de Geografia e Estatística (2020). IBGE Cidades - Campo Grande. Disponível em: https://www.ibge.gov.br/cidades-e-estados/ms/campo-grande.html. Acesso em: 07/2021.

JOHNS HOPKINS UNIVERSITY \& MEDICINE. Coronavirus Resource Center. Disponível em: https://coronavirus.jhu.edu/map.html Acesso em: 08/2021.

MINAYO, Maria Cecília de Souza (org.). Pesquisa social: teoria, método e criatividade. 6. ed. Petrópolis, RJ : Vozes, 2007

NUNES JR, Vidal Serrano (coord.). Enciclopédia Jurídica da PUCSP, tomo II (recurso eletrônico): direito administrativo e constitucional / coord. Vidal Serrano Nunes Jr. [et al.] - São Paulo: Pontifícia Universidade Católica de São Paulo, 2017.

PINTO, Alexandre Guimarães Gavião. Os princípios mais relevantes do Direito Administrativo. Revista da EMERJ, v. 11, no 42, abr/maio/jun, 2008, ISSN 1415-4951, p. 130141.

SECCHI, Leonardo. Políticas Públicas: Conceitos, esquemas, casos práticos. 2a. ed. São Paulo: Cengage Learning, 2013.

SOUZA, Celina. Políticas Públicas: uma revisão da literatura. Sociologias, Porto Alegre, ano 8, no 16, jul/dez 2006, p. 20-45. 


\title{
ANÁLISE SOBRE AS AÇÕES DE RECUPERAÇÃO DAS JAZIDAS DO PROJETO “EÓLICAS DE CASA NOVA"
}

\author{
Cícero Natanael de Oliveira Silva \\ Mestre em Administração e Desenvolvimento Rural pela Universidade Federal Rural de \\ Pernambuco (UFRPE/PADR). \\ cicerooliveirasilva@gmail.com \\ Romilson Marques Cabral \\ Doutor em Administração pela Universidade Federal da Bahia (UFBA), Salvador, BA, Brasil \\ romilsonmarquescabral10@gmail.com \\ José Lincoln Pinheiro Araújo \\ Doutor em Ingeniero Agronomo pela Universidad de Córdoba (UCO), Córdoba, Espanha \\ lincoln.araujo@embrapa.br \\ Rebert Coelho Correia \\ Mestre em Economia Rural pela Universidade Federal do Ceará (UFC), Fortaleza, CE, Brasil \\ rebert.correia@embrapa.br
}

\section{RESUMO}

A geração comercial de energia eólica causa impactos ao meio ambiente e à população residente nas proximidades dos parques eólicos (DUTRA, 2001; CASTRO, 2009; STAUT, 2011; MENDES, 2016). Por isto, os órgãos ambientais exigiram a realização de ações mitigatórias para a obra da Central Geradora Eólica de Casa Nova. A Chesf, Embrapa e outras instituições elaboraram e executaram o Projeto "Ações de Desenvolvimento para Produtores Agropecuários do Entorno do Parque Eólico de Casa Nova - BA", e um objetivo foi reflorestar com caatinga a área onde houve a retirada de material utilizado na construção. Este trabalho objetivou responder: Quais os efeitos da recuperação das áreas de jazidas do Projeto "Eólicas de Casa Nova" sobre a vida dos agricultores? Através de relatórios e entrevistas semiestruturadas foi identificada a satisfação dos agricultores com as atividades desenvolvidas, sendo a perfuração de poços artesianos nas propriedades considerada o principal benefício do Projeto.

Palavras-chave: Agricultura Familiar; Caatinga; Desenvolvimento; Parque Eólico; Reflorestamento. 


\begin{abstract}
ANALYSIS ABOUT RECOVERY ACTIONS OF THE FIELDS OF THE PROJECT “EÓLICAS DE CASA NOVA"

The commercial generation of wind energy causes impacts to the environment and the population residing in the vicinity of wind farms (DUTRA, 2001; CASTRO, 2009; STAUT, 2011; MENDES, 2016). So, the environmental agencies demanded the realization of mitigating actions for the work of the Central Geradora Eólica de Casa Nova. Thereat, Chesf, Embrapa and other institutions elaborated and executed the Project "Ações de Desenvolvimento para Produtores Agropecuários do Entorno do Parque Eólico de Casa Nova - BA", and one objective was reforest with caatinga the area where was removed the material used in the construction. This work aimed to answer: What are the effects of the recovery of the fields of the "Eólicas de Casa Nova" Project on the lives of farmers? Through reports and semi-structured interviews the satisfaction of farmers with the activities was identified and the drilling of artesian wells was considered the main benefit of the Project.
\end{abstract}

Keywords: Family Farming; Caatinga; Development; Wind Farm; Reforestation. 


\section{INTRODUÇÃO}

A geração de energia elétrica no Brasil é predominantemente realizada por hidrelétricas. Esta fonte é considerada renovável, no entanto causa um significativo impacto à região de implantação, ocupando um grande espaço com a usina e com o represamento de água. Em vista disso, emerge a necessidade de gerar energia por fontes que, além de renováveis, resultem em um dano menos expressivo à localidade de implantação.

Mesmo representando mais que a metade da geração comercial de energia no País, nas últimas décadas, principalmente a partir de 1990, a hegemonia hidrelétrica foi dividindo espaço com outras fontes. Uma alternativa que obteve crescimento neste período foi a fonte eólica, que foi impulsionada pela necessidade de diversificação da matriz brasileira diante da crise energética que ocorreu em meados dos anos 2000. Esta crise resultou em um período de frequente falta de energia elétrica em todo o território nacional (STAUT, 2011).

Em meio à crise, o argumento que a fonte eólica seria um bom investimento sob a perspectiva renovável e sustentável foi fortalecido e resultou no crescimento de 780 vezes na capacidade instalada no Brasil, considerando o período entre os anos de 2005 e 2020 (MEDEIROS JÚNIOR, 2018; ABEEÓLICA, 2020).

Entretanto, mesmo considerando o potencial sustentável, Castro (2009) salienta que um empreendimento eólico, como qualquer outro para fim comercial, também causa impactos ao meio ambiente e à população da localidade entorno da área de instalação. Por este motivo, os órgãos ambientais definem condições para a implantação dos parques eólicos.

A condicionante que os órgãos ambientais impõem tem o intuito de ampliar o impacto positivo e diminuir e/ou eliminar o negativo. As mudanças ocorridas em uma localidade onde é construído um parque eólico são diversificadas (STAUT, 2011; MENDES, 2016; MEDEIROS JÚNIOR, 2018; VECCHIA, 2019) e podem representar benéficos ou malefícios para os moradores do local.

Na implantação da Central Geradora Eólica (CGE) de Casa Nova (BA), as mudanças facilmente identificadas foram o desmatamento da caatinga, a perfuração do solo (jazida) para a retirada de material e o aumento no fluxo de pessoas. Com isso, houve a necessidade da realização de um programa de compensação do impacto da construção do parque eólico.

Sendo assim, a Companhia Hidro Elétrica do São Francisco (Chesf) - responsável pelo empreendimento - estabeleceu parceria com a Empresa Brasileira de Pesquisa Agropecuária (Embrapa) e organizações locais para a realização de ações mitigadoras na localidade. Esta colaboração resultou na elaboração e execução do Projeto intitulado "Ações de Desenvolvimento Para Produtores Agropecuários do Entorno do Parque Eólico de Casa Nova - BA", iniciado em janeiro de 2018 e com o 
término definido para dezembro de 2020, que busca, entre outros objetivos, reflorestar com caatinga as áreas onde houve a retirada do material utilizado na construção.

Com a execução do Projeto, este trabalho justificou-se pelo interesse em compreender a influência do processo de expansão dos parques eólicos sobre as populações locais, e teve o objetivo de responder: Quais os efeitos da recuperação das áreas de jazidas do Projeto "Eólicas de Casa Nova" sobre a vida dos agricultores?

Para alcançar este propósito foi realizada uma abordagem sob a perspectiva dos moradores que tiveram suas propriedades atingidas pela construção do empreendimento. $O$ interesse em abordar as percepções deste grupo é pelo entendimento que elas descrevem experiências vivenciadas pelo mesmo e que podem influenciar seus sentidos, pois são consideradas como conhecimentos empíricos (CHAUI, 2000; TOSETTO, 2005; ROCHA et al., 2016).

Com o entendimento sobre as possibilidades na abordagem direta aos agricultores, esta foi utilizada para compreender a dinâmica em torno do objeto da presente pesquisa. Alcançado esta finalidade, o trabalho pode contribuir para ampliar o conhecimento acerca das demandas das populações locais em relação à execução de um projeto que visa realizar ações de recuperação ambiental e desenvolvimento local.

\section{DESENVOLVIMENTO}

\subsection{ENERGIA EÓLICA E PARQUES EÓLICOS NO BRASIL}

A geração de energia eólica para fim comercial no Brasil teve início no ano de 1992, a partir da instalação de um aerogerador no arquipélago de Fernando de Noronha - PE, que também foi o primeiro na América Latina. O empreendimento ocorreu por meio da parceria entre o Centro Brasileiro de Energia Eólica (CBEE) e a Companhia Energética de Pernambuco (CELPE), financiado pelo Instituto Folkecenter (Dinamarca) e com capacidade de gerar 225 kilowatt (kW) (ABEEÓLICA, 2020).

O interesse pela utilização da fonte eólica cresceu por ela ser considerada menos agressiva ao ambiente, em comparação às hidrelétricas (SANTOS, 2015), e devido à sua baixa emissão de gás carbônico no processo de fabricação e de implantação, além de não emitir poluentes durante a operacionalização das torres, contribuindo "para que o Brasil cumpra seus objetivos no Acordo do Clima" (ABEEÓLICA, 2018, p. 16).

A fonte eólica ganhou destaque nas últimas décadas devido às suas características de funcionamento e pelo potencial de geração no País, impulsionando o desenvolvimento de novas tecnologias para os aerogeradores. Este crescimento foi impulsionado por um discurso fortemente associado à necessidade de fonte alternativa, renovável e competitiva, que atenda aos parâmetros 
sustentáveis e auxilie as necessidades de consumo e produção da sociedade (LIMA, 2018; MEDEIROS JÚNIOR, 2018).

Diante dos benefícios destacados, Medeiros Júnior (2018) reconhece o papel importante que os movimentos ambientalistas tiveram dentro do contexto, mas enfatiza que não se deve pensar que todo o esforço voltado para o crescimento da geração de energia eólica foi impulsionado pela preocupação do Governo e da sociedade com as questões ambientais. Para o autor, entre os fatores determinantes estão a perspectiva de lucro para os investidores e o colapso na exploração do petróleo, ou seja, "o que determinou estes movimentos na tecnologia dos aerogeradores foram os fatores econômico, políticos e sociais" (MEDEIROS JÚNIOR, 2018, p. 31).

\subsection{ENERGIA EÓLICA NA BAHIA E EM CASA NOVA}

No cenário brasileiro de geração de energia eólica, o Nordeste se destaca pelas condições favoráveis que oferece para este modelo de produção energética. Na perspectiva de Aragão, Albuquerque e Santos (2016), o Estado da Bahia é referenciado por possuir ótimas condições geográficas e ambientais para a instalação de empreendimentos eólicos, principalmente em três aspectos: (1으) a velocidade elevada e estável dos ventos - que também ocorre nos demais estados nordestinos; (2ํ) a extensão territorial - sendo o maior estado da região e um vasto campo para implantação de parques eólicos; e (3ํ) é o estado nordestino mais próximo ao Sudeste - que é a maior consumidora energética do País e uma potencial compradora, facilitando a logística e diminuindo o custo de transmissão.

O maior potencial de geração na Bahia está localizado nas regiões interioranas, pois no seu litoral, os ventos não possuem as mesmas forças se comparados aos outros estados nordestinos. No interior da BA, os maiores parques eólicos estão localizados nos municípios de Caetité, Campo Formoso, Gentio do Ouro, Guanambi, Igaporã, Pindaí e Sento Sé. Outros municípios que estão ampliando suas fronteiras geradoras são: Bonito, Brotas de Macaúbas, Brumado, Cafarnaum, Casa Nova, Dom Basílio, Morro do Chapéu, Mulungu do Morro, Sobradinho e Xique-Xique (CREA-BA, 2018).

Entre esses empreendimentos eólicos listados, a implantação que está ocorrendo em Casa Nova chamou a atenção para a análise realizada no presente trabalho. O município é enraizado pelas rodovias BA-210, BR-324 e BR-407 e fica no norte da Bahia. Possui clima quente e semiárido e tem uma população estimada para 2019 de 71.969 habitantes (IBGE, 2020). A ênfase neste local ocorreu devido à expressividade da obra e, principalmente, pelas características do projeto de compensação ambiental que está sendo executado na localidade, que visa mitigar ou eliminar os impactos gerados pela construção do empreendimento. 


\subsection{IMPACTO DOS PARQUES EÓLICOS}

A instalação de um parque eólico gera mudanças que podem ser consideradas positivas ou negativas para a população local, em parâmetros ambientais, sociais e econômicos (DUTRA, 2001; CASTRO, 2009; STAUT, 2011; MENDES, 2016; MEDEIROS JÚNIOR, 2018).

No trabalho realizado por Medeiros Júnior (2018), foram verificadas três vertentes da sustentabilidade, onde na (1으) vertente ambiental foi analisado o licenciamento, a fiscalização, o monitoramento, o cumprimento das normas, a utilização da terra e os impactos ambientais causados pela instalação do parque eólico; na $\left(2^{\circ}\right)$ vertente social foi abordada a participação pública no processo de implantação dos parques, a qualidade de vida na comunidade, a influência sobre os hábitos e costumes das pessoas e a relação entre a empresa, o órgão ambiental e a comunidade; e na (3ํ) vertente econômica foi avaliada a geração de trabalho, renda e crescimento econômico da localidade.

No que diz respeito à vertente ambiental, a instalação desses empreendimentos requer a elaboração de um plano de compensação do impacto, onde são descritos os programas que deverão ser executados com a finalidade de "evitar, mitigar ou compensar os impactos ambientais das fases de instalação e operação" (CHESF, 2011, p. 4). Esta etapa precisa ser realizada para que haja a liberação do licenciamento ambiental para a construção.

Nas perspectivas econômicas e sociais, Staut (2011) listou como pontos positivos da instalação de um parque eólico: (1ํ) a geração de emprego e renda para os moradores das comunidades, tanto na fase de implantação quanto de operação; (2) o aumento na arrecadação de impostos municipais e estaduais; (3ㅇ) a dinamização da economia local; (4으) a possibilidade de geração de atrativos turísticos nas proximidades do empreendimento; (5ㅇ) a melhoria do sistema elétrico da região; (6ㅇ) a melhoria da infraestrutura da comunidade e do município; e (7으) a oferta de treinamento e capacitação para os moradores da comunidade.

No trabalho de Mendes (2016) foram listados como pontos positivos: (1ㅇ) o acesso à energia elétrica e à moradia de qualidade e (2) a melhoria do transporte escolar e das vias de acesso à comunidade. No entanto, a autora enfatiza que as melhorias foram resultantes da luta dos moradores perante a justiça brasileira, por intermédio da formação de associação comunitária e a participação em discussões no Ministério Público. Como ponto negativo listou: (1ํํ) a oferta de emprego com baixa remuneração e $\left(2^{\circ}\right)$ a falta de pessoal com a especialidade exigida para trabalhar no parque eólico.

Outros pontos negativos gerados por um parque eólico são listados por Dutra (2001, p. 28), que aponta o "impacto visual, ruído, interferência eletromagnética, ofuscamento e dano à fauna". 
Porém, ressalta que esses impactos podem ser minimizados ou eliminados por meio do planejamento adequado e do uso de tecnologia. $\mathrm{O}$ autor também cita a modificação que ocorre nos terrenos devido à construção das vias de acessos às instalações, a interferência no trânsito do município e a prostituição (principalmente na fase de construção dos parques).

Em relação a alguns pontos negativos listados, Castro (2009) argumenta que o impacto visual causado pelos aerogeradores é uma questão de gosto pessoal, podendo ou não causar desconforto aos moradores da comunidade. No que diz respeito ao ruído (mecânico ou aerodinâmico), o autor aponta que existe alternativa da instalação de turbinas com baixo ruído, no entanto, esta emissão é inevitável, independente da velocidade do vento.

Diante do propósito do presente trabalho em discutir o projeto de mitigação do impacto gerado pela construção do Parque Eólico de Casa Nova, torna-se pertinente enfatizar as características da Central Geradora Eólica foco desta discussão.

\subsection{CARACTERIZAÇÃO DO PARQUE EÓLICO DE CASA NOVA - BA}

A autorização para construção da Central Geradora Eólica de Casa Nova ocorreu no ano de 2010 e tinha previsão de término em 2013. O parque eólico I foi o primeiro iniciado (de um total de três), sendo o maior do complexo e o que resultou nos principais impactos à localidade de instalação. Para implantação do empreendimento foi necessária a reforma das estradas para suportar a movimentação dos veículos de grande porte, que transportaram os equipamentos de montagem dos aerogeradores. Com isso, foram perfuradas jazidas que abrangeram áreas entre 0,96 a 10,85 hectares, onde houve a retirada do material utilizado no revestimento das vias de acesso (CORREIA, 2017).

A denominação de "jazida" é utilizada devido ao local concentrar uma ou mais substancias minerais (emersas ou imersas) que possuem algum valor econômico, que, nesta construção, teve a importância para utilização na restauração das estradas das comunidades.

Em meados de 2011, a empresa argentina contratada pela Chesf para executar a obra entrou em processo de recuperação judicial e, posteriormente, em falência, resultando na interrupção da obra no ano de 2014. No período em que o serviço do primeiro parque estava sendo executado havia o objetivo de erguer 120 aerogeradores, no entanto somente 30 foram montados, porém abandonados e sem funcionamento (PITOMBO, 2019).

Os parques eólicos Casa Nova II e III foram iniciados posteriormente, por outra construtora contratada pela Chesf, e foram concluídos em dezembro de 2017, com inauguração em março de 2018. Estes correspondem, respectivamente, a 14 e 12 aerogeradores, no total de 26 torres, com a 
capacidade de geração de 61,1 MW (CHESF, 2017; TCU, 2017). Para esses dois empreendimentos não foi necessária a perfuração de novas jazidas, pois foram utilizadas as mesmas estradas e rotas.

Devido ao impacto causado no início da obra da CGE de Casa Nova, os órgãos ambientais impuseram a exigência da recuperação das áreas de jazidas para que houvesse a liberação do licenciamento ambiental para operação do empreendimento. Com isso, foi firmada a parceria entre a Chesf e a Embrapa Semiárido, a fim de elaborar o Projeto de compensação ambiental.

\subsection{PROJETO “AÇÕES DE DESENVOLVIMENTO PARA PRODUTORES AGROPECUÁRIOS DO ENTORNO DO PARQUE EÓLICO DE CASA NOVA - BA"}

A criação do Projeto foi motivada pela condição que os órgãos ambientais impuseram para a liberação da licença de continuidade da obra do Parque Eólico de Casa Nova. Com isso, o Projeto propôs, entre outras, a realização de ações para mitigar/eliminar os impactos negativos causados à localidade (Embrapa, 2020).

Na elaboração do Projeto, foram envolvidas outras instituições e houve a separação da função de cada uma. A Chesf ficou encarregada pelo financiamento, monitoramento, acompanhamento, avaliação e articulação com as demais partes do processo e a Embrapa Semiárido pela articulação com outras unidades da Embrapa e com a execução das atividades.

O objetivo de recuperar as áreas de jazidas por meio do reflorestamento com plantas nativas da caatinga foi o motivo principal da criação do projeto. O local onde houve a retirada do material ficou sem estrutura para se recuperar naturalmente, pois não havia condição fértil suficiente para a recomposição espontânea. Com isso, entre as ações houve a perfuração de poços artesianos, montagem do sistema de irrigação e a abertura de barreiros nas propriedades, que são utilizados para a irrigação das plantas no período de seca (CORREIA, 2017).

Considerando que há a presença de animais nas áreas e que seriam plantadas plantas bastante palatáveis da caatinga, tornou-se necessário cercar o local, tendo o Projeto fornecido os materiais (arame farpado, estacas, moirões, grampos, etc.) e os produtores contribuíram com a mão de obra da montagem.

Os outros planos do Projeto são direcionados para gerir e coordenar as atividades; desenvolver a produção agrícola e pecuária; estimular a apicultura; e realizar o estudo comparativo quantitativo e qualitativo do Projeto. Em algumas ações há atividades que não necessitam da participação direta dos agricultores, pois é estritamente mecanizada e/ou pragmática. Porém, outras requerem a presença e a troca de informações entre o técnico e o agricultor, a fim de buscar um resultado que depende de ambos. 


\section{METODOLOGIA}

Foi realizada pesquisa bibliográfica e documental (GERHARDT; SILVEIRA, 2009), utilizando da consulta a trabalhos como o de Staut (2011), Mendes (2016), Medeiros Júnior (2018), Vecchia (2019), entre outros, e da análise ao documento oficial do Projeto e aos relatórios de acompanhamento de empreendimento da Usina de Energia Eólica de Casa Nova.

O presente trabalho foi construído através da pesquisa exploratória, com objetivo descritivo em relação à expectativa, percepção e consideração dos agricultores relacionados à atividade de reflorestamento das áreas de jazidas do Projeto. O método foi o indutivo, inferindo que o conhecimento sobre esta realidade pode descrever ou se aproximar da realidade encontrada em outras localidades onde foram implantados parques eólicos, mas não exatamente idêntica (LAKATOS; MARCONI, 2003).

A coleta dos dados com os agricultores ocorreu por meio da pesquisa de campo (FONSECA, 2002), através de visitas às comunidades e às residências dos participantes. Foram realizadas duas entrevistas no dia 28 de outubro de 2019 e outras quatro em 05 de novembro do mesmo ano, no total de seis entrevistados. Nessas ocasiões, foi possível observar a produção agropecuária, a infraestrutura das estradas, a estrutura das moradias, a área das propriedades e distância entre as casas e o parque eólico.

Todos os agricultores com jazidas na propriedade foram entrevistados neste trabalho. Eles tiveram suas propriedades modificadas em decorrência da execução da obra da CGE de Casa Nova, principalmente com a perfuração de jazidas para a retirada de material. Nestas áreas estão sendo realizadas atividades de recomposição do solo e reflorestamento da caatinga desmatada.

A abordagem utilizada foi qualitativa (DIEHL; TATIM, 2004), com a finalidade de aprofundar o conhecimento a respeito do impacto da construção e do efeito da execução do Projeto de compensação ambiental sobre a vida dos agricultores. Na coleta dos dados, foi utilizado um roteiro de entrevista semiestruturada (GONÇALVES, 2001; LAKATOS; MARCONI, 2003), que continha 14 tópicos e que está descrito no Quadro 1. 
Quadro 1 - Estruturante do roteiro de entrevista com os agricultores

\begin{tabular}{|c|c|c|}
\hline $\begin{array}{l}\text { Categor } \\
\text { ia analítica }\end{array}$ & Autor(es) & Tópico de entrevista \\
\hline Ocupação & $\begin{array}{l}\text { Paulo (2018); } \\
\text { IBGE (2020); }\end{array}$ & (1a) Profissão; \\
\hline Renda & $\begin{array}{l}\text { Weisheimer (2009); } \\
\text { Noce (2017); } \\
\text { Paulo (2018); }\end{array}$ & $\begin{array}{l}\text { (2a) Fonte de renda (monetária e não monetária) dos membros da } \\
\text { família; }\end{array}$ \\
\hline \multirow{3}{*}{ Propriedade } & Weisheimer (2009); & (3a) Atividade desempenhada na propriedade; \\
\hline & Brasil (2013); & (4ㄹ) Tamanho da propriedade; \\
\hline & $\begin{array}{l}\text { Weisheimer (2009); } \\
\text { Cribb et al. (2011); }\end{array}$ & (5a) Percepção sobre a utilização da propriedade; \\
\hline \multirow{4}{*}{ Parque eólico } & Staut (2011); & (6a) Consideração sobre a criação do Parque Eólico; \\
\hline & $\begin{array}{l}\text { Mendes (2016); } \\
\text { Medeiros Júnior (2018); }\end{array}$ & (7ạ) Mudança na vida decorrente da criação do Parque Eólico; \\
\hline & $\begin{array}{l}\text { Staut (2011); } \\
\text { Medeiros Júnior (2018); }\end{array}$ & (8ª) Mudança na comunidade após a criação do Parque Eólico; \\
\hline & $\begin{array}{l}\text { Dutra (2001); } \\
\text { Castro (2009); } \\
\text { Staut (2011); } \\
\text { Medeiros Júnior (2018); } \\
\text { Mendes (2016); }\end{array}$ & (9a) Percepção geral sobre o Parque Eólico; \\
\hline \multirow{5}{*}{ Projeto } & Dereti (2009); & (10a) Atividade que já participou no Projeto da Embrapa/Chesf; \\
\hline & $\begin{array}{l}\text { Dereti (2009); } \\
\text { Freire (2013); }\end{array}$ & (11a) Avaliação da atividade que já participou; \\
\hline & Dereti (2009); & (12a) Resultado alcançado com o Projeto; \\
\hline & Noce (2017); & (13a) Expectativa com a continuidade do Projeto; \\
\hline & $\begin{array}{l}\text { Dereti (2009); } \\
\text { Freire (2013); }\end{array}$ & (14å) Percepção geral sobre o Projeto da Embrapa/Chesf; \\
\hline
\end{tabular}

Fonte: Elaborado pelos autores (2020).

Foi utilizado o recurso de gravação em áudio durante as entrevistas. Para isso, foi solicitada a autorização do participante e, após sua concordância, houve a captação do áudio (todos concordaram). As gravações foram transcritas e, em posse de todo o texto, foi realizada a análise de conteúdo baseada na abordagem de Bardin (2011), que analisa a mensagem por meio da organização, codificação, categorização, inferência e tratamento informativo da mensagem, permitindo definir as informações relevantes para o trabalho.

Nos resultados e discussão do trabalho, algumas informações foram acrescentadas a partir das observações feitas durante a pesquisa de campo, que foram registradas através de fotografias e notas de campo (GIBBS, 2009) e por meio da consulta aos relatórios referentes às atividades executadas no Projeto. 


\section{RESULTADOS E DISCUSSÃO}

No primeiro ano do Projeto, 2018, alguns acontecimentos resultaram no atraso das atividades. Os recursos foram aprovados em janeiro, mas o orçamento foi liberado somente em março e o período desde a elaboração de edital até a contratação da empresa executora se estendeu até agosto do mesmo ano. Em seguida, houve o período eleitoral, ocasionando uma pausa nas ações. Somente após o encerramento das eleições foram iniciadas plenamente as atividades de campo.

De acordo com o interesse do presente trabalho em identificar os efeitos do processo de reflorestamento das jazidas sobre a vida dos agricultores, a discussão dos resultados obtidos está sequenciada pela descrição das atividades desempenhadas pelos agricultores, os efeitos da construção do parque eólico de Casa Nova e os efeitos da execução do Projeto.

\subsection{ATIVIDADES DESEMPENHADAS PELOS AGRICULTORES}

Todos os agricultores que se dispuseram a responder as perguntas foram homens. Participou da entrevista o membro familiar que teve mais proximidade com a obra do parque eólico de Casa Nova e com o Projeto Embrapa/Chesf. Sendo assim, foi perceptível que os sujeitos masculinos estiveram mais presentes no cotidiano e nos assuntos relacionados à propriedade.

$\mathrm{Na}$ abordagem sobre a fonte de renda familiar dos agricultores, não houve o enfoque para definir o valor monetário recebido, o interesse foi identificar os meios considerados geradores de renda. A justificativa foi porque na agricultura familiar a gestão da atividade produtiva, do meio de produção e da propriedade é de responsabilidade da própria família e, em muitas situações, o trabalho não gera uma remuneração periodicamente regular (WEISHEIMER, 2009).

Os meios de obtenção de renda definidos pelos agricultores participantes da pesquisa estão descritos no Gráfico 1. Houve respondente que citou somente uma fonte e outros que citaram mais de uma. 
Gráfico 1 - Fonte da renda familiar dos agricultores participantes da pesquisa

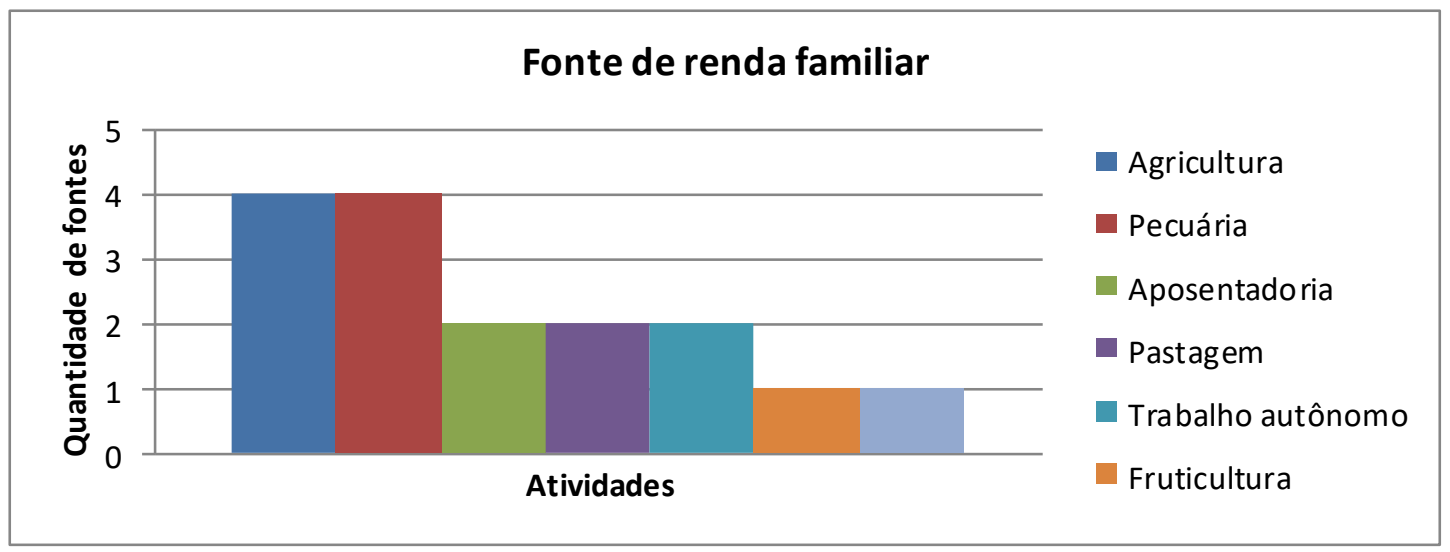

Fonte: Dados da pesquisa de campo (2020).

As atividades relacionadas ao meio rural, citadas como fonte de renda, foram a agricultura, pecuária, fruticultura e pastagem, sendo realizadas nas suas propriedades. Outra fonte relacionada ao rural foi o trabalho informal, praticado por um participante, que se referiu à atividade de plantação e colheita realizada ocasionalmente na propriedade de outro produtor. O trabalho autônomo é uma fonte complementar para dois participantes, que são donos de estabelecimentos comerciais na zona urbana do município, e o recebimento de aposentadoria foi citado por dois agricultores, onde um apontou como fonte complementar e o outro considerou como a única fonte de renda.

Entre as fontes de renda citadas, $75 \%$ estão relacionadas ao meio rural e $25 \%$ não dependem da utilização da propriedade. O contexto de residir na zona rural e possuir renda na localidade também foi ressaltado no trabalho realizado por Noce (2017), que identificou que $64 \%$ dos agricultores participantes do estudo tinham a propriedade rural como o principal meio de obtenção de renda, e na pesquisa de Paulo (2018), onde os jovens rurais participantes declararam que $61,8 \%$ das mães eram agricultoras e $85,7 \%$ dos pais agricultores. Estas informações reforçam o entendimento que os moradores da área rural possuem grande ligação com o próprio meio no que diz respeito à obtenção de renda.

Foi identificado também que os agricultores abordam de formas diferentes as atividades que geram ou não um rendimento financeiro, pois não consideravam como um meio de renda o resultado do trabalho que tinha a finalidade para o consumo familiar ou para o suprimento de outro serviço realizado na propriedade.

Após o entendimento sobre as atividades desempenhadas, houve a abordagem sobre a área de ocupação das propriedades, conforme demonstra o Gráfico 2. 
Gráfico 2 - Tamanho da propriedade dos agricultores participantes da pesquisa

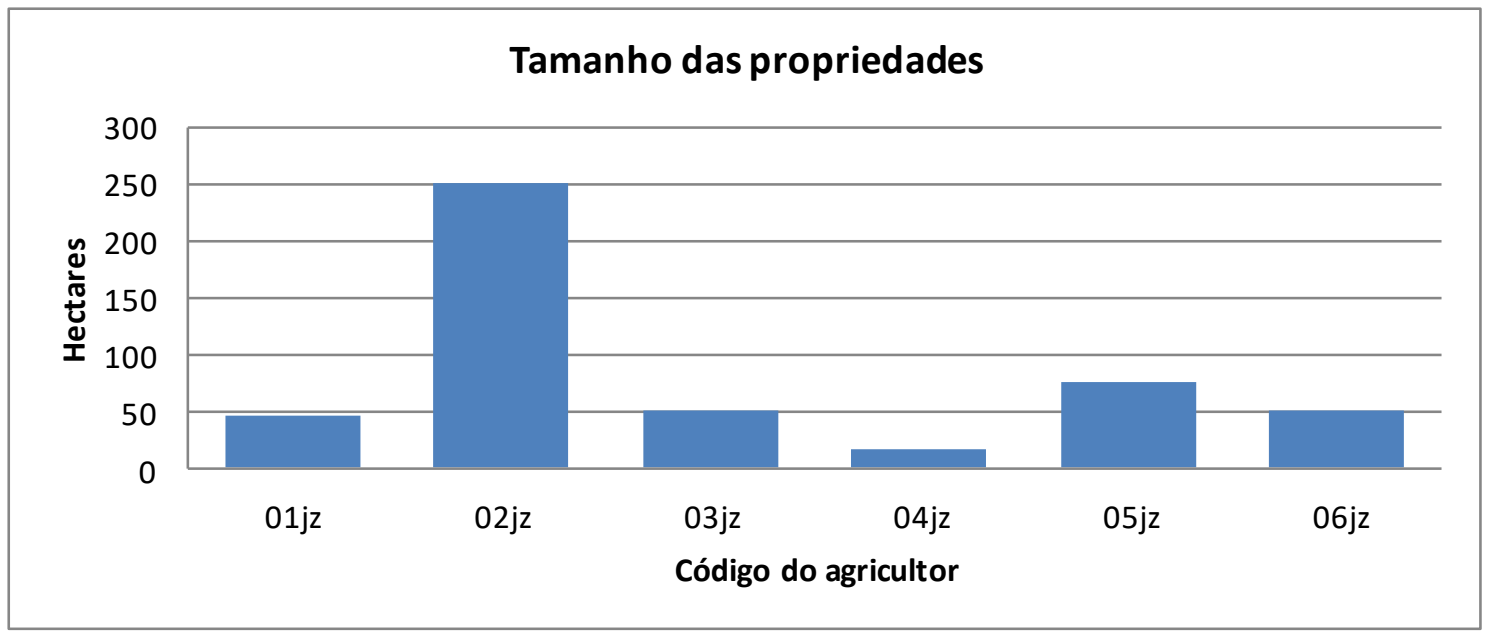

Fonte: Dados da pesquisa de campo (2020).

De acordo com o Gráfico 2, pode-se determinar que, de acordo com o Instituto Nacional de Colonização e Reforma Agrária - INCRA, todas as ocupações podem ser definidas como pequenas propriedades, pois possuem até quatro módulos fiscais. Ao averiguar o Sistema Nacional de Cadastro Rural, no índice básico de 2013 (último disponível) para o município de Casa Nova, um módulo fiscal tem 65 hectares. Com isto, uma pequena propriedade no município supracitado abrange uma área de até 260 hectares (BRASIL, 2013).

Com estas considerações, se compreende que a dinâmica na propriedade dos agricultores remete ao modelo de agricultura familiar, pois, na perspectiva de Cribb et al. (2011), a organização é baseada na própria família e varia de acordo com a quantidade de membros, disponibilidade financeira e tamanho da propriedade.

Weisheimer (2009) acrescenta que na agricultura familiar, dentro da sociedade capitalista, o trabalho agrícola é baseado em relações familiares e não salariais. Segundo a definição da Lei no 11.326 de 24 de Julho de 2006, pode ser considerado agricultor familiar ou empreendedor familiar rural o sujeito que possui uma propriedade com até quatro módulos fiscais; utiliza predominantemente o trabalho familiar nas atividades; tem uma percentagem mínima da renda obtida na propriedade; e administra o estabelecimento com os familiares (BRASIL, 2006).

Com o entendimento sobre a utilização das propriedades, houve a discussão sobre os efeitos gerados pela a construção do Parque Eólico de Casa Nova.

\subsection{EFEITOS DA CONSTRUÇÃO DO PARQUE EÓLICO DE CASA NOVA - BA}

As perspectivas dos seis agricultores sobre a criação do parque eólico foram semelhantes em relação à expectativa de ampliação do acesso à energia elétrica, à geração de emprego, auferição de 
renda, melhoria da qualidade de vida e melhoria da estrutura da comunidade. Estas expectativas são semelhantes às identificadas entre os participantes do trabalho realizado por Staut (2011), que abordou sobre a análise do impacto ambiental e o processo jurídico acerca da implantação de parques eólicos.

A principal mudança destacada foi relacionada à questão financeira, no que diz respeito à aquisição de rendimento monetário pela indenização do espaço utilizado pela obra dentro da propriedade. Também foi mencionada a frequente negociação de valores com a empresa responsável, o interesse externo pela compra da propriedade e a desordem gerada. Um agricultor considerou que não houve mudança ocasionada pela obra, pois a única alteração na propriedade foi à perfuração da jazida, no entanto ocorreu em um local distante da residência.

A indenização que alguns agricultores informaram estar recebendo não foi citada como fonte de renda e a justificativa foi a imprecisão no valor contratual, a incerteza do período de recebimento e a dependência da Chesf na manutenção do pagamento, ou seja, foi considerada fora dos seus próprios domínios.

O frequente diálogo referente à questão financeira também foi identificado nos trabalhos de Medeiros Júnior (2018), que apontou que a obra gerou a necessidade recorrente de ajustes contratuais; e de Mendes (2016), que identificou que a população local precisou recorrer à justiça para conseguir melhorias na localidade.

Em relação à mudança na comunidade, no período de funcionamento da obra, houve a reforma das estradas, o aumento no fluxo de pessoas e a geração de emprego. Com a interrupção, as estradas ficaram desgastadas, muitas pessoas foram demitidas, foi necessário solicitar advogado para tratar dos contratos e houve o crescimento do número de furtos, tanto aos equipamentos abandonados quanto às propriedades dos moradores.

De acordo com a percepção do grupo, a mudança comunitária foi semelhante aos resultados obtidos nos trabalhos de Staut (2011) e Medeiros Júnior (2018), em aspectos sociais e econômicos. Porém, foi divergente por não ter ampliado o acesso à energia elétrica, pois mesmo com parte da Central Geradora Eólica funcionando, ainda há comunidades sem eletricidade.

Na percepção geral sobre o parque eólico de Casa Nova, entre os seis agricultores, três acreditam na conclusão da obra do Parque Eólico I, pois observam a retomada da construção do escritório e a contratação de pessoas. Para os três que desacreditam na retomada, as justificativas foram a quantidade de promessas não cumpridas, os políticos envolvidos e o cenário desfavorecido pela quantidade de furtos aos equipamentos (Figura 1). 
Figura 1 - Obra parada do Parque Éólico de Casa Nova I

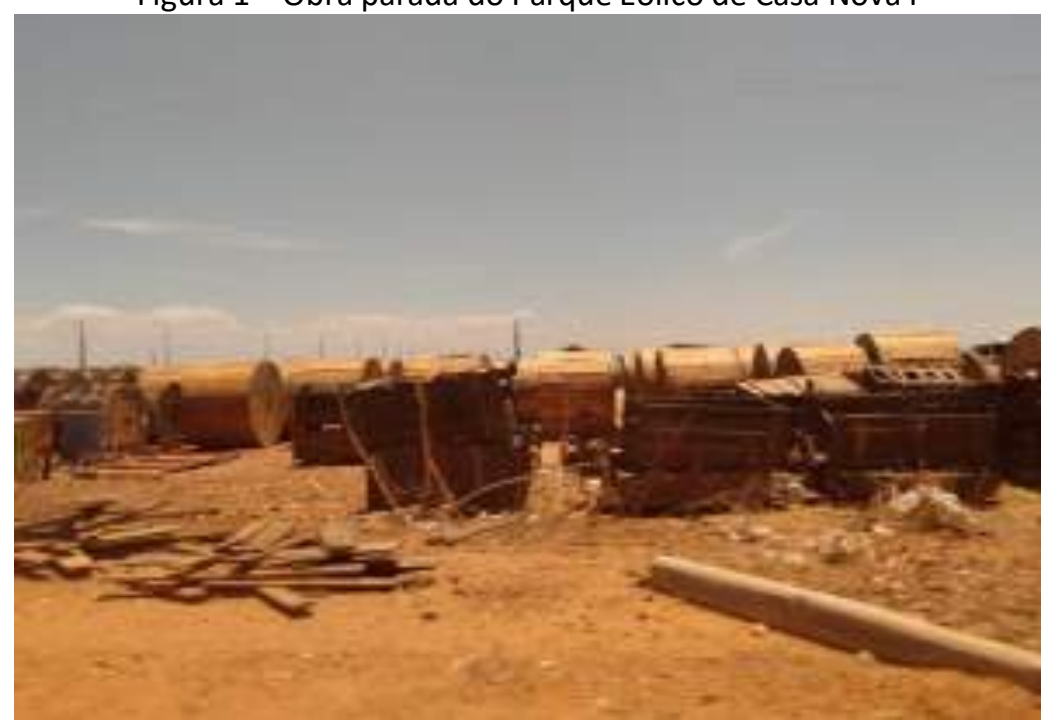

Fonte: Os Autores (2020).

As considerações do grupo foram focadas no rendimento financeiro, modificação na comunidade e incerteza na continuação da obra. O cenário durante o processo de funcionamento foi considerado benéfico. Em relação aos problemas gerados, estes ocorreram, principalmente, com a paralisação da obra, pois gerou desemprego, incertezas sobre o empreendimento, divergências contratuais e aumento no índice de violência. Um problema apontado, que não foi gerado pelo parque eólico, mas que houve a expectativa de resolução através dele, foi a falta de energia elétrica em algumas comunidades. O argumento de Mendes (2016) sobre a ampliação do acesso à energia elétrica nas comunidades de implantação de empreendimentos eólicos não foi reforçado no presente trabalho.

Questões abordadas nos trabalhos de Dutra (2001) e Castro (2009), relacionadas ao incômodo causado aos moradores devido ao ruído e à interferência visual das torres, não foram citadas pelos os agricultores. Para alguns deles, a obra está distante das residências e não houve interferência.

Nas áreas próximas às torres foi percebida a realização de cultivos a poucos metros das bases dos aerogeradores, porém deixando o espaço necessário para a movimentação de funcionários em torno dos mesmos, como mostra a Figura 2. 
Figura 2 - Cultivos realizados próximos ao Parque Eólico de Casa Nova - BA

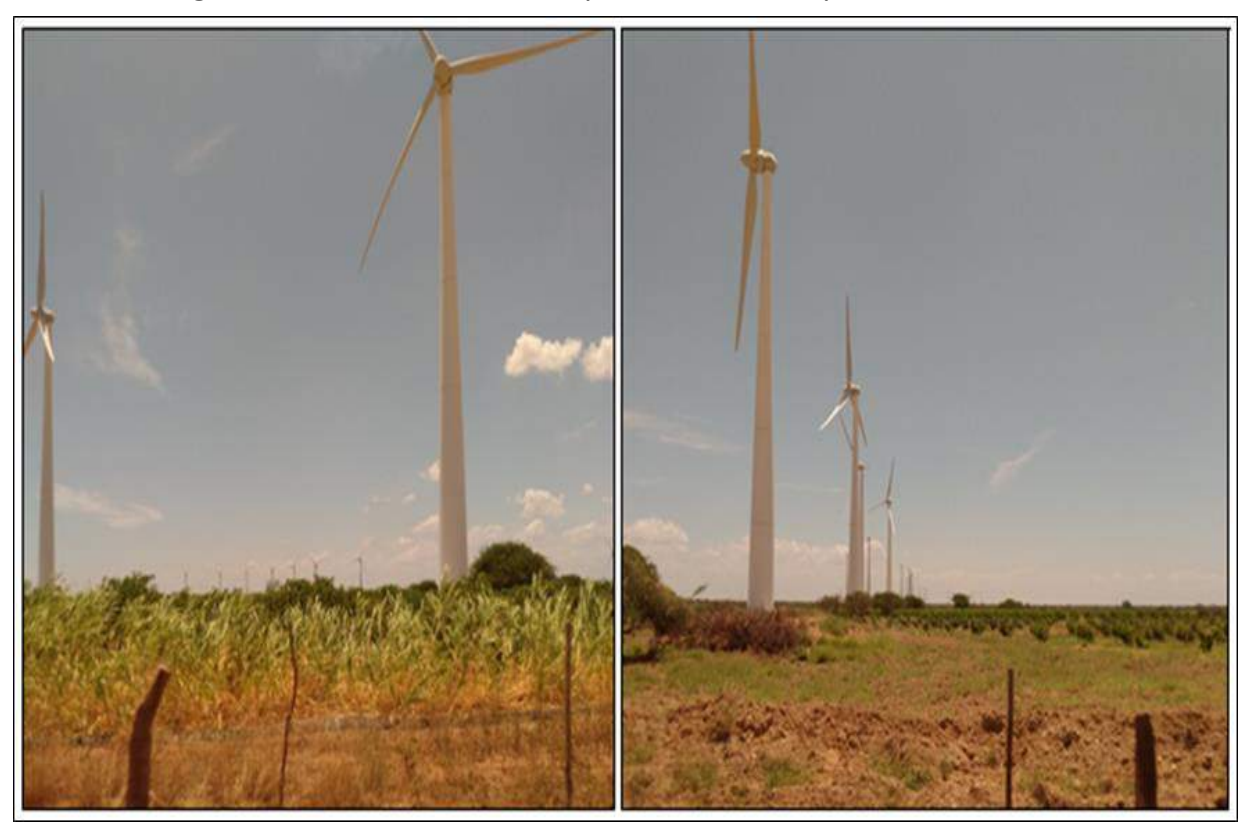

Fonte: Os Autores (2020).

Sobre os agricultores não ressaltarem incômodos sonoros ou visuais devido à instalação das torres, na perspectiva de Castro (2009), o desconforto com estes aspectos é muito particular e há indivíduos que os desconsideram.

\subsection{PERSPECTIVAS SOBRE O PROJETO “AÇÕES DE DESENVOLVIMENTO PARA PRODUTORES AGROPECUÁRIOS DO ENTORNO DO PARQUE EÓLICO DE CASA NOVA - BA"}

Em todas as propriedades com jazida foram perfurados poços, com profundidades entre $60 \mathrm{e}$ 100 metros. A vazão média alcançada entre 1.000 a 3.600 litros/hora (CORREIA, 2019). Estas perfurações serviram para auxiliar na irrigação das mudas plantadas nas áreas.

Foi identificado que nenhum agricultor participou diretamente das atividades realizadas nas jazidas, exceto na construção dos cercados. As justificativas para a não participação estavam relacionadas a problemas de saúde, outras ocupações na propriedade e a dedicação de tempo em trabalhos fora do meio rural. No entanto, eles alegam participar indiretamente, através de reuniões sobre o Projeto, auxílio na irrigação, suporte aos técnicos e presença no evento "Dia de Campo", que é realizado nas áreas onde já houve alguma ação, tendo o intuito de demonstrar o desempenho da atividade e o encaminhamento do resultado.

Mesmo compreendendo o motivo para não participar diretamente das atividades, seria importante uma maior presença dos agricultores, pois, na concepção de Dereti (2009), a articulação 
ordenada dos fatores possibilita ganhos de produção, produtividade e benefícios econômicos, sociais e ambientais para os indivíduos envolvidos.

A participação direta ou indireta dos agricultores nas atividades gerou uma percepção sobre as mesmas. Nas considerações positivas foi ressaltado que o serviço realizado no Projeto está sendo bem executado e tem melhorado a região, e em relação aos técnicos, foi apontada a empolgação e a boa interação com os participantes. Nas avaliações negativas, foi citado que os equipamentos foram retirados da propriedade, mesmo com o agricultor precisando dos mesmos, e houve um respondente que alegou ser contrário à realização do reflorestamento na sua jazida, pois ele realiza o corte de árvores na região.

A avaliação das atividades feita pelos agricultores, independente de participar diretamente ou não da realização, foi baseada na didática e na interação com o técnico que a executou. Por este motivo, Dereti (2009) destaca a importância da formação de um grupo técnico diversificado em conhecimentos e métodos de trabalho, para que ocorra uma boa interligação entre a instituição e os usuários.

Em relação aos resultados já obtidos com o Projeto, o principal destacado pelos agricultores foi o bom desenvolvimento das plantas nativas nas jazidas, como a leucena, gliricídia e umbu. Nos cinco relatos que apontaram bons resultados, foram citados que as culturas estão "vivas", "bonitas" e "desenvolvendo bem", por isto, acreditam que terá um bom resultado final. No depoimento que trouxe uma informação divergente, o agricultor apontou a ausência do técnico ou responsável no cotidiano do cultivo.

Com a continuação do Projeto, a expectativa dos agricultores é obter uma área reflorestada com caatinga após os cinco anos estabelecidos para o crescimento das culturas. O interesse está relacionado à pretensão de deixar o espaço como reserva, cultivar outras pastagens, melhorar o ambiente degradado, valorizar a propriedade e, principalmente, utilizar para a alimentação animal no período de pouca chuva, pois a pecuária é a atividade mais desempenhada pelos participantes.

Em relação à percepção geral sobre o Projeto, foi comum ver que os agricultores têm adquirido novos conhecimentos, estão satisfeitos com o trabalho dos técnicos e percebem que as ações têm melhorado as condições de vida da comunidade através da assistência técnica oferecida, e, por isto, acreditam em um bom resultado. Como sugestão, recomendaram a ampliação da abrangência dos planos para outros moradores e houve críticas ao serviço da Coelba, por não fornecer energia elétrica, e à Chesf, por não prestar um serviço integral.

Com os resultados obtidos no presente trabalho foi perceptível que houve uma boa relação entre os agricultores e os técnicos. O bom relacionamento entre o profissional e o público envolvido 
pode trazer um bom resultado para o processo extensionista, a partir de momento que possibilita que haja uma maior interação no processo de construção do conhecimento (FREIRE, 2013).

\section{CONSIDERAÇÕES FINAIS}

Os resultados do trabalho apontam que a construção do Parque Eólico de Casa Nova proporcionou a reforma das estradas, geração de emprego, aumento no fluxo de pessoas e crescimento da movimentação financeira na localidade. Porém, com a interrupção da obra o cenário mudou e resultou na demissão de funcionários, quebra de contratos com os moradores, disputas judiciais e, principalmente, no aumento no índice de furtos nas comunidades devido ao abandono das instalações.

Em relação ao Projeto “Ações de Desenvolvimento Para Produtores Agropecuários do Entorno do Parque Eólico de Casa Nova - BA", os agricultores informaram que não participaram cotidianamente das atividades de recuperação das jazidas, no entanto percebem que o plantio realizado pelos técnicos e ajudantes está se desenvolvendo bem e, por isto, há a expectativa de utilizar a área reflorestada com caatinga para, principalmente, realizar a atividade pecuária.

Foi possível identificar que um dos principais efeitos do Projeto sobre a vida dos agricultores, até o momento da realização da presente pesquisa, foi o benefício proporcionado pela perfuração dos poços artesianos nas propriedades, pois esta ação viabilizou a utilização de água na residência, na agricultura e na pecuária. Também foi identificado que os participantes estão satisfeitos com os resultados já alcançados e demonstram confiança nas ações que estão sendo executadas.

Para trabalhos futuros as sugestões são a realização de entrevista semiestruturada com os agricultores após o término do Projeto, a fim de verificar a evolução do resultado alcançado de maneira qualitativa e quantitativa; e a utilização do roteiro de entrevista deste trabalho na abordagem sobre a implantação de outros parques eólicos, a fim de aperfeiçoar os tópicos analisados.

\section{REFERÊNCIAS}

ABEEÓLICA - Associação Brasileira de Energia Eólica. Boletim Anual de Geração Eólica. São Paulo, SP: Visão Gráfica. 2018. Disponível em: http://abeeolica.org.br/wp-content/uploads/2019/05/BoletimAnual 2018.pdf. Acesso em: 10 jun. 2020.

ABEEÓLICA - Associação Brasileira de Energia Eólica. Dados ABEEólicas. Disponível em: http://abeeolica.org.br/. Acesso em: 10 mar. 2020.

ARAGÃO, I. S.; ALBUQUERQUE, R. R.; SANTO, M. C. G. Energias Renováveis: a eólico-eletricidade como alternativa energética sustentável na Bahia. In: ENCONTRO NACIONAL DE ESTUDANTES DE ENGENHARIA AMBIENTAL, 14., 2016, FÓRUM LATINO AMERICANO DE ENGENHARIA E 
SUSTENTABILIDADE, 2., 2016, SIMPÓSIO BRASILEIRO DE ENGENHARIA AMBIENTAL, 1., 2016, Brasília. Anais [...]. Brasília: Universidade de Brasília, 2016.

BARDIN, L. Análise de conteúdo. São Paulo: Edições 70, 2011, 229 p.

BRASIL. Lei no 11.326, de 24 de julho de 2006. Estabelece as diretrizes para a formulação da Política Nacional da Agricultura Familiar e Empreendimentos Familiares Rurais. Subchefia para Assuntos Jurídicos, Brasília, DF, 2006. Disponível em: http://www.planalto.gov.br/ccivil 03/Ato20042006/2006/Lei/L11326.htm. Acesso em: 10 jun. 2020.

BRASIL. Instituto Nacional de Colonização e Reforma Agrária. Sistema Nacional de Cadastro Rural. 2013. Disponível em: http://www.incra.gov.br/sites/default/files/uploads/estruturafundiaria/regularizacao-fundiaria/indices-cadastrais/indices basicos 2013 por municipio.pdf.

Acesso em: 01 abr. 2020.

CASTRO, R. M. G. Introdução à Energia Eólica. Energias Renováveis e Produção Descentralizada. Instituto Superior Técnico. Universidade Técnica de Lisboa, DEEC. 2009.

CHAUI, M. Convite à Filosofia. São Paulo: Ática, 2000. 567 p.

CHESF - Companhia Hidro Elétrica do São Francisco. Plano Básico Ambiental - PBA: Central Geradora Eólica Casa Nova. Brasília: MRS Estudos Ambientais. 2011.

CHESF - Companhia Hidro Elétrica do São Francisco. Relatório Anual e de Sustentabilidade. 2017. Disponível em: http://www.chesf.gov.br/sustentabilidade/Documents/Relat\%C3\%B3rio\%20de\%20Sustentabilidade \%202017\%20Final.pdf. Acesso em: 10 jun. 2020.

CORREIA, R. C. (Coord.). IV RELATÓRIO TÉCNICO - Ações de desenvolvimento para produtores agropecuários do entorno do parque eólico de Casa Nova - BA - Eólicas de Casa Nova. Petrolina: Embrapa Semiárido e CHESF, 2019. 45 p.

CORREIA, R. C. (Coord.). Projeto Ações de desenvolvimento para produtores agropecuários do entorno do parque eólico de Casa Nova BA. Petrolina: Embrapa Semiárido e CHESF, 2017. 41 p.

CREA-BA - Conselho Regional de Engenharia e Agronomia da Bahia. Revista CREA BA. v. 16, n. 60, 2018.

CRIBB, A. Y.; CRIBB, S. L. S. P.; FREIRE JUNIOR, M.; SILVA, F. T. Adoção tecnológica e gestão cooperativista: um estudo de caso na agricultura familiar. In: Cadernos de Ciência \& Tecnologia. v. 28, n. 1, jan./abr. 2011. ISSN 0104-1096. pp. 133-157. Brasília, DF: Empresa Brasileira de Pesquisa Agropecuária. $2011 . \quad$ Disponível em: http://seer.sct.embrapa.br/index.php/cct/issue/view/361/showToc. Acesso em: 10 mar. 2020.

DERETI, R. M. Transferência e validação de tecnologias agropecuárias a partir de instituições de pesquisa. Desenvolvimento e Meio Ambiente. n. 19, p. 29-40, jan./jun. 2009. Curitiba: Editora UFPR, 2009.

DIEHL, A. A; TATIM, D. C. Pesquisa em ciências aplicadas: métodos e técnicas. São Paulo: Prentice Hall, 2004. 168 p. ISBN: 858791894X. 
DUTRA, R. M. Viabilidade Técnico-Econômica da Energia Eólica Face ao Novo Marco Regulatório do Setor Elétrico Brasileiro. 2001. 259 p. Dissertação (Mestrado em Ciências em Planejamento Energético) - Universidade Federal do Rio de Janeiro, Rio de Janeiro, 2001.

EMBRAPA - Empresa Brasileira de Pesquisa Agropecuária. Quem somos. Disponível em: https://www.embrapa.br/. Acesso em 10 de mar. de 2020.

FONSECA, J. J. S. Metodologia da pesquisa científica. Apostila. Fortaleza: UEC, 2002.

FREIRE, P. Extensão ou comunicação? Tradução: Rosiska Darcy de Oliveira. 1. ed. Rio de Janeiro: Paz e Terra, 2013. 93 p.

GERHARDT, T. E.; SILVEIRA, D. T. Métodos de pesquisa. Porto Alegre: Editora da UFRGS, 2009. 120 p.

GIBBS, G. Análise de dados qualitativos. Tradução: Roberto Cataldo Costa. Porto Alegre: Artmed, 2009. 197 p.

GONÇALVES, E.P. Iniciação à pesquisa científica. Campinas, SP: Editora Alínea, 2001.

IBGE - Instituto Brasileiro de Geografia e Estatística. Cidades. Disponível em: https://cidades.ibge.gov.br/brasil/ba/casa-nova/panorama. Acesso em: 10 mar. 2020.

LAKATOS, E. M.; MARCONI, M. A. Fundamentos de metodologia científica. 5. ed. São Paulo: Atlas, 2003. $311 \mathrm{p}$.

LIMA, R. C. A indústria de aerogeradores e o desenvolvimento regional: perspectivas de consolidação na Bahia. 2018. 142 p. Dissertação (Mestrado em Engenharia Industrial) - Universidade Federal da Bahia, Salvador, 2018.

MEDEIROS JÚNIOR, J. M. Para onde sopram os ventos? Impactos e vulnerabilidades socioambientais do parque eólico na Comunidade de Queimadas. 2018. 106 p. Dissertação (Mestrado em Desenvolvimento e Meio Ambiente) - Universidade Federal do Rio Grande do Norte, Natal, 2018.

MENDES, J. S. Parques eólicos e comunidades tradicionais no nordeste brasileiro: estudo de caso da comunidade de Xavier, litoral oeste do Ceará, por meio da abordagem ecológica/participativa. 2016. 160 p. Tese (Doutorado em Geografia) - Universidade Federal do Ceará, Fortaleza, 2016.

NOCE, M. A. Análise do processo de transferência de tecnologias no Sistema de Integração LavouraPecuária-Floresta, para Agricultores familiares na região central de Minas Gerais. 2017. 184 p. Tese (Doutorado em Extensão Rural) - Universidade Federal de Viçosa, Viçosa, 2017.

PAULO, M. A. L. A interiorização das universidades federais e o acesso de jovens rurais ao ensino superior: o caso da UAST/UFRPE. Raízes, Campina Grande, v. 38, p. 162-177, jun. 2018.

PITOMBO, J. P. Nove anos após leilão, torres eólicas estão abandonadas na Bahia. 2019. Disponível em: https://www1.folha.uol.com.br/mercado/2019/10/nove-anos-apos-leilao-torres-eolicas-estaoabandonadas-na-bahia.shtml. Acesso em: 10 jun. 2020.

ROCHA, F. E. C.; TRÓCCOLI, B. T.; MACHADO, M. S.; SANTOS, J. F. Modelo lógico da transferência de tecnologia no contexto da avaliação de programas. Brasília, DF: Embrapa, 2016. Disponível em: 
http://www.sapc.embrapa.br/arquivos/consorcio/publicacoes tecnicas/rocha-01.pdf. Acesso em: 10 mar. 2020.

SANTOS, J. A. F. A. Planejamento energético para a Bahia em 2050: cenários e discussões relacionados às energias renováveis para geração de eletricidade. 2015. 246 p. Dissertação (Mestrado em Engenharia Industrial) - Universidade Federal da Bahia, Salvador, 2015.

STAUT, F. O processo de implantação de parques eólicos no nordeste brasileiro. 2011. 164 p. Dissertação (Mestrado em Engenharia Ambiental Urbana) - Universidade Federal da Bahia, Salvador, 2011.

TCU - Tribunal De Contas da União. Relatório de Fiscalização. 2017. Disponível em: https://www.camara.leg.br/internet/comissao/index/mista/orca/orcamento/OR2018/Fiscobras2017 Lanexo/SINTETICOS/Sint\%C3\%A9tico 2017 112.pdf. Acesso em: 10 jun. 2020.

TOSETTO, A. Percepção visual e háptica de comprimentos de linha apresentados em diferentes formas. 2005. 107 p. Dissertação (Mestrado em Ciências) - Faculdade de Filosofia, Ciências e Letras, Universidade de São Paulo, Ribeirão Preto, 2005.

VECCHIA, D. D. Desafios para a consolidação das fontes de energia renováveis não convencionais: uma análise em três ensaios. 2019. 142 p. Tese (Doutorado em Economia) - Universidade Federal da Bahia, Salvador, 2019.

WEISHEIMER, N. A situação juvenil na agricultura familiar. 2009. 330 p. Tese (Doutorado em Sociologia) - Programa de Pós-Graduação em Sociologia, Universidade Federal do Rio Grande do Sul, Porto Alegre, 2009. 